FHWA/IN/JTRP-2002/4

Final Report

LOAD TESTS ON PIPE PILES FOR DEVELOPMENT OF CPT-BASED DESIGN METHOD

Rodrigo Salgado

Junhwan Lee

Kwangkyum Kim

November 2002 
Final Report

FHWA/IN/JTRP-2002/4

\title{
LOAD TESTS ON PIPE PILES FOR DEVELOPMENT OF CPT-BASED DESIGN METHOD
}

\author{
By \\ Kwangkyun Kim \\ Graduate Research Assistant \\ and \\ Rodrigo Salgado \\ Principal Investigator \\ Associate Professor \\ School of Civil Engineering \\ Purdue University \\ Junhwan Lee \\ Co-Principal Investigator \\ Formerly with Research Division \\ Indiana Department of Transportation \\ Kyuho Paik \\ Assistant Professor \\ School of Civil Engineering \\ Kwandong University
Joint Transportation Research Program
Project No. C-36-45R
File No. 6-18-16
SPR-2361 \\ Conducted in Cooperation with the \\ Indiana Department of Transportation \\ and the U.S. Department of Transportation \\ Federal Highway Administration
}

The contents of this report reflect the views of the authors who are responsible for the facts and accuracy of the data presented herein. The contents do not necessarily reflect the official views or policies of the Indiana Department of Transportation and Federal Highway Administration. This report does not constitute a standard, specification, or regulation.

Purdue University

West Lafayette, Indiana

November 2002 
TECHNICAL REPORT STANDARD TITLE PAGE

\begin{tabular}{|c|c|c|}
\hline $\begin{array}{l}\text { 1. Report No. } \\
\text { FHWA/IN/JTRP-2002/4 }\end{array}$ & 2. Government Accession No. & 3. Recipient's Catalog No. \\
\hline \multirow{2}{*}{\multicolumn{2}{|c|}{$\begin{array}{l}\text { 4. Title and Subtitle } \\
\text { Load Tests on Pipe Piles for Development of CPT-Based Design Method }\end{array}$}} & $\begin{array}{l}\text { 5. } \quad \text { Report Date } \\
\text { November } 2002\end{array}$ \\
\hline & & 6. Performing Organization Code \\
\hline \multicolumn{2}{|l|}{$\begin{array}{l}\text { 9. Performing Organization Name and Address } \\
\text { Joint Transportation Research Program } \\
1284 \text { Civil Engineering Building } \\
\text { Purdue University } \\
\text { West Lafayette, IN 47907-1284 }\end{array}$} & 10. Work Unit No. \\
\hline \multirow{2}{*}{\multicolumn{2}{|c|}{$\begin{array}{l}\text { 12. Sponsoring Agency Name and Address } \\
\text { Indiana Department of Transportation } \\
\text { State Office Building } \\
100 \text { North Senate Avenue } \\
\text { Indianapolis, IN } 46204\end{array}$}} & $\begin{array}{l}\text { 13. Type of Report and Period Covered } \\
\text { Final Report }\end{array}$ \\
\hline & & 14. Sponsoring Agency Code \\
\hline \multicolumn{3}{|l|}{ 15. Supplementary Notes } \\
\hline
\end{tabular}

\section{Abstract}

This research focused on the drivability and load-carrying capacity of both open and closed-ended steel pipe piles. Two pipe piles (one open-ended, the other closed-ended) were installed in a sandy soil to the same depth. The site was extensively characterized. SPT and CPT tests were performed both before and after pile installation. A variety of soil indices and shear strength parameters (such as the constant-volume friction angle) were measured in the laboratory. The piles were fully instrumented, permitting separate measurement of shaft and base capacity for the closed-ended pile and shaft, annulus and soil plug capacities for the open-ended pile.

The results are presented in a variety of ways. In particular, values of pile resistance are presented normalized with respect to CPT cone resistance values both along the shaft and base of the piles for quick reference. The test results for the openended piles are quite unique. Two design methods are proposed for open-ended piles based on the field load test as well as on results found in the literature. In one method, pile resistances are referred to either the soil plug length or incremental filling ratio. In the other method, pile resistances are correlated to the CPT cone resistance.

Comparisons of the proposed methods with the load test results and with methods currently in use are quite favorable. The present research suggests current pile design methods may be excessively conservative. It seems that cost savings from similar research, where complete measurement of all variables of interest both for the piles and for the soil deposit where the piles are installed are done, can be very substantial if the methods proposed here are validated further. It appears that such savings would be in the interest of DOT's and the FHWA.

\section{Key Words}

piles, piling, pipe piles, open-ended pipe piles, closedended pipe piles, cone penetration test, CPT, cone resistance, bearing capacity, sand

18. Distribution Statement

No restrictions. This document is available to the public through the National Technical Information Service, Springfield, VA 22161

\begin{tabular}{|c|c|c|c|}
\hline $\begin{array}{c}\text { 19. Security Classif. (of this report) } \\
\text { Unclassified }\end{array}$ & 20. Security Classif. (of this page) & 21. No. of Pages & 221 \\
\hline
\end{tabular}




\section{TECHNICAL Summary}

Technology Transfer and Project Implementation Information

\section{Load Tests on Pipe Piles for Development of CPT-Based Design Method}

\section{Introduction}

Both open-ended and closed-ended pipe piles are often used in practice, but high-quality information available on the bearing capacity of these piles is very limited. The core of the present study was the pile load tests done on two pipe piles: one open-ended and the other closed-ended. The information generated by the load tests is particularly useful for engineers interested in the design of openended pipe piles in sand, as detailed data was collected on soil plug formation during driving and on static plug resistance. Better understanding of the load-carrying capacity of these piles can lead to significant cost savings. This appears to be especially true for open-ended piles. Both the driving response and static bearing capacity of open- ended piles are affected by the soil plug that forms inside the pile during pile driving. The formation of the soil plug and its effect on pile load response are still not completely understood.

In order to investigate the effect of the soil plug on the static and dynamic response of an open-ended pile and the load capacity of pipe piles in general, field pile load tests were performed on instrumented open- and closed-ended piles driven into sand. The experimental data accumulated during pile driving and during the static load tests were then used to enhance understanding of the drivability and load capacity of both closed-ended and open-ended pipe piles.

\section{Findings}

Driving of open-ended piles can take place with varying degrees of soil plug formation. The open-ended pipe pile in this study was driven in a partially plugged mode. Measurement of the soil plug length during driving permitted calculation of the IFR as a function of penetration depth. It was found, by comparison with the CPT cone resistance profile, that the IFR increased when the relative density of the sand also increased. It was also observed that the cumulative blow count was lower to drive the open-ended pile than the closedended pile to the same depth, but that the difference was mostly due to the early stages of driving, when the soil plug was not well developed.

Whether open-ended piles are driven in the fully coring (fully unplugged) mode or in the partially plugged mode, the plug does contribute to static pile base capacity; however, this contribution is not presently well understood.
Annular resistance also adds to pile base capacity. The open-ended test pile was instrumented in a way that allows separation of plug from annulus resistance, helping shed some light on this important issue. In addition to separation of factors contributing to the base capacity of openended piles, the base capacity of closed-ended piles and the shaft resistance of both closed- and open-ended piles were also studied through the load tests. The base resistance and shaft capacity of the open-ended pile, normalized by average cone resistances, resulted $36 \%$ and $52 \%$ lower than the corresponding values for the closedended pile. For the open-ended pile, the plug resistance was only about $30 \%$ of the annulus resistance, and the average shear stress between the soil plug and inner surface of the pile was $45 \%$ higher than the outside shaft resistance. Results are presented both raw and normalized with respect to cone resistance $\mathrm{q}_{\mathrm{c}}$. 
Based on the field and calibration chamber pile load tests, new relationships for determination of the load capacity of open-ended piles were proposed. The relationships are based on soil-state variables (relative density and stress state) and CPT results. The proposed methods were established based on results from the full-scale field pile load tests and model pile load tests in the calibration chamber. The predicted pile load capacities from the proposed methods were compared with measured capacities from case histories and results calculated from existing pile design methods. The proposed CPT-based method was added to the CONPILE (SPR-2142), the pile load capacity calculation program.

\section{Implementation}

The research results are immediately relevant to pile design practice. INDOT and other DOT's should refer to these results when designing piles under similar conditions. Given that research findings suggest significant cost savings can result from extending this study, it would be advisable for INDOT and FHWA to consider additional funding for similar efforts so that results such as those presented here can find their way into pile design practice across the country.

\section{Contacts}

For more information:

\section{Prof. Rodrigo Salgado}

Principal Investigator

School of Civil Engineering

Purdue University

West Lafayette IN 47907

Phone: (765) 494-5030

Fax: (765) 496-1364

\section{Indiana Department of Transportation}

Division of Research

1205 Montgomery Street

P.O. Box 2279

West Lafayette, IN 47906

Phone: (765) 463-1521

Fax: (765) 497-1665

\section{Purdue University}

Joint Transportation Research Program

School of Civil Engineering

West Lafayette, IN 47907-1284

Phone: (765) 494-9310

Fax: (765) 496-1105 


\section{TABLE OF CONTENTS}

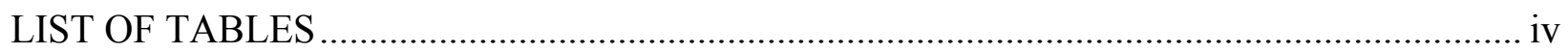

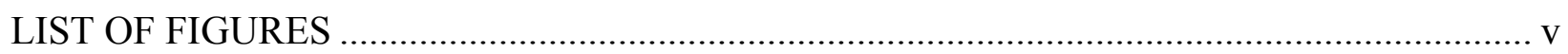

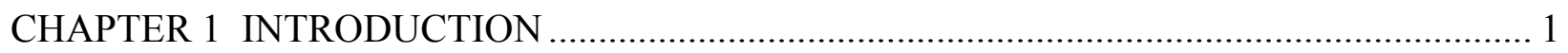

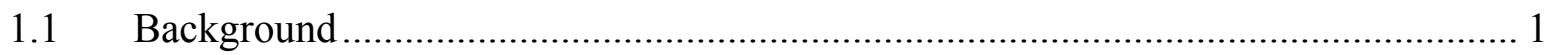

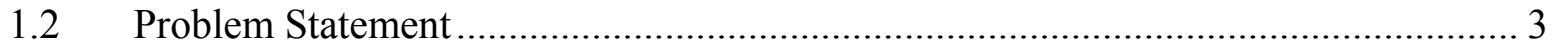

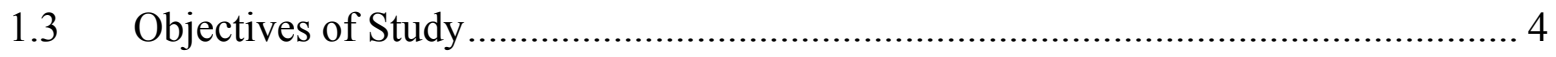

CHAPTER 2 LOAD CARRYING MECHANISMS OF PIPE PILES.......................................... 5

2.1 Displacement versus Non-Displacement Piles .................................................... 5

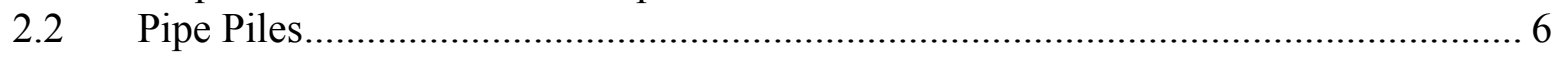

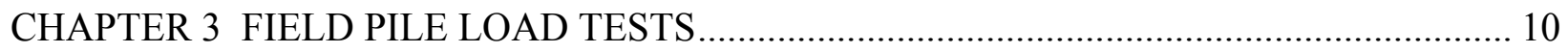

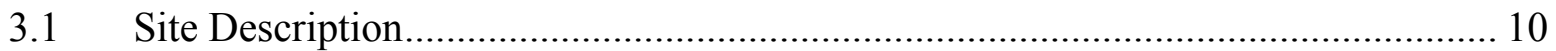

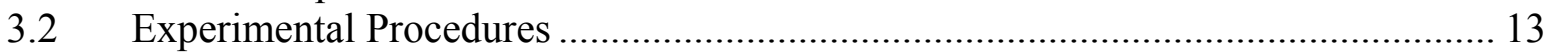

3.2.1 Test Pile Details and Instrumentation........................................................... 13

3.2.2 Pile Driving and Dynamic Testing ………................................................ 16

3.2.3 Static Load Tests................................................................................ 18

3.2.4 Determination of Limit Load Capacity ......................................................... 21

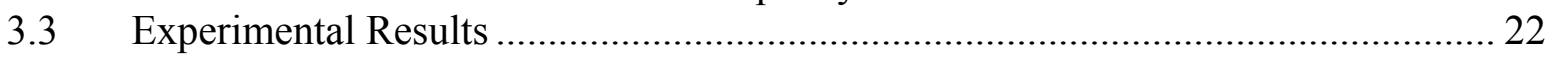

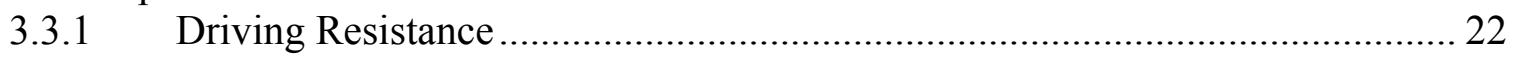

3.3.2 Soil Plugging in the Open-Ended Pile .......................................................... 28

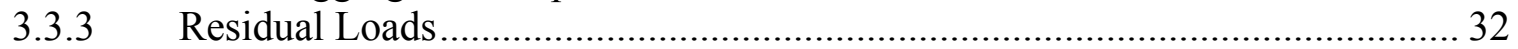

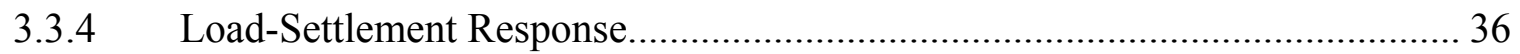

3.3.5 Base and Shaft Load Capacity ...................................................................... 38

3.3.6 Bearing Capacity Comparison for the Open- and Closed-Ended Piles ............ 43

CHAPTER 4 DETERMINATION OF BEARING CAPACITY OF OPEN-ENDED PILES IN

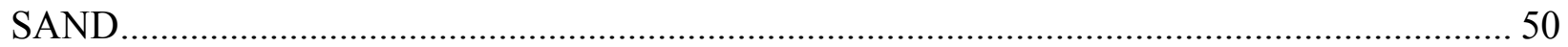

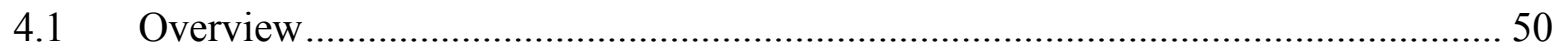

4.2 Calibration Chamber Test Procedures ………………........................................... 51

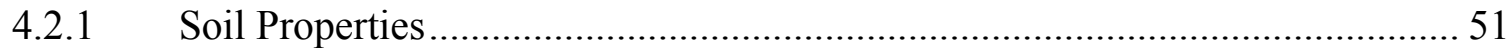

4.2.2 Calibration Chamber and Sample Preparation................................................. 52

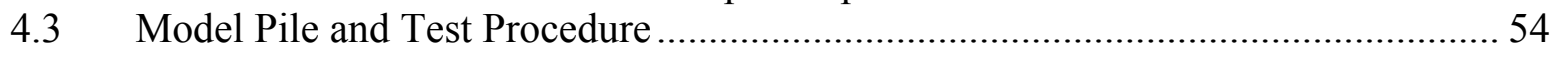

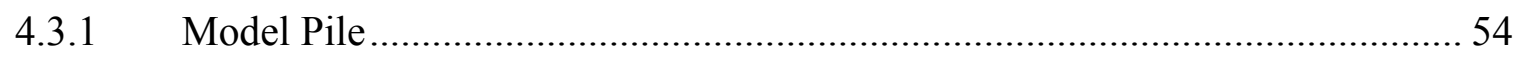

4.3.2 Test Program........................................................................................... 57 


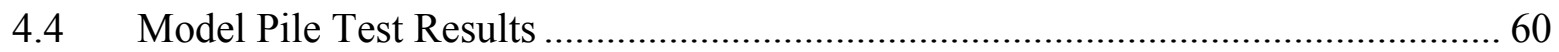

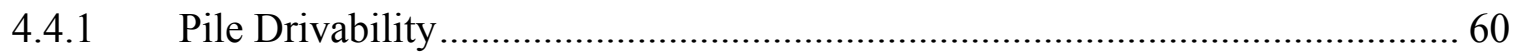

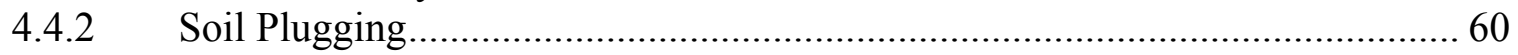

4.4.3 Base and Shaft Load Capacities....................................................................... 67

4.5 Correction of Chamber Test Results for Chamber Size Effects ............................... 70

4.5.1 Adjustment of Pile Diameter .................................................................... 70

4.5.2 Field Pile Load Capacity............................................................................... 76

4.6 New Design Equations for Load Capacity of Open-Ended Piles …………….......... 77

4.6.1 Base Load Capacity …………………………............................................ 77

4.6.2 Shaft Load Capacity................................................................................... 79

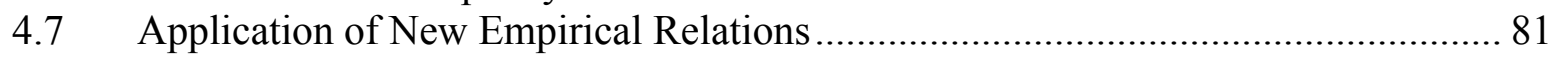

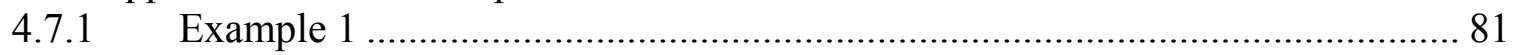

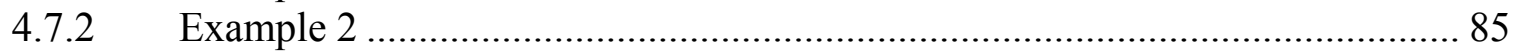

CHAPTER 5 ESTIMATION OF THE LOAD CAPACITY OF PIPE PILES IN SAND BASED

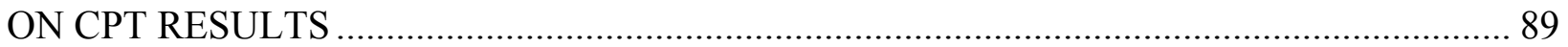

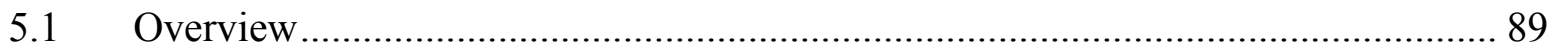

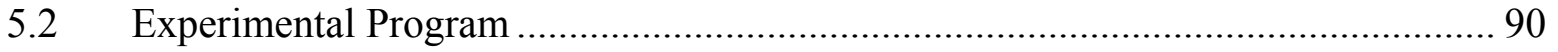

5.2.1 Calibration Chamber Tests ..................................................................... 90

5.2.2 Field Pile Load Tests ................................................................................. 96

5.3 Consideration of Size Effect for Calibration Chamber Test Results ......................... 98

5.3.1 Size Effect in Calibration Chamber Tests...................................................... 98

5.3.2 Correction for Size Effect in Calibration Chamber Tests ............................... 102

5.4 Pile Load Capacity Based on CPT Results ............................................................. 103

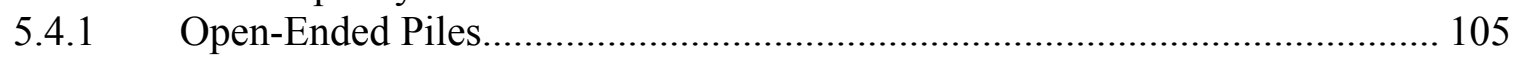

5.4.2 Closed-Ended Piles .......................................................................................... 107

5.4.3 Normalized Pile Load Capacity from Field Pile Load Tests ........................... 107

5.4.4 Estimation of IFR for Open-Ended Piles ...................................................... 113

5.4.5 Estimation of Pile Load Capacity Based on CPT Results ............................... 119

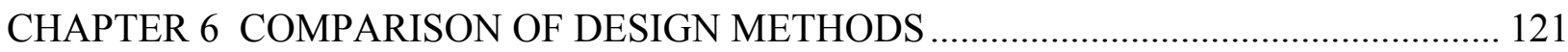

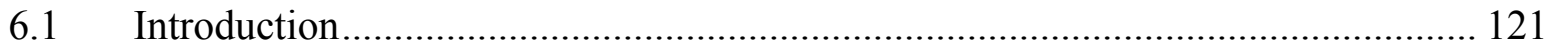

6.2 Comparison of Design Methods for Open-Ended Piles........................................... 121

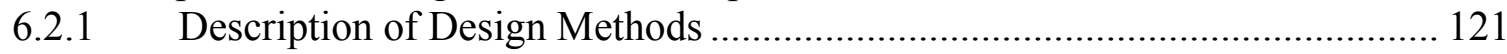

6.2.1.1 American Petroleum Institute (API) Method............................................. 121

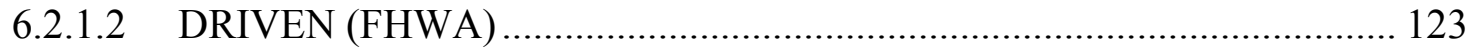

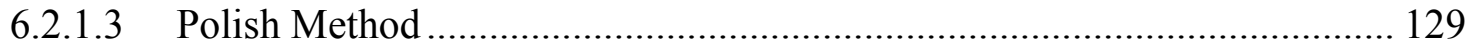

6.2.2 Predicted and Measured Pile Load Capacity .................................................. 132

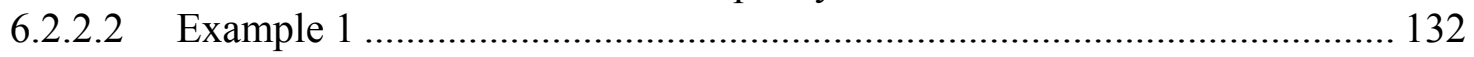

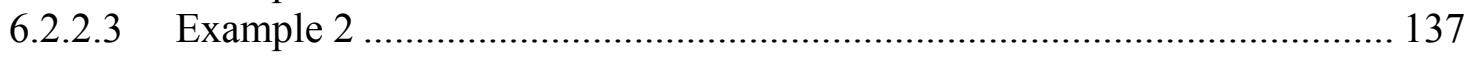

6.3 Comparison of Design Methods for Closed-Ended Piles ....................................... 141

6.3.1 Description of Design Methods ................................................................. 141

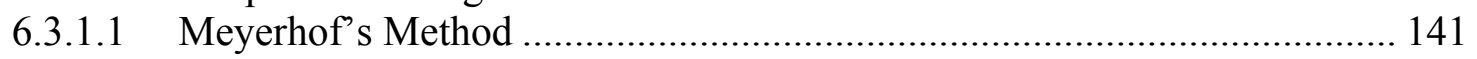

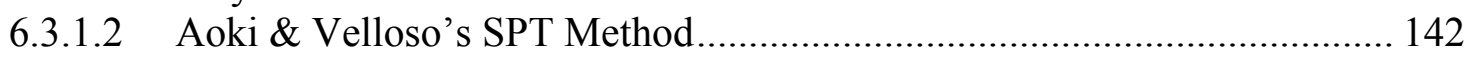


6.3.1.3 Bazaraa and Kurkur's Method ................................................................. 143

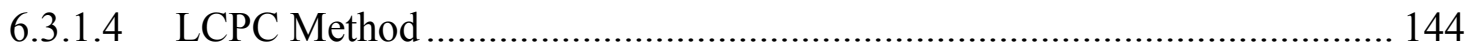

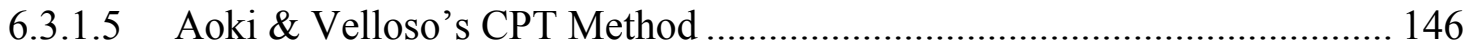

6.3.2 Predicted and Measured Pile Load Capacity ............................................ 147

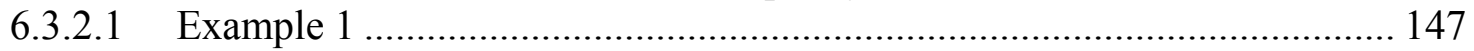

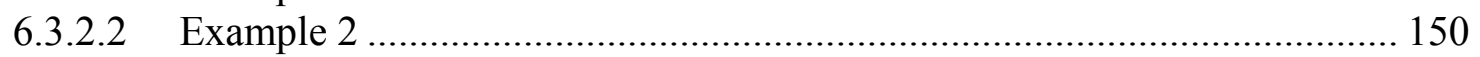

C.4 Cost Evaluation .......................................................................................... 153

6.5 Potantial Cost Savings from Implementation of the Proposed Design Method in

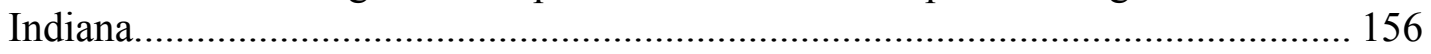

CHAPTER 7 SUMMARY AND CONCLUSIONS ......................................................... 157

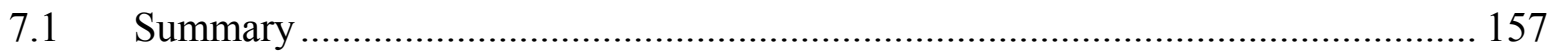

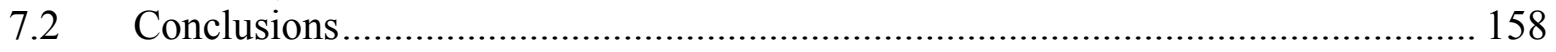

LIST OF REFERENCES......................................................... 162

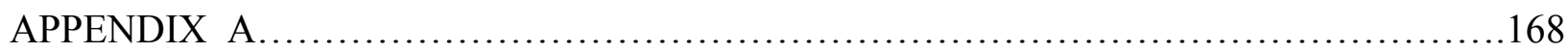

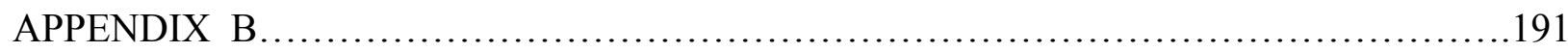




\section{LIST OF TABLES}

Table

Page

3.1 Summary of measured and estimated key load capacities..................... 42

3.2 Summary of normalized unit resistances................................ 49

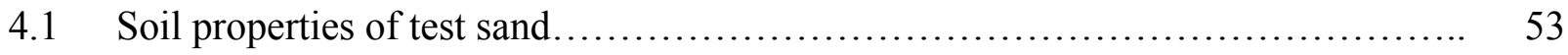

4.2 Summary of model pile test program.................................... 58

4.3 Summary of model pile test results and size effect factors $\ldots \ldots \ldots \ldots \ldots \ldots \ldots \ldots \ldots \quad 74$

5.1 Soil densities and stress states used in calibration chamber tests ............... 92

5.2 Properties of Han River sand......................................... 93

5.3 Size effect factor for calibration chamber tests.............................. 104

5.4 Resistance ratio for closed- and open-ended piles as a function of driving depth (after Paik et al. 1994)........................................................ 109

5.5 Base resistance ratio for displacement and non-displacement piles................ 112

5.6 Normalized pile resistance of closed- and open-ended piles................... 120

6.1 Design parameters for cohesionless siliceous soil.......................... 122

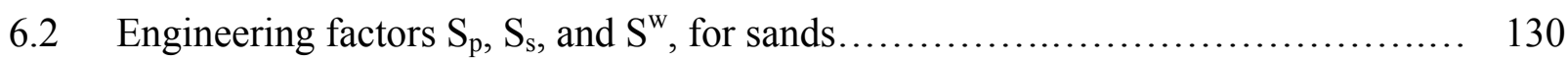

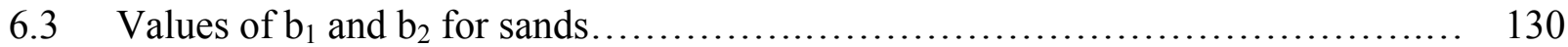

6.4 Unit base resistance $\mathrm{q}_{\mathrm{b}}$ for different soil types............................... 131

6.5 Unit shaft resistance $\mathrm{f}_{\mathrm{s}}$ for different soil types.............................. 131

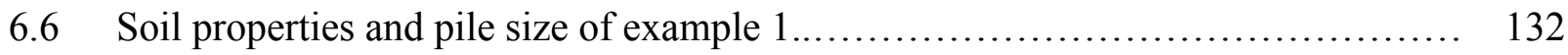

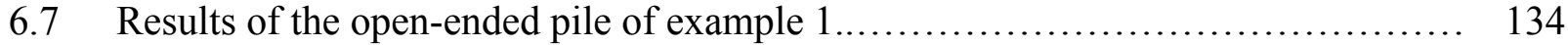

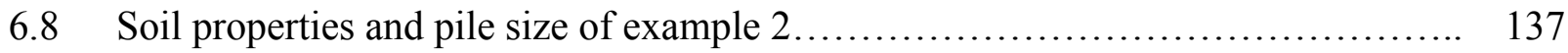

6.9 Results of the open-ended pile of example $2 \ldots \ldots \ldots \ldots \ldots \ldots \ldots \ldots \ldots \ldots \ldots \ldots \ldots \ldots$

6.10 Values of $\mathrm{K}$ and $\alpha$ for different soil types................................. 142

6.11 Values of $F_{1}$ and $F_{2}$ for different pile types............................... 143

6.12 Pile categories for selection of $\mathrm{n}_{\mathrm{s}}$ and $\mathrm{n}_{\mathrm{b}}$ according to Bazaraa \& Kurkur .......... 143

6.13 Factors $n_{s}$ and $n_{b}$ according to Bazaraa \& Kurkur (1986)..................... 144

6.14 Values of $\alpha_{2}$ for different soil and pile types.............................. 145

6.15 Values of $c_{b}$ for different soil and pile types............................. 146

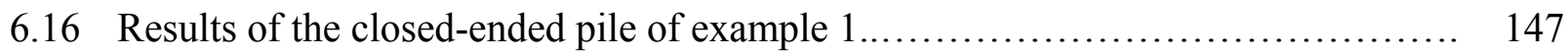

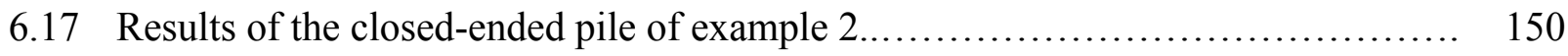

6.18 Cost evaluation for open-ended pile foundations............................ 154

6.19 Cost evaluation for closed-ended pile foundations.......................... 155

6.20 Pile length and cost driven in Indana $(11 / 17 / 1998-5 / 12 / 2002) \ldots \ldots \ldots \ldots \ldots \ldots \ldots \ldots$ 


\section{LIST OF FIGURES}

Figure Page

2.1 Stresses in soil plug for open-ended piles (after Randolph et al. 1991)........... 8

3.1 Test layout of pile load and in-situ tests.................................. 11

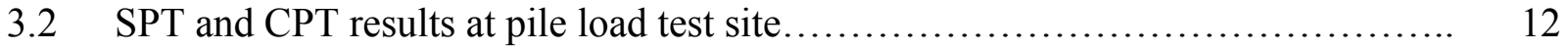

3.3 Schematic of test piles: (a) closed-ended pile and (b) open-ended pile............. 14

3.4 Determination of plug resistance and annulus resistance....................... 17

3.5 Measurement of soil plug length during pile driving......................... 19

3.6 Schematic view of static load test ......................................... 20

3.7 Driving record for open- and closed ended piles: (a) blow counts versus penetration depth, and (b) penetration depth per blow versus penetration depth.....

3.8 Variation of penetration resistances with penetration depth: (a) calculated base and shaft penetration resistances versus penetration depth, and (b) drivability versus penetration depth

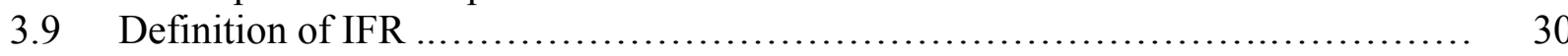

3.10 IFR and soil plug length versus penetration depth for open-ended pile............ 31

3.11 Distributions of residual loads measured along the closed-ended pile (CEP) and the inner and outer pipes of the open-ended pile (OEP) ..................... 33

3.12 Load-settlement curves for static and dynamic load tests...................... 37

3.13 Load distribution curves for closed-ended pile.............................. 39

3.14 Load distribution curves: (a) for base resistance of open-ended pile, and (b) for shaft resistance of open-ended pile.

3.15 Comparison between normalized unit base and shaft resistances of open- and closed-ended piles: (a) normalized unit base resistance, and (b) normalized unit shaft resistance.

3.16 Comparison between normalized unit inside and outside shaft resistances in openended pile.

4.1 Schematic of model pile in calibration chamber tests......................... 56

4.2 Load-settlement curves from model pile load tests........................... 59

4.3 Driving test results: (a) hammer blow count, and (b) soil plug length............. 61

4.4 IFR versus (a) relative density for $\sigma_{\mathrm{v}}{ }^{\prime}=98.1 \mathrm{kPa}$ and $\mathrm{K}_{0}=0.4$, (b) vertical stress for $\mathrm{D}_{\mathrm{R}}=90 \%$ and $\sigma_{\mathrm{h}}{ }^{\prime}=39.2 \mathrm{kPa}$, and (c) horizontal stress for $\mathrm{D}_{\mathrm{R}}=90 \%$ and $\sigma_{\mathrm{v}}{ }^{\prime}=$ $98.1 \mathrm{kPa} .$.

4.5 PLR versus IFR (a) for chamber test results, and (b) for other test results......... 66

4.6 Unit base resistance versus (a) relative density for $\sigma_{\mathrm{v}}{ }^{\prime}=98.1 \mathrm{kPa}$ and $\mathrm{K}_{0}=0.4$, (b) vertical stress for $\mathrm{D}_{\mathrm{R}}=90 \%$ and $\sigma_{\mathrm{h}}{ }^{\prime}=39.2 \mathrm{kPa}$, and (c) horizontal stress for $\mathrm{D}_{\mathrm{R}}=$ $90 \%$ and $\sigma_{\mathrm{v}}{ }^{\prime}=98.1 \mathrm{kPa}$. 
4.7 Normalized unit base resistance versus IFR (a) for $\sigma_{v}^{\prime}=98.1 \mathrm{kPa}$ and $\mathrm{K}_{\mathrm{o}}=0.4$, and

(b) for $\mathrm{D}_{\mathrm{R}}=90 \%$.

4.8 Unit shaft resistance (a) versus relative density for $\sigma_{v}^{\prime}=98.1 \mathrm{kPa}$ and $\mathrm{K}_{\mathrm{o}}=0.4$, (b) vertical stress for $\mathrm{D}_{\mathrm{R}}=90 \%$ and $\sigma_{h}^{\prime}=39.2 \mathrm{kPa}$, and (c) horizontal stress for $\mathrm{D}_{\mathrm{R}}=90 \%$ and $\sigma_{v}^{\prime}=98.1 \mathrm{kPa}$

$4.9 \quad$ Normalized field unit base resistance versus IFR ............................ 78

4.10 Normalized field unit shaft resistance versus IFR......................... 80

$4.11 \mathrm{CPT}$ and SPT results and OCR profile at test site.......................... 82

4.12 Load-settlement curves from field pile load test............................ 83

4.13 Comparison of predicted with measured load capacities; (a) example 1,

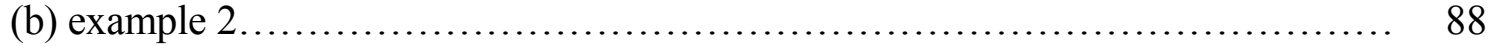

5.1 Test pile details used in calibration chamber load tests......................... 91

5.2 Unit load vs. settlement curves for (a) closed-ended pile base, (b) open-ended pile base, (c) closed-ended pile shaft, and (d) open-ended pile shaft ..................... 94

5.3 Load-settlement curves from field load tests for (a) pile base and (b) pile shaft...... 97

5.4 Base, plug and annulus resistance from field open-ended pile load tests............ 99

5.5 Normalized unit annulus resistance as a function of driving depth for calibration chamber open-ended piles............................................... 101

5.6 Normalized pile unit resistances for open-ended piles: (a) $\mathrm{q}_{\mathrm{b}} / \mathrm{q}_{\mathrm{c}}$ versus $\mathrm{D}_{\mathrm{R}}$, (b) $\mathrm{q}_{\mathrm{b}} / \mathrm{q}_{\mathrm{c}}$ versus IFR, (c) $\mathrm{q}_{\mathrm{plug}} / \mathrm{q}_{\mathrm{c}}$ versus $\mathrm{D}_{\mathrm{R}}$, (d) $\mathrm{q}_{\text {plug }} / \mathrm{q}_{\mathrm{c}}$ versus IFR, (e) $\mathrm{q}_{\mathrm{s}} / \mathrm{q}_{\mathrm{c}}$ versus $\mathrm{D}_{\mathrm{R}}$, and (f) $\mathrm{q}_{\mathrm{s}} / \mathrm{q}_{\mathrm{c}}$ versus IFR.

5.7 Normalized unit pile resistances for closed-ended piles: (a) $q_{b} / q_{c}$ versus $D_{R}$ and (b) $\mathrm{q}_{\mathrm{s}} / \mathrm{q}_{\mathrm{c}}$ versus $\mathrm{D}_{\mathrm{R}}$

5.8 Normalized load-settlement curves from field pile load test for (a) pile base and (b) pile shaft.

5.9 Normalized unit load vs. settlement curves for closed-ended piles (CEP) and openended piles (OEP) compared with lower and upper bounds of base resistance for driven piles.

5.10 Relationships between IFR and $\mathrm{L}_{\text {up }} / \mathrm{L}_{\mathrm{wp}}$ versus driving depth.................. 116

5.11 Relationship between normalized IFR (NIFR) and relative density $\mathrm{D}_{\mathrm{R}} \ldots \ldots \ldots \ldots \ldots 118$

6.1 Chart for estimating (a) bearing capacity factor $\mathrm{N}_{\mathrm{q}}$ (b) dimensionless factor $\alpha \ldots \ldots \quad 124$

6.2 Relationship between unit pile base resistance and friction angle for cohesionless

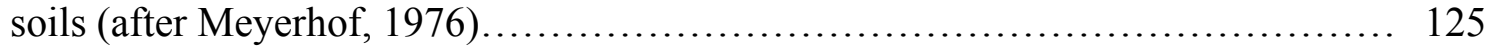

6.3 Design curves for evaluating $\mathrm{K}_{\delta}$ when (a) $\phi=25^{\circ}$, (b) $\phi=30^{\circ}$, (c) $\phi=35^{\circ}$, and (d) $\phi=40^{\circ}$.

6.4 (a) Correction factor for $\mathrm{K}_{\delta}$ when $\delta \neq \phi$. (b) Relation of $\delta / \phi$ and pile volume $\mathrm{v}$ for various types of piles (after Nordlund 1979).

6.5 Cone resistance $\mathrm{q}_{\mathrm{c}}$ and SPT N-value for pile load test site of example $1 \ldots \ldots \ldots \ldots . . \ldots 133$

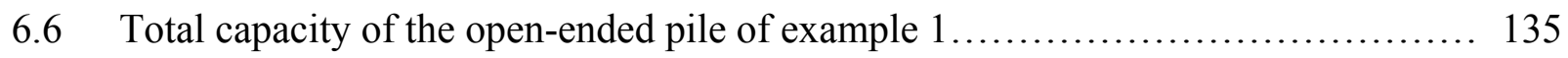

6.7 (a) Base capacity and (b) Shaft capacity of the open-ended pile of example 1...... 136

6.8 CPT profile for pile load test site of example $2 \ldots \ldots \ldots \ldots \ldots \ldots \ldots \ldots \ldots \ldots \ldots \ldots \ldots \ldots$ 


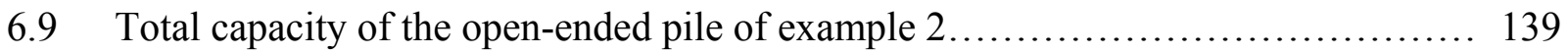

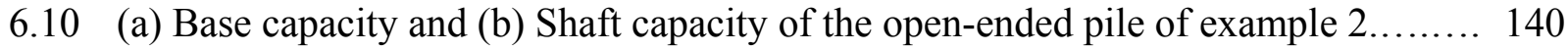

6.11 Total capacity of the closed-ended pile of example $1 \ldots \ldots \ldots \ldots \ldots \ldots \ldots \ldots \ldots \ldots \ldots$

6.12 (a) Base capacity and (b) Shaft capacity of the closed-ended pile of example 1.... 149

6.13 Total capacity of the closed-ended pile of example $2 \ldots \ldots \ldots \ldots \ldots \ldots \ldots \ldots \ldots \ldots \ldots \ldots$

6.14 (a) Base capacity and (b) Shaft capacity of the closed-ended pile of example 2.... 152

6.15 Schematic plot of the bridge carrying S.R. 157 over Lemon Creek................ 153

6.16 Cost evaluation for open-ended pile foundations........................... 154

6.17 Cost evaluation for closed-ended pile foundations.......................... 155 


\section{CHAPTER 1 \\ INTRODUCTION}

\subsection{Background}

With the growing interest of the geotechnical engineering profession and of the INDOT geotechnical engineering group, in particular, in the cone penetration test (CPT), it becomes essential to develop interpretation methods for the CPT that can be readily used by INDOT staff and that will produce accurate estimates of foundation load capacities. Project (SPR-2142) was completed, which aimed to develop one such method for piles. It was apparent after conclusion of that project that an insufficient number of instrumented pile load tests is available both in Indiana and in the general literature to yield the type of information that is required to develop a CPT-based pile design method that can be used reliably. Instrumented pile load tests permit separation of pile base and shaft loads during loading, information that is essential to ascertain whether the correct shaft and base capacities are being calculated.

Based on the method of installation, piles are classified as either displacement (driven) or non-displacement (bored) piles. The installation of non-displacement piles does not significantly change the state (density and stress state) of the soil. This allows the use of a variety of methods to determine the load capacity of non-displacement piles, including calibration chamber tests and numerical simulations (Lee and Salgado 1999a, 2000). These two approaches typically assume that soil conditions are the same before and after pile installation. Determination of pile load capacity for displacement piles, on the other hand, involves a higher degree of uncertainty, as installation induces marked changes in soil state around the pile. 
In certain areas of the U.S., pipe piles are often used in piling practice. Pipe piles can be either open-ended or closed-ended. It has been documented that the behavior of open-ended piles is different from that of closed-ended piles (Szechy, 1961; Carter et. al., 1979; Randolph et. al., 1979; Klos and Tejchman, 1981; Lu, 1985; Smith et. al., 1986, Paikowsky and Whitman, 1990). According to the field test results of Szechy (1959), the blow count necessary for driving a pile to a certain depth in sands is lower for an open-ended pile than for a closed-ended pile. Thus, it is generally acknowledged that an open-ended pile requires less installation effort than a closedended pile under the same soil conditions. Other research results (McCammon and Golder, 1970; Lu, 1985; Smith et al., 1986; Brucy et. al., 1991) have shown that the mode of pile driving is an important factor in driving resistance. If a pile is driven in a fully coring (or fully unplugged) mode, soil enters the pile at the same rate as it advances. On the other hand, if a pile is driven under plugged or partially plugged conditions, a soil plug attaches itself to the inner surface of the pile, preventing additional soil from entering the pile. A pile driven in the plugged mode behaves similarly as a closed-ended pile. Typically, a large-diameter pipe pile driven in sand will tend to be driven in a fully coring mode, while smaller diameter piles will plug, at least partially. Larger penetration depths and lower relative densities facilitate soil plug formation.

In order to study the load capacity of open-ended piles bearing in sand, both an openended and a closed-ended pipe pile with the same diameter $(356 \mathrm{~mm})$ were driven to roughly the same depth $(7 \mathrm{~m})$ at the same site. The base of each pile was embedded in a sand layer. The piles were fully instrumented before driving, and load-tested to failure. Cone penetration tests and SPTs were performed both before and after driving at several locations both close and away from the piles. Based on results from the field pile load tests and calibration chamber load tests, design methods for estimation of pile load capacity are presented. 


\subsection{Problem Statement}

It is known that a short open-ended pile has lower load capacity than an equivalent closed-ended pile. However, as pile length (or penetration depth) increases, the load capacity of the open-ended pile approaches that of the equivalent closed-ended pile. This is due to the greater degree of soil plugging with larger penetration depth (Klos and Tejchman, 1981; Paikowsky and Whitman, 1990). According to Szechy (1961), the settlement of an open-ended pile is greater than that of a closed-ended pile under the same load and soil conditions. This means that, if ultimate load capacity is defined with reference to a standard settlement of $10 \%$ of the pile diameter, for example, the load capacity of open-ended piles is typically lower than that of closed-ended piles. However, the difference in load capacities varies within a wide range, depending on the degree of soil plugging during driving. Lehane and Randolph (2001), for example, postulate that pipe piles driven in fully coring mode have base capacity only slightly higher than that of non-displacement piles, while piles driven in fully plugged mode develop base capacities that approach those of closed-ended piles. Despite the overwhelming impact of soil plug formation on pile capacity, most design criteria do not satisfactorily consider the soil

plug contribution to the load capacity of open-ended piles. Developing design approaches for open-ended piles that consider soil plug effect is one of the main objectives of the present research. 


\subsection{Objectives of Study}

The objectives of the present research project are to perform well-planned instrumented pile load tests and to further develop pile design methods. Detailed goals are as follows:

(1) Performance of fully-instrumented pile load tests.

(2) Development of design methods for estimation of pile load capacities of closedand open-ended pipe piles.

(3) Validation of CPT-based pile design methods in sand. 


\section{CHAPTER 2}

\section{LOAD CARRYING MECHANISMS OF PIPE PILES}

\subsection{Displacement versus Non-Displacement Piles}

For both non-displacement and displacement piles, the total pile load capacity consists of shaft and base capacities, as given by:

$$
Q_{t}=Q_{s}+Q_{b}
$$

where $\mathrm{Q}_{\mathrm{t}}=$ total pile load capacity; $\mathrm{Q}_{\mathrm{s}}$ and $\mathrm{Q}_{\mathrm{b}}=$ shaft and base load capacities. Since the subsoil profile is in general not homogeneous, the calculation of the shaft load capacity requires division of the entire soil profile into several layers. It is usually observed that the maximum shaft resistance is mobilized at early loading stages, well before the maximum base resistance is mobilized. When both the shaft and base resistance have been fully mobilized, the applied load can no longer increase, leading to plunging of the pile. The magnitude of the base resistance at this stage is referred to as the limit base resistance $\mathrm{q}_{\mathrm{bL}}$, and is usually attained, if at all, at very large settlements (Salgado 1995, Lee and Salgado 1999a).

The limit base resistance $\mathrm{q}_{\mathrm{bL}}$ is theoretically the same for geometrically identical nondisplacement and displacement piles and the same initial soil conditions. It is also closely approximated by the cone resistance $\mathrm{q}_{\mathrm{c}}$ at the pile base level (De Beer 1984, 1988, Ghionna et al. 1993, Lee and Salgado 1999a). For low to moderate settlement levels, however, the loadsettlement responses of displacement and non-displacement piles are significantly different (De Beer 1984, 1988). This difference is due to differences in the installation process. The installation of displacement piles causes considerable change in the soil state around the pile. 
This process could be seen as preloading of the soil in the immediate neighborhood of the pile base and shaft, hence the stiffer response when compared with non-displacement piles (Lee and Salgado 1999a, b). However, the difference between the pile base loads carried by the two types of piles for the same settlement level becomes less pronounced as the load approaches the limit base load at theoretically infinite settlement (Jamiolkowski and Lancellotta 1988, Ghionna et al. 1993).

\subsection{Pipe Piles}

Closed-ended pipe piles are displacement piles. The behavior of open-ended piles is more complex, with a response generally intermediate between that of non-displacement and displacement piles. As an open-ended pile is driven into the soil, a soil column (or soil plug) forms inside the pile. The length of this plug may be equal to or less than the pile driving depth. If it is the same, the pile has been driven in a fully coring or unplugged mode throughout. If driving takes place in a partially or fully plugged mode at least during part of the way, the length of the soil plug within the pile will be less than that of the pile. It may be possible to observe all three driving modes (fully coring, partially plugged or fully plugged) during the driving of a single pile (Paikowski et al. 1989).

When the pile is loaded statically, after installation is completed, its capacity will depend on the response of the soil plug, in addition to resistances mobilized at the pile annulus and along the pile shaft. Thus, for open-ended pipe piles, (2.1) applies with the base capacity defined as

$$
Q_{b}=Q_{\text {plug }}+Q_{a n n}
$$

where $\mathrm{Q}_{\mathrm{b}}=$ base capacity; $\mathrm{Q}_{\text {plug }}=$ soil plug capacity; and $\mathrm{Q}_{\mathrm{ann}}=$ annulus capacity. 
Although the installation of open-ended piles imparts less change to the surrounding soil than closed-ended or full displacement piles, the soil conditions are certainly different from those before installation (Randolph et al. 1979, Nauroy and Le Tirant 1983). The unplugged or fully coring mode is commonly observed during the initial stages of pile driving. As penetration and formation of the soil plug continue, internal frictional resistance mobilizes between the inner pile surface and the soil plug, densifying the lower part of the soil plug. However, some soil continues to enter the pile, characterizing partially plugged driving. Finally, with further driving, soil intrusion is prevented by the now sufficiently high frictional resistance between the soil plug and inner pile surface and by the large soil plug stiffness. The behavior of the open-ended pile at this stage is nearly identical to that of a closed-ended pile, and driving is said to take place under fully plugged conditions.

Several authors have investigated the behavior of open-ended piles both experimentally and analytically (Smith et al. 1986, O'Neill and Raines 1991, Randolph et al. 1991,1992, Paik and Lee 1993, De Nicola and Randolph 1997). Randolph et al. (1991) suggested a formulation for soil plug resistance based on one-dimensional equilibrium. Considering the stresses shown in Fig. 2.1:

$$
\frac{d \sigma_{v}^{\prime}}{d z}=\gamma^{\prime}+\frac{4}{B_{i}} \beta \sigma_{v}^{\prime}
$$

where $\sigma^{\prime}{ }_{\mathrm{v}}=$ effective vertical stress within the soil plug; $\mathrm{B}_{\mathrm{i}}=$ internal pile diameter; $\mathrm{z}=$ depth from the top of the soil plug; $\gamma^{\prime}=$ effective unit weight of soil plug; $\beta=$ ratio of shear stress between the plug and the pile inner surface to $\sigma_{\mathrm{v}}^{\prime}$. Integrating $(2.3)$, the stress $\left(\sigma_{\mathrm{v}}^{\prime}\right)$ within the soil plug and the total soil plug resistance $\left(\mathrm{q}_{\text {plug }}\right)$ can be obtained as:

$$
\sigma_{v}^{\prime}=\left(p_{u}+\frac{\gamma^{\prime} B_{i}}{4 \beta}\right) \exp \left(\frac{4 \beta}{B_{i}} z\right)-\frac{B_{i}}{4 \beta} \gamma^{\prime}
$$




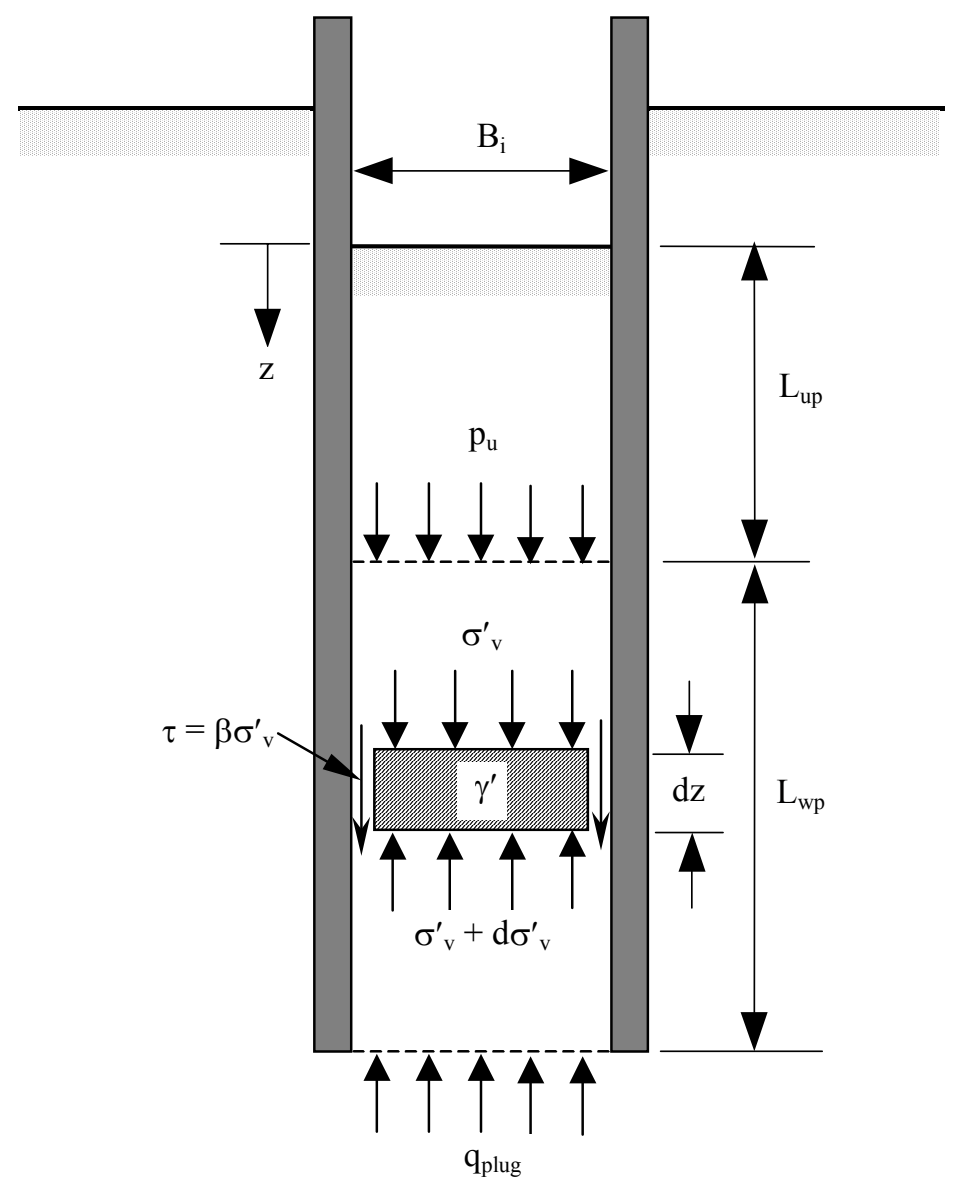

Figure 2.1 Stresses in soil plug for open-ended piles (after Randolph et al. 1991). 
so that

$$
\frac{q_{p l u g}}{\gamma^{\prime} L_{w p}}=\left[\frac{L_{u p}}{L_{w p}}+\left(\frac{B_{i}}{L_{w p}}\right) \frac{1}{4 \beta}\right] \exp \left(\frac{4 \beta L_{w p}}{B_{i}}\right)-\left(\frac{B_{i}}{L_{w p}}\right) \frac{1}{4 \beta}
$$

where, $\mathrm{p}_{\mathrm{u}}=$ surcharge from unwedged soil plug; $\mathrm{L}_{\mathrm{wp}}$ and $\mathrm{L}_{\mathrm{up}}=$ wedged and unwedged plug length. Detailed derivation of (2.4) and (2.5) can also be found in O'Neill and Raines (1991). If the values of $\mathrm{L}_{\mathrm{wp}}$ (or $\mathrm{L}_{\mathrm{up}}$ ), $\beta$, and $\gamma^{\prime}$ are known, the soil plug resistance $\mathrm{q}_{\text {plug }}$ can be calculated from (2.5). While one-dimensional plug analysis is an attractive formulation of the problem of the plug capacity of open-ended piles, it requires estimates of $L_{w p}$ and $\beta$, which presents some difficulties. It appears desirable to have an alternative method, where plug capacity could be directly estimated from an in-situ test, such as the cone penetration test (CPT). The rest of this report is devoted to establishing this relationship, as well as the relationship between all other components of load capacity for both closed- and open-ended piles and CPT cone resistance. 


\section{CHAPTER 3 \\ FIELD PILE LOAD TESTS}

\subsection{Site Description}

The test site is located on the south side of a bridge construction site over the Pigeon River, on State Road 9, at Lagrange County in Indiana. As shown in the test layout of Fig. 3.1, a total of three SPT, designated $\mathrm{S}_{1}$ through $\mathrm{S}_{3}$, and 5 CPTs $\left(\mathrm{C}_{1}\right.$ through $\left.\mathrm{C}_{5}\right)$ were conducted before and after pile installation. Approximately $2 \mathrm{~m}$ of the fill material around the test piles were removed before pile driving. From SPT split soil samples obtained at different depths, the soil at the site is predominantly gravelly sand down to a depth of around $13 \sim 14 \mathrm{~m}$. At greater depths, stiff till, containing clays and silts, is found.

The maximum and minimum dry unit weights of the gravelly sand were $18.64 \mathrm{kN} / \mathrm{m}^{3}$ and $15.61 \mathrm{kN} / \mathrm{m}^{3}$, respectively. The corresponding maximum and minimum void ratios were 0.68 and 0.41 , respectively, based on the measured specific gravity $\left(\mathrm{G}_{\mathrm{S}}\right)$, equal to 2.67 . The critical-state friction angle measured from triaxial compression tests was $33.3^{\circ}$. Grain size analysis shows the gravelly sand to contain no fines.

Results of SPTs and CPTs performed before pile driving are shown in Figs. 3.2. These results indicate that the first 3 meters of the gravelly sand deposit are in a loose state, while the rest of the deposit down to a depth of $13-14 \mathrm{~m}$ is in dense to very dense state, with SPT N values ranging from 15 to 60 , and $q_{c}$, from 15 to $25 \mathrm{MPa}$. 


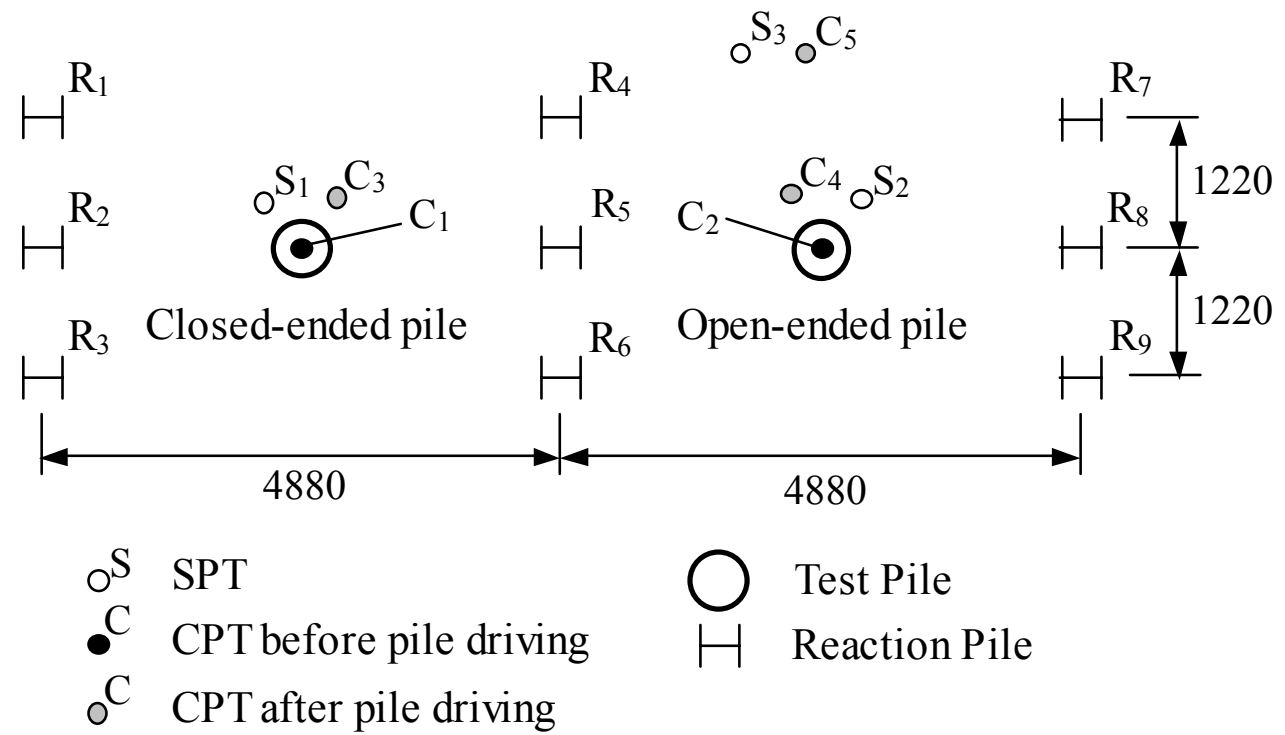

All dimensions in $\mathrm{mm}$

Figure 3.1 Test layout of pile load and in-situ tests. 


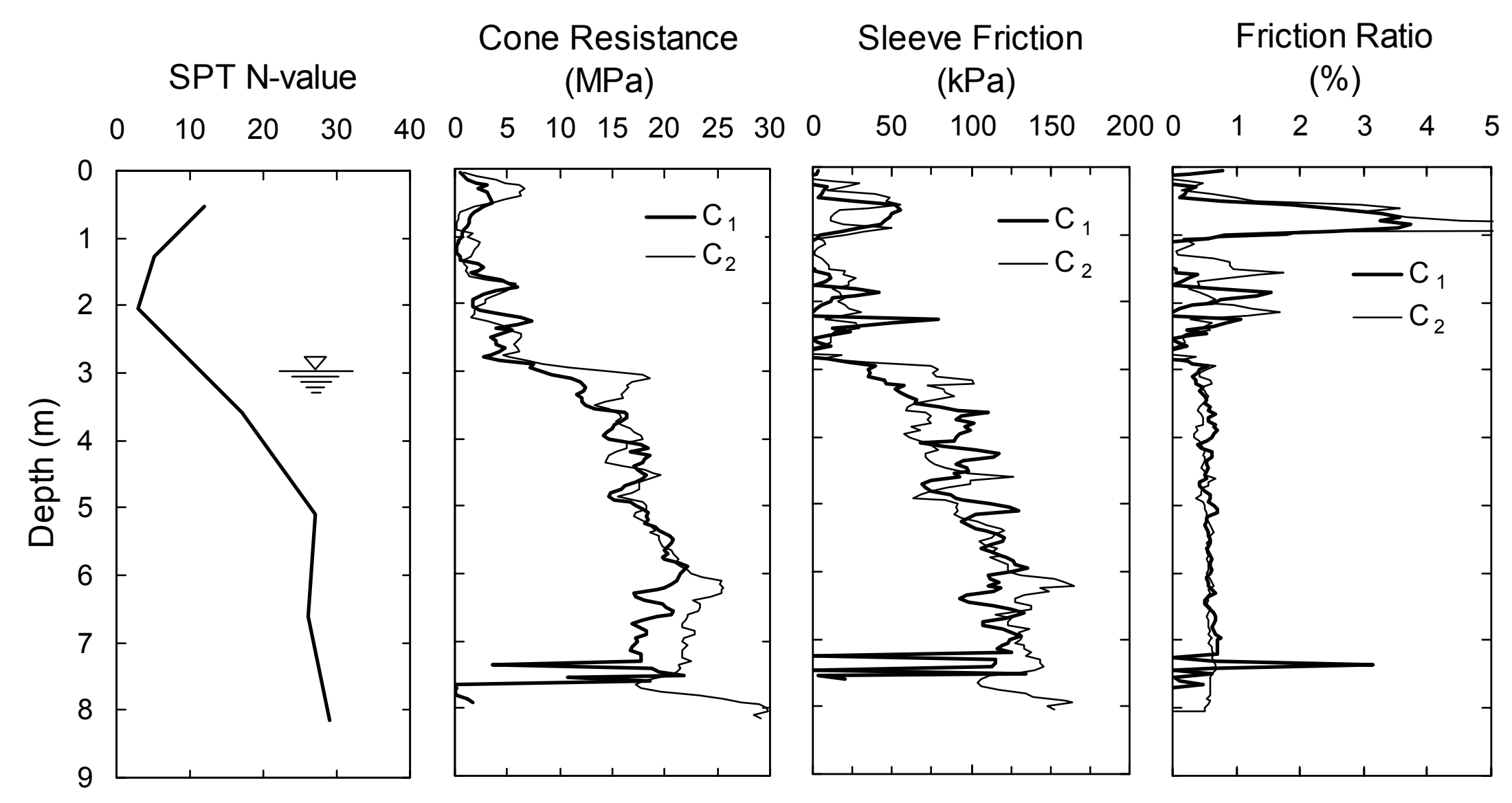

Figure 3.2 SPT and CPT results at pile load test site 


\subsection{Experimental Procedures}

\subsubsection{Test Pile Details and Instrumentation}

The load capacity of closed-ended piles consists of two components: base and shaft resistances. For open-ended pipe piles, base capacity is further decomposed into annulus and plug resistance (Paikowsky and Whitman, 1990; API, 1991). In many model and field pile load tests on conventional closed-ended piles, strain gauges have been used to separate base and shaft resistance from the total load. For partially plugged open-ended piles, a common case in practice, the pile load capacity is composed of plug, annulus and shaft resistances. In order to separate all the resistance components of open-ended piles, the instrumented double walled pile system (Paik and Lee, 1993; Choi and O'Neill, 1997) can be used. This technique has been applied to many model pile tests done in calibration chambers, but had never been used in full-scale field tests.

In this study, both closed- and open-ended piles were instrumented using the techniques mentioned above to separate the different components of pile load capacity (base and shaft resistances for the closed-ended pile; and annulus, plug, and shaft resistances for the open-ended pile). The closed-ended test pile had an outside diameter of $356 \mathrm{~mm}$, wall thickness equal to 12.7 $\mathrm{mm}$, and length equal to $8.24 \mathrm{~m}$. Eighteen strain gauges were attached directly opposite each other at nine levels along the pile shaft, as shown in Fig. 3.3(a). Strain gauges were placed closer together near the pile base, since the load transfer rate tends to be higher in that part of the pile.

The open-ended test pile was assembled by combining two pipe piles with different diameters. The outside diameters of the outer and inner pipes were $356 \mathrm{~mm}$ and $305 \mathrm{~mm}$, respectively; both had the same wall thickness of $6.4 \mathrm{~mm}$. Twenty strain gauges were attached at ten different elevations to the outside surface of the inner pipe so as to separate the base 


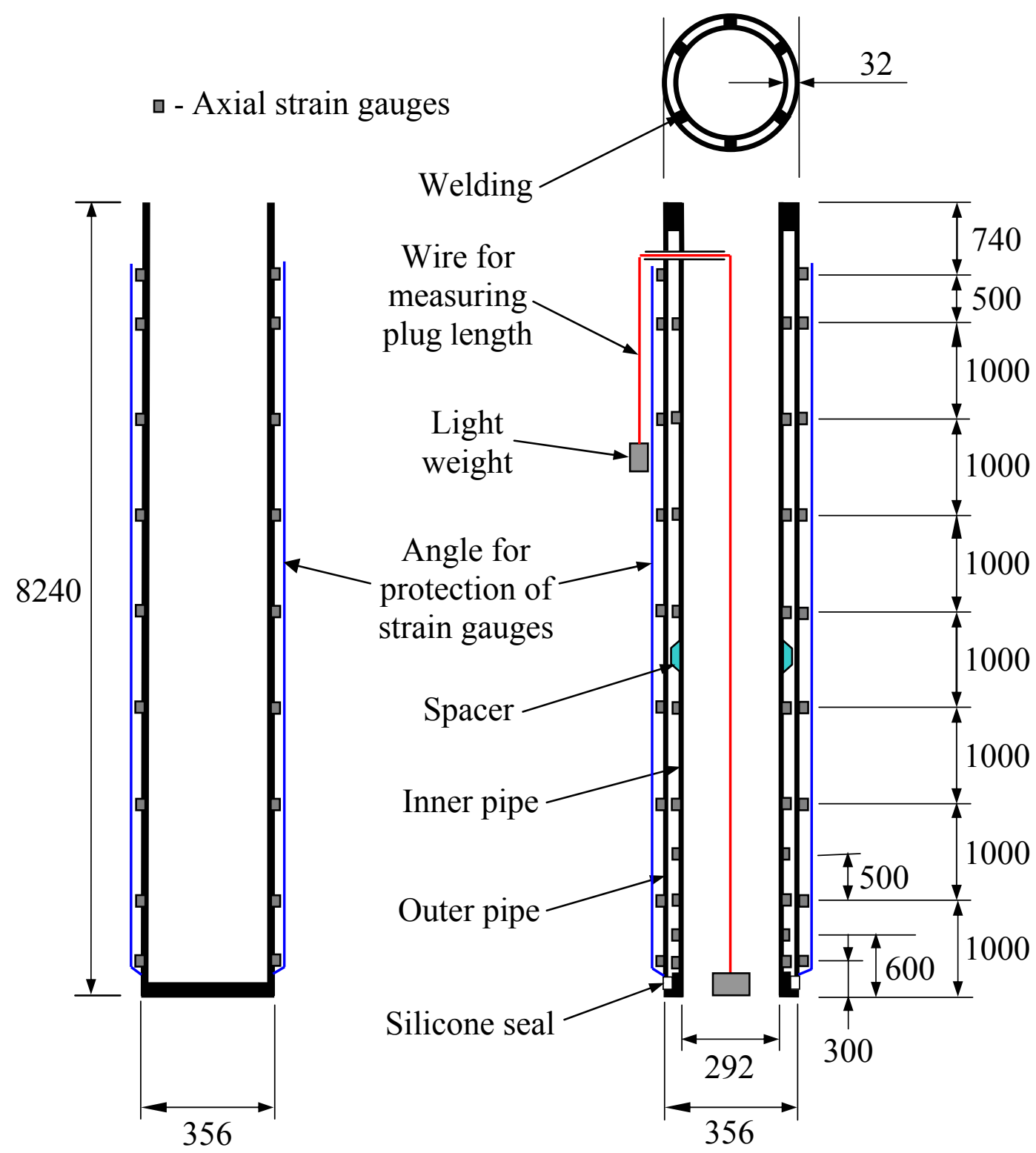

(a)

(b)

(All dimensions in $\mathrm{mm}$ )

Figure 3.3 Schematic of test piles: (a) closed-ended pile and (b) open-ended pile. 
resistance into plug and annulus resistances. Eighteen strain gauges were also attached to the outside surface of the outer pipe (i.e., pile shaft) at nine different elevations to measure the distribution and magnitude of the shaft resistance. The detailed configuration of the instrumentation for the open-ended pile is shown in Fig. 3.3(b). All strain gauges attached to the closed- and open-ended test piles were sealed with silicon to protect them from groundwater, and then covered with an angled steel plate to prevent damage from direct contact between the strain gauges and the soil during pile driving. After completion of strain gauge installation, the inner pipe was inserted into the outer pipe. Four spacers were welded to the outside surface of the inner pipe to center it with respect to the outer pipe, preventing buckling of the inner pipe upon application of load at the pile head. The assembled open-ended pile had outside and inside diameters of $356 \mathrm{~mm}$ and $292 \mathrm{~mm}$, and length equal to $8.24 \mathrm{~m}$, the same length as for the closedended pile. Detailed information for load test design is included in an appendix.

In order to measure the soil plug length during pile driving, two different weights were used. The weights were connected to each other by means of a steel wire. The heavier weight was placed inside the pile and rested on top of the soil plug during pile driving. The lighter weight hanged outside the pile. This allowed measurement of the soil plug length by referring to the location of the lighter weight during pile driving [see Fig. 3.3(b)]. A gap of $30 \mathrm{~mm}$ between the outer pipe and the pile toe prevented the base resistance from being transferred to the outer pipe. This gap was sealed with silicon to avoid intrusion of soil particles into the gap during pile driving.

The values obtained from the strain gauges were transformed into loads using the elastic load-strain relations for each pile. The base resistance of the open-ended pile, which is partly due 
to the resistance of the annular area, partly due to the soil plug resistance, was measured from the strain gauges on the inner pipe, as shown in Fig. 3.4. The annulus and plug resistances were estimated under the assumption that frictional resistance between the pile and soil plug is the same between the lowest strain gauge and the pile base as it is between the lowest and second lowest strain gauge. In general, the frictional resistance between the soil plug and the pile increases dramatically near the pile base. The linear extrapolation used herein to estimate the

plug resistance, therefore, may result in a slight underestimation of the plug resistance. The shaft resistance of the open-ended pile was obtained both from the strain gauges attached to the outer pipe and from the difference between the total and base resistances. There was a good match between these two values (the shaft resistance obtained from the strain gauges was $98 \%$ of the difference between the total and base resistance). The base resistance of the closed-ended pile was also estimated by assuming the shaft resistance to be the same between the last strain gauge and the pile base as between the two lowest strain gauges.

\subsubsection{Pile Driving and Dynamic Testing}

The open- and closed-ended piles were driven using an ICE 42-S single acting diesel hammer, which has a ram weight of $18.2 \mathrm{kN}$ with a maximum hammer stroke of $3.12 \mathrm{~m}$ and a rated maximum driving energy of $56.8 \mathrm{kN} \cdot \mathrm{m}$. The open- and closed-ended piles were driven to depths of $7.04 \mathrm{~m}$ and $6.87 \mathrm{~m}$, respectively. Because the ground surface at the test site slopes gently, the pile base was at the same level for both piles.

Dynamic load tests were performed on both piles both during driving and during the restriking, 8 days after completion of the static load tests. Two strain transducers and two piezoelectric accelerometers were attached to the outside wall of the closed-ended pile, and to 


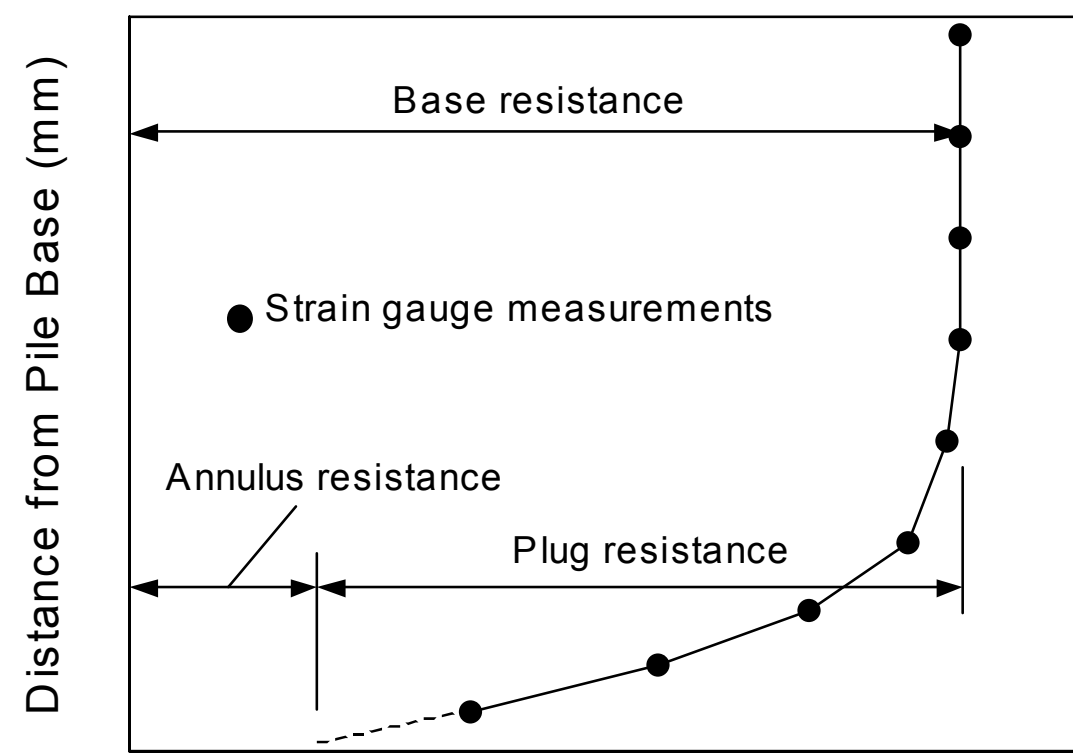

Vertical Load in Soil Plug (kN)

Figure 3.4 Determination of plug resistance and annulus resistance. 
the inside wall of the open-ended pile. The actual driving energy delivered to the pile head was about $36 \%$ of the free fall energy of the ram. The delivered energy during the series of blows ranged from 19.0 to $28.5 \mathrm{kN} \cdot \mathrm{m}$ and caused the permanent displacement per blow of the piles to vary from $9 \mathrm{~mm}$ to $15 \mathrm{~mm}$ per blow. The pile capacities of both the closed- and open-end piles were estimated by GRL and Associates (2000) based on signal matching analysis using CAPWAP (GRL and Associates, 1997).

During pile driving, the hammer blow count necessary for driving the test piles was recorded to investigate the drivability of similar closed- and open-ended piles under the same driving energy and soil conditions. As shown in Fig.3.5, the soil plug length during pile driving was also measured continuously using the two weights described earlier. The heavier weight rested on top of the soil plug during pile driving, and the lighter weight hanged by the wire joining the two weights outside the pile. A scale, marked on the outside of the pile, allowed measurement of the length of the soil plug inside the pile. This, in turn, allows calculation of the incremental filling ratio, IFR, which is defined as the increment in soil plug length per unit increase of penetration depth.

\subsubsection{Static Load Tests}

The load test setup is illustrated in Fig. 3.6. The total load applied to the pile head during each static load test was measured by a load cell with a capacity of $2.0 \mathrm{MN}$. The vertical settlement of the pile head was measured by two dial gauges attached to reference beams with supports placed at least 6.8 pile diameters away. The values of all strain gauges attached to both test piles were re-zeroed both before pile driving and at the start of the load tests in order to independently measure both the residual loads after pile driving and the loads induced along the 


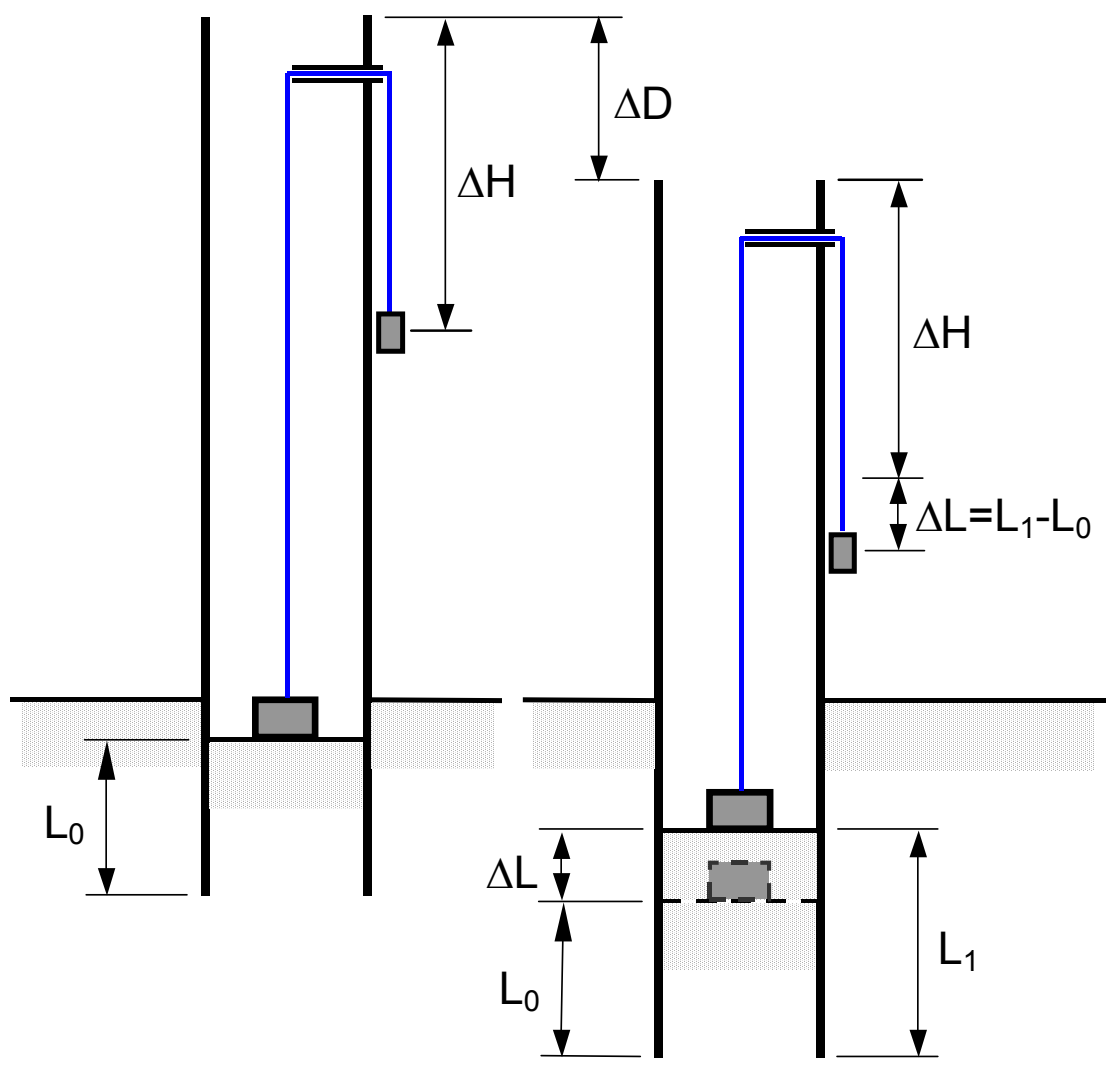

Figure 3.5 Measurement of soil plug length during pile driving. 


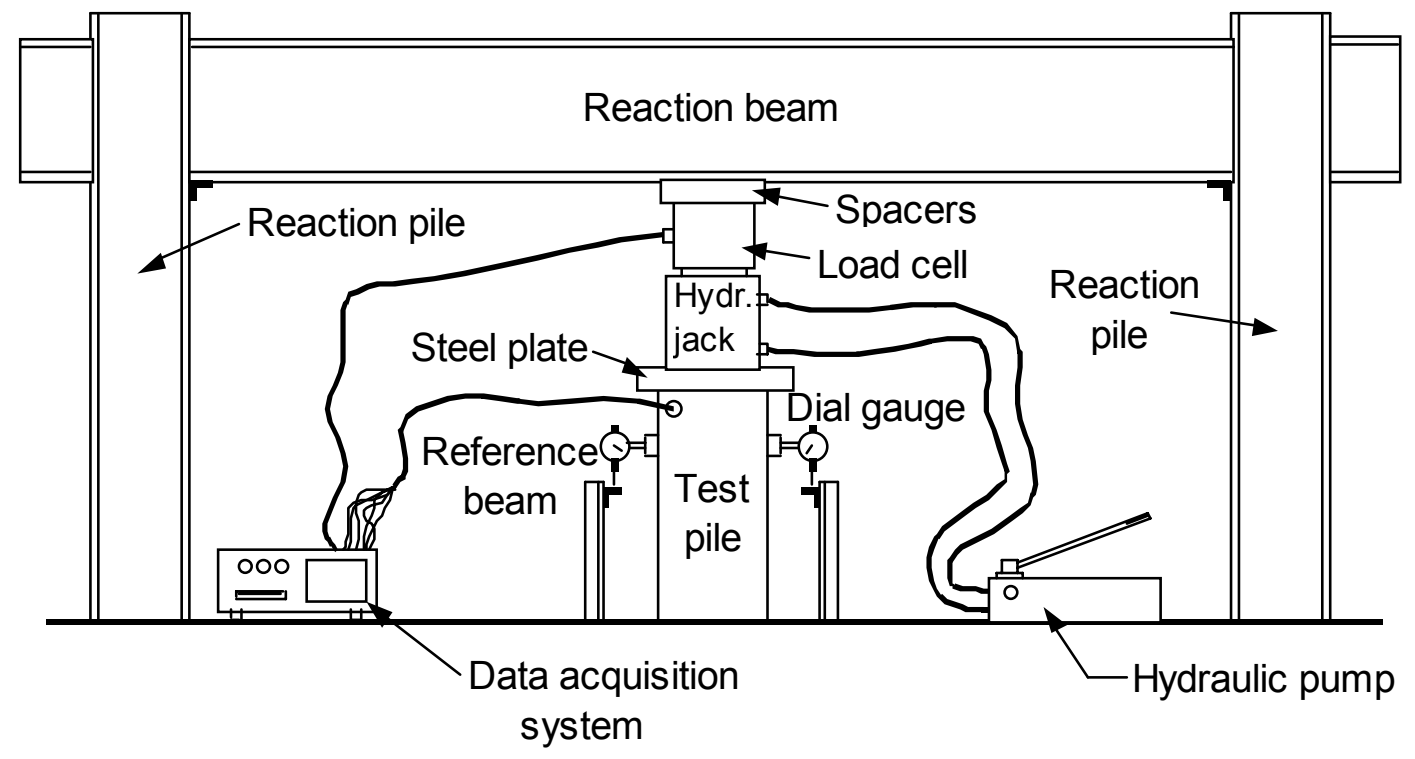

Fig. 3.6 Schematic view of static load test 
length of the test piles during the load tests. The soil plug length was measured both before and after the static load tests in order to detect any possible change of IFR.

The load was applied to the test pile in increments of $147 \mathrm{kN}$; this increment was reduced to $49-98 \mathrm{kN}$ near the end of the test. Each load was maintained until the settlement rate stabilized at less than $0.5 \mathrm{~mm} / \mathrm{hr}$. During each load step, the settlements at the pile head were recorded at 5 , $15,35,55,75,95$, and $120 \mathrm{~min}$. When settlement stabilization required longer than two hours, the settlement was measured after stabilization ensued. Strain gauge measurements were taken for every loading step at the time of settlement stabilization.

\subsubsection{Determination of Limit Load Capacity}

The limit load capacity of a pile may be defined in a general way as the load at which the increase of pile settlement for even a small load increment becomes very high. In this study, the static load tests were continued until the pile settlement reached about 14.6-15.2 cm (about 42\% of the outside pile diameter) for both the open- and closed-ended piles.

There are different ways to extrapolate the load-settlement curves beyond $42 \%$ of the pile diameter to estimate the limit load. In this study, Chin's method was used to estimate the limit load capacity of both piles. The method (Chin, 1970) is based on the assumption that the loadsettlement relation is hyperbolic:

$$
\frac{s}{Q}=C_{1} \cdot s+C_{2}
$$

in which $\mathrm{Q}=$ load applied to the pile; $\mathrm{s}=$ settlement corresponding to the load $\mathrm{Q} ; C_{1}$ and $C_{2}=$ slope and intercept of the load-settlement curve in s/Q vs. s space. The limit load capacity is 
equal to $1 / C_{1}$.

Test results show that the shaft resistance reached a limit value well before the final load step, while the base resistance was still increasing at the final load step. Thus, the limit shaft load capacities of the closed- and open-ended piles were determined as those mobilized at the final load step. The limit total load capacity was obtained for each pile by adding the limit base load capacity estimated by the method of Chin to the measured limit shaft load capacity. In the case of the open-ended pile, the Chin extrapolation was done for the base load $\left(\mathrm{Q}_{\mathrm{b}}\right)$, which is a summation of the plug load $\left(\mathrm{Q}_{\text {plug }}\right)$ and the annulus load $\left(\mathrm{Q}_{\mathrm{ann}}\right)$. The resulting limit base capacity was then separated into a limit annulus capacity and a limit plug capacity in the same proportion as $\mathrm{Q}_{\mathrm{ann}} / \mathrm{Q}_{\mathrm{plug}}$ for the last loading step of the pile load test.

\subsection{Experimental Results}

\subsubsection{Driving Resistance}

The hammer blow count required for driving the two test piles down to the final penetration depth and penetration depth per blow are plotted versus pile penetration depth in Fig. 3.7. It can be seen in Fig. 3.7(a) that the cumulative hammer blow count for the open-ended pile was consistently lower than for the closed-ended pile. For a penetration depth of $6.87 \mathrm{~m}$, which is the final penetration depth for the closed-ended pile, the cumulative blow counts were 250 and 211 blows for the closed- and open-ended piles, respectively. The difference in hammer blow counts between the open- and closed-ended piles was quite significant initially, but decreased gradually as the penetration depth increased. This is consistent with the results of Szechy (1959), who showed that the blow count required for driving open-ended piles approaches the blow 


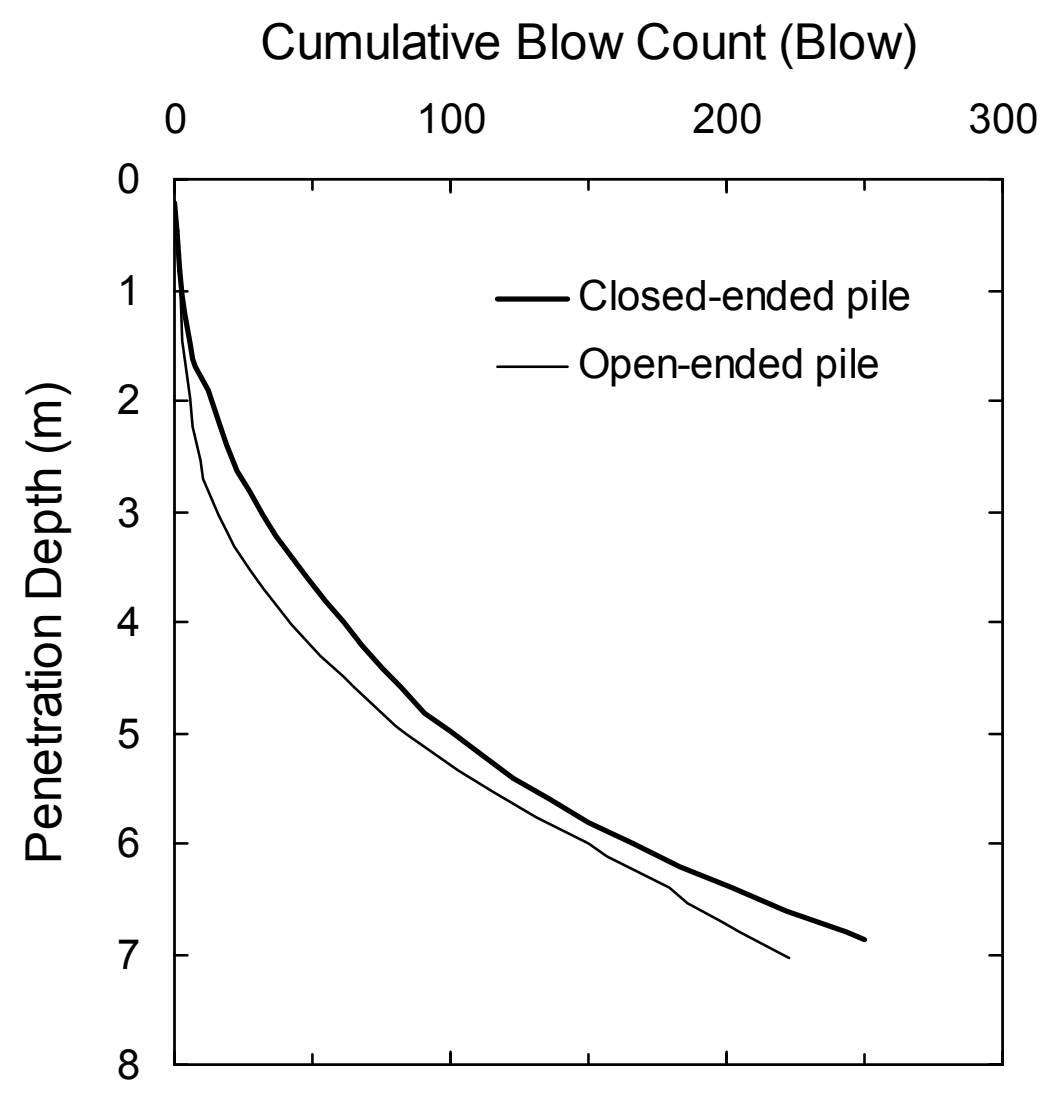

(a)

Figure 3.7 Driving record for open- and closed-ended piles: (a) blow counts versus penetration depth, and (b) penetration depth per blow versus penetration depth. 


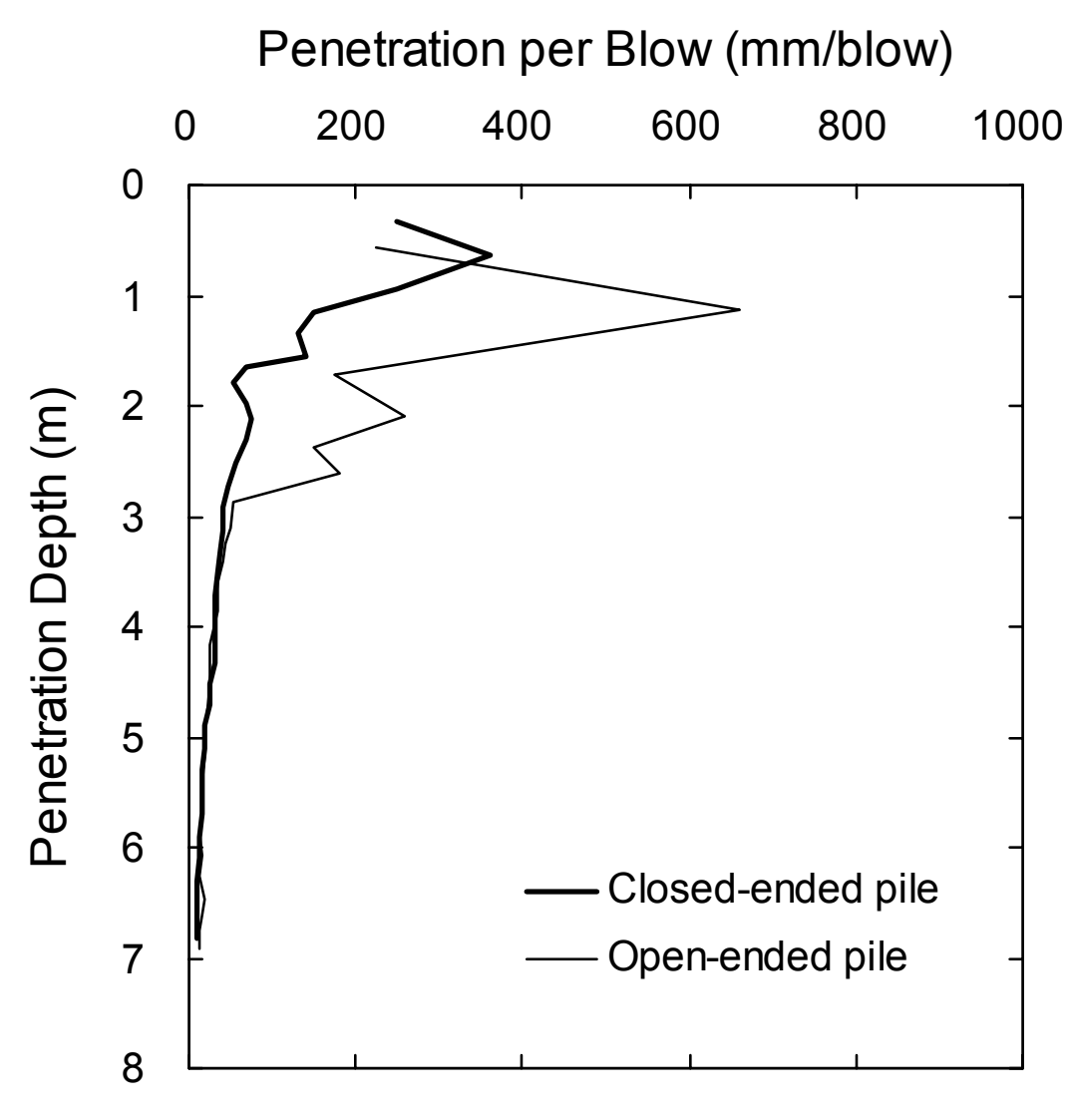

(b)

Figure 3.7 Driving record for open- and closed-ended piles: (a) blow counts versus penetration depth, and (b) penetration depth per blow versus penetration depth(continued). 
count required for driving closed-ended piles with increasing penetration depth. This can be seen more clearly in Fig. 3.7(b), which shows pile penetration depth vs. penetration depth per blow. As shown in the figure, the penetration depth per blow for the open-ended pile was greater than for the closed-ended pile until a penetration depth approximately equal to $3.5 \mathrm{~m}$. After $3.5 \mathrm{~m}$, which is approximately 10 times the outside pile diameter, the penetration rate for the openended pile is nearly the same as for the closed-ended pile. This can be attributed to the increase of penetration resistance for the open-ended pile due to the increasing degree of soil plugging with penetration depth.

The rate of pile penetration during pile driving depends on the dynamic penetration resistance developed along the pile shaft and base. In order to identify the relative effect of base and shaft resistances on the rate of pile penetration, the static shaft penetration resistance $\left(R_{s}\right)$ and base penetration resistance $\left(R_{b}\right)$ were estimated at every penetration depth using the CPT results, as follows:

$$
\begin{gathered}
R_{s}=\sum f_{s i} \cdot \Delta A_{s i} \\
R_{b}=q_{c} \cdot A_{b}
\end{gathered}
$$

in which $f_{s i}=\mathrm{CPT}$ sleeve friction for each sub-layer $i ; \Delta A_{s i}=$ shaft area of piles for each sublayer $i ; q_{c}=$ cone resistance; $A_{b}=$ gross base area of piles. The indices calculated in (3.2) and (3.3) are clearly not accurate representations of the actual resistances during driving. These indices were used only for assessing qualitatively the relationship between trends in base and shaft dynamic resistances and pile driving resistance. The calculated shaft and base penetration resistances for the open- and closed-ended piles were plotted together with the blow counts per unit penetration versus penetration depth in Fig. 3.8. It can be seen in Fig. 3.8(a) that the 


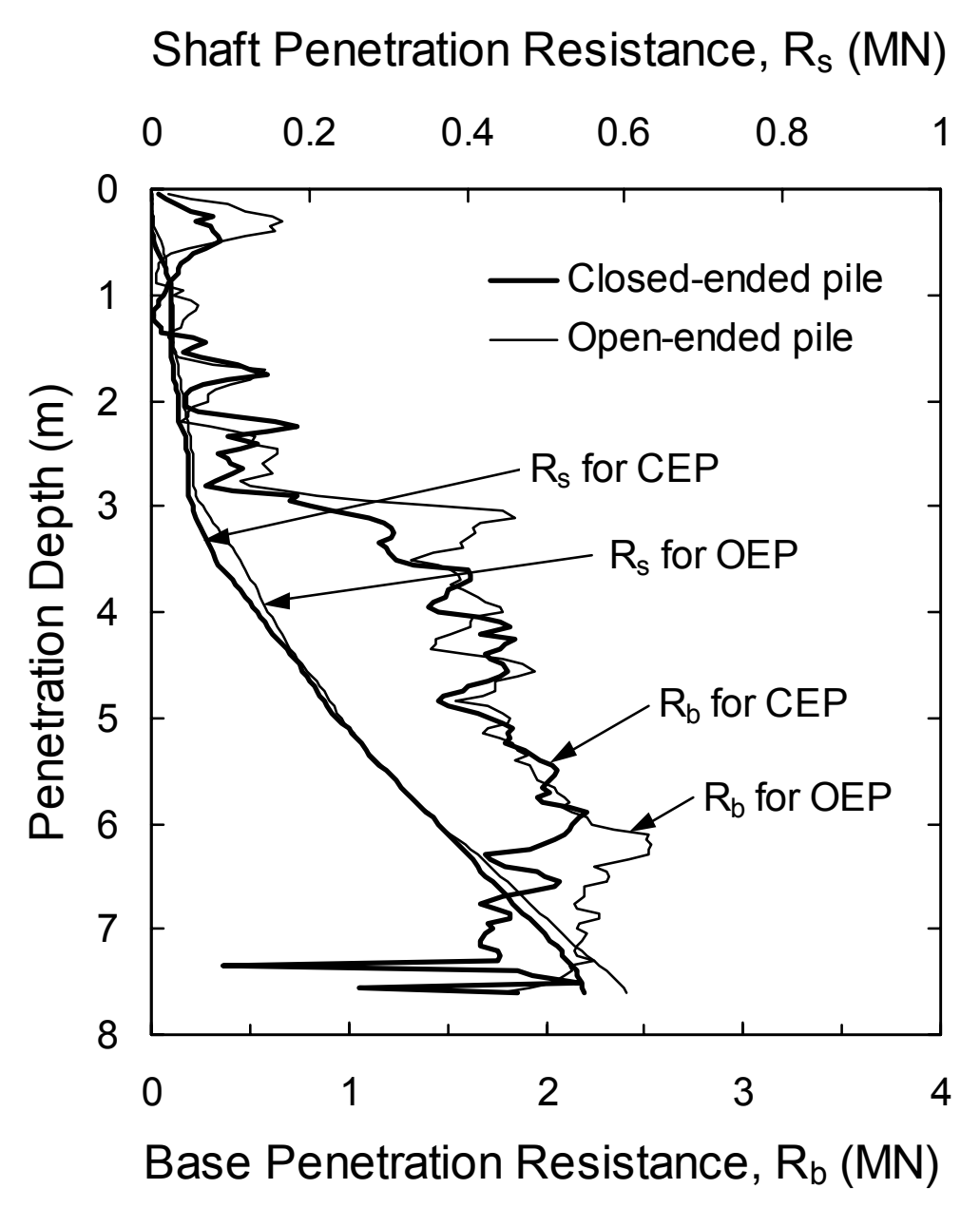

(a)

Figure 3.8 Variation of penetration resistances with penetration depth: (a) calculated base and shaft penetration resistances versus penetration depth, and (b) drivability versus penetration depth. 

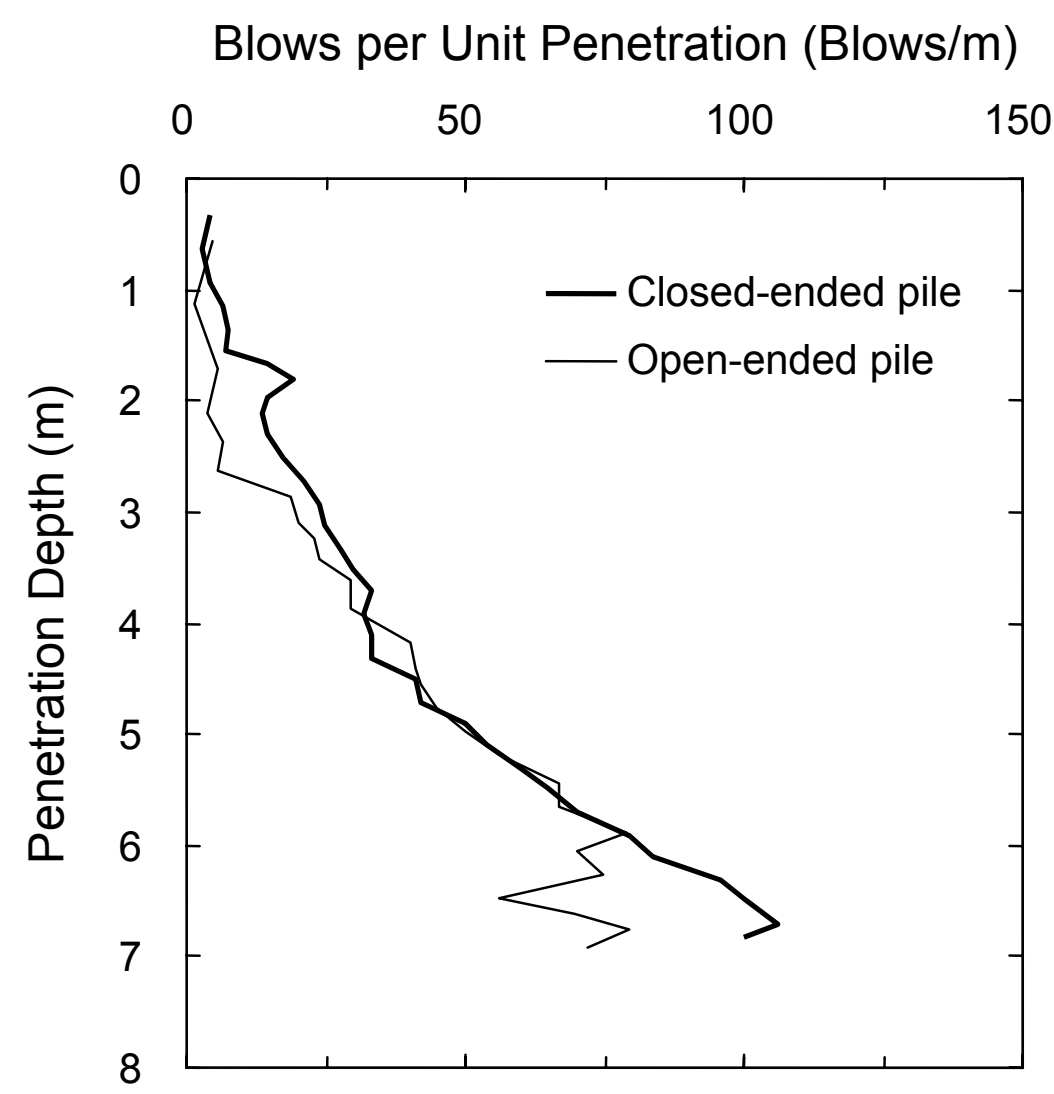

(b)

Figure 3.8 Variation of penetration resistances with penetration depth: (a) calculated base and shaft penetration resistances versus penetration depth, and (b) drivability versus penetration $\operatorname{depth}($ continued). 
calculated shaft penetration resistance increases at a low rate with penetration depth down to a penetration depth of $3.0 \mathrm{~m}$, and then increases at a significantly higher rate with penetration depth (due to higher cone resistance).

Fig. 3.8(b) shows measured blow count per unit penetration versus penetration depth. In general, the driving resistance of piles would be related to both the base and shaft resistance. However, a qualitative comparison of the plots suggests that the blow counts per unit penetration depth trend is similar to the trend of calculated base penetration resistance down to the penetration depth of $3.0 \mathrm{~m}$. For depths greater than $3.0 \mathrm{~m}$, the measured blow count resembles more strongly the calculated shaft penetration resistance rather than the calculated base penetration resistance. Based on this observation, it may be concluded that driving resistance depends more strongly on the base resistance of piles at shallow depths (in this test, down to a depth of approximately 9 times the pile diameter). As depth increases, penetration resistance is increasingly related to the shaft resistance. This is in contrast with the finding of Yamagata et al. (1985), according to whom the penetration resistance during pile driving in sand depends mostly on base resistance rather than shaft resistance.

\subsubsection{Soil Plugging in the Open-Ended Pile}

Formation of a soil plug in an open-ended pile is a very important factor in determining pile behavior both during driving and during static loading. The degree of soil plugging can be represented by the incremental filling ratio (IFR), defined as

$$
I F R=\frac{\Delta L}{\Delta D} \times 100(\%)
$$

where $\Delta \mathrm{L} / \Delta \mathrm{D}$ expresses the increase of soil plug length $\mathrm{L}$ per unit increase of penetration depth $D$ 
(see Fig. 3.9).

Fig. 3.10 shows changes of the soil plug length and IFR with penetration depth during pile driving. In the figure, the dashed line represents the fully coring pile driving mode for which the soil plug length is equal to the pile penetration depth. It can be seen from the figure that the open-ended pile was partially plugged from the outset of pile driving. It can also be seen that the pile never reached a fully plugged state (for which IFR would be equal to zero). At the final penetration depth, IFR for the pile was $77.5 \%$. This is consistent with most test results by other authors (Paikowsky et al., 1989; Paik and Lee, 1993), which show that most open-ended piles with small to moderately large diameters driven into sands are driven in a partially plugged mode.

It is also seen in Fig. 3.10 that the IFR decreases sharply from $94.1 \%$ to $71.2 \%$ in the first $2.0 \mathrm{~m}$ of penetration and then increases to $88.3 \%$ at a penetration depth of about $4.0 \mathrm{~m}$. As driving continues, IFR gradually decreases again until the end of installation. These variations of IFR are closely linked with the relatively density of soil. Test results obtained from various chamber tests on open-ended piles showed that the IFR of piles driven into uniform sand gradually decreases with penetration depth and with decreasing relative density (Klos and Tejchman, 1977; De Nicola and Randolph, 1997). Based on these results, the abrupt change of IFR near the penetration depth of about $2 \mathrm{~m}$ shown in Fig. 3.10 is due to the change of relative density at that depth. This can be confirmed by the relative density of the sand as estimated using the results of CONPOINT (Salgado et al. 1997), a program that allows calculation of the relative density of soil based on the CPT results. The estimated relative densities were about $30 \%$ for the first $3 \mathrm{~m}$ and about $80 \%$ for depths greater than $3 \mathrm{~m}$.

Since the soil plug length was measured both before and after the static load test, it was possible to ascertain that there was not a change in the soil plug length as a result of the static 


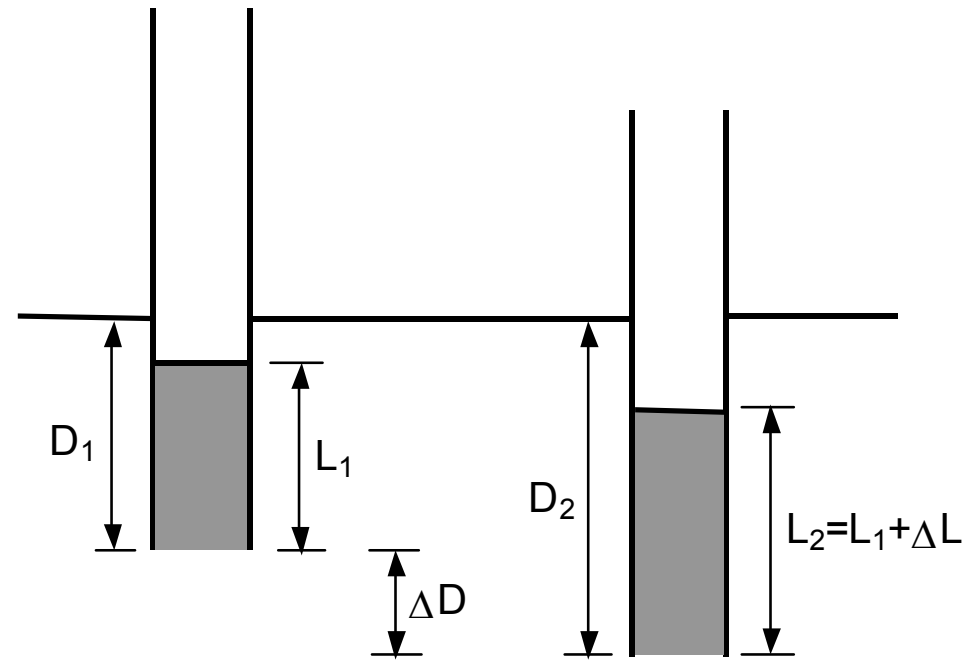

Figure 3.9 Definition of IFR 


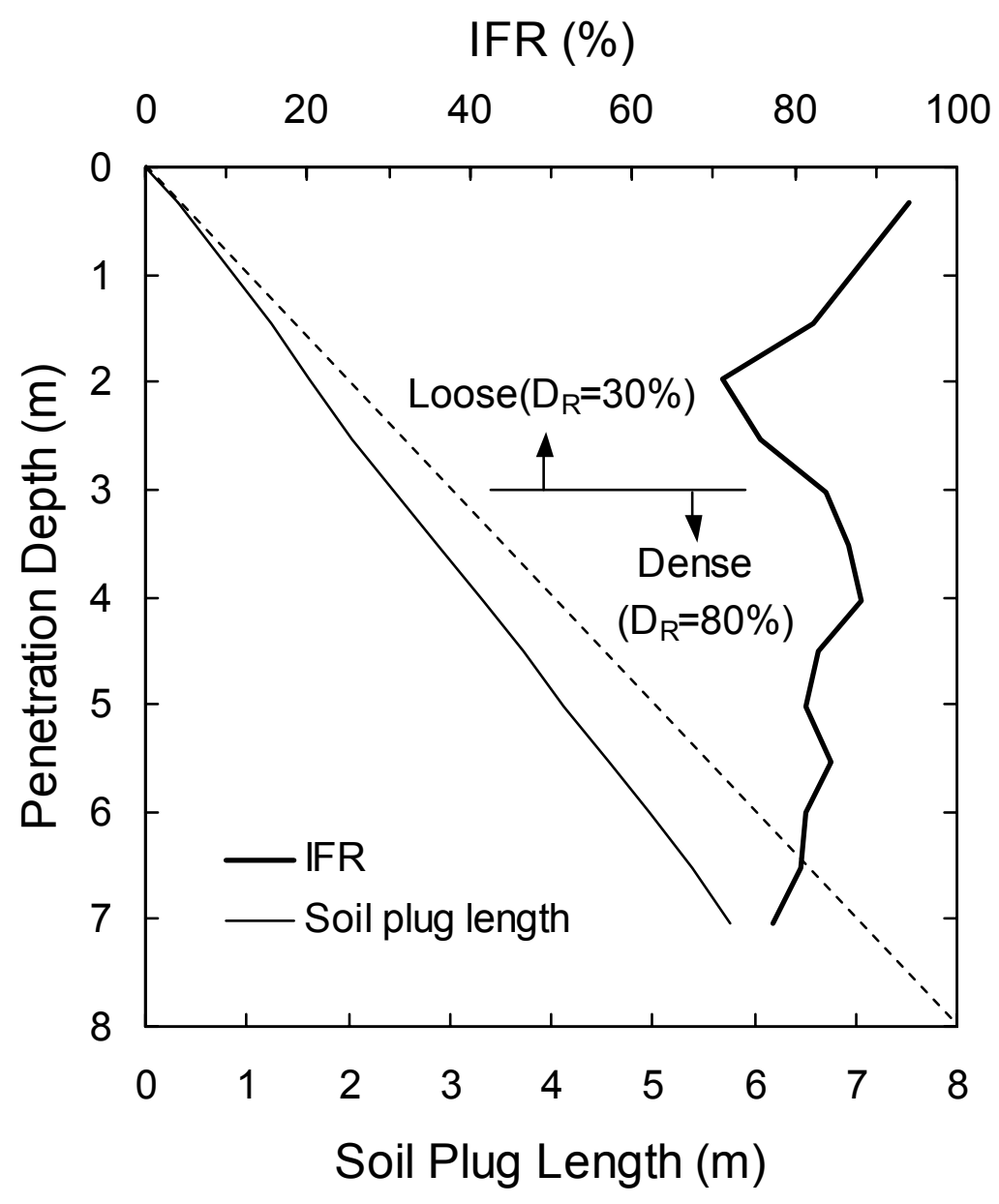

Figure 3.10 IFR and soil plug length versus penetration depth for open-ended pile. 
load test. This result confirms the findings of Beringen (1979), Paikowsky et al. (1989), and Paik and Lee (1993), who showed that open-ended piles behave as fully plugged piles in static loading, regardless of the values of IFR achieved at the end of driving. This reinforces the fact that soil plug behavior is very different under dynamic and static penetration conditions.

\subsubsection{Residual Loads}

Piles are driven by repeated hammer blows, which subject each cross section of the pile to a sequence of compression/tension pulses. At the end of each hammer blow, and, in particular, at the end of the last hammer blow, the pile reaches static equilibrium. That does not mean the loads along the pile length are zero. There always are residual loads left in the pile; these are always compressive at the pile base. For equilibrium to be established, the upward (compressive) residual base load must equal the downward resultant of the residual shaft loads.

There are two ways to measure residual loads in driven piles (Darrag, 1987): (1) reading the values of the strain gauges after pile driving (the strain gauges are zeroed before pile driving); (2) using the load distribution curves from compressive and tensile load tests obtained from strain gauges re-zeroed before each load test. We used the first method for both load tests discussed in this report. Fig. 3.11 shows the distributions of residual loads measured along the closed-ended pile (CEP) and the inner and outer pipes of the open-ended pile (OEP). In Fig. 3.11, $\mathrm{Q}_{\mathrm{rb}}$ is the residual base load for both the open-ended and the closed-ended piles, $\mathrm{Q}_{\mathrm{rp}}$ is the residual soil plug load for the open-ended pile, and $\mathrm{Q}_{\mathrm{ra}}$ is the residual annulus load for the openended pile.

The residual base loads of the open- and closed-ended piles are $171 \mathrm{kN}$ and $225 \mathrm{kN}$, respectively. These residual loads equal $24 \%$ and $26 \%$, respectively, of the base load at a 


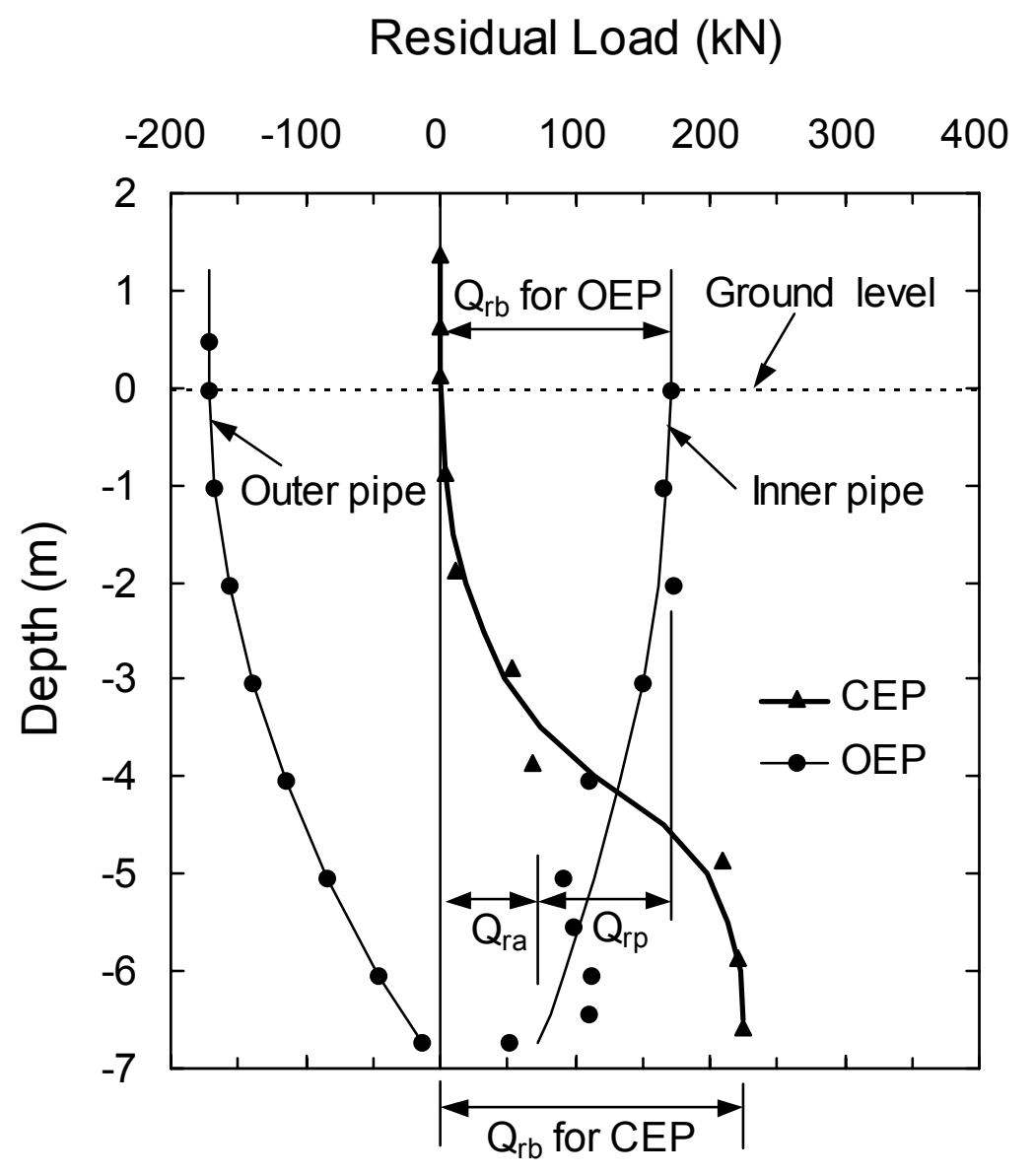

Figure 3.11 Distributions of residual loads measured along the closed-ended pile (CEP) and the inner and outer pipes of the open-ended pile (OEP) 
settlement corresponding to $10 \%$ of the pile diameter for each pile $(10 \%$ of the outer pile diameter for the open-ended pile). For the open-ended pile, the residual plug and annulus loads estimated from the load distribution along the inner pipe are $108 \mathrm{kN}$ and $63 \mathrm{kN}$, respectively, corresponding to $41 \%$ and $14 \%$ of the plug and annulus loads at a settlement of $10 \%$ of the pile diameter. Measurement of the residual load distribution along the outer shaft was not possible due to uncertainties in the readings due to drift of the strain gauge values. Therefore, the residual load distribution along the outer shaft of the open-ended pile was obtained under the assumption that the distribution of unit shaft resistance is triangular and fully balances the sum of the residual plug and annulus loads, as is required by equilibrium considerations.

Darrag (1987) reported that the magnitude and distribution of residual loads are affected by the total load capacity of the pile, the ratio of shaft to total load capacity, the pile material (i.e., the pile axial stiffness), and the length and cross-sectional area of the pile. Our test results indicate that the residual load in the closed-ended pile is greater than that in the open-ended pile. Given that the pile material, length and gross cross-sectional area of both test piles are the same, the different residual loads are due mostly to the difference in compaction of the soil around the pile during driving caused by the difference in the cross sections of the two piles.

If the goal of a load test is simply to assess the total load capacity of a given pile, residual loads should not be taken into account, as they do not affect the total load capacity of the pile (the summation of residual shaft and base loads for the pile must equal zero). For similar piles installed in a similar way in the same soil, the residual loads are likely to be similar, so that the actual load capacity available to support super-structure loadings can be assumed not to include residual loads. However, it would be conceptually correct to account for residual loads if the purpose of the load testing is to establish base and shaft unit resistances for use in designing 
other piles installed under conditions different from those prevailing for the load-tested piles. To see why it is so, consider the case of the base load capacity. The true, total unit base resistance for a driven pile includes the residual compressive unit base load for that pile. If another pile with, say, smaller residual unit base load is to be designed using the unit base resistance obtained for the first pile, it will have a higher proportion of the total unit base resistance available to support super-structure loads than the original pile.

Note that extrapolation of results of load test experience to piles installed under conditions other than those existing for the test piles (such as piles with different length installed in the same soil profile, or similar piles installed in soil profiles that differ in some way from that where the test piles were installed) requires estimation of the residual loads for these piles. This is not currently easy to do in practice. Additionally, there are situations in which residual loads may vanish, such as in soils susceptible to stress relaxation ("soil creep") or in seismic areas, where piles may at some time undergo loading and unloading cycles (Rieke and Crowser 1987). Clearly, residual loads should not be considered as a part of the permanent load capacity in these situations.

The previous discussion suggests that if residual loads are not considered in the interpretation of compressive load test results for driven piles, the base load capacity may be underestimated and the shaft load capacity may be overestimated for other piles under compressive loads (Kraft, 1991). However, given the difficulties involved in either measuring or estimating residual loads in practice, caution is in order when attempting to account for residual loads in design. The permanent load capacity that would be available to support structural loads for the two piles load-tested for this research does not include the residual loads; in this report, test results are reported accordingly. However, all the information the reader needs to account for 
residual loads in calculations involving the load test results presented here is provided in Fig. 3.11. Additionally, we do provide values both including and not including residual loads for the quantities most likely to be used in design (such as limit unit resistances).

\subsubsection{Load-Settlement Response}

Fig. 3.12 shows the load-settlement curves for both test piles obtained from the static load tests and CAPWAP analyses. It is observed that the settlement of the open-ended pile is always greater than that of the closed-ended pile for any given load. This is expected, as the closedended pile is a full-displacement pile, while the open-ended pile was installed under conditions of partial plugging and is not therefore a full-displacement pile. The maximum loads applied to the open- and closed-ended piles in the static load tests were $1.28 \mathrm{MN}$ and $1.77 \mathrm{MN}$, respectively. The limit load capacities of the open- and closed-ended piles estimated by Chin's method were 1.33 MN and 1.86 MN, respectively.

The load-settlement curves by CAPWAP analysis were somewhat in contrast with what was observed in the static load tests. The pile capacity predicted by the CAPWAP analysis was 1.28 $\mathrm{MN}$ for the open-ended pile and $0.90 \mathrm{MN}$ for the closed-ended pile. These CAPWAP predictions are based on the re-strike tests. The load-settlement curve estimated using CAPWAP for the open-ended pile is stiffer than that estimated for the closed-ended pile. This is not consistent with either the observations from the load tests or with the expected load response of open vs. closed-ended piles. It is likely that the CAPWAP pile capacity estimated for the openended pile is not reliable because the pile is double-walled. The CAPWAP pile capacity for the closed-ended pile was also off, corresponding to only $51 \%$ of the load at the end of the static load test, an estimate that is clearly conservative. 


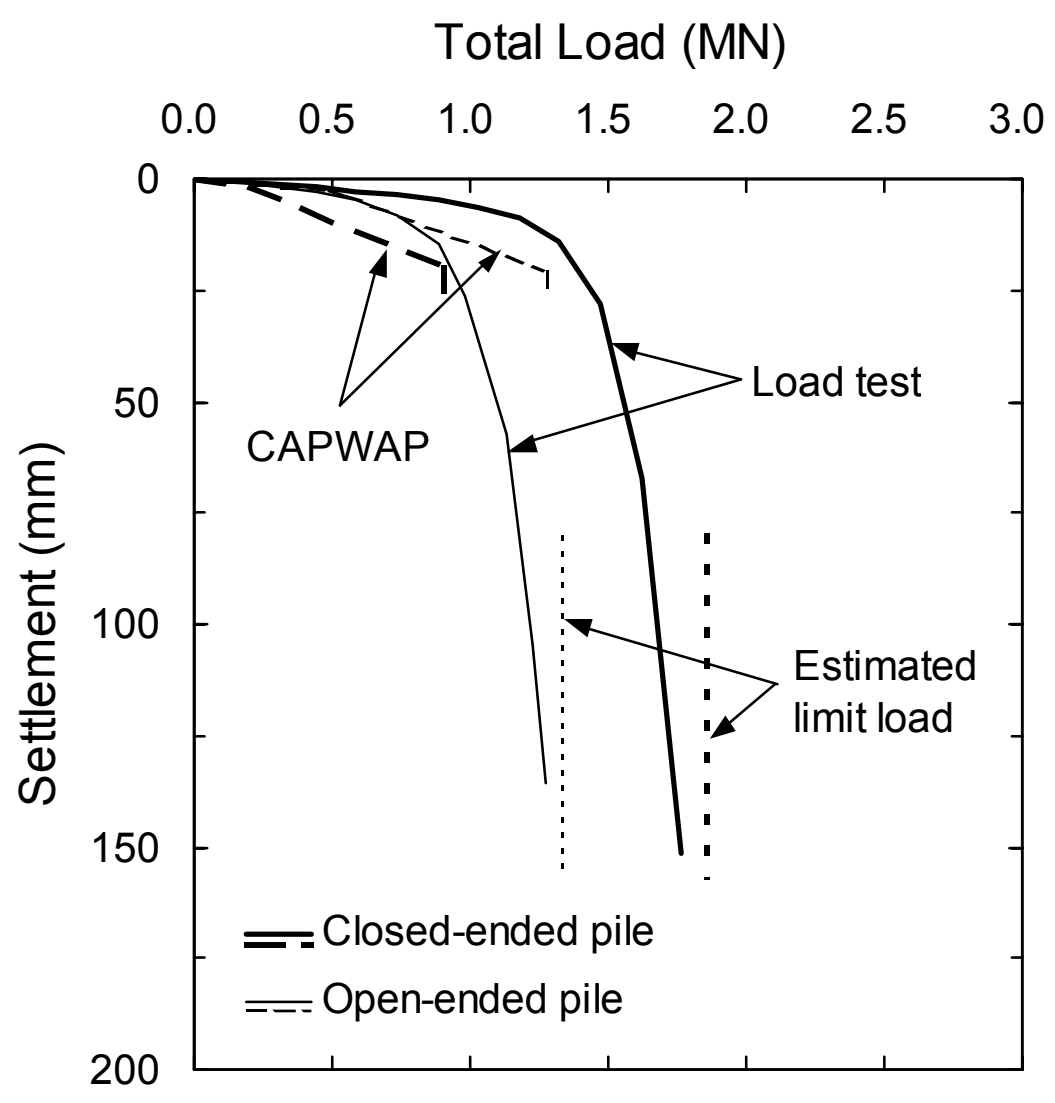

Figure 3.12 Load-settlement curves for static and dynamic load tests. 


\subsubsection{Base and Shaft Load Capacity}

In the static load test on the closed-ended pile, the load was applied in eleven increments taking the load to $0.29,0.44,0.59,0.74,0.88,1.03,1.18,1.32,1.47,1.62$, and $1.77 \mathrm{MN}$. The load distribution along the test pile length is shown in Fig. 3.13 for each load step. For the final load step, the load distribution including residual loads is also plotted as a dotted line. It is seen from the figure that the load applied to the pile is mainly supported by shaft resistance for initial loading stages. The load is then gradually transferred to the pile base. It is also found that most of the shaft resistance is developed along the lower $3.0 \mathrm{~m}$ of the pile.

Fig. 3.14 shows the load distributions for the inner and outer pipes of the open-ended pile. The load distribution in the inner pipe, shown in Fig. 3.14(a), represents changes of transferred load along the soil plug, while the load distribution in the outer pipe, shown in Fig. 3.14(b), shows the distribution of the shaft resistance. Some of the strain gauges at the lower part of the outer pipe were damaged during pile driving, and the interrupted shaft resistance distributions for some of the load steps reflect this. The load distributions in the inner and outer pipes were measured for the loading steps corresponding to applied loads equal to $0.15,0.29$, $0.44,0.59,0.74,0.88,0.98,1.13,1.23$, and 1.28 MN. As shown in Fig. 3.14(a), the total base load was solely supported by the annular area, with nearly zero soil plug resistance mobilized, up to the $0.59 \mathrm{MN}$ loading step. For loads greater than $0.74 \mathrm{MN}$, some of the applied load was transferred to the soil plug. It is also observed that, for the final load increments, most of the soil plug resistance was mobilized within a distance of 6.8 times the inside pile diameter measured from the pile base.

Table 3.1 shows both measured and estimated values of the total, base and shaft load capacities of both test piles. It also has the soil plug and annulus capacities of the open-ended 


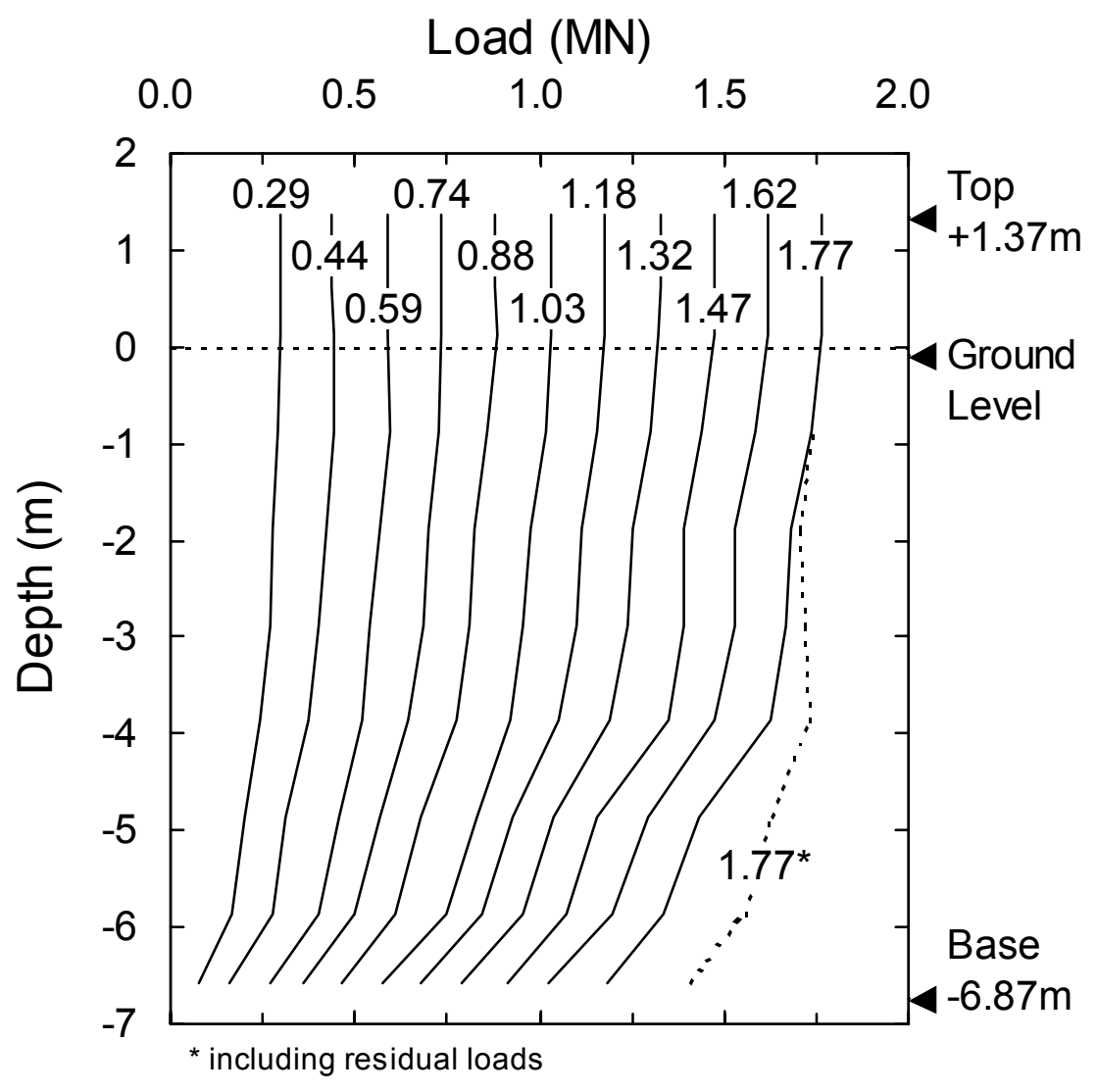

Figure 3.13 Load distribution curves for closed-ended pile. 


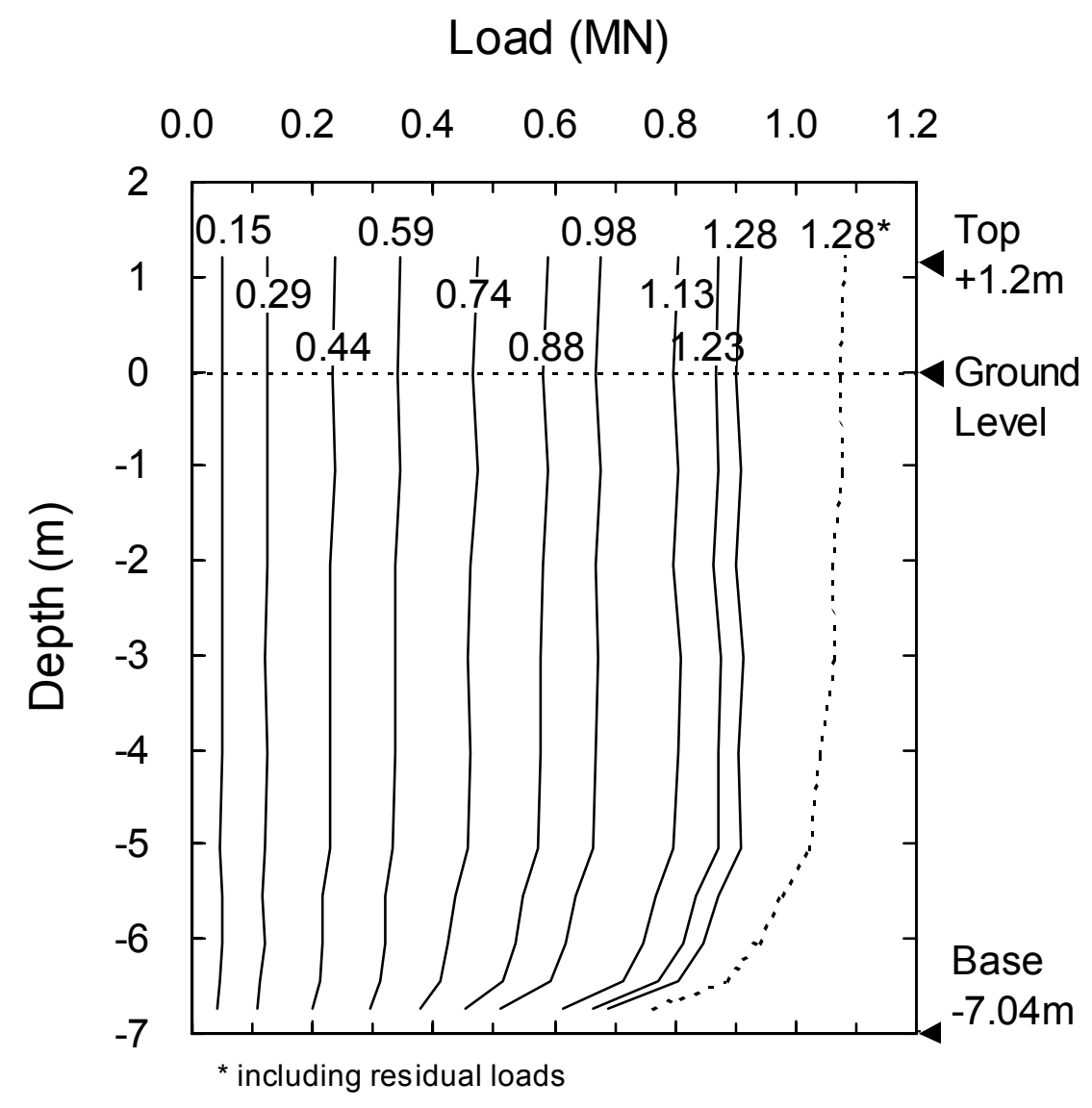

(a)

Figure 3.14 Load distribution curves: (a) for base resistance of open-ended pile, and (b) for shaft resistance of open-ended pile. 


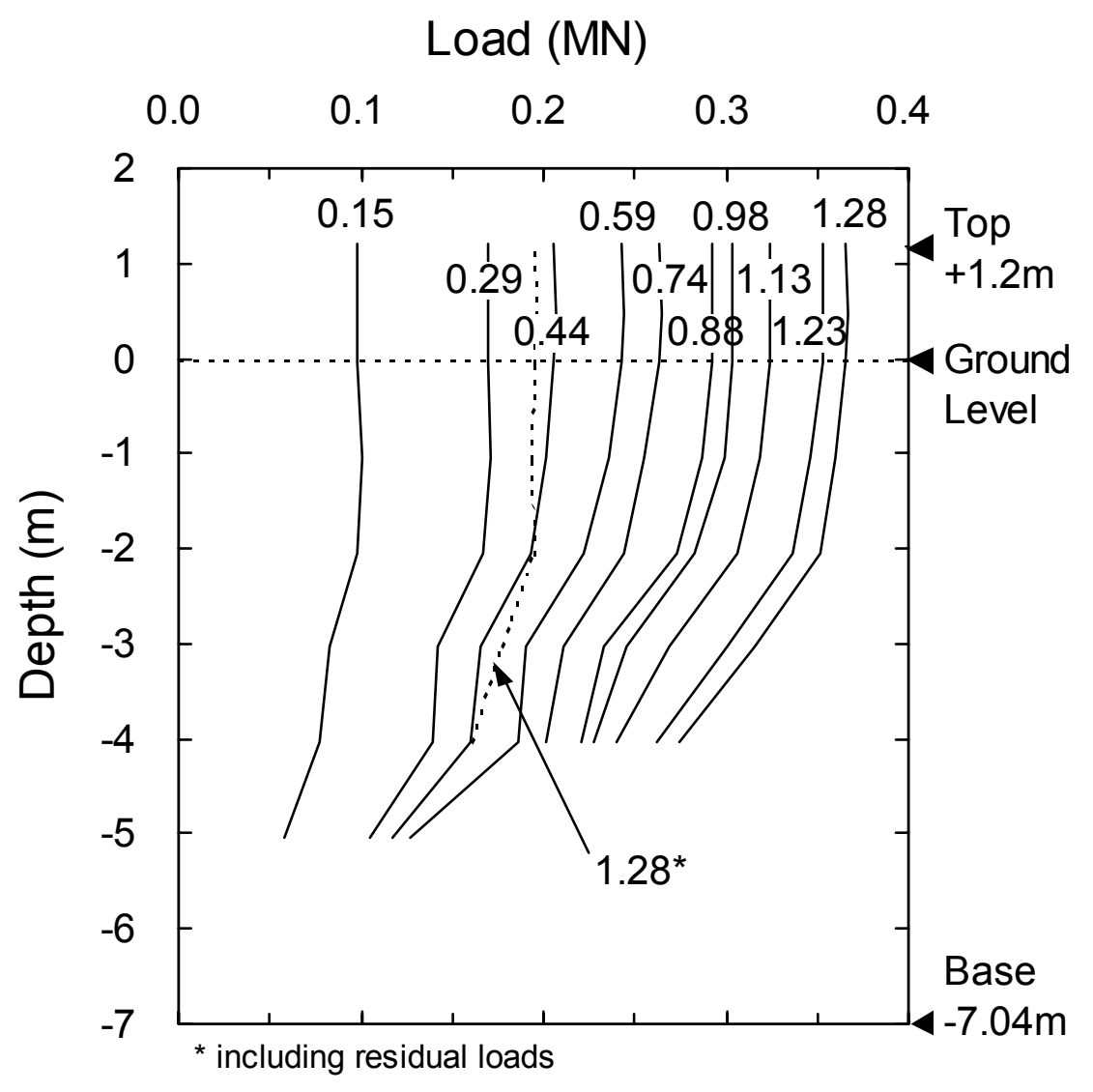

(b)

Figure 3.14 Load distribution curves: (a) for base resistance of open-ended pile, and (b) for shaft resistance of open-ended pile (continued). 
Table 3.1. Summary of measured and estimated key load capacities

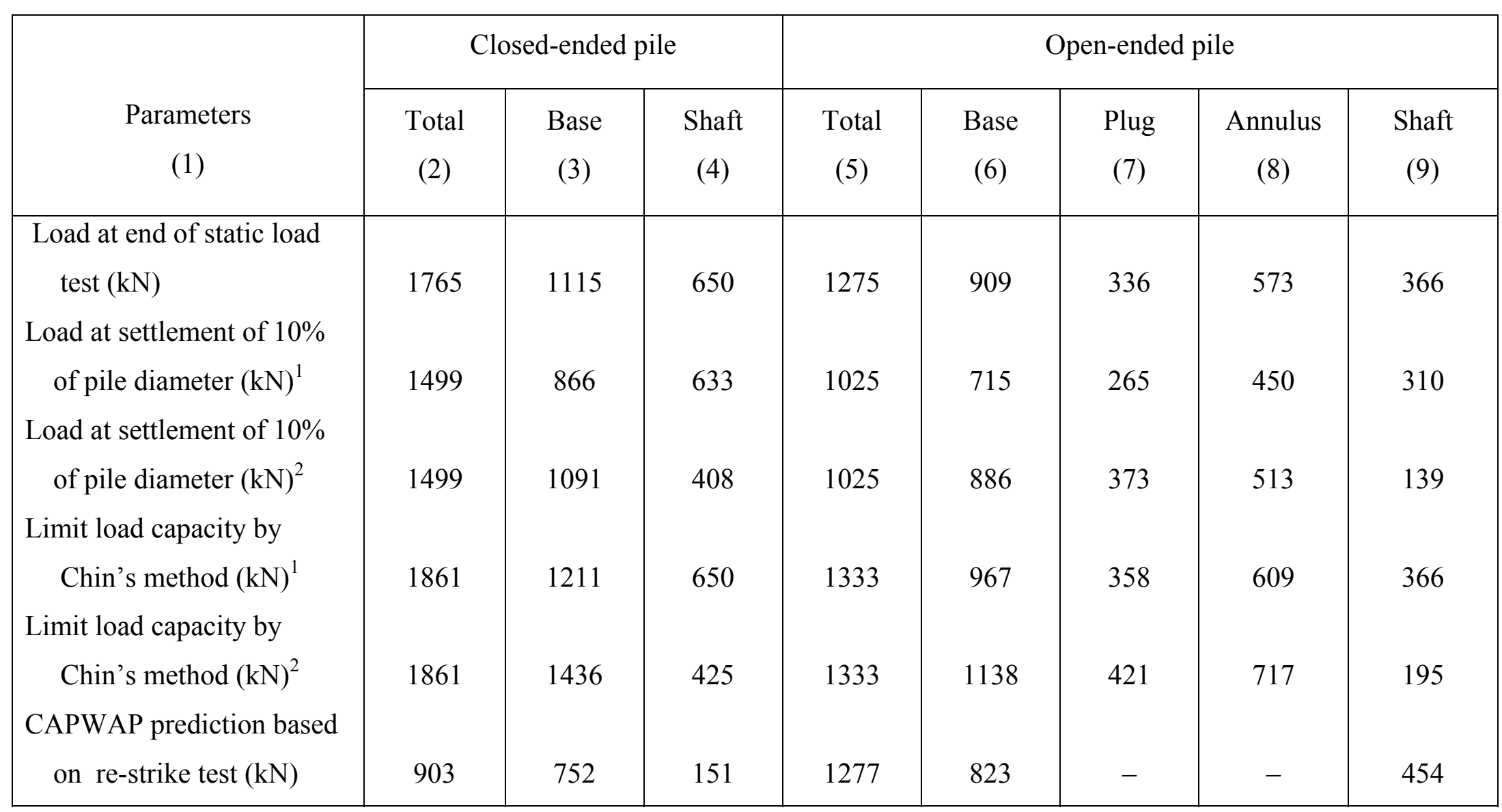

1: not accounting for residual loads

2: accounting for residual loads 
pile. Specifically, the table contains, for each test, the loads at the end of the test, the loads extrapolated using Chin's method, the loads both including and not including residual loads at a settlement equal to $10 \%$ of the pile diameter, and the CAPWAP predictions based on re-strike. It is found from Table 3.1 that the limit base and shaft loads for the closed-ended pile are $25 \%$ and $78 \%$ larger than for the open-ended pile, respectively. When taking the load at a settlement of $10 \%$ of the pile diameter as the pile load capacity, the base and shaft load capacities for the closed-ended pile are then $21 \%$ and $104 \%$ larger than for the open-ended pile, respectively. The higher base and shaft resistances of the closed-ended pile, compared with the open-ended pile, are due to the large differences in the installation of the two piles. The closed-ended pile is clearly a full-displacement pile, which considerably pre-loads the soil beneath and around it. The open-ended pile was installed without a significant degree of plugging and without pre-loading the soil around it to any significant extent. It behaves more as a small-displacement than as a full-displacement pile, with accordingly lower shaft and base load capacities.

For the open-ended pile, the limit load capacity of the annular area is greater than that of the soil plug, although the annulus area of the open-ended pile is only $33 \%$ of the gross pile base area. This implies that the soil resistance underneath the annulus is significantly higher than that for the soil plug.

\subsubsection{Bearing Capacity Comparison for the Open- and Closed-Ended Piles}

Fig. 3.15 shows the normalized unit resistance-settlement curves for the base and shaft of both test piles. In this figure, in order to eliminate the differences in pile load capacities that might be caused by the differences between soil properties (as evidenced by the slightly different CPT cone resistance profiles at $C_{1}$ and $C_{2}$ obtained before pile installation, as shown in Fig. 3.1), 


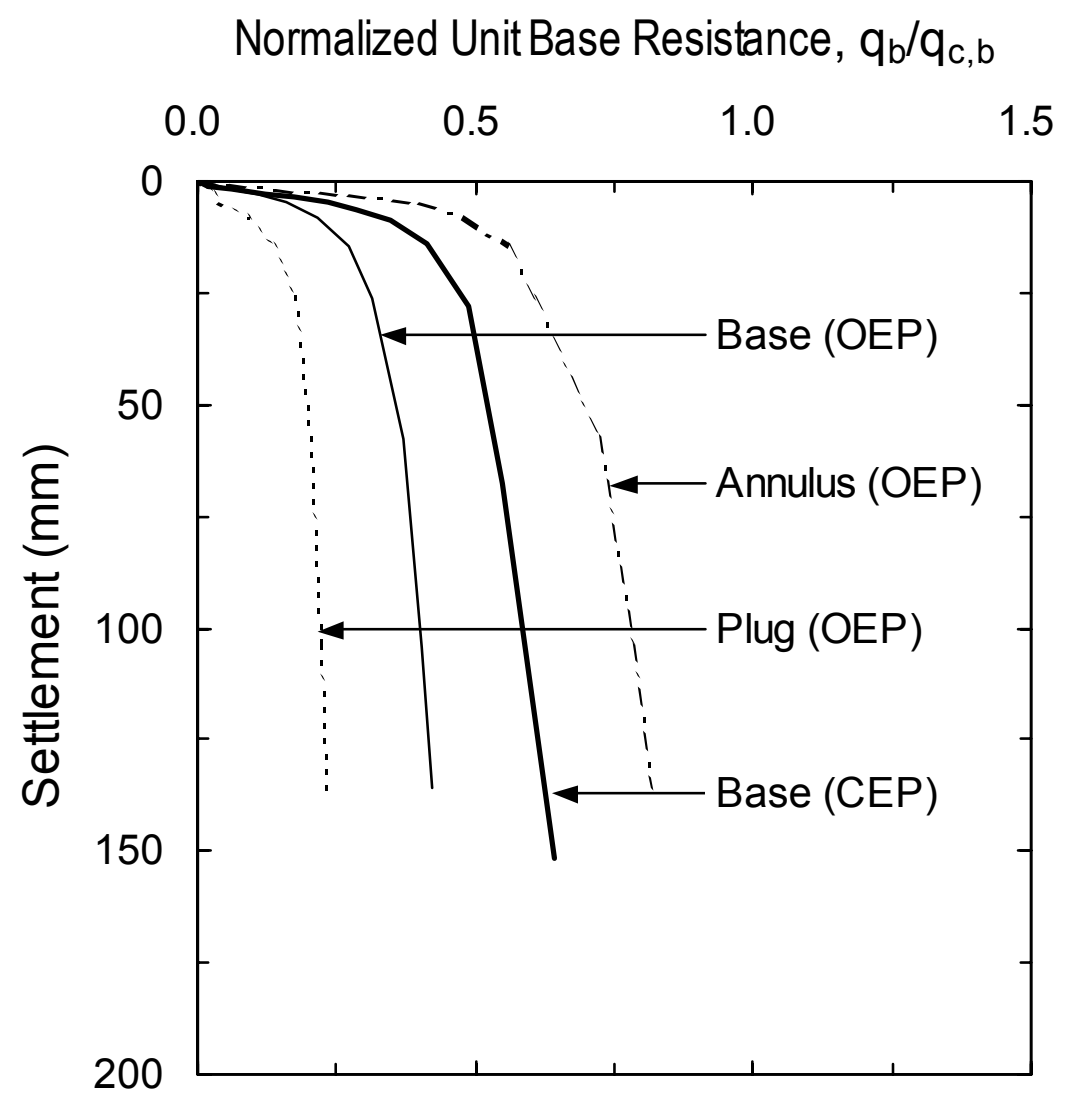

(a)

Figure 3.15 Comparison between normalized unit base and shaft resistances of open- and closed-ended piles: (a) normalized unit base resistance, and (b) normalized unit shaft resistance. 


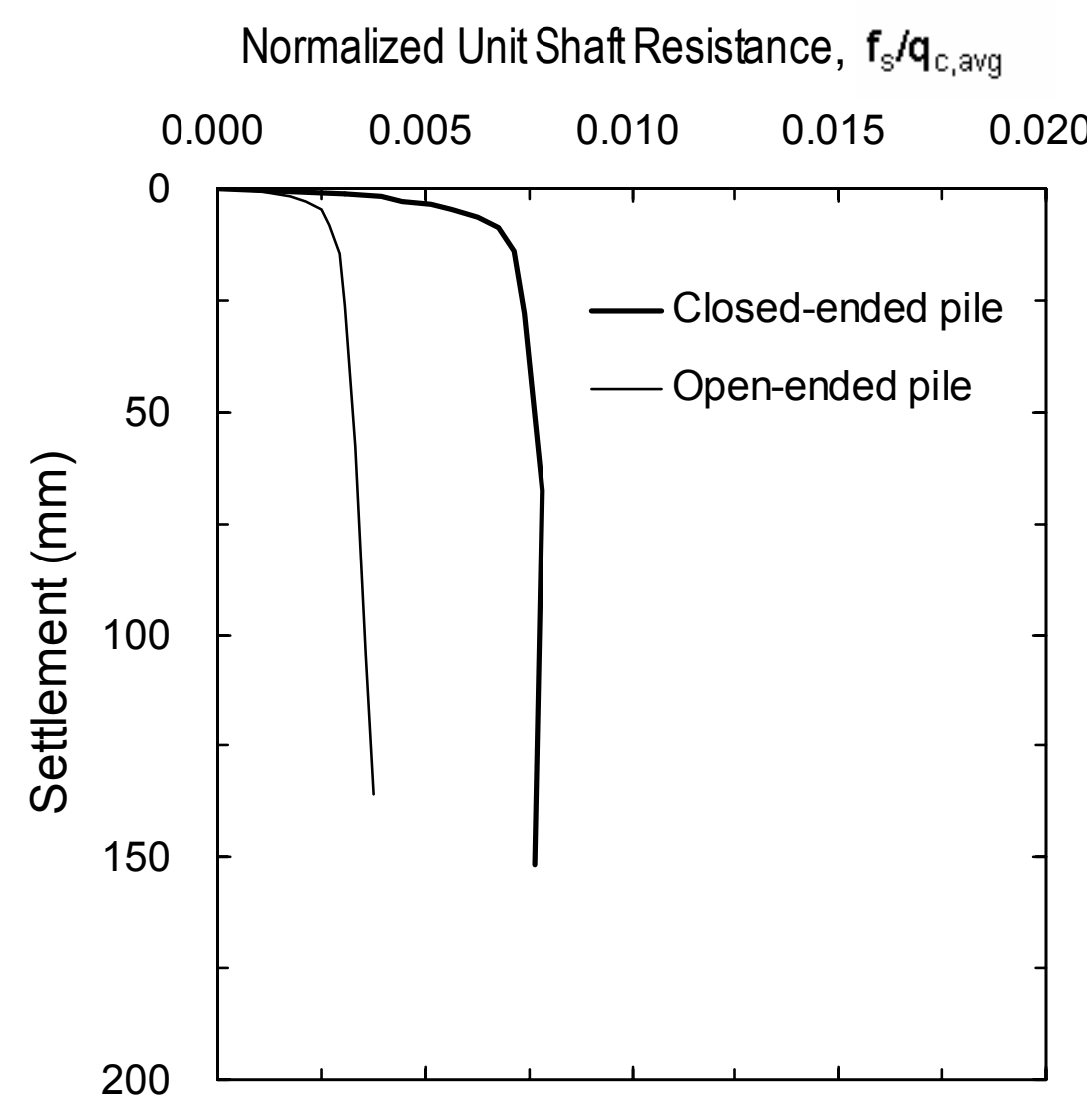

(b)

Figure 3.15 Comparison between normalized unit base and shaft resistances of open- and closed-ended piles: (a) normalized unit base resistance, and (b) normalized unit shaft resistance (continued). 
the unit base and shaft resistances were normalized with respect to average values of base and shaft cone resistances, $\mathrm{q}_{\mathrm{c}, \mathrm{b}}$ and $\mathrm{q}_{\mathrm{c}, \text { avg, }}$, respectively. The average base cone resistance $\mathrm{q}_{\mathrm{c}, \mathrm{b}}$ used for normalizing unit base resistance was defined for each pile as the average $\mathrm{q}_{\mathrm{c}}$ value from the corresponding CPT test from the pile base to 2 pile diameter below the pile base. It is important to stress that this is just a conventional way of normalizing unit base resistance, and that based on recent research by Salgado et al. (1997) and Lee and Salgado (1999), for example, pile base load capacity is controlled substantially by $\mathrm{q}_{\mathrm{c}}$ values below the pile base, and not by values above the base level.

The average shaft cone resistance $\left(\mathrm{q}_{\mathrm{c}, \mathrm{avg}}\right)$ for normalizing unit shaft resistance was calculated along the whole length of each pile. The normalized average base cone resistance $\left(\mathrm{q}_{\mathrm{c}, \mathrm{b}} / \sigma_{\mathrm{v}}^{\prime}\right)$ calculated for each pile by dividing the average base cone resistance by the vertical effective stress at the pile base are 207 and 169 for the open- and closed-ended piles, respectively. The normalized average shaft cone resistance $\left(\mathrm{q}_{\mathrm{c}, \text { avg }} / \sigma_{\mathrm{v}, \mathrm{avg}}^{\prime}\right)$, calculated by dividing the average cone resistance by the average vertical effective stress along the pile shaft, is 207 for the openended pile and 186 for the closed-ended pile.

As shown in Fig. 3.15(a), the normalized unit base resistance for the open-ended pile (OEP) was $0.42,28 \%$ lower than the 0.58 observed for the closed-ended pile (CEP) at a settlement of $140 \mathrm{~mm}$ (corresponding to a settlement equal to around $40 \%$ of the pile diameter). However, the annular area in the open-ended test pile was approximately $33 \%$ of the gross crosssectional area of the pile. This is significantly greater than the typical $11 \%$ for conventional open-ended pipe piles. Accordingly, in practice, the difference between the base loads of geometrically similar open- and closed-ended piles installed in the same soil to the same depth would be more pronounced. 
It is also seen in Fig. 3.15(a) that the unit annulus resistance of the open-ended pile is higher than the unit pile base resistance of the closed-ended pile. The unit annulus resistance of the open-ended pile and the unit base resistance of the closed-ended pile are about $81 \%$ and $58 \%$ of the average cone resistance $\left(\mathrm{q}_{\mathrm{c}, \mathrm{b}}\right)$ values obtained from $\mathrm{C}_{1}$ and $\mathrm{C}_{2}$. The unit soil plug resistance is about one third of the unit annulus resistance. These results justify the assumption made by some authors (e.g., Lehane and Randolph 2002) that the unit annulus resistance is approximately the same as the cone resistance at the same depth.

Fig. 3.15(b) shows that the normalized unit limit shaft resistance is, as discussed earlier, much greater for the closed-ended pile than for the open-ended pile, even though they have the same diameter and were installed to the same penetration depth. These were 0.0078 for the closed-ended pile and 0.0038 for the open-ended pile. This large difference is due to the different amounts of radial displacements experienced by the soil around the piles during pile driving, as discussed earlier, and is consistent with the findings of Randolph et al. (1979) and Nauroy and Le Tirant (1983). The normalized unit base and shaft resistances for both test piles are summarized in Table 3.2.

Fig. 3.16 shows the traction between the soil plug and the inner surface of the pile as well as the unit outer shaft resistance (the traction between the pile and surrounding soils). As mentioned earlier, the unit soil plug resistance is smaller than the unit annulus resistance. However, the soil plug resistance develops only because sufficient friction develops between the soil plug and the inner surface of the pile. The unit inner shaft resistance was found to be greater than the unit outer shaft resistance, as shown in Fig. 3.16, except for small settlements. Physically, this can be understood as resulting from the higher contact stresses existing between the high compressed soil plug and the inner pile surface than those between the outer surface of the pile and the surrounding soil. 


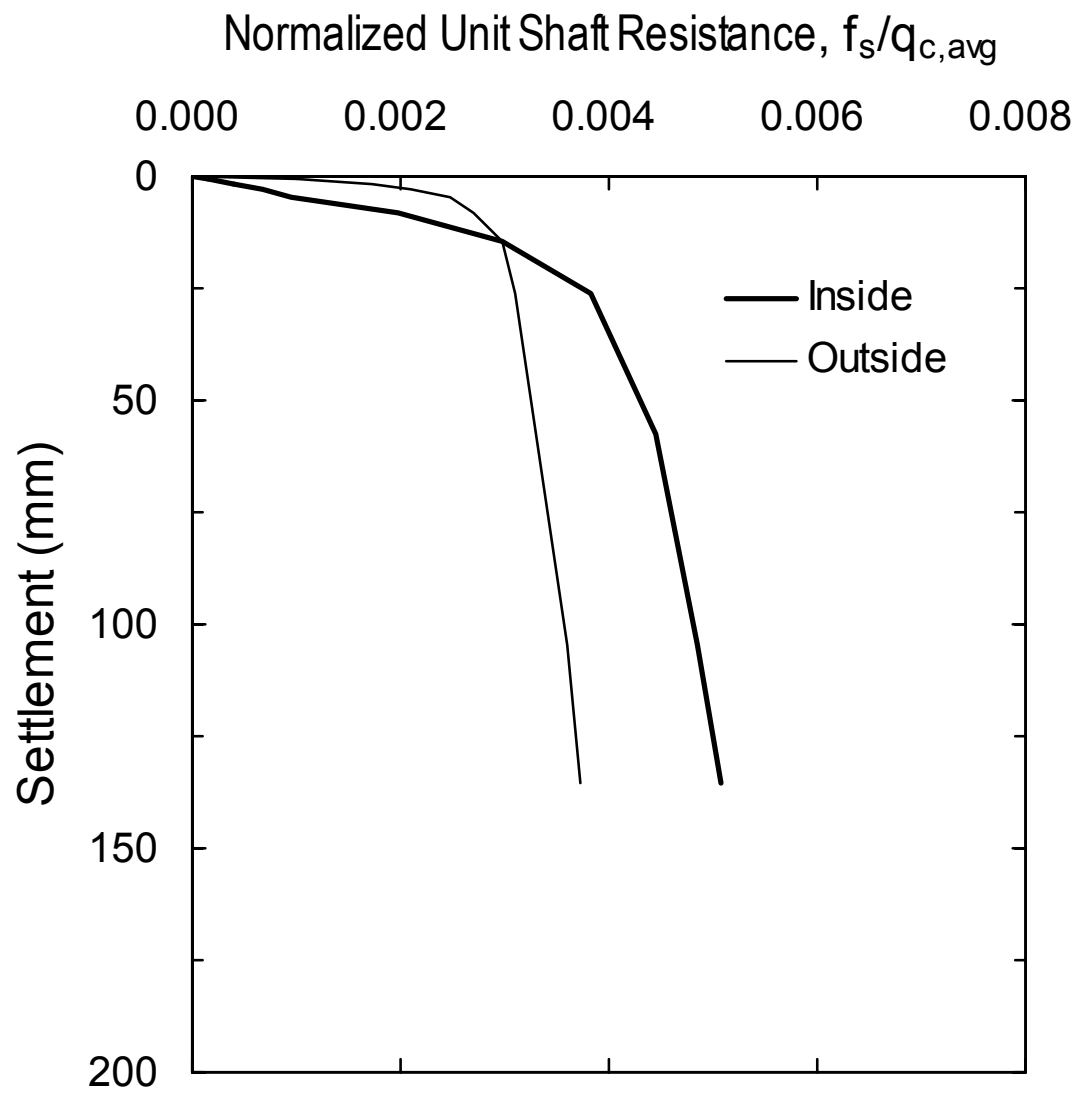

Figure 3.16 Comparison between normalized unit inside and outside shaft resistances in openended pile. 
Table 3.2. Summary of normalized unit resistances

\begin{tabular}{|c|c|c|c|c|c|c|c|}
\hline \multirow{2}{*}{$\begin{array}{l}\text { Unit resistance normalized } \\
\text { with respect to } \mathrm{q}_{\mathrm{c}} \\
\text { (1) }\end{array}$} & \multirow{2}{*}{$\begin{array}{l}\text { Residual } \\
\text { Loads } \\
\text { (2) }\end{array}$} & \multicolumn{2}{|c|}{ Closed-ended pile } & \multicolumn{4}{|c|}{ Open-ended pile } \\
\hline & & $\begin{array}{c}\text { Base } \\
(3)\end{array}$ & $\begin{array}{l}\text { Shaft } \\
\text { (4) }\end{array}$ & $\begin{array}{c}\text { Base } \\
\text { (5) }\end{array}$ & $\begin{array}{l}\text { Plug } \\
(6)\end{array}$ & $\begin{array}{c}\text { Annulus } \\
\text { (7) }\end{array}$ & $\begin{array}{c}\text { Shaft } \\
(8)\end{array}$ \\
\hline $\begin{array}{l}\text { Based on load at settlement } \\
\text { of } 10 \% \text { of pile diameter } \\
\text { Based on load at end of } \\
\text { static load test } \\
\text { Based on load estimated by } \\
\text { Chin's method }\end{array}$ & not included & 0.47 & 0.0076 & 0.33 & 0.18 & 0.81 & 0.0032 \\
\hline $\begin{array}{l}\text { Based on load at settlement } \\
\text { of } 10 \% \text { of pile diameter } \\
\text { Based on load at end of } \\
\text { static load test } \\
\text { Based on load estimated by } \\
\text { Chin's method }\end{array}$ & included & 0.72 & 0.0049 & 0.50 & 0.23 & 0.67 & 0.0014 \\
\hline
\end{tabular}

base, plug and annulus resistances normalized with respect to $\mathrm{q}_{\mathrm{c}, \mathrm{b}}$; shaft resistance normalized with respect to $\mathrm{q}_{\mathrm{s}, \mathrm{avg}}$ 


\section{CHAPTER 4}

\section{DETERMINATION OF BEARING CAPACITY OF OPEN-ENDED PILES IN SAND}

\subsection{Overview}

Many design criteria for open-ended piles, based on field and chamber test results or analytical methods, have been suggested (e.g., Klos and Tejchman, 1977; Nishida et al., 1985; API, 1991; Randolph et al., 1991). For example, in the case of API RP2A (1991), the bearing capacity of an open-ended pile can only be estimated for either the fully coring mode or the fully plugged mode of penetration, although most open-ended piles are driven into sands in a partially plugged mode. Stefanoff and Boshinov (1977) suggested the use of one-dimensional plug analysis, in which the soil plug is treated as a series of horizontal thin discs and the force equilibrium condition is applied to each disc, to calculate plug capacity of an open-ended pile.

There have been modifications of one-dimensional plug analysis to improve predictive accuracy, such as the introduction of the concept of the wedged soil plug (Murff et al., 1990; O'Neill and Raines, 1991; Randolph et al, 1991). Many test results show that the soil plug can be divided into a wedged plug zone and an unwedged plug zone. While the wedged plug zone transfers load to the soil plug, the unwedged plug zone transfers no load but provides a surcharge pressure on top of the wedged plug zone. However, it is not easy to apply the one-dimensional analysis to practical cases, because of the sensitivity of the method to the lateral earth pressure coefficient, which is not easily estimated (Brucy et al, 1991; Leong and Randolph, 1991). De Nicola and Randolph (1997) addressed this by proposing a profile of the lateral earth pressure 
coefficient $K$ along the soil plug length.

An alternative design method can be based on the incremental filling ratio (IFR). The degree of soil plugging is adequately quantified using the IFR, which is defined as the increment of soil plug length corresponding to unit pile penetration (Paikowsky et al., 1989; Paik and Lee, 1993). The fully plugged and fully coring modes correspond to IFR $=0 \%$ and IFR $=100 \%$, respectively. A value of IFR between 0 and $100 \%$ means that the pile is partially plugged. A series of model pile tests, using a calibration chamber, were conducted on model open-ended piles instrumented with strain gauges in order to investigate the effect of IFR on the two components of bearing capacity: base load capacity and shaft load capacity. Based on the calibration chamber test results, empirical relationships between the IFR and the components of pile load capacity are proposed. In order to verify the accuracy of predictions made using the two empirical relationships, a full-scale static pile load test was conducted on a fully instrumented open-ended pile driven into dense sand. The predicted pile load capacities are compared with the capacities measured in the pile load test. Another example, extracted from the literature, is also presented to illustrate the predictive capacity of the proposed relationships.

\subsection{Calibration Chamber Test Procedures}

\subsubsection{Soil Properties}

Han river sand, a subangular quartz sand with $\mathrm{D}_{10}=0.17 \mathrm{~mm}$ and $\mathrm{D}_{50}=0.34 \mathrm{~mm}$, was used for all the calibration chamber model pile tests. The test sand is classified as poorly graded (SP) in the Unified Soil Classification System, so the maximum dry density of the sand is near the low end of the typical range for sands. The maximum and minimum dry unit weights of the sand 
were $15.89 \mathrm{kN} / \mathrm{m}^{3}$ and $13.04 \mathrm{kN} / \mathrm{m}^{3}$, respectively.

A series of laboratory tests were conducted to characterize the sand. The results from these tests are summarized in Table 4.1. The internal friction angle of the sand and the interface friction angle between the sand and steel were measured from direct shear tests under normal stresses of 40-240 $\mathrm{kPa}$. The peak friction angles of the sand with relative densities of $23 \%, 56 \%$, and $90 \%$ were $34.8^{\circ}, 38.2^{\circ}$, and $43.4^{\circ}$, respectively, and the critical-state friction angle was $33.7^{\circ}$. The peak interface friction angles between the pile and the sand were $17.0^{\circ}, 17.5^{\circ}$, and $18.4^{\circ}$ for $\mathrm{D}_{\mathrm{R}}=23 \%, 56 \%$, and $90 \%$, respectively, and the critical-state interface friction angle was $16.7^{\circ}$. This angle is lower than commonly reported values because the test pile was made of stainless steel pipe with a very smooth surface.

\subsubsection{Calibration Chamber and Sample Preparation}

All model pile tests were conducted in soil samples prepared within a calibration chamber with a diameter of $775 \mathrm{~mm}$ and a height of $1250 \mathrm{~mm}$. In order to simulate various field stress conditions, two rubber membranes, which can be controlled independently, were installed on the bottom and inside the lateral walls of the calibration chamber. The consolidation pressure applied to the two rubber membranes was maintained constant by a regulator panel throughout each pile test.

The soil samples were prepared by the raining method with a constant fall height. The falling soil particles passed through a sand diffuser composed of No.8 and No. 10 sieves in order to control flow uniformity and fall velocity. The soil samples had $D_{R}=23 \%, 56 \%$, and $90 \%$. After sample preparation, the samples were consolidated to the desired stress state during approximately 30 hours by compressed air transferred to the rubber membranes. 
Table 4.1 Soil properties of test sand

\begin{tabular}{|l|c|}
\hline \multicolumn{1}{|c|}{ Property } & Value \\
\hline Coefficient of uniformity, $\mathrm{C}_{\mathrm{u}}$ & 2.21 \\
Coefficient of gradation, $\mathrm{C}_{\mathrm{c}}$ & 1.23 \\
Maximum void ratio, $\mathrm{e}_{\max }$ & 0.986 \\
Minimum void ratio, $\mathrm{e}_{\min }$ & 0.629 \\
Minimum dry density, $\gamma_{\mathrm{d}, \min }$ & $13.04 \mathrm{kN} / \mathrm{m}^{3}$ \\
Maximum dry density, $\gamma_{\mathrm{d}, \mathrm{max}}$ & $15.89 \mathrm{kN} / \mathrm{m}^{3}$ \\
Specific gravity, $\mathrm{G}_{\mathrm{s}}$ & 2.64 \\
Peak friction angle, $\phi_{\text {peak }}$ & $34.8-43.4^{\circ}$ \\
Critical-state friction angle, $\phi_{\mathrm{c}}$ & $33.7^{\circ}$ \\
Peak interface friction angle, $\delta$ & $17.0-18.4^{\circ}$ \\
Critical-state interface friction angle, $\delta_{\mathrm{c}}$ & $16.7^{\circ}$ \\
\hline
\end{tabular}


Measurements made in calibration chambers are subject to chamber size effects. Many researchers have attempted to estimate the chamber size needed for boundary effects on pile bearing capacity or cone resistance to become negligible. Parkin and Lunne (1982) suggested 50 times the cone diameter as the minimum chamber diameter for chamber size effect on cone penetration resistance to become acceptably small. Salgado et al. (1998), based on cavity expansion analyses, found that 100 times the cone diameter was the minimum chamber diameter to reduce chamber size effects on cone resistance to negligible levels. Diameters of the chamber and test pile used in this study are $775 \mathrm{~mm}$ and $42.7 \mathrm{~mm}$, respectively. The lateral and bottom boundaries are located at a distance equal to 18.2 pile radii from the pile axis and 23.0 pile radii below the maximum depth reached by the pile base, respectively. Considering the results of the research on chamber size effects mentioned above, the size of the chamber used in this study is not sufficiently large for chamber size effects on pile bearing capacity to be neglected. The flexible boundary causes lower radial stresses than those that would exist in the field. Accordingly, the chamber tests done as part of this study produce lower pile load capacities than those that would be observed in the field. A correction for chamber size effects is then necessary. It is discussed in a later section.

\subsection{Model Pile and Test Procedure}

\subsubsection{Model Pile}

An open-ended pile is generally driven into sands in a partially plugged mode, and its bearing capacity is composed of plug resistance, annulus resistance, and shaft resistance. In order to separate pile load capacity into its components, an instrumented double-walled pile was used 
in the testing. A schematic diagram of the pile is shown in Fig. 4.1. The model pile was made of two very smooth stainless steel pipes with different diameters. It had an outside diameter of 42.7 $\mathrm{mm}$, inside diameter of $36.5 \mathrm{~mm}$, and length of $908 \mathrm{~mm}$.

The wall thickness of the test piles used in this study is larger than those of piles typically used in practice. Szechy (1959) showed that the degree of soil plugging and bearing capacity of two piles with different wall thicknesses don't differ in a significant way (with bearing capacity increasing only slightly with increasing wall thickness); only driving resistance depends significantly upon the wall thickness. So the load capacity of the test piles reported in this report are probably larger, but only slightly so, than what would be observed in the field.

Eighteen strain gauges were attached to the outside surface of the inner pipe at nine different levels in order to measure the base load capacity (summation of plug and annulus load capacities) from the load transfer curve along the inner pipe. Two strain gauges were also attached to the outside surface of the outer pipe in order to measure shaft load capacity. A gap of $4 \mathrm{~mm}$ between the outer pipe and the pile toe, which was sealed with silicone, prevented the base load from being transferred to the outer pipe. The outer pipe, therefore, experienced only the shaft load.

Many researchers have relied on linear extrapolation to separate the base load capacity into plug and annulus capacities (Paik and Lee, 1993; Choi and O'Neill, 1997; Lehane and Gavin, 2001). Linear extrapolation would apply strictly only if the inside unit friction between the pile and soil plug were constant between the second lowest strain gauge and the pile base, as shown in Fig. 3.4. In reality, the inside unit friction between the soil plug and the test pile increases dramatically near the pile base. Use of linear extrapolation, therefore, leads to an overestimation of annular resistance. This overestimation increases as the distance between the 


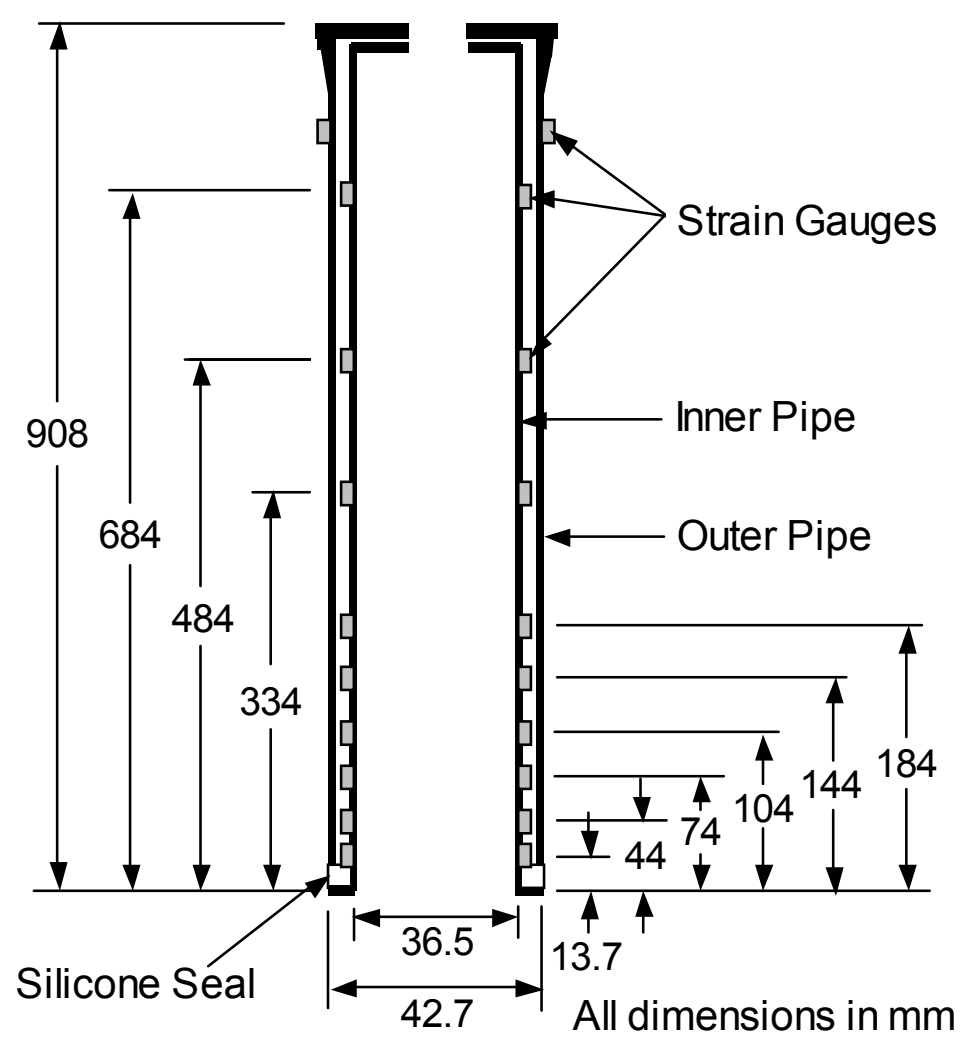

Figure 4.1 Schematic of model pile in calibration chamber tests. 
lowest strain gauge and the pile base increases. In part to avoid this uncertainty, in this report we use the base load capacity to analyze the test results instead of the plug and annulus load capacities separately. The base load capacity of the test pile was obtained from the upper strain gauges located on the inner pipe, for which the measured vertical loads reached a limit value (Fig. 3.4).

\subsubsection{Test Program}

Seven model pile tests were performed in dry soil samples with three different relative densities and five different stress states. Each test is identified by a symbol with three letters $(\mathrm{H}$ : high, M: medium, L: low), signifying the levels of the relative density, vertical and horizontal stresses of the sample, respectively. A summary of all model pile tests is presented in Table 4.2. Five model pile tests were conducted in dense samples with $\mathrm{D}_{\mathrm{R}}=90 \%$ and five different stress states. Two model pile tests were conducted in loose and medium samples consolidated to a vertical stress of $98.1 \mathrm{kPa}$ and horizontal stress of $39.2 \mathrm{kPa}$. The model piles were driven by a 39.2 $\mathrm{N}$ hammer falling from a height of $500 \mathrm{~mm}$. During pile driving, the soil plug length and the pile penetration depth were measured at about $40 \mathrm{~mm}$ intervals, corresponding to $94 \%$ of the pile diameter, in order to calculate the incremental filling ratio (IFR). The change in soil plug length during pile driving was measured using a ruler introduced through an opening at the top plate of the pile (see Fig. 4.1). In order to measure the soil plug length, driving operations were suspended for no more than a minute each time. Static pile load tests were performed when the pile base was located at depths of $250,420,590$, and $760 \mathrm{~mm}$. The pile load tests were continued until the pile settlement reached about $19 \mathrm{~mm}$ (44\% of the pile diameter), at which point all the test piles had reached a plunging limit state (Fig. 4.2). The ultimate load of each test pile is 
Table 4.2 Summary of model pile test program

\begin{tabular}{|c|c|c|c|c|}
\hline $\begin{array}{c}\text { Test } \\
\text { Indicator }\end{array}$ & $\begin{array}{c}\text { Initial } \\
\text { relative } \\
\text { density } \\
(\%)\end{array}$ & $\begin{array}{c}\text { Initial } \\
\text { vertical } \\
\text { stress } \\
(\mathrm{kPa})\end{array}$ & $\begin{array}{c}\text { Initial } \\
\text { horizontal } \\
\text { stress } \\
(\mathrm{kPa})\end{array}$ & $\begin{array}{c}\text { Initial } \\
\text { earth } \\
\text { pressure } \\
\text { coefficient }\end{array}$ \\
\hline HLL & 90 & 39.2 & 39.2 & 1.0 \\
HML & 90 & 68.6 & 39.2 & 0.6 \\
HHL & 90 & 98.1 & 39.2 & 0.4 \\
HHM & 90 & 98.1 & 68.6 & 0.7 \\
HHH & 90 & 98.1 & 98.1 & 1.0 \\
LHL & 23 & 98.1 & 39.2 & 0.4 \\
MHL & 56 & 98.1 & 39.2 & 0.4 \\
\hline
\end{tabular}




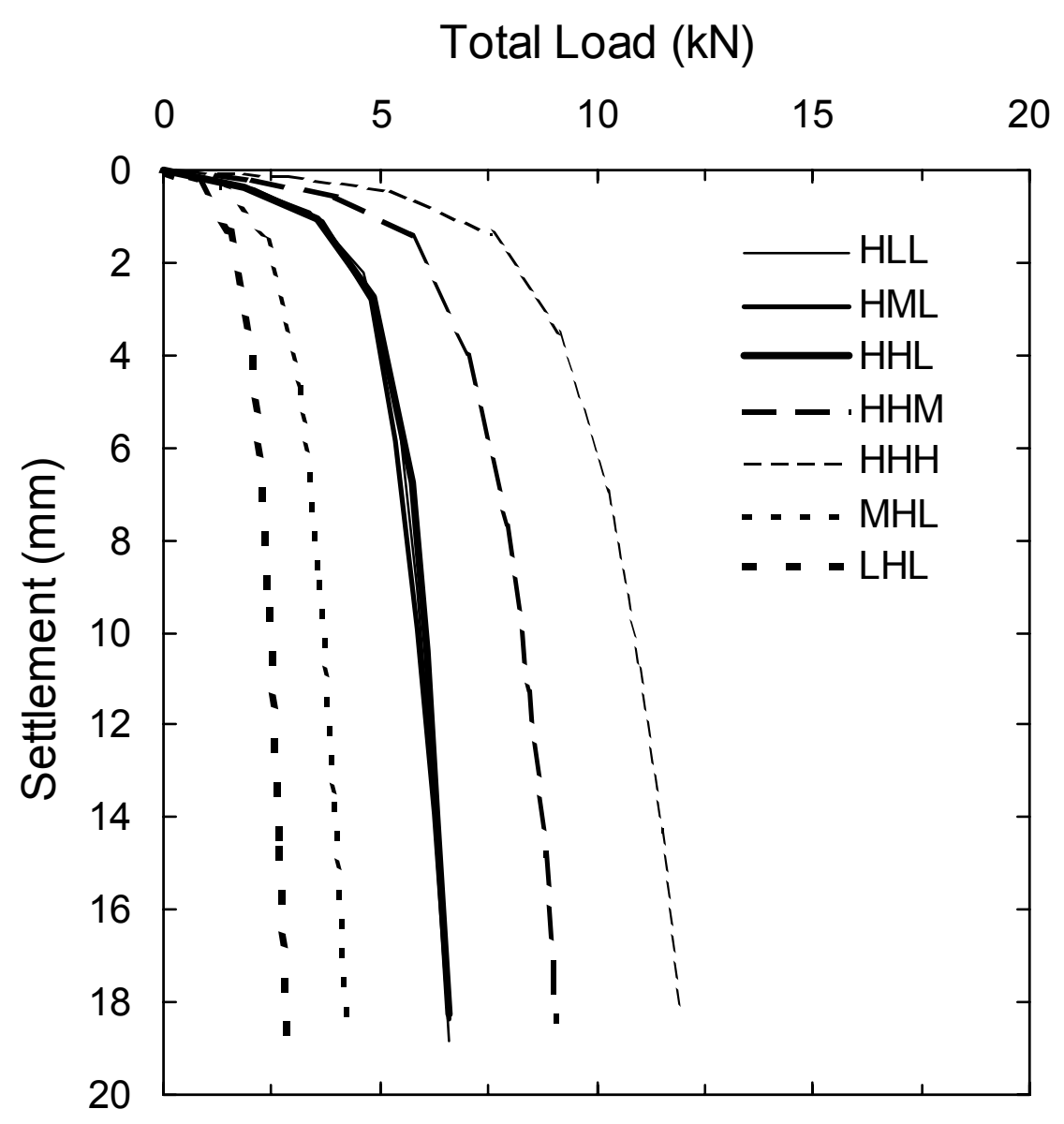

Figure 4.2 Load-settlement curves from model pile load tests. 
defined as the load at a settlement of $4.27 \mathrm{~mm}$, corresponding to $10 \%$ of the pile diameter. The total load applied to the pile head was measured by a load cell, and settlement of the pile head was measured by two dial gauges. Details of the model pile, sample preparation, and test program have been described by Paik and Lee (1993).

\subsection{Model Pile Test Results}

\subsubsection{Pile Drivability}

Fig. 4.3(a) shows pile penetration depth vs. hammer blow count for all the test piles. As shown in the figure, the hammer blow count per unit length of penetration increases as pile penetration depth increases, since the penetration resistances acting on the base and shaft of the piles during driving generally increase with penetration depth. The vertical stress applied to the soil sample had little effect on the cumulative blow count. However, the blow count necessary to drive the pile to a certain depth decreased rapidly with decreasing horizontal stress. It is also seen in Fig. 4.3(a) that the blow count necessary for driving the pile to some required depth increases with increasing relative density.

\subsubsection{Soil Plugging}

The degree of soil plugging in an open-ended pile affects pile behavior significantly. The IFR is a good indicator of the degree of soil plugging. During the model pile tests, the IFR was measured at increments of $40 \mathrm{~mm}$ of penetration. The change of the soil plug length with pile penetration depth is plotted in Fig. 4.3(b). It is seen in the figure that the soil plug length developed during pile driving increases as the horizontal stress of the soil sample increases for 


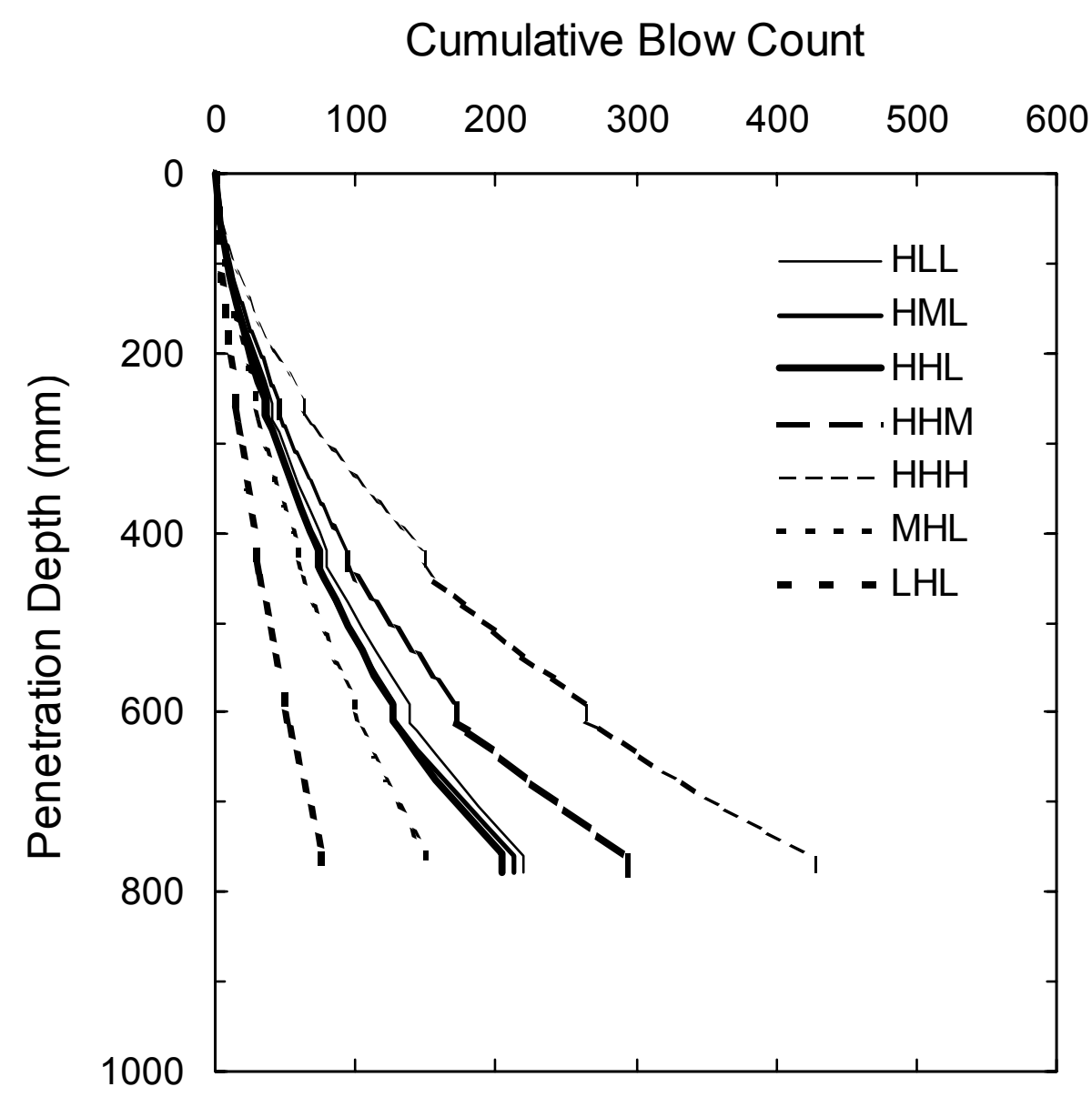

(a)

Figure 4.3 Driving test results: (a) hammer blow count, and (b) soil plug length. 


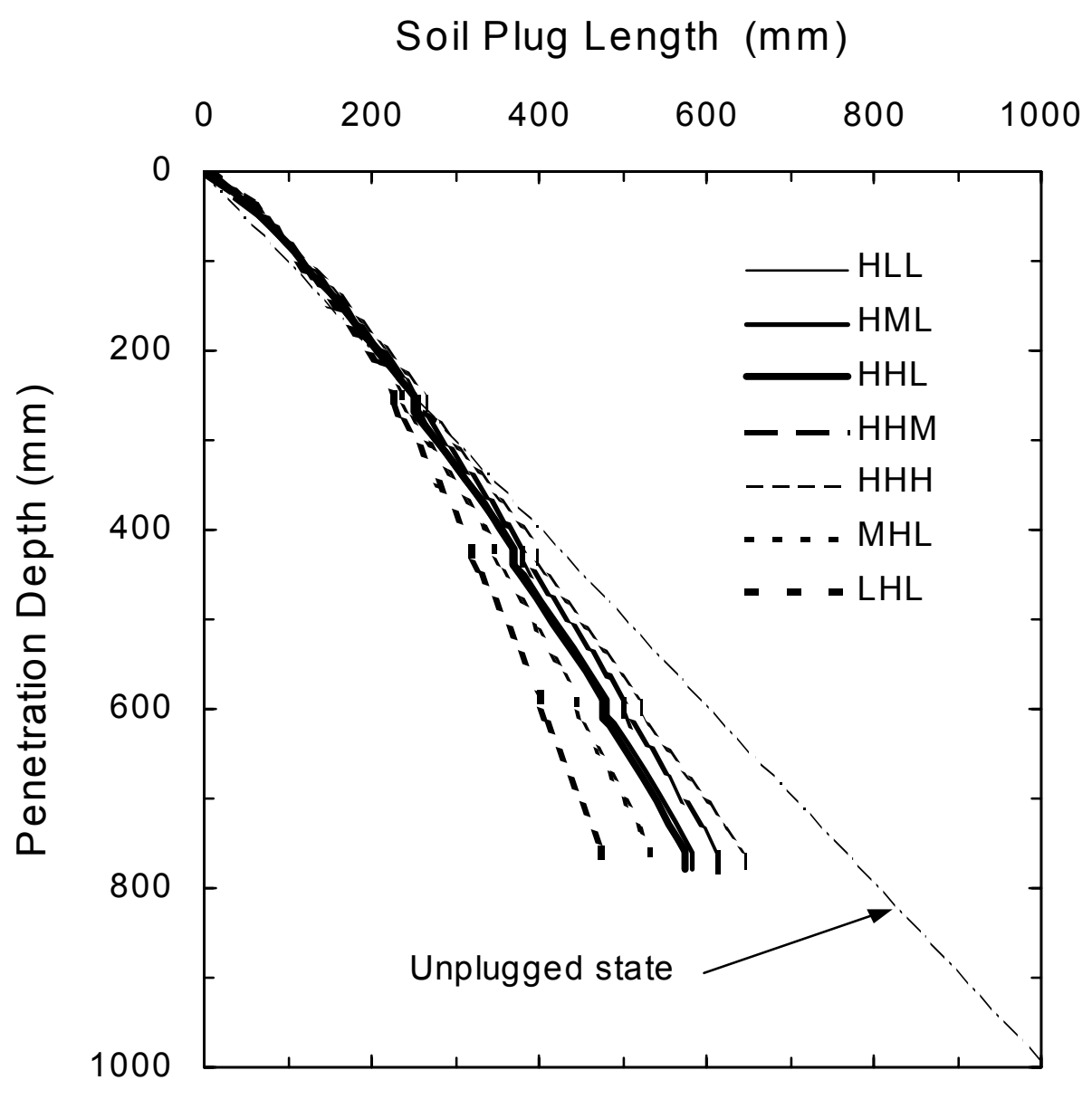

(b)

Figure 4.3 Driving test results: (a) hammer blow count, and (b) soil plug length (continued). 
the same relative density, and as the relative density increases for the same stress. It can also be seen that every test pile, during static load testing, advances in fully plugged mode, irrespective of the initial soil condition and the degree of soil plugging during pile driving. The static load tests appear as short vertical lines in Fig. 4.3(b), meaning that penetration depth increases while soil plug length remains unchanged.

Fig. 4.4 shows changes of IFR with soil state (relative density, vertical stress, and horizontal stress). Fig. $4.4(\mathrm{a})$ shows IFR vs. $\mathrm{D}_{\mathrm{R}}$ for tests with $\sigma_{v}^{\prime}=98.1 \mathrm{kPa}$ and $\mathrm{K}_{\mathrm{o}}=0.4$. Fig 4.4(b) shows IFR vs. $\sigma_{v}^{\prime}$ for tests with $\mathrm{D}_{\mathrm{R}}=90 \%$ and $\sigma_{h}^{\prime}=39.2 \mathrm{kPa}$. Fig. 4.4(c) shows IFR vs. $\sigma_{h}^{\prime}$ for $\mathrm{D}_{\mathrm{R}}=90 \%$ and $\sigma_{v}^{\prime}=98.1 \mathrm{kPa}$. It is observed that the IFR increases markedly with increasing relative density and with increasing horizontal stress. These changes in IFR reflect the decreasing amount of compaction of the soil plug during pile driving as the relative density and stress level in the soil increase. However, the IFR is relatively insensitive to changes in the vertical stress applied to the soil sample. This means that the IFR of an open-ended pile would be higher for an overconsolidated sand than for a normally consolidated sand at the same $D_{R}$ and $\sigma_{v}^{\prime}$.

Fig. 4.5 shows IFR versus plug length ratio PLR for the chamber test results and for the test results of Szechy (1959), Klos and Tejchman (1977), Brucy et al. (1991), and Paik et al. (2002). The plug length ratio PLR is defined as the ratio of soil plug length to pile penetration as (see Fig. 3.9):

$$
P L R=\frac{L}{D}
$$

In Fig. 4.5(b), the data from Paik et al. (2002) was obtained from a full-scale pile with diameter 


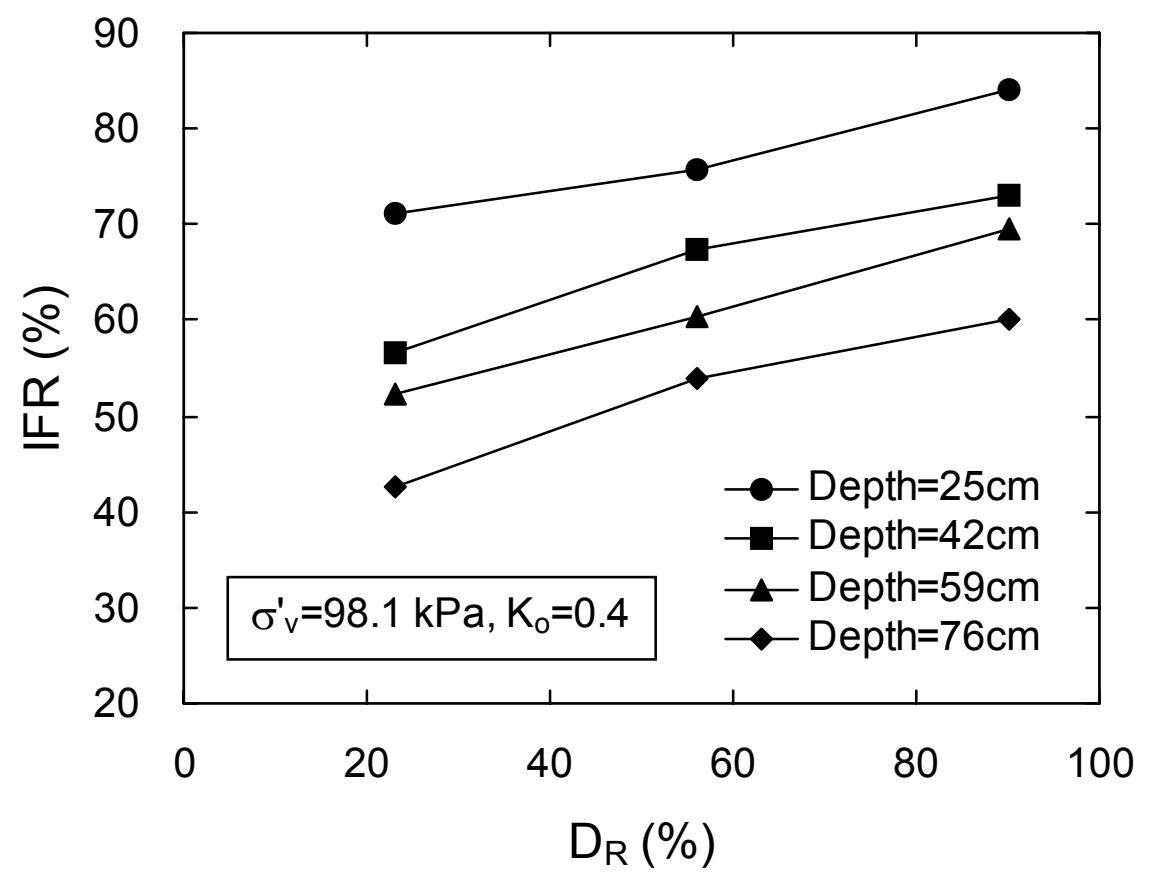

(a)

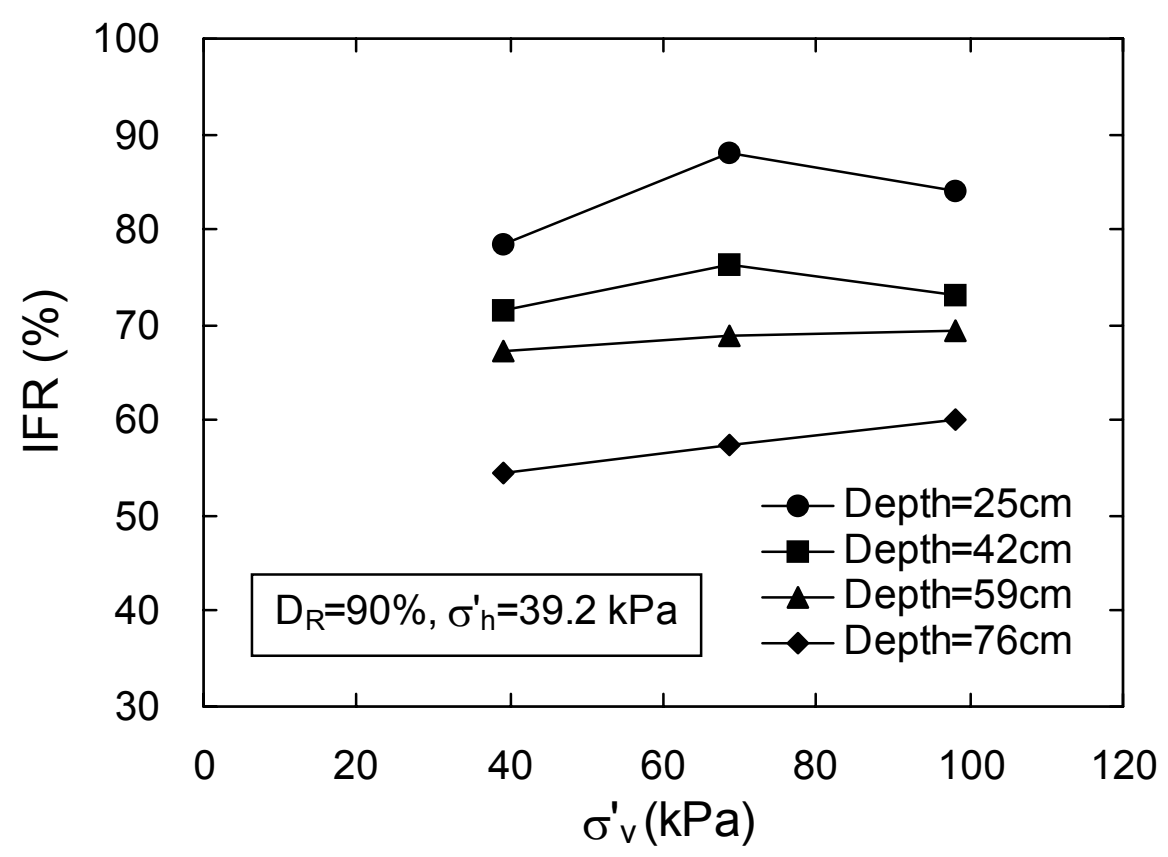

(b)

Figure 4.4 IFR versus (a) relative density for $\sigma_{\mathrm{v}}{ }^{\prime}=98.1 \mathrm{kPa}$ and $\mathrm{K}_{0}=0.4$, (b) vertical stress for $D_{R}=90 \%$ and $\sigma_{h}{ }^{\prime}=39.2 \mathrm{kPa}$, and (c) horizontal stress for $\mathrm{D}_{\mathrm{R}}=90 \%$ and $\sigma_{\mathrm{v}}{ }^{\prime}=98.1 \mathrm{kPa}$. 


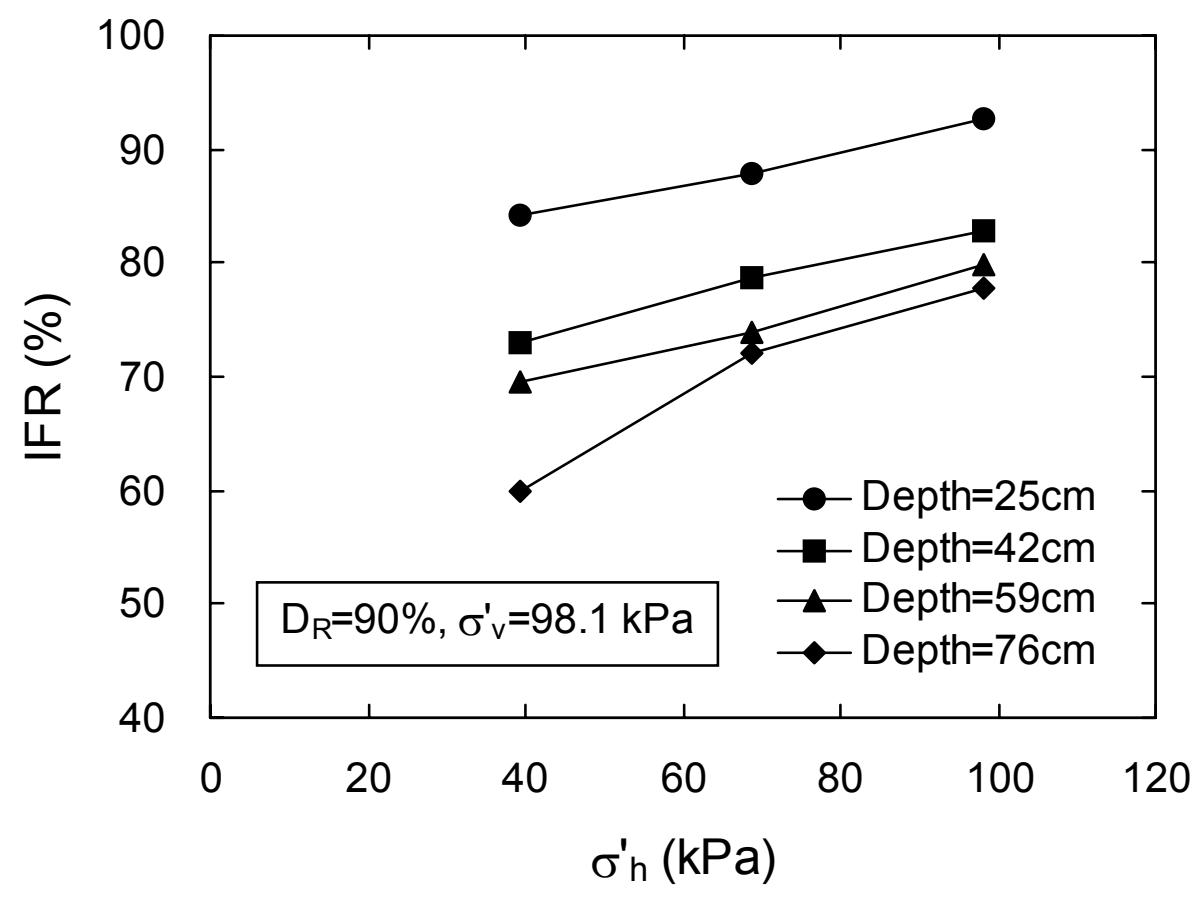

(c)

Figure 4.4 IFR versus (a) relative density for $\sigma_{\mathrm{v}}{ }^{\prime}=98.1 \mathrm{kPa}$ and $\mathrm{K}_{0}=0.4$, (b) vertical stress for $\mathrm{D}_{\mathrm{R}}=90 \%$ and $\sigma_{\mathrm{h}}{ }^{\prime}=39.2 \mathrm{kPa}$, and (c) horizontal stress for $\mathrm{D}_{\mathrm{R}}=90 \%$ and $\sigma_{\mathrm{v}}{ }^{\prime}=98.1 \mathrm{kPa}$ (continued). 


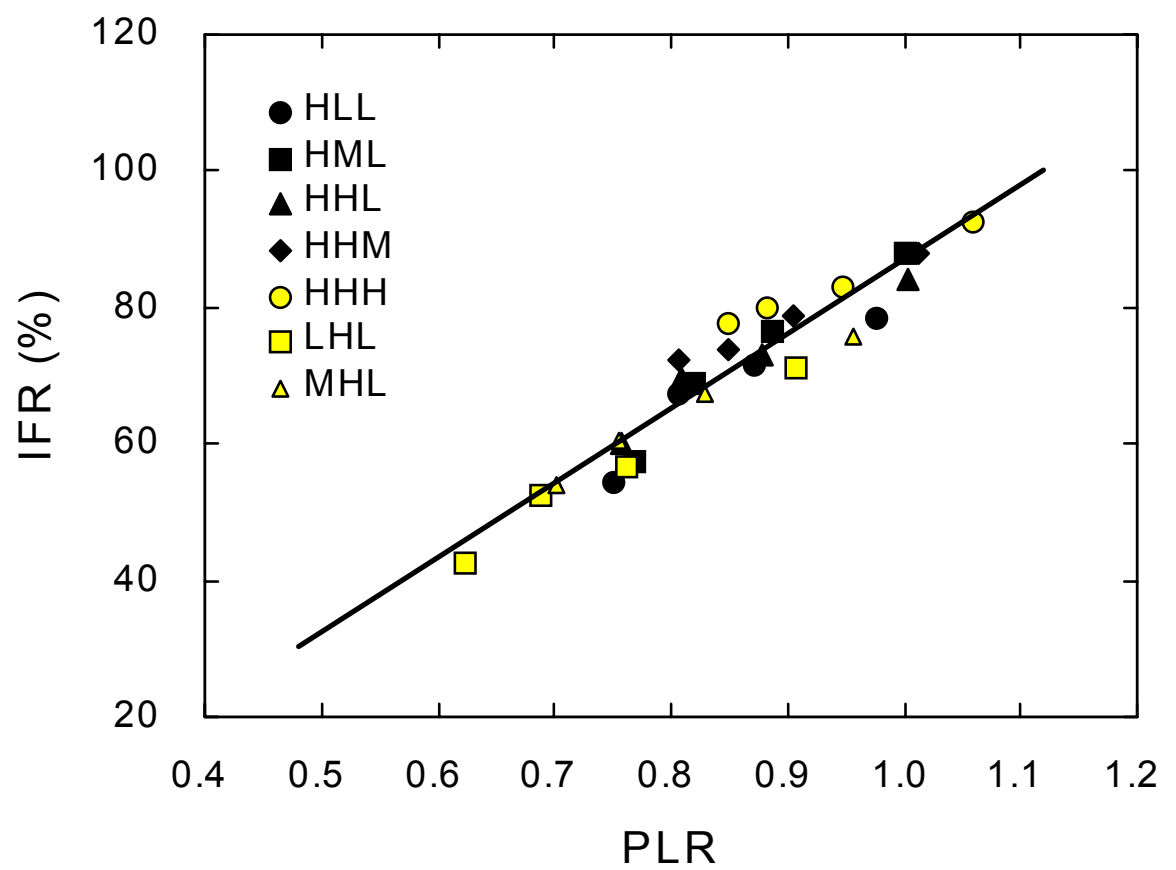

(a)

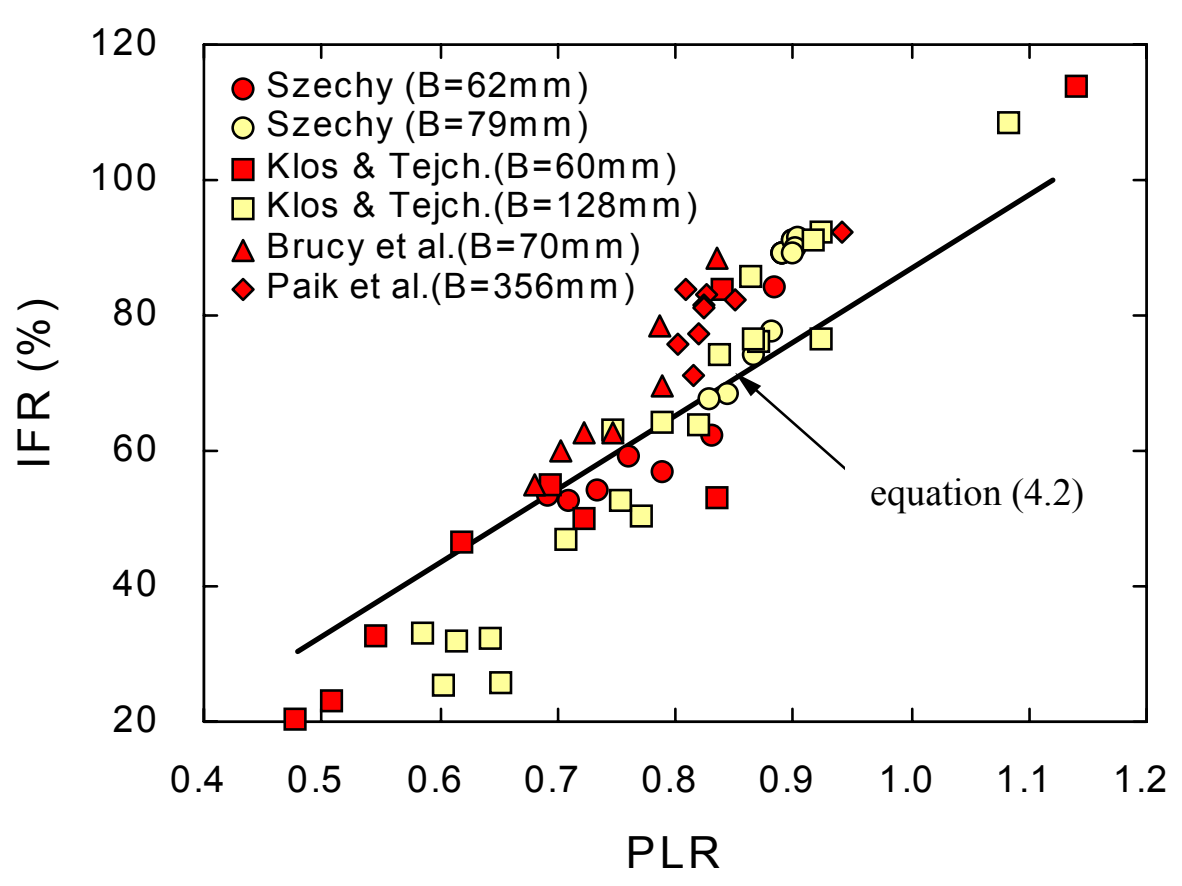

(b)

Figure 4.5 PLR versus IFR (a) for chamber test results, and (b) for other test results. 
of $356 \mathrm{~mm}$ driven into submerged dense sands. The remaining data were obtained from model pile tests using piles with various diameters driven into dry sand ranging from loose to medium dense (the diameter of each test pile is indicated in the figure). Fig. 4.5(a) shows that IFR, measured at the final penetration depth, increases linearly with increasing PLR. The relationship between PLR and IFR for the calibration chamber tests can be expressed as follows:

$$
\operatorname{IFR}(\%)=109 \cdot P L R-22
$$

This equation slightly underestimates the IFR for PLR values greater than 0.8 and slightly overestimates it for PLR values lower than 0.7, as shown in Fig. 4.5(b). In general, it is known that the IFR is a better indicator of the degree of soil plugging than the PLR (Paikowsky et al., 1989; Paik and Lee, 1993). In the field, however, it is easier to measure the PLR than the IFR. Equation (4.2) can be used to estimate the IFR from the PLR, when only the PLR is measured in the field.

\subsubsection{Base and Shaft Load Capacities}

The ultimate unit base resistance $q_{b, c}$ measured in the calibration chamber is plotted versus relative density (for $\sigma_{v}^{\prime}=98.1 \mathrm{kPa}$ and $\mathrm{K}_{\mathrm{o}}=0.4$ ), versus vertical stress (for $\mathrm{D}_{\mathrm{R}}=90 \%$ and $\sigma_{h}^{\prime}=$ $39.2 \mathrm{kPa}$ ) and versus horizontal stress (for $\mathrm{D}_{\mathrm{R}}=90 \%$ and $\sigma_{v}^{\prime}=98.1 \mathrm{kPa}$ ) in Fig. 4.6. It is apparent that the ultimate unit base resistance increases significantly with increasing relative density and increasing horizontal stress, but is relatively insensitive to vertical stress. This is consistent with experimental results of Baldi et al. (1981), Houlsby and Hitchman (1988), and Vipulanandan et al. (1989), which showed that cone resistance was a function of lateral effective stress. 


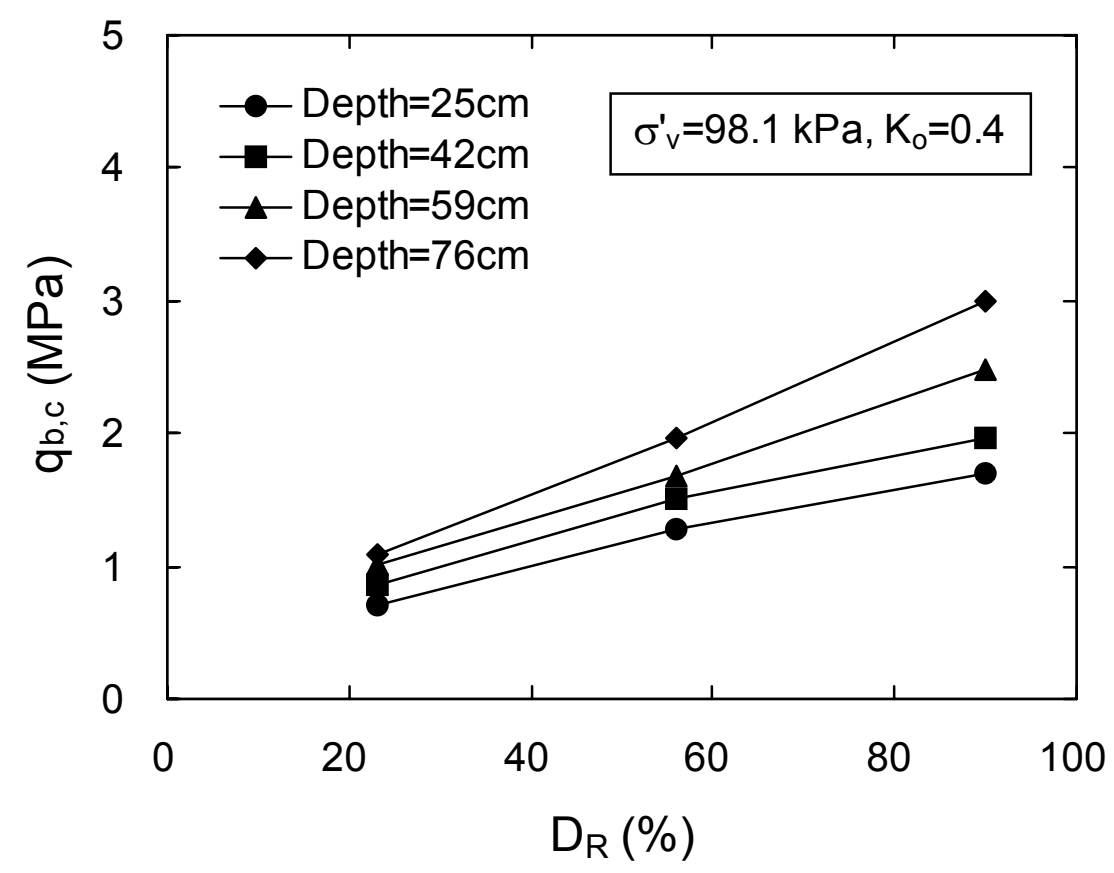

(a)

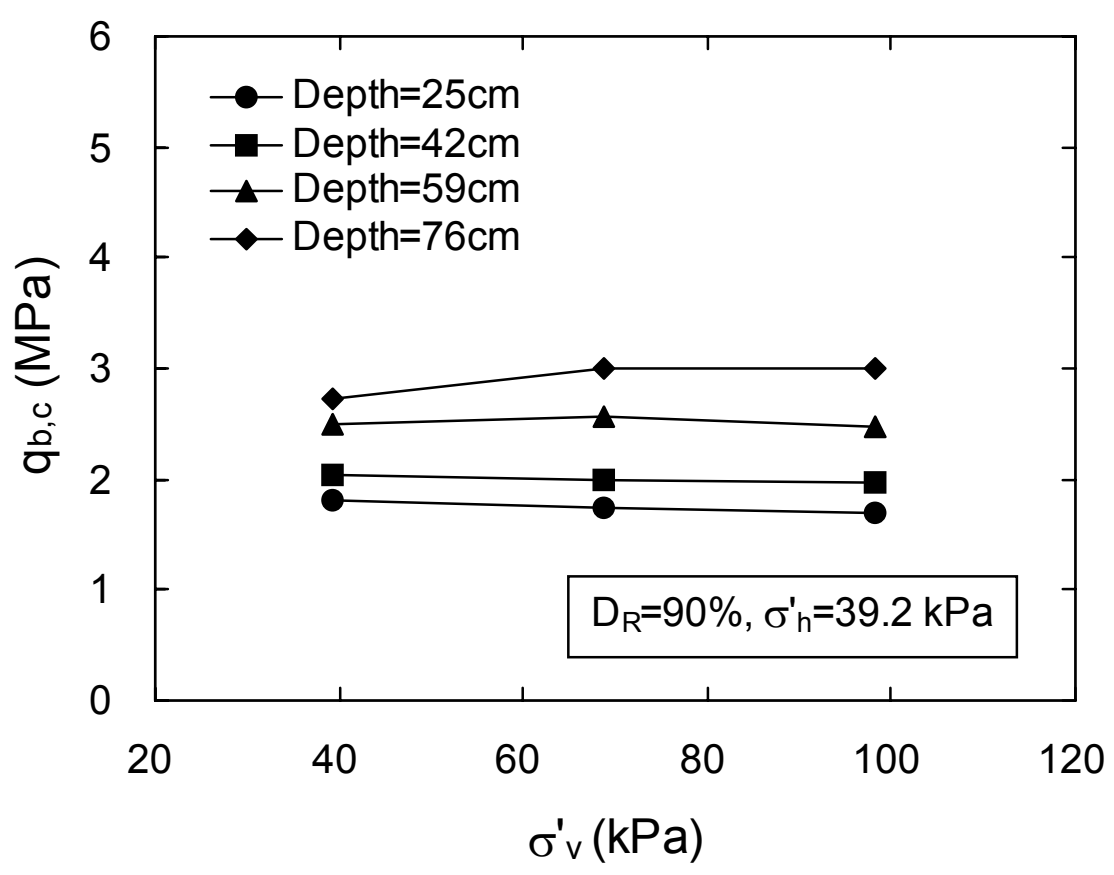

(b)

Figure 4.6 Unit base resistance versus (a) relative density for $\sigma_{\mathrm{v}}{ }^{\prime}=98.1 \mathrm{kPa}$ and $\mathrm{K}_{0}=0.4$, (b) vertical stress for $\mathrm{D}_{\mathrm{R}}=90 \%$ and $\sigma_{\mathrm{h}}{ }^{\prime}=39.2 \mathrm{kPa}$, and (c) horizontal stress for $\mathrm{D}_{\mathrm{R}}=90 \%$ and $\sigma_{\mathrm{v}}{ }^{\prime}=$ $98.1 \mathrm{kPa}$. 


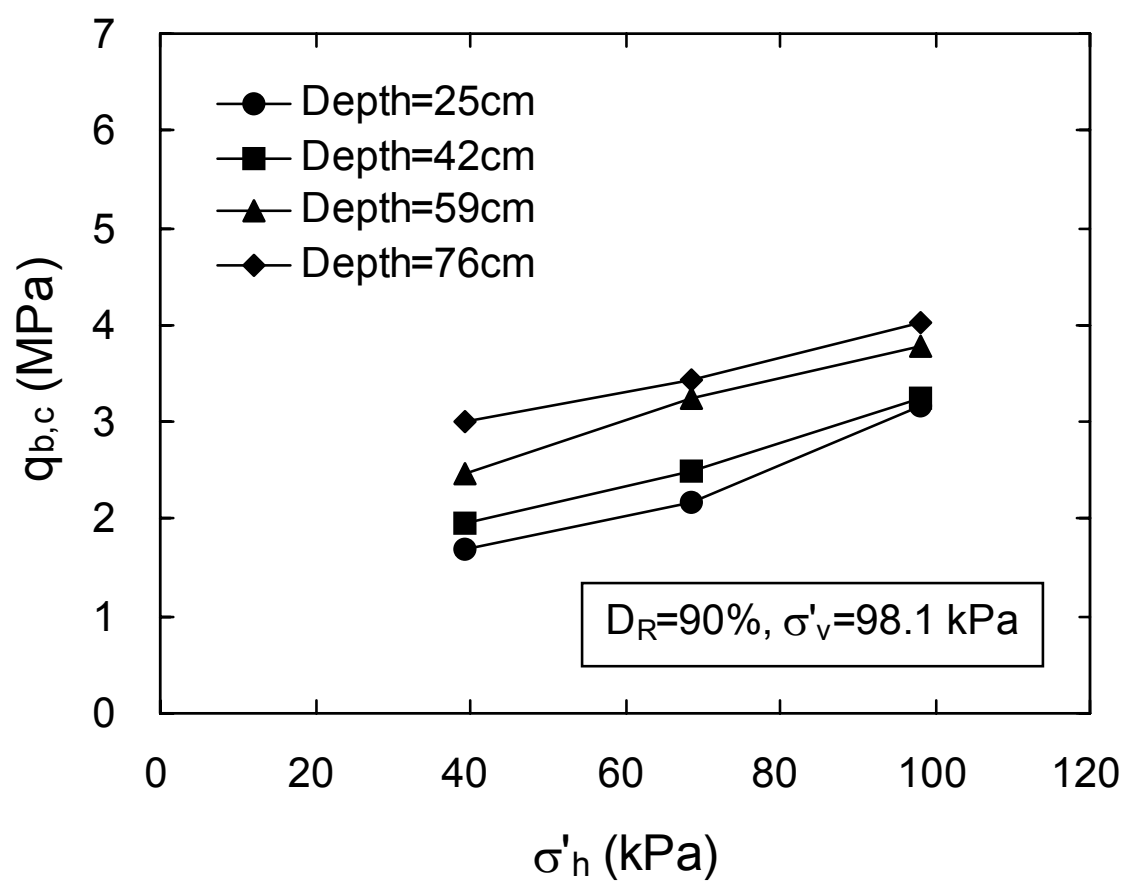

(c)

Figure 4.6 Unit base resistance versus (a) relative density for $\sigma_{\mathrm{v}}{ }^{\prime}=98.1 \mathrm{kPa}$ and $\mathrm{K}_{0}=0.4$, (b) vertical stress for $\mathrm{D}_{\mathrm{R}}=90 \%$ and $\sigma_{\mathrm{h}}{ }^{\prime}=39.2 \mathrm{kPa}$, and (c) horizontal stress for $\mathrm{D}_{\mathrm{R}}=90 \%$ and $\sigma_{\mathrm{v}}{ }^{\prime}=$ $98.1 \mathrm{kPa}$ (continued). 
Fig. 4.7 shows the ultimate unit base resistance, normalized with respect to the horizontal stress, vs. IFR for different relative densities, and the ultimate unit base resistance vs. IFR for dense sand. It can be seen in Figs. 4.7(a) and (b) that the ultimate unit base resistance of openended piles increases with decreasing IFR and that the rate of change of ultimate unit base resistance with IFR increases with $D_{R}$. It is also seen that the ultimate unit base resistance increases with relative density at constant IFR.

Fig. 4.8 shows the ultimate unit shaft resistance $f_{s o, c}$ measured in the calibration chamber versus relative density, vertical stress, and horizontal stress. Similarly to what is observed for ultimate unit base resistance, the ultimate unit shaft resistance of an open-ended pile increases with both relative density and horizontal stress, but is insensitive to the vertical stress. It is clear from Fig. 4.8(c) that the ultimate unit shaft resistance is linearly related to the horizontal stress. The ultimate base and shaft load capacities of the test piles are listed in Table 4.3.

\subsection{Correction of Chamber Test Results for Chamber Size Effects}

\subsubsection{Adjustment of Pile Diameter}

Pile load capacities measured in a calibration chamber are different from those measured in the field under the some soil state due to chamber size effects. In order to use the calibration chamber test results for computation of pile load capacity in the field, corrections for chamber size effects were performed for every chamber test. In the estimation of chamber size effects, the ratio of the chamber to the equivalent diameter of the model pile used in the tests is required. The equivalent diameter of an open-ended pile is the diameter that a pile with solid cross-section 


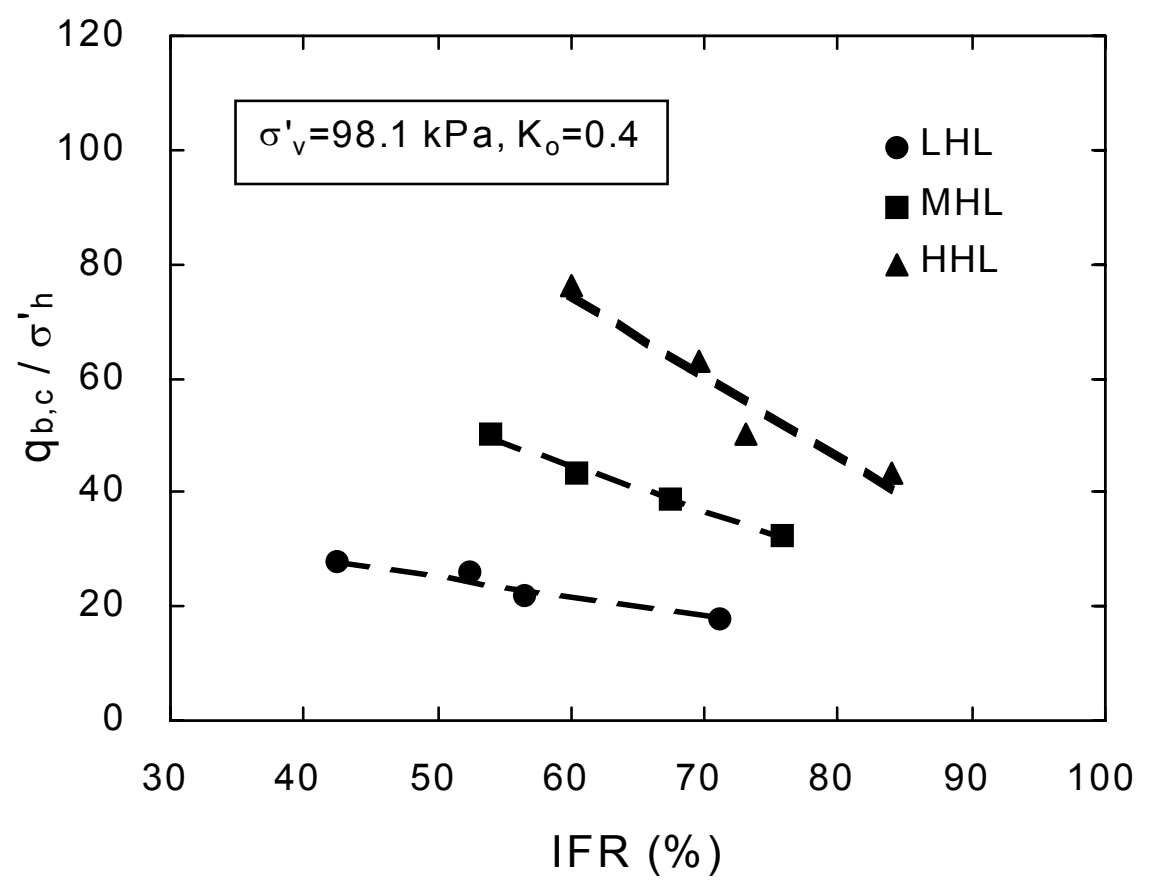

(a)

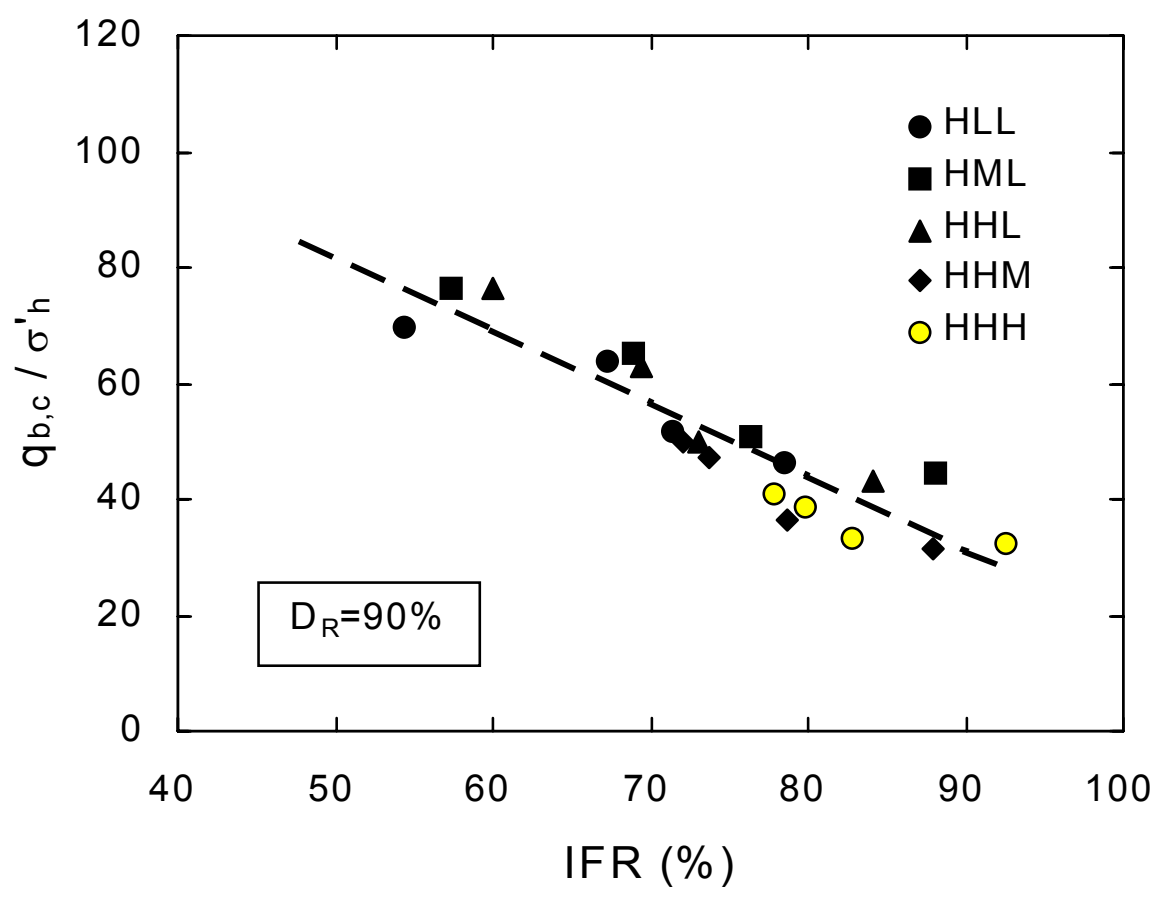

(b)

Figure 4.7 Normalized unit base resistance versus IFR (a) for $\sigma_{v}^{\prime}=98.1 \mathrm{kPa}$ and $\mathrm{K}_{\mathrm{o}}=0.4$, and (b) for $\mathrm{D}_{\mathrm{R}}=90 \%$. 


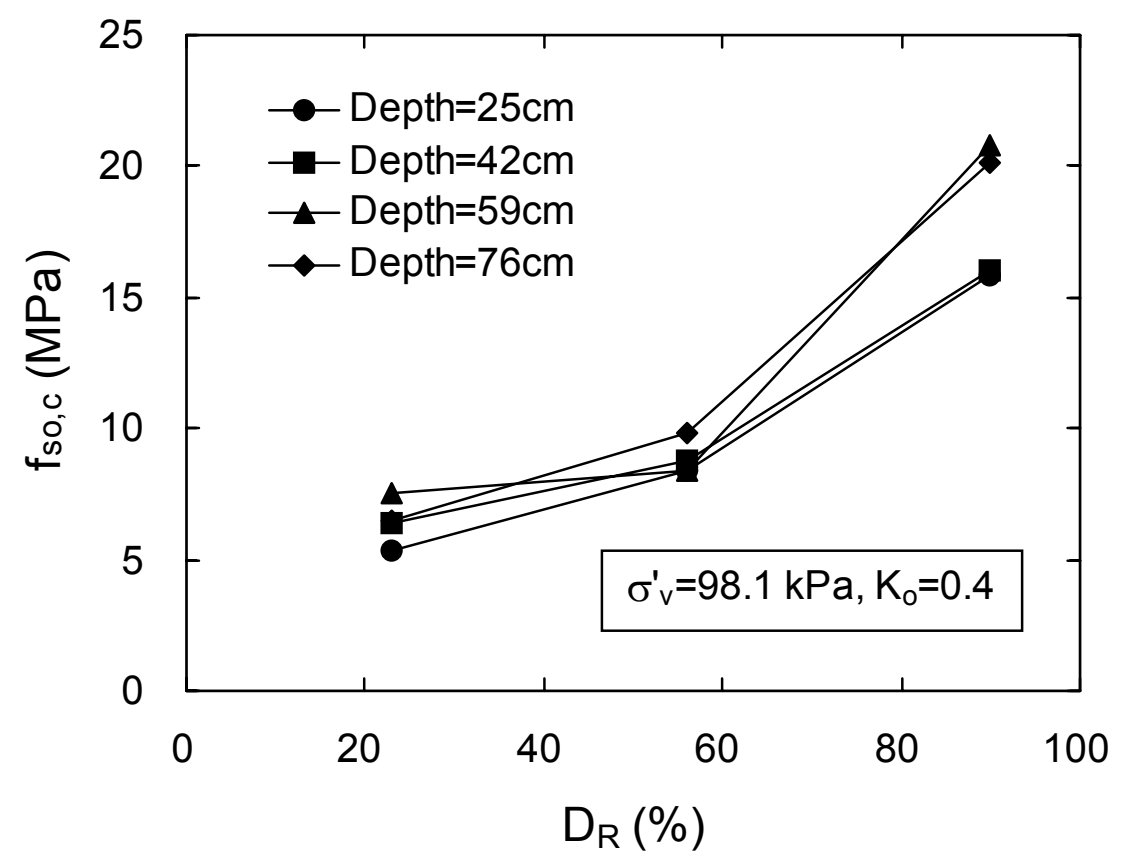

(a)

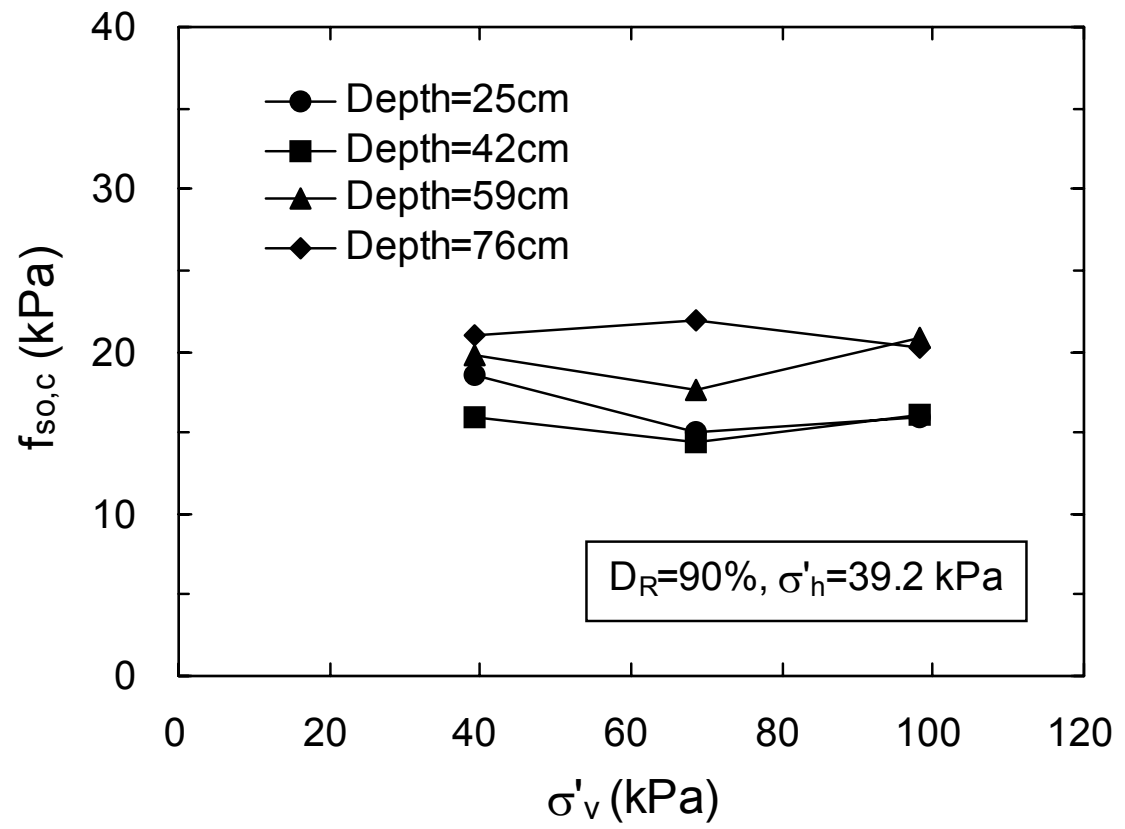

(b)

Figure 4.8 Unit shaft resistance (a) versus relative density for $\sigma_{v}^{\prime}=98.1 \mathrm{kPa}$ and $\mathrm{K}_{\mathrm{o}}=0.4$, (b) vertical stress for $\mathrm{D}_{\mathrm{R}}=90 \%$ and $\sigma_{h}^{\prime}=39.2 \mathrm{kPa}$, and (c) horizontal stress for $\mathrm{D}_{\mathrm{R}}=90 \%$ and $\sigma_{v}^{\prime}=98.1 \mathrm{kPa}$ 


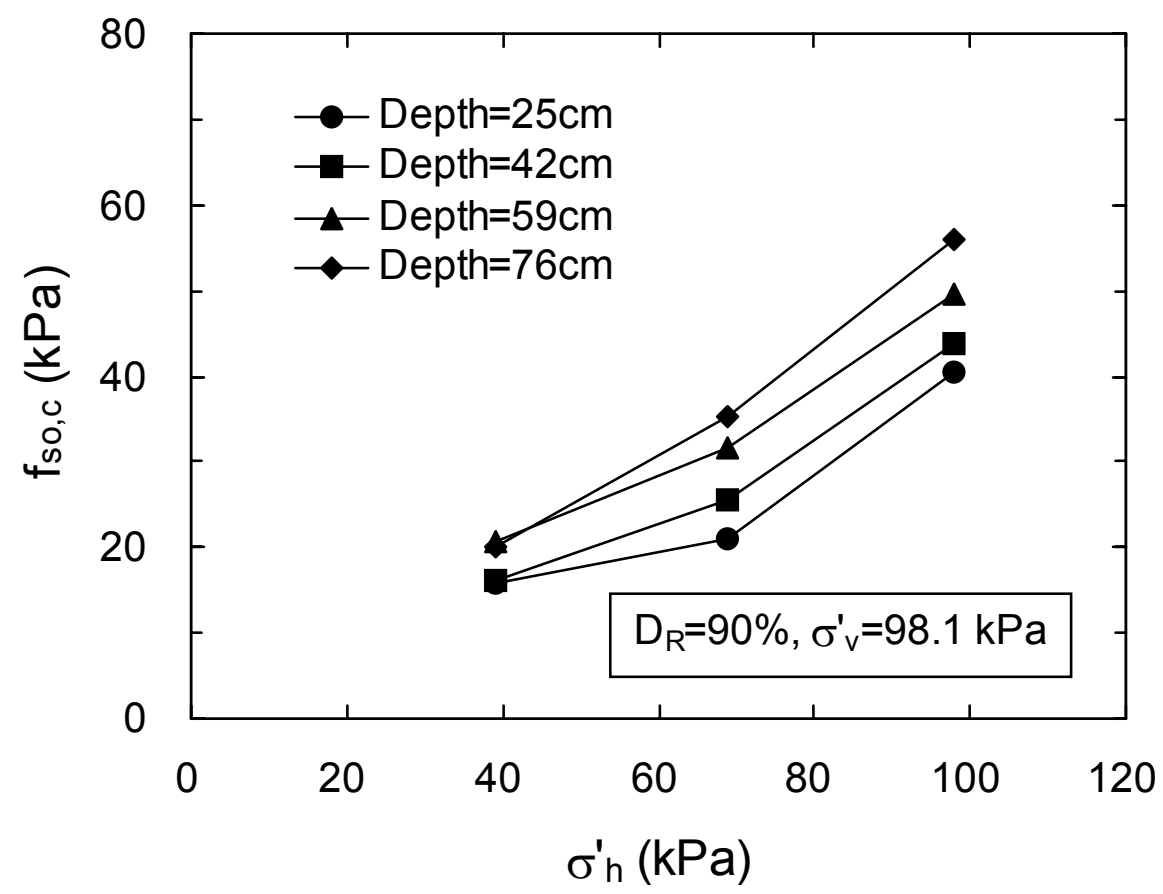

(c)

Figure 4.8 Unit shaft resistance (a) versus relative density for $\sigma_{v}^{\prime}=98.1 \mathrm{kPa}$ and $\mathrm{K}_{\mathrm{o}}=0.4$, (b) vertical stress for $\mathrm{D}_{\mathrm{R}}=90 \%$ and $\sigma_{h}^{\prime}=39.2 \mathrm{kPa}$, and (c) horizontal stress for $\mathrm{D}_{\mathrm{R}}=90 \%$ and $\sigma_{v}^{\prime}=98.1 \mathrm{kPa}$ (continued). 
Table 4.3 Summary of model pile test results and size effect factors

\begin{tabular}{|c|c|c|c|c|c|c|c|c|}
\hline \multirow[b]{2}{*}{$\begin{array}{c}\text { Test } \\
\text { indicator } \\
\text { (1) }\end{array}$} & \multirow{2}{*}{$\begin{array}{r}\text { Test } \\
\text { depth } \\
(\mathrm{mm}) \\
(2)\end{array}$} & \multirow{2}{*}{$\begin{array}{l}\text { Soil } \\
\text { plug } \\
\text { length } \\
(\mathrm{mm}) \\
(3)\end{array}$} & \multirow[b]{2}{*}{$\begin{array}{l}\text { IFR } \\
(\%) \\
(4)\end{array}$} & \multirow[b]{2}{*}{$\begin{array}{l}\text { PLR } \\
\text { (5) }\end{array}$} & \multirow{2}{*}{$\begin{array}{c}\text { Base } \\
\text { load } \\
\text { capacity } \\
(\mathrm{kN}) \\
(6)\end{array}$} & \multirow{2}{*}{$\begin{array}{c}\text { Shaft } \\
\text { load } \\
\text { capacity } \\
(\mathrm{kN}) \\
(7)\end{array}$} & \multicolumn{2}{|c|}{ Size effect factor } \\
\hline & & & & & & & $\begin{array}{c}\text { Base } \\
\text { load } \\
(8)\end{array}$ & $\begin{array}{c}\text { Shaft } \\
\text { load } \\
(9)\end{array}$ \\
\hline HLL & $\begin{array}{l}256 \\
420 \\
592 \\
760\end{array}$ & $\begin{array}{l}250 \\
366 \\
478 \\
571\end{array}$ & $\begin{array}{l}78.4 \\
71.4 \\
67.0 \\
54.4\end{array}$ & $\begin{array}{l}0.98 \\
0.87 \\
0.81 \\
0.75\end{array}$ & $\begin{array}{l}2.60 \\
2.91 \\
3.59 \\
3.91\end{array}$ & $\begin{array}{l}0.63 \\
0.90 \\
1.57 \\
2.13\end{array}$ & $\begin{array}{l}0.50 \\
0.49 \\
0.48 \\
0.46\end{array}$ & $\begin{array}{l}0.54 \\
0.51 \\
0.50 \\
0.49\end{array}$ \\
\hline HML & $\begin{array}{l}250 \\
420 \\
589 \\
760\end{array}$ & $\begin{array}{l}251 \\
373 \\
483 \\
583\end{array}$ & $\begin{array}{l}88.0 \\
76.3 \\
69.0 \\
57.4\end{array}$ & $\begin{array}{l}1.00 \\
0.89 \\
0.82 \\
0.77\end{array}$ & $\begin{array}{l}2.50 \\
2.85 \\
3.67 \\
4.30\end{array}$ & $\begin{array}{l}0.50 \\
0.81 \\
1.39 \\
2.23\end{array}$ & $\begin{array}{l}0.52 \\
0.50 \\
0.48 \\
0.47\end{array}$ & $\begin{array}{l}0.54 \\
0.52 \\
0.50 \\
0.49\end{array}$ \\
\hline HHL & $\begin{array}{l}250 \\
420 \\
590 \\
758\end{array}$ & $\begin{array}{l}251 \\
369 \\
477 \\
575\end{array}$ & $\begin{array}{l}84.2 \\
73.0 \\
69.5 \\
60.0\end{array}$ & $\begin{array}{l}1.00 \\
0.88 \\
0.81 \\
0.76\end{array}$ & $\begin{array}{l}2.42 \\
2.81 \\
3.54 \\
4.29\end{array}$ & $\begin{array}{l}0.53 \\
0.90 \\
1.65 \\
2.05\end{array}$ & $\begin{array}{l}0.51 \\
0.49 \\
0.48 \\
0.47\end{array}$ & $\begin{array}{l}0.54 \\
0.51 \\
0.50 \\
0.49\end{array}$ \\
\hline HHM & $\begin{array}{l}252 \\
420 \\
591 \\
761\end{array}$ & $\begin{array}{l}255 \\
381 \\
501 \\
614\end{array}$ & $\begin{array}{l}87.9 \\
78.6 \\
73.9 \\
72.1\end{array}$ & $\begin{array}{l}1.01 \\
0.90 \\
0.85 \\
0.81\end{array}$ & $\begin{array}{l}3.09 \\
3.57 \\
4.66 \\
4.91\end{array}$ & $\begin{array}{l}0.70 \\
1.45 \\
2.49 \\
3.60\end{array}$ & $\begin{array}{l}0.52 \\
0.50 \\
0.49 \\
0.49\end{array}$ & $\begin{array}{l}0.55 \\
0.52 \\
0.51 \\
0.50\end{array}$ \\
\hline $\mathrm{HHH}$ & $\begin{array}{l}251 \\
420 \\
590 \\
760\end{array}$ & $\begin{array}{l}266 \\
398 \\
521 \\
644\end{array}$ & $\begin{array}{l}92.6 \\
82.9 \\
79.8 \\
77.8\end{array}$ & $\begin{array}{l}1.06 \\
0.95 \\
0.88 \\
0.85\end{array}$ & $\begin{array}{l}4.53 \\
4.66 \\
5.40 \\
5.78\end{array}$ & $\begin{array}{l}1.36 \\
2.46 \\
3.93 \\
5.70\end{array}$ & $\begin{array}{l}0.53 \\
0.51 \\
0.50 \\
0.50\end{array}$ & $\begin{array}{l}0.56 \\
0.53 \\
0.52 \\
0.51\end{array}$ \\
\hline MHL & $\begin{array}{l}247 \\
419 \\
589 \\
757\end{array}$ & $\begin{array}{l}236 \\
347 \\
445 \\
532\end{array}$ & $\begin{array}{l}75.9 \\
67.4 \\
60.5 \\
53.9\end{array}$ & $\begin{array}{l}0.96 \\
0.83 \\
0.76 \\
0.70\end{array}$ & $\begin{array}{l}1.82 \\
2.17 \\
2.41 \\
2.82\end{array}$ & $\begin{array}{l}0.28 \\
0.49 \\
0.65 \\
1.00\end{array}$ & $\begin{array}{l}0.53 \\
0.51 \\
0.50 \\
0.49\end{array}$ & $\begin{array}{l}0.58 \\
0.55 \\
0.53 \\
0.52\end{array}$ \\
\hline LHL & $\begin{array}{l}247 \\
419 \\
581 \\
756\end{array}$ & $\begin{array}{l}224 \\
319 \\
401 \\
472\end{array}$ & $\begin{array}{l}71.1 \\
56.5 \\
52.4 \\
42.6\end{array}$ & $\begin{array}{l}0.91 \\
0.76 \\
0.69 \\
0.62\end{array}$ & $\begin{array}{l}1.01 \\
1.23 \\
1.46 \\
1.56\end{array}$ & $\begin{array}{l}0.18 \\
0.36 \\
0.59 \\
0.66\end{array}$ & $\begin{array}{l}0.61 \\
0.58 \\
0.57 \\
0.56\end{array}$ & $\begin{array}{l}0.66 \\
0.62 \\
0.60 \\
0.59\end{array}$ \\
\hline
\end{tabular}


would have to have in order to displace the same soil volume during installation as the openended pile. The equivalent diameter of open-ended piles varies with the degree of soil plugging, because the soil displacement around the pile due to pile driving increases with decreasing IFR (Randolph et al, 1979). For example, if a pile is driven in fully coring mode, the equivalent pile diameter is calculated from an equivalent area equal to the annular area. If a pile is fully plugged during driving, the gross cross-sectional area of the pile should be used. For piles driven in a partially plugged mode, the equivalent pile diameter can be determined through interpolation with respect to the IFR. This is summarized, mathematically, as follows:

$$
\begin{gathered}
\text { If IFR } \geq 100 \%, d_{p}=\sqrt{\left(d_{o}^{2}-d_{i}^{2}\right)} \\
\text { If IFR }=0 \%, d_{p}=d_{o} \\
\text { If } 0 \% \leq I F R \leq 100 \%, d_{p}=d_{o}-\left(d_{o}-\sqrt{\left(d_{o}^{2}-d_{i}^{2}\right)}\right) \cdot \frac{\operatorname{IFR}(\%)}{100}
\end{gathered}
$$

in which $d_{p}=$ equivalent pile diameter; $d_{o}=$ outer pile diameter, and $d_{i}=$ inner pile diameter.

Considering the pile driving mechanism of an open-ended pile, the base load capacity of the pile depends on the IFR measured at the final penetration depth. The shaft load capacity should be related to the average value of the IFR measured during driving, which is equal to the PLR at the pile penetration depth. In this study, therefore, the equivalent pile diameters for each test were computed for the base and shaft load capacities using equations (4.3). The IFR and PLR at the pile penetration depth are used for correction of the base and the shaft load capacity, respectively. 


\subsubsection{Field Pile load capacity}

Salgado et al. (1998) conducted a theoretical analysis of chamber size effect for cone penetration resistance in sand and quantified the size effect as a function of soil state $\left(D_{R}\right.$ and $\left.\sigma_{h}^{\prime}\right)$ and chamber to pile diameter ratio. According to their results, which also apply to displacement piles, the ratio $\mathrm{q}_{\mathrm{c}, \mathrm{cc}} / \mathrm{q}_{\mathrm{c}, \text { ff }}$ of chamber to field cone resistances for normally consolidated sands with $D_{R}=23 \%, 56 \%, 90 \%$ and diameter ratio in the $10-45$ range can be approximated as:

$$
\frac{q_{c, c c}}{q_{c, f f}}=\left(1.08 \times 10^{-2} \times\left(\frac{D_{c}}{d_{p}}\right)+0.31\right)
$$

for $\mathrm{D}_{\mathrm{R}}=23 \%$

$$
\frac{q_{c, c c}}{q_{c, f f}}=\left(1.02 \times 10^{-2} \times\left(\frac{D_{c}}{d_{p}}\right)+0.24\right)
$$

for $\mathrm{D}_{\mathrm{R}}=56 \%$

$$
\frac{q_{c, c c}}{q_{c, f f}}=\left(7.79 \times 10^{-3} \times\left(\frac{D_{c}}{d_{p}}\right)+0.27\right)
$$

for $\mathrm{D}_{\mathrm{R}}=90 \%$

In these equations, $q_{c, c c}=$ cone resistance measured in a calibration chamber; $q_{c, f f}=$ field cone resistance; $D_{c} / d_{p}=$ ratio of chamber to equivalent pile diameter. The chamber size effect factors for the base and shaft load capacities estimated by (4.4) are listed in Table 4.3. The field pile load capacity can then be obtained by dividing the chamber pile load capacity by the corresponding size effect factors. 


\subsection{New Design Equations for Load Capacity of Open-Ended Piles}

\subsubsection{Base Load Capacity}

Fig. 4.9 shows the ultimate unit field base resistance $q_{b, f}$, normalized with respect to the horizontal effective stress $\sigma_{h}^{\prime}$ at the pile base, versus IFR for piles driven into sands with various relative densities. The figure shows that the normalized unit field base resistance increases linearly with decreasing IFR. The relationship between $q_{b, f} / \sigma_{h}^{\prime}$ and IFR can be expressed as:

$$
\frac{q_{b, f}}{\alpha \cdot \sigma_{h}^{\prime}}=326-295 \cdot \frac{\operatorname{IFR}(\%)}{100}
$$

with a coefficient of determination, $r^{2}$, equal to 0.82 . In this equation, the $\alpha$ values, function of the relative density, were obtained from the calibration chamber tests as equal to 1.0 for dense sands, 0.6 for medium sands, and 0.25 for loose sands. In the case of fully plugged piles (IFR=0), which behave as closed-ended piles, unit field base resistance is expressed as $q_{b, f}=326 \sigma_{h}^{\prime}=130 \sigma_{v}^{\prime}$ for normally consolidated dense sands with $K_{o}=0.4$. This is consistent with the unit base resistance of a closed-ended pile in dense sand proposed by the Canadian Foundation Engineering Manual (1992). In order to predict base load capacity of open-ended piles using (4.5), it is necessary to know either the IFR or the soil plug length at the final penetration depth (from which the IFR can be estimated through (4.2)). A technique for measuring IFR during pile installation will be described in a later section. Note that equation (4.5) should be used only for piles driven into sands, not for piles installed using vibratory hammers. 


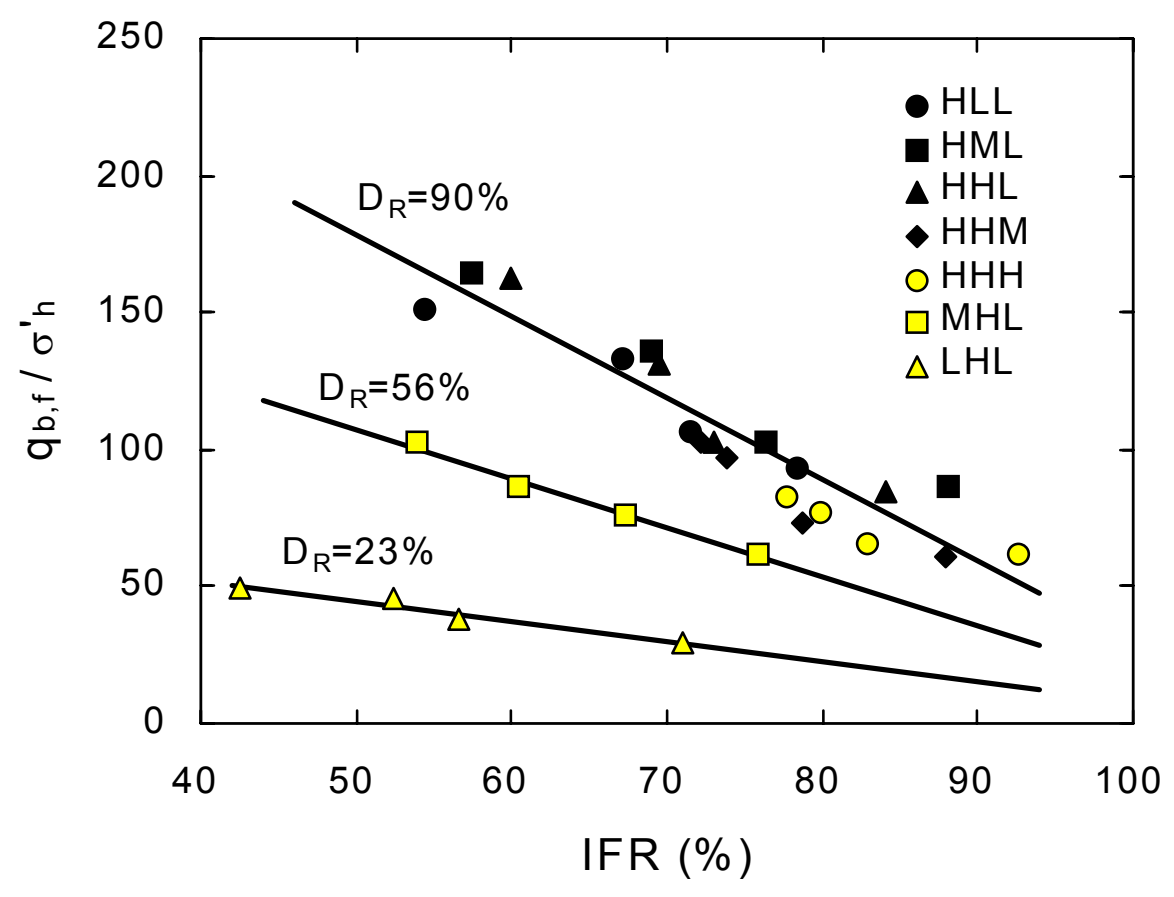

Figure 4.9 Normalized field unit base resistance versus IFR. 


\subsubsection{Shaft Load Capacity}

The average ultimate field unit shaft resistance $\mathrm{f}_{\mathrm{so}, \mathrm{f}}$ for the model piles, normalized with respect to $K_{o} \sigma_{v}^{\prime} \tan \delta_{c}$, is plotted versus PLR in Fig. 4.10 for various relative densities. It can be seen in the figure that the normalized ultimate field unit shaft resistance increases with decreasing PLR. The field unit shaft resistance of piles driven into dense sand can be expressed as follows:

$$
\frac{f_{s o, f}}{\left(K_{o} \sigma_{v}^{\prime} \tan \delta_{c}\right) \beta}=7.2-4.8 \cdot P L R
$$

in which $f_{s o, f}=$ average ultimate unit shaft resistance in the field, $K_{o}=$ lateral earth pressure coefficient before pile driving; $\sigma_{v}^{\prime}=$ average vertical effective stress over the whole penetration depth; $\delta_{c}=$ critical-state interface friction angle between the pile and the soil; and $\beta=$ function of the relative density. The $\beta$ values were obtained from the calibration chamber tests as equal to 1.0 for dense sands, 0.4 for medium sands, and 0.22 for loose sands. In the case of closed-ended piles in normally consolidated dense sands with $K_{o}=0.4$, the normalized unit shaft resistance equals 7.2. This equation may be interpreted as implying that the lateral stress on the closedended pile driven in dense sands is 7.2 times higher than that before pile driving. This is consistent with the lateral earth pressure coefficient of $K=2-3$, which the Canadian Foundation Engineering Manual (1992) suggested for steel piles with $\delta=20^{\circ}$ driven into a normally consolidated dense sand. 


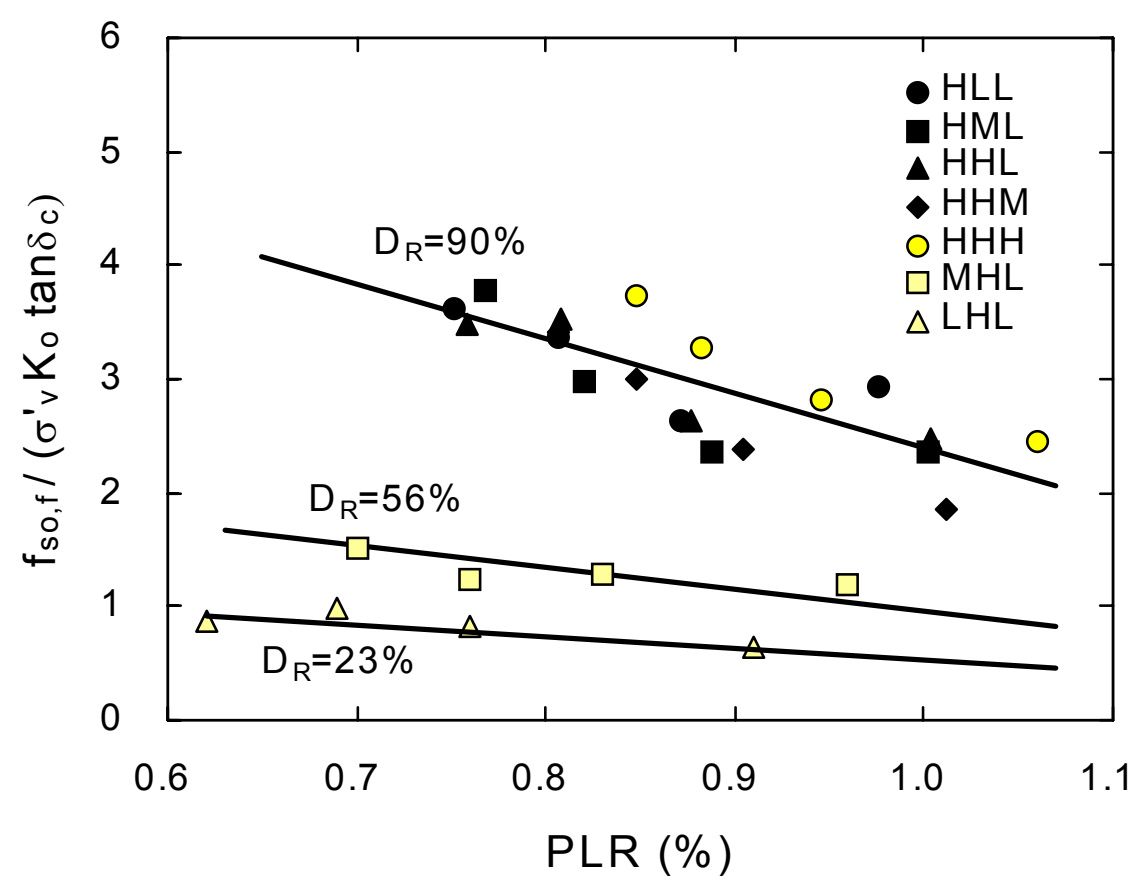

Figure 4.10 Normalized field unit shaft resistance versus PLR. 


\subsection{Application of New Empirical Relations}

\subsubsection{Example 1}

\section{Field Pile Load Test}

In this example, we use the field load tests described in the previous chapter. The soil at the site is gravelly sand with maximum and minimum dry unit weights of $18.64 \mathrm{kN} / \mathrm{m}^{3}$ and 15.61 $\mathrm{kN} / \mathrm{m}^{3}$, respectively. A $2.0 \mathrm{~m}$ thick fill layer was removed before pile driving. The groundwater table is at a depth of $3 \mathrm{~m}$ below the soil surface. SPT and CPT results indicate that the first 3 meters of the gravelly sand deposit are in a loose state $\left(D_{R} \approx 30 \%\right)$, but the rest of the deposit is in a dense to very dense state $\left(D_{R} \approx 80 \%\right)$, as shown in Fig. 4.11. Note that the fill originally present at the site was removed before the piles were installed and tested, and Fig 4.11 accordingly does not include data for the fill. The resulting over consolidation ratio (OCR) is also shown in Fig. 4.11 as a function of depth.

\section{Static Load Test Results}

Fig. 4.12 shows the load-settlement curves for the base and shaft load capacities of the full-scale open-ended pile. As shown in the figure, the shaft load capacity reached its limit value before the final load step. The ultimate total and base load capacities were also determined as the loads at a settlement of $35.6 \mathrm{~mm}$, corresponding to $10 \%$ of the pile diameter. The ultimate base and shaft load capacities not accounting for residual loads were $715 \mathrm{kN}$ and $310 \mathrm{kN}$, respectively. The ultimate base and shaft load capacities accounting for residual loads were $886 \mathrm{kN}$ and $139 \mathrm{kN}$, respectively. In practice, it is difficult to account for residual loads. 


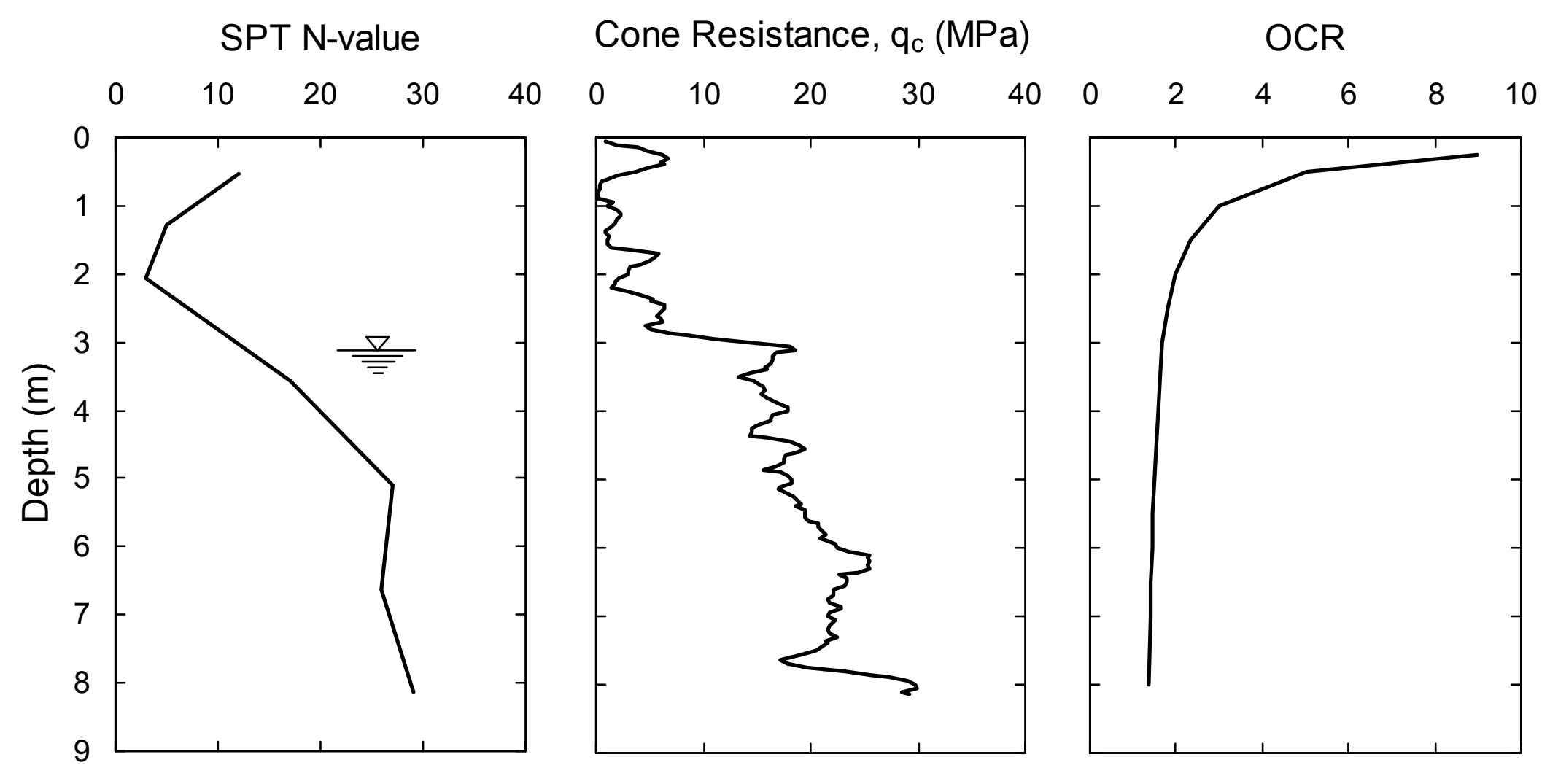

Figure 4.11 CPT and SPT results and OCR profile at test site. 


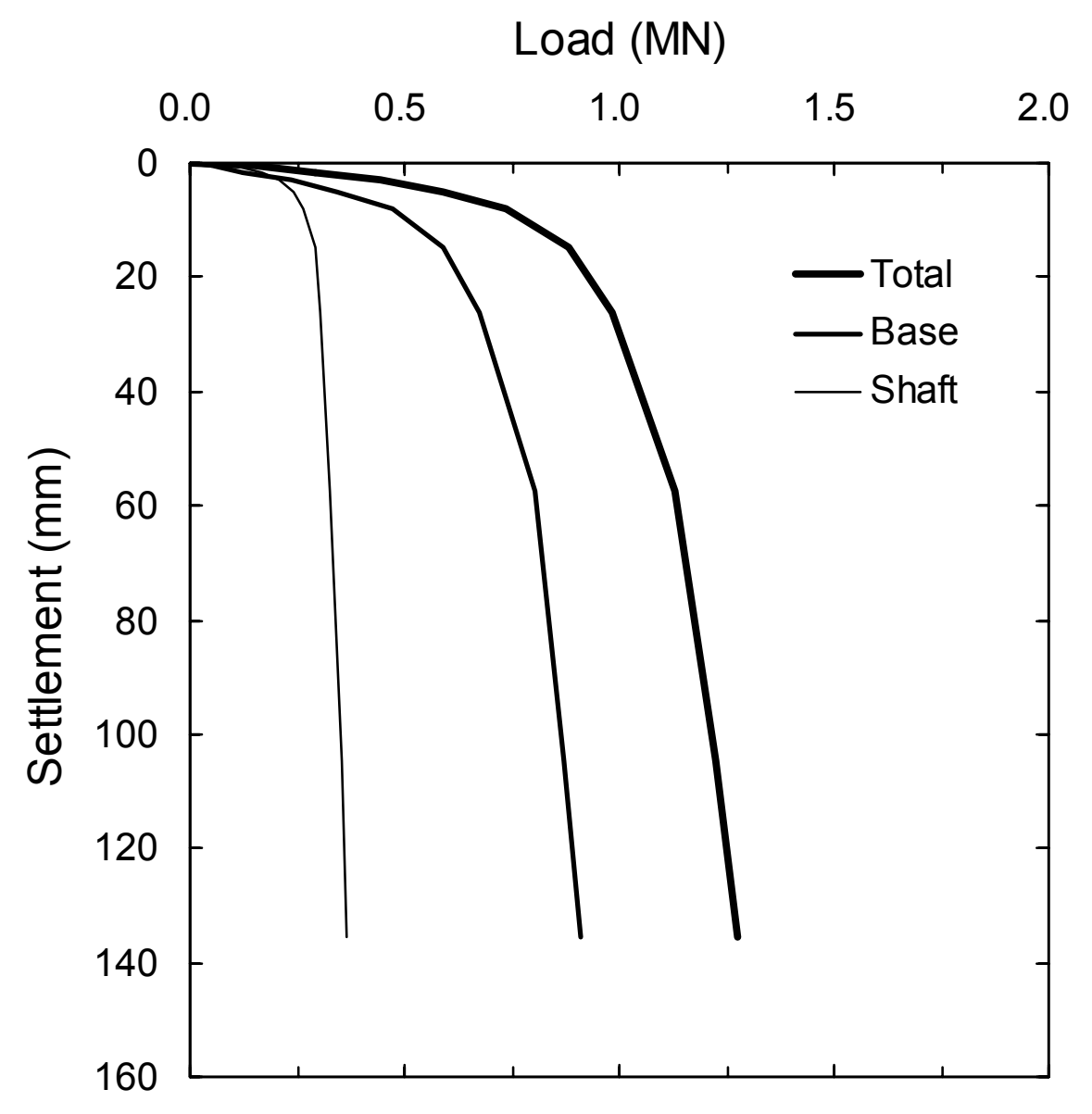

Figure 4.12 Load-settlement curves from field pile load test. 
Residual loads are induced in every driven pile, but their magnitude depends on several factors. The use of the unit base and shaft resistance values that have been corrected for residual loads for designing a different pile installed in a different sand site would require estimation of the residual loads for that pile. This is very difficult to do in practice. Accordingly, we base our suggested design values of shaft and base resistances on the values measured without any correction for residual loads, as is customary.

\section{Comparison of Computed and Measured Capacities}

The bearing capacity of the test pile was predicted using the empirical relationships suggested in this study. Since the soil deposit was over-consolidated by removal of the fill layer, the lateral earth pressure coefficient $K_{o}$ was taken as (Mayne and Kulhaway, 1982):

$$
K_{o}=(1-\sin \phi) O C R^{\sin \phi}
$$

Saturated unit weights of the sand are $\gamma_{\mathrm{sat}}=20.1 \mathrm{kN} / \mathrm{m}^{3}$ for the loose sand and $21.2 \mathrm{kN} / \mathrm{m}^{3}$ for the dense sand, respectively. The mean particle size is $0.4 \mathrm{~mm}$. The critical state friction angle for the sand obtained from triaxial compression tests is $\phi_{\mathrm{c}}=33.3^{\circ}$; the interface friction angle between the pile and sand is taken as $\delta_{\mathrm{c}}=2 \phi_{\mathrm{c}} / 3=22.2^{\circ}$, which is adequate for typical pipe piles. At the depth of the pile base, $O C R=1.41$, and $K_{o}$ results equal to 0.55 . Using (4.5), the ultimate base load capacity $Q_{\text {base }}$ can be obtained as:

$$
\begin{aligned}
& \frac{q_{b, f}}{\alpha \cdot \sigma_{h}^{\prime}}=326-295 \cdot \frac{\operatorname{IFR}(\%)}{100}=326-295 \cdot \frac{77.5}{100}=97.4 \\
& Q_{\text {base }}=q_{b, f} \cdot A_{b}=97.4 \cdot \alpha \cdot \sigma_{h}^{\prime}\left(\frac{\pi \cdot d_{o}^{2}}{4}\right)=97.4(1.0)(0.55 \times 101.2)(0.0995)=539.4 \mathrm{kN}
\end{aligned}
$$


The ultimate shaft load capacity can be computed using (4.6). The $\beta$ values used in the calculations are 0.3 for the first $3 \mathrm{~m}$ in loose sand and 1.0 for depth greater than $3 \mathrm{~m}$ in dense sands. The variation of $K_{o}$ with $O C R$ along the whole depth of the pile was considered in the calculations, which are summarized next:

$$
\begin{aligned}
\frac{f_{s o, f}}{\left(K_{o} \sigma_{v}^{\prime} \tan \delta_{c}\right) \beta} & =7.2-4.8 \cdot P L R=7.2-4.8(0.82)=3.26 \\
Q_{\text {shaft }}=f_{s o, f} \cdot A_{s o} & =3.26 K_{o} \sigma_{v}^{\prime} \tan \delta_{c} \beta\left(\pi \cdot d_{o} D\right)=3.26 \Sigma\left(\beta_{i} K_{o i} \sigma_{v i}^{\prime} D_{i}\right) \pi \cdot d_{o} \tan \delta_{c} \\
& =3.26(0.3 \times 63.4+1.0 \times 191.3) \pi(0.356) \tan 22.2^{\circ}=312.9 \mathrm{kN}
\end{aligned}
$$

in which $D=$ penetration depth of the pile. Thus, the ultimate total load capacity can be calculated as

$$
Q_{\text {total }}=Q_{\text {base }}+Q_{\text {shaft }}=539.4+312.9=852.3 \mathrm{kN}
$$

The base and shaft load capacities predicted using equations (4.5) and (4.6) were 75.4\% and $100.9 \%$ of the ultimate values measured in the pile load test, respectively. The predicted $Q_{\text {total }}=852.3 \mathrm{kN}$ is a reasonably close, conservative estimate of the measured value, as shown in Fig. 4.13(a).

\subsubsection{Example 2}

\section{Field Pile Load Test}

Beringen et al. (1979) described field pile load tests on an instrumented open-ended pipe pile driven into a dense, overconsolidated sand. The wet unit weight of the sand is $20 \mathrm{kN} / \mathrm{m}^{3}$, and 
the average friction angle for the sand measured from drained triaxial tests is $\phi=38^{\circ}$ and $\delta=2 \phi / 3$ $=25.3^{\circ}$. The ground water level is $3.1 \mathrm{~m}$ under the soil surface, and CPT cone resistance at the pile base level is $43 \mathrm{MPa}$. The upper 2.2 meters of sand are in a medium state, while the lest of the layer is in a very dense state. Because the $O C R$ is not reported, lateral earth pressure coefficient was calculated using the theoretical analysis results of Salgado et al. (1997b), who calculate the CPT cone resistance for the horizontal stress and relative density using the program CONPOINT (Salgado et al., 1997a; Salgado et al., 1998). The $K_{o}$ value calculated for $\mathrm{D}_{\mathrm{R}}=90 \%$ is 0.70 , and the OCR can be estimated as equal to 2.65 by (4.7). The pile was driven down to 7.0 $\mathrm{m}$, and the soil plug length measured at the final penetration depth was $4.6 \mathrm{~m}$. The inside and outside pile diameters were $324 \mathrm{~mm}$ and $356 \mathrm{~mm}$, respectively.

The reported base and shaft load capacities in compression were $1130 \mathrm{kN}$ and $1310 \mathrm{kN}$ at the last loading stage, $966 \mathrm{kN}$ and $1260 \mathrm{kN}$ at settlement of $10 \%$ of pile diameter respectively. The reported shaft load capacity in tension was $830 \mathrm{kN}$, same at both stages. However, it is not possible to separate the total compression load capacity into base and shaft load capacities using only strain gauges, unless the pile is a double-walled pile. It seems to be more appropriate to calculate the base load capacity by subtracting the shaft load capacity in tension from the total load capacity in compression. For the purposes of this study, therefore, the base load capacity $Q_{\text {base }}=1396 \mathrm{kN}$ and the shaft load capacity $Q_{\text {shaft }}=830 \mathrm{kN}$.

\section{Comparison of Computed and Measured Capacities}

The IFR at the final penetration depth can be estimated using (4.2) as

$$
\operatorname{IFR}(\%)=109 \cdot\left(\frac{4.6}{7.0}\right)-22=49.6 \%
$$


Thus, the limit plug load capacity can be predicted from (4.5) as

$$
\begin{aligned}
& \frac{q_{b, f}}{\alpha \cdot \sigma_{h}^{\prime}}=326-295 \cdot \frac{\operatorname{IFR}(\%)}{100}=326-295 \cdot \frac{49.6}{100}=179.7 \\
& Q_{\text {base }}=q_{b, f} \cdot A_{b}=179.7 \cdot \alpha \cdot \sigma_{h}^{\prime}\left(\frac{\pi \cdot d_{o}^{2}}{4}\right)=179.7(1.0)(0.70 \times 101.8)(0.0995)=1274.1 \mathrm{kN}
\end{aligned}
$$

The limit shaft load capacity can be computed using (4.6) (The variation of $K_{o}$ with $O C R$ for the whole depth of the pile was considered in this calculation):

$$
\begin{aligned}
\frac{f_{s o, f}}{\left(K_{o} \sigma_{v}^{\prime} \tan \delta_{c}\right) \beta} & =7.2-4.8 \cdot P L R=7.2-4.8(0.657)=4.05 \\
Q_{\text {shaft }}=f_{s o, f} \cdot A_{s o} & =4.05 K_{o} \sigma_{v}^{\prime} \tan \delta_{c} \beta\left(\pi \cdot d_{o} D\right)=4.05 \Sigma\left(\beta_{i} K_{o i} \sigma_{v i}^{\prime} D_{i}\right) \pi \cdot d_{o} \tan \delta_{c} \\
& =4.05(0.4 \times 30.5+1.0 \times 251.3) \pi(0.356) \tan 25.3^{\circ}=564.18 \mathrm{kN}
\end{aligned}
$$

in which $D=$ penetration depth of the pile. Thus, the limit total load capacity can be calculated as

$$
Q_{\text {total }}=Q_{\text {base }}+Q_{\text {shaft }}=1274.1+564.2=1838.3 \mathrm{kN}
$$

The base and shaft load capacities predicted using equations (4.5) and (4.6) was 91.2\% and $67.9 \%$ of the limit values measured in the pile load test, respectively. The predicted value of $Q_{\text {total }}=1838.3 \mathrm{kN}$ is about $82.6 \%$ of the measured value. It can be seen in Fig. $4.13(\mathrm{~b})$ that the proposed relations can satisfactorily predict the load capacities of the test pile. 


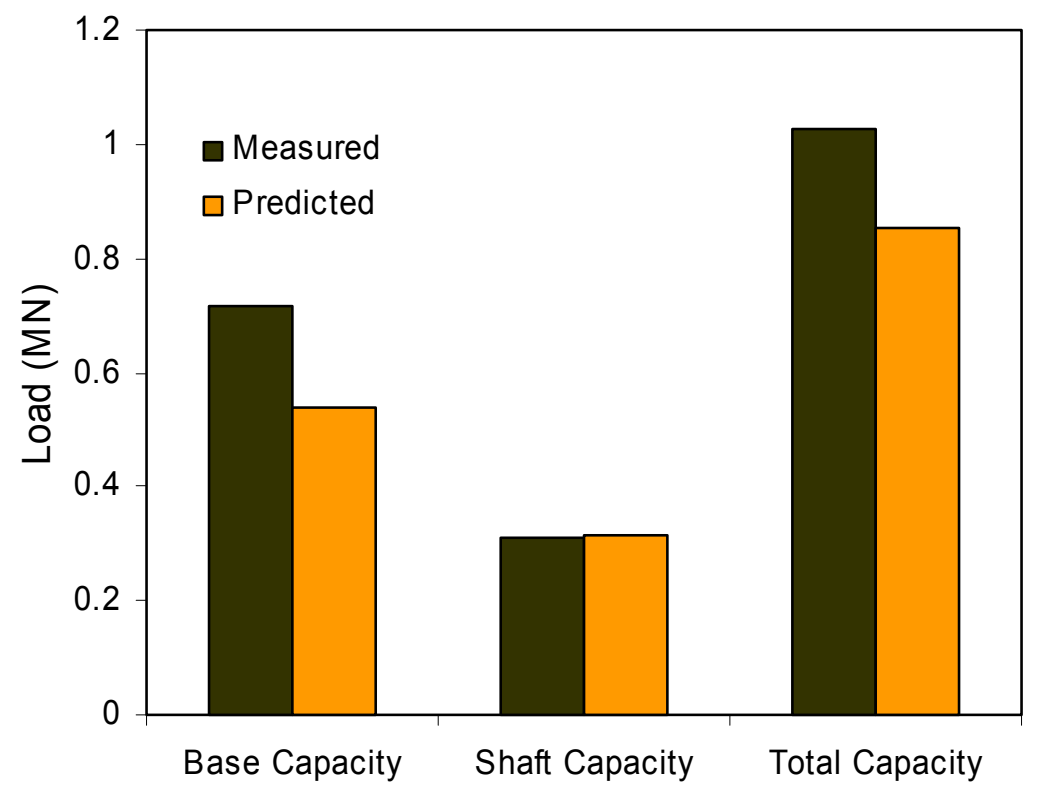

(a)

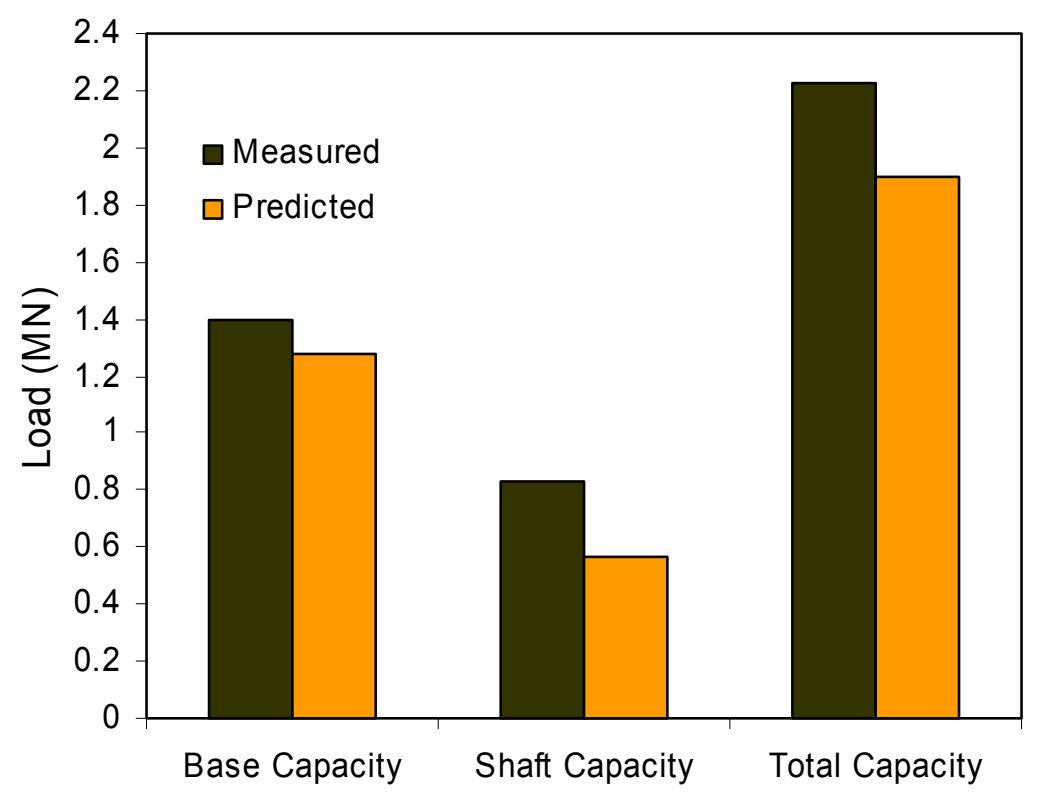

(b)

Figure 4.13 Comparison of predicted with measured load capacities; (a) example 1, (b) example 2 


\section{CHAPTER 5}

\section{ESTIMATION OF THE LOAD CAPACITY OF PIPE PILES IN SAND BASED ON CPT RESULTS}

\section{$5.1 \quad$ Overview}

Open-ended piles cause less change in the soil state than closed-ended piles with the same diameter, but more so than non-displacement piles with the same diameter. A major difference between closed- and open-ended piles is the possible formation of a "soil plug" inside the open-ended pile during driving. If no soil entered the pile during installation, open-ended piles would behave exactly as closed-ended piles. As the soil enters the pile, frictional resistance is mobilized between the soils and the inner surface of the pile. Until sufficient friction develops between the soil plug and the pile inner surface and the plug becomes sufficiently stiff, soil continues to enter the pile. The base resistance of open-ended piles is a combination of the soil plug resistance and the annulus resistance.

Numerous investigations of the behavior of open-ended piles have been conducted either experimentally or analytically (e.g., Paikowski and Whitman 1990, Randolph et al. 1991, Leong and Randolph 1991, Paik and Lee 1993, De Nicola and Randolph 1997). Most of the experimental investigations were done using calibration chamber load tests on model piles driven into the soil. In this project, the pile load capacity of both closed- and open-ended driven piles in sand are investigated using fully instrumented field pile load tests and calibration chamber pile load tests. The relationship between pile load capacity and CPT cone resistance is established based on the determination of cone penetration resistance $\mathrm{q}_{\mathrm{c}}$ for the same conditions as in the 
tests. Pile unit resistances normalized with respect to the cone resistance $\mathrm{q}_{\mathrm{c}}$ are provided for various soil densities and driving conditions.

\subsection{Experimental Program}

\subsubsection{Calibration Chamber Tests}

Calibration chamber tests have been used in several instances to investigate pile behavior (Ghionna et al. 1993, Salgado et al. 1998, Lee and Salgado 2000, 2001). Paik and Lee (1993) and Paik et al. (1994) conducted a series of calibration chamber tests for both open- and closed-ended driven piles. A total of 36 calibration chamber load tests on closed- and open-ended piles were performed (Paik et al. 1993, 1994). All the tests were instrumented in order to separately measure each component of pile load capacity. The calibration chamber used in the tests has a diameter of $0.775 \mathrm{~m}$ and a height of $1.25 \mathrm{~m}$. The test piles were driven into the sand samples using a falling hammer until a desired pile base depth was reached. Four different pile base depths $(250,420,590$, and $790 \mathrm{~mm})$ were used in the load tests. Fig. 5.1 shows the detailed dimensions of the test piles. The tests were performed on samples with different soil densities and stress states (see Table 5.1). The sand was Han River sand, a uniformly graded silica sand with properties given in Table 5.2.

Fig. 5.2 shows base and shaft load-settlement curves for closed-ended piles [Figs. 5.2(a) and (c)] and open-ended piles [Figs. 5.2(b) and (d)] driven to four different pile depths (250, 420, 590 , and $760 \mathrm{~mm}$ ) measured from the top of the calibration chamber soil samples. For the openended piles, the base resistance $\mathrm{q}_{\mathrm{b}}$ was obtained from the combination of the soil plug $\left(\mathrm{Q}_{\mathrm{plug}}\right)$ and 

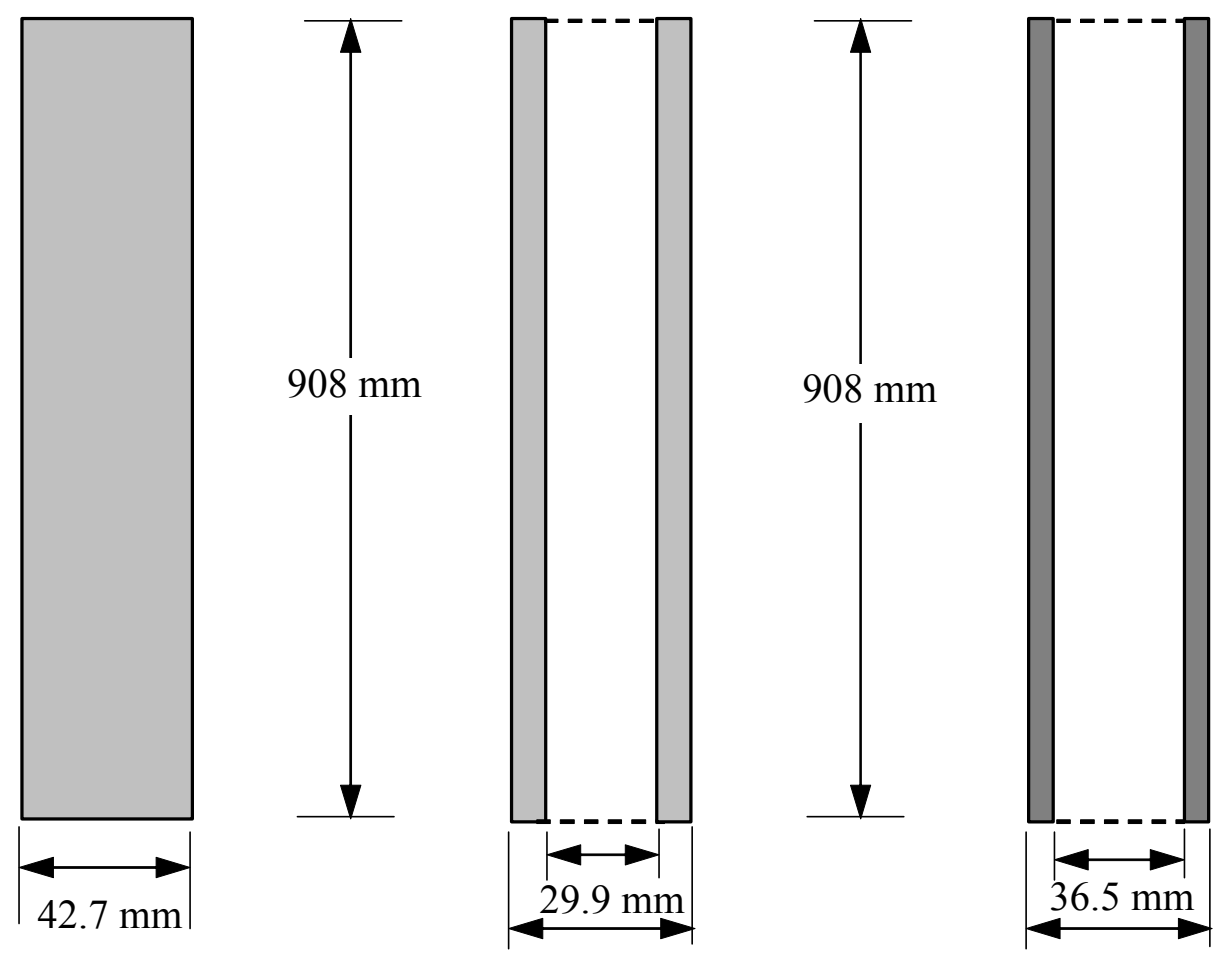

$42.7 \mathrm{~mm}$

$42.7 \mathrm{~mm}$

Closed-ended pile

Open-ended pile

Open-ended pile

Figure 5.1 Test pile details used in calibration chamber load tests. 
Table 5.1. Soil densities and stress states used in calibration chamber tests

\begin{tabular}{cccccc}
\hline $\begin{array}{c}\text { Pile } \\
\text { material }\end{array}$ & Base type & Sand type & $\begin{array}{c}\mathrm{D}_{\mathrm{R}} \\
(\%)\end{array}$ & $\begin{array}{c}\sigma_{{ }_{\mathrm{V}}}^{\prime} \\
(\mathrm{kPa})\end{array}$ & $\begin{array}{c}\sigma^{\prime}{ }_{\mathrm{h}} \\
(\mathrm{kPa})\end{array}$ \\
\hline Steel & Closed & Han River & 90 & 98.1 & 39.2 \\
Steel & Open & Han River & 90 & 98.1 & 39.2 \\
Steel & Open & Han River & 23 & 98.1 & 39.2 \\
Steel & Open & Han River & 56 & 98.1 & 39.2 \\
Steel & Open & Han River & 90 & 39.2 & 39.2 \\
Steel & Open & Han River & 90 & 68.7 & 39.2 \\
Steel & Open & Han River & 90 & 98.1 & 39.2 \\
Steel & Open & Han River & 90 & 98.1 & 68.7 \\
Steel & Open & Han River & 90 & 98.1 & 98.1 \\
\hline
\end{tabular}


Table 5.2. Properties of Han River sand

\begin{tabular}{cccccccc}
\hline $\mathrm{G}_{\mathrm{s}}$ & $\mathrm{C}_{\mathrm{u}}{ }^{\mathrm{a}}$ & $\mathrm{C}_{\mathrm{c}}{ }^{\mathrm{b}}$ & $\phi_{\mathrm{c}}$ & $\mathrm{e}_{\max }$ & $\mathrm{e}_{\min }$ & $\begin{array}{c}\gamma_{\max } \\
\left(\mathrm{kN} / \mathrm{m}^{3}\right)\end{array}$ & $\begin{array}{c}\gamma_{\min } \\
\left(\mathrm{kN} / \mathrm{m}^{3}\right)\end{array}$ \\
\hline 2.64 & 2.21 & 1.23 & $33.7^{\circ}$ & 0.99 & 0.63 & 15.88 & 13.03 \\
\hline
\end{tabular}

${ }^{\mathrm{a}} \mathrm{C}_{\mathrm{u}}$ : coefficient of uniformity

${ }^{\mathrm{b}} \mathrm{C}_{\mathrm{c}}$ : coefficient of curvature 


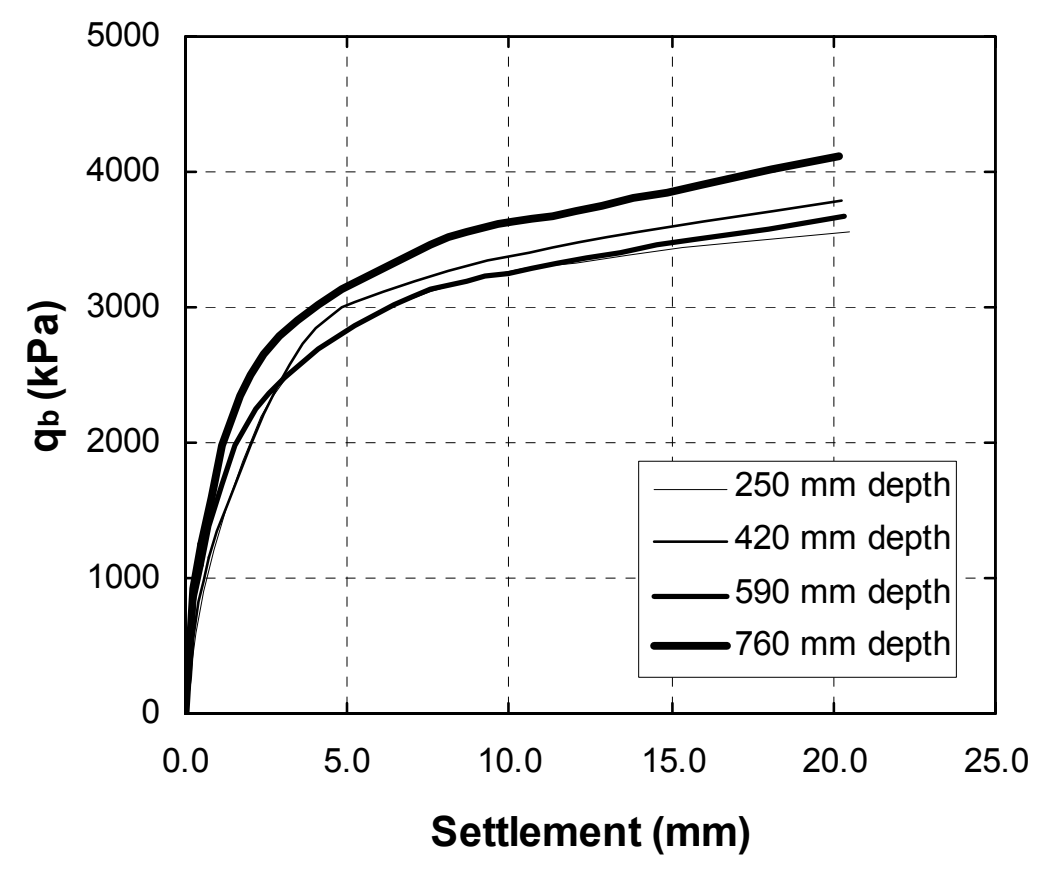

(a)

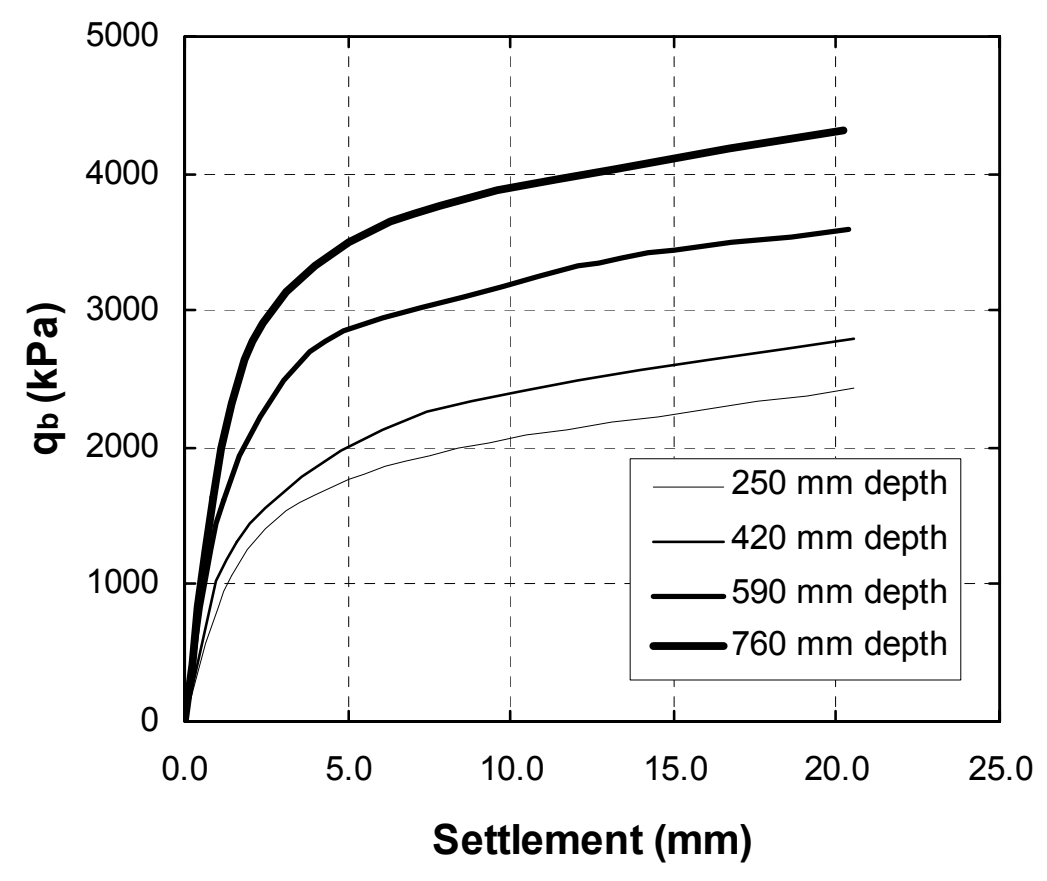

(b)

Figure 5.2 Unit load vs. settlement curves for (a) closed-ended pile base, (b) open-ended pile base, (c) closed-ended pile shaft, and (d) open-ended pile shaft. 


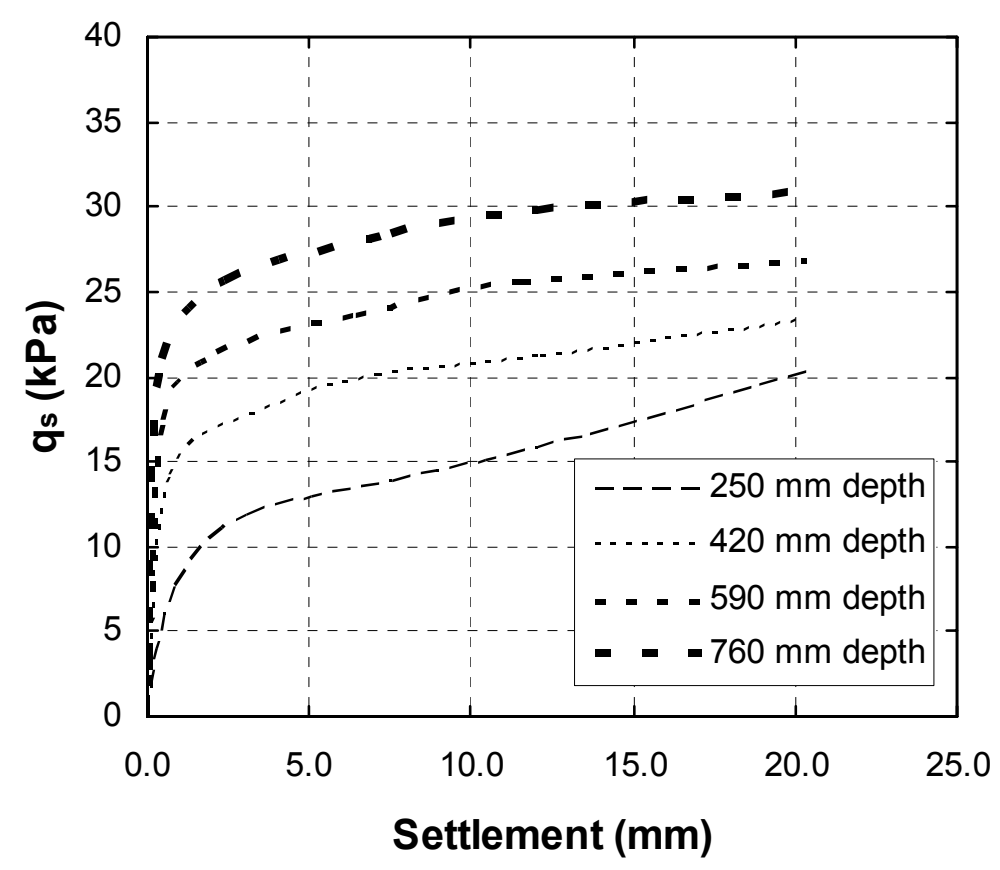

(c)

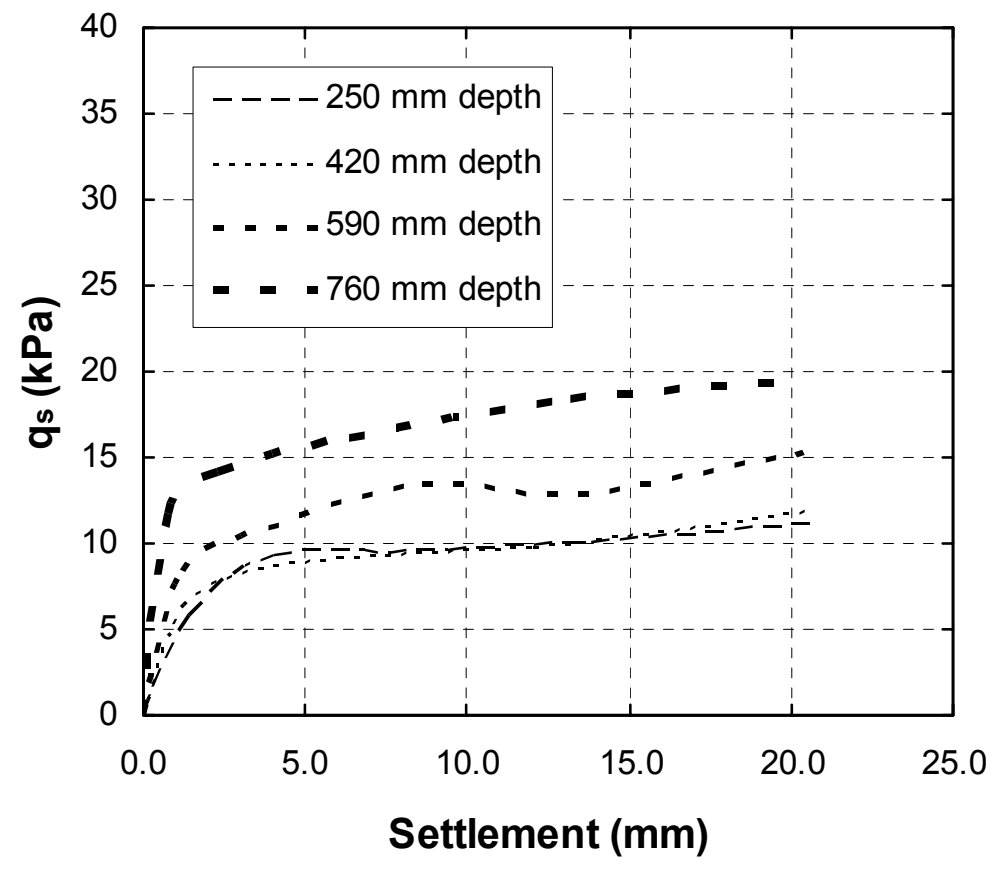

(d)

Figure 5.2 Unit load vs. settlement curves for (a) closed-ended pile base, (b) open-ended pile base, (c) closed-ended pile shaft, and (d) open-ended pile shaft (continued). 
annulus $\left(\mathrm{Q}_{\mathrm{ann}}\right)$ load capacities, divided by the gross cross-sectional area of the pile. As shown in Fig 5.2(a), the base load-settlement curves of the closed-ended piles were virtually the same, irrespective of the pile base depth. On the other hand, the base load-settlement curves of openended piles in Fig. 5.2(b) differ significantly for different pile base depths. This is mainly due to the better formation of the soil plug with increasing depth. It is seen that the base load-settlement curve of the open-ended pile for a driving depth equal to $760 \mathrm{~mm}$ is close to that of the closedended pile. This driving depth corresponds to approximately 17 times the outer pile diameter.

Referring to the average shaft load-settlement curves in Fig. 5.2(c) and (d), both closedand open-ended piles show increasing resistance as the driving depth increases. In terms of resistance magnitudes, the shaft resistances of closed-ended piles are much higher than the shaft resistances of open-ended piles at all settlements. This is due to the displacement of a much higher soil volume by the driving of closed-ended piles than the driving of open-ended piles.

\subsubsection{Field Pile Load Tests}

Fig. 5.3 shows the unit load-settlement responses of the pile base and shaft for the closedand open-ended piles. Similarly to what was done for the calibration chamber tests, the base unit load $\mathrm{q}_{\mathrm{b}}$ of the field open-ended pile was calculated by dividing the combined plug and annulus loads by the gross pile base area. The unit base resistance of the closed-ended pile at $\mathrm{s} / \mathrm{B}=0.10$ (i.e., at a settlement of $10 \%$ of the pile diameter) is about $8.8 \mathrm{MPa}$, higher than the unit base resistance of the open-ended pile, which equals 7.2 MPa. The unit loads at the last loading stage (for which $\mathrm{s} / \mathrm{B} \approx 0.38$ ) were 10.9 and $9.2 \mathrm{MPa}$ for the closed- and open-ended piles, respectively. The relatively small difference of base resistances between the closed- and open-ended piles is in 


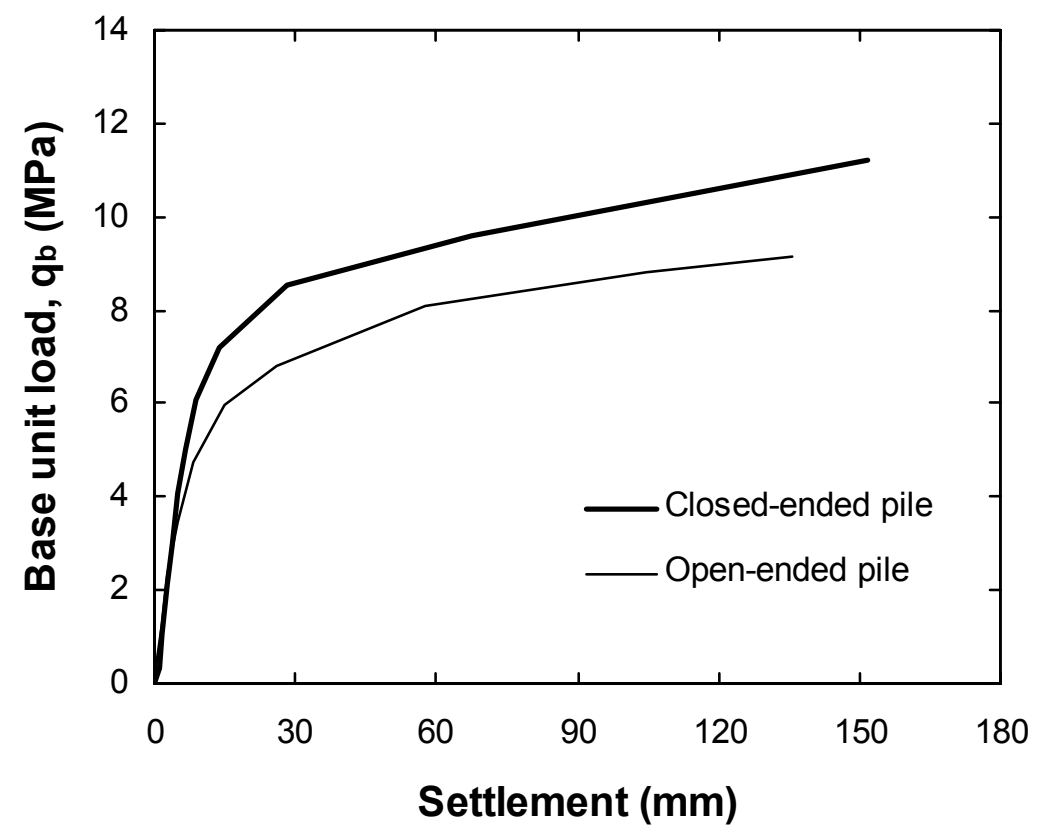

(a)

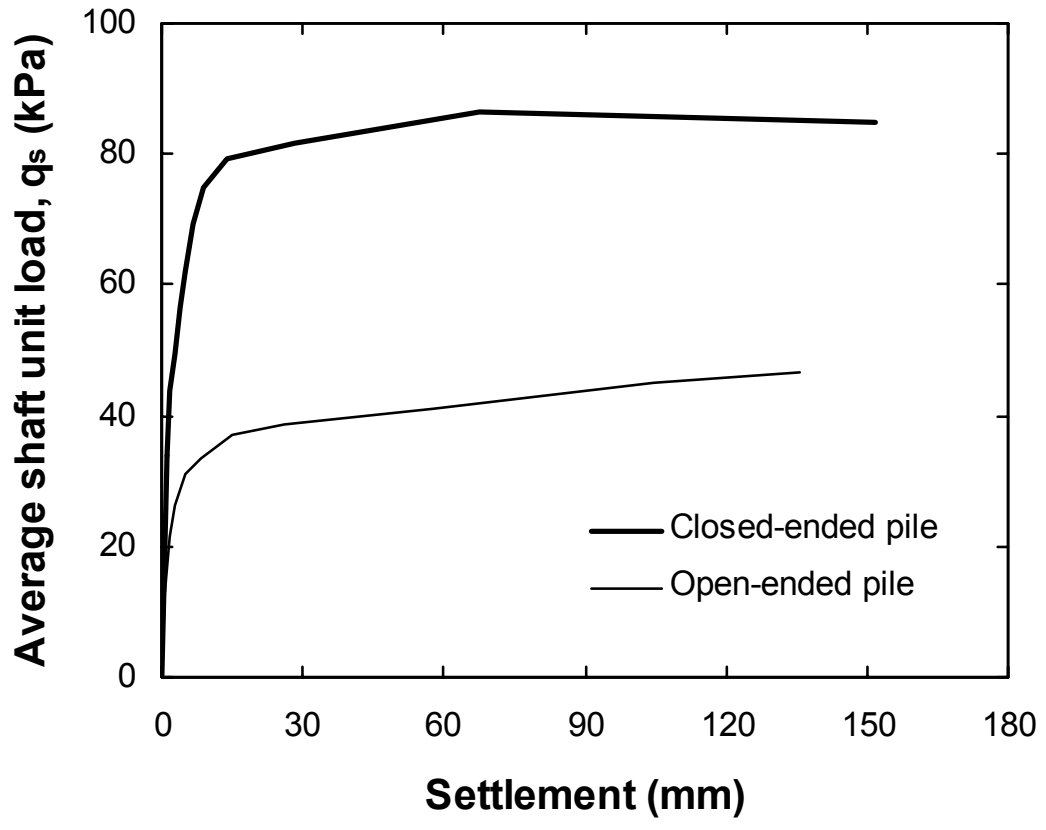

(b)

Figure 5.3 Load-settlement curves from field load tests for (a) pile base and (b) pile shaft. 
part due to the relatively large annular area of the open-ended test pile used in this study $(32 \%$ of the gross area, vs. approximately $11 \%$ for typical open-ended piles).

The shaft resistances of the closed- and open-ended piles are quite different [Fig. 5.3(b)]. This is due to the different degree of soil densification or lateral stress increases around the piles resulting from the different volumes of displaced soil. Based on the measurements from the load tests, the shaft resistance of the closed-ended pile is twice as large as that of the open-ended pile. It is also of note that the shaft resistance reached its limit value at a relative settlement $\mathrm{s} / \mathrm{B}$ in the $1-3 \%$ range, much smaller than required for full mobilization of the base resistance.

Fig. 5.4 shows the annulus and plug components of the unit base resistance for the openended pile. It is observed that, since unit loads were used in the figure, the annulus resistance was the highest of the two, equal to about $17.7 \mathrm{MPa}$ at a settlement of $130 \mathrm{~mm}(\mathrm{~s} / \mathrm{B}=0.37)$. Based on the CPT sounding results, the annulus resistance at large s/B values appears to be quite close to the cone resistance $\mathrm{q}_{\mathrm{c}}$ of about $20 \mathrm{MPa}$ at the same depth. This is in agreement with the suggestion that the annulus resistance of open-ended piles be taken as equal to the cone resistance at the pile base depth (Lehane and Randolph 2002).

\subsection{Consideration of Size Effect for Calibration Chamber Test Results}

\subsubsection{Size Effect in Calibration Chamber Tests}

Results from calibration chamber tests may not be the same as those from the field, due to chamber size effects. Calibration chamber size effects have been extensively investigated for cone penetration resistance and for the base resistance of non-displacement piles (Houlsby and Hitchman 1988, Schnaid and Houlsby 1991, Salgado et al. 1998, Lee and Salgado 2000, 2001). 


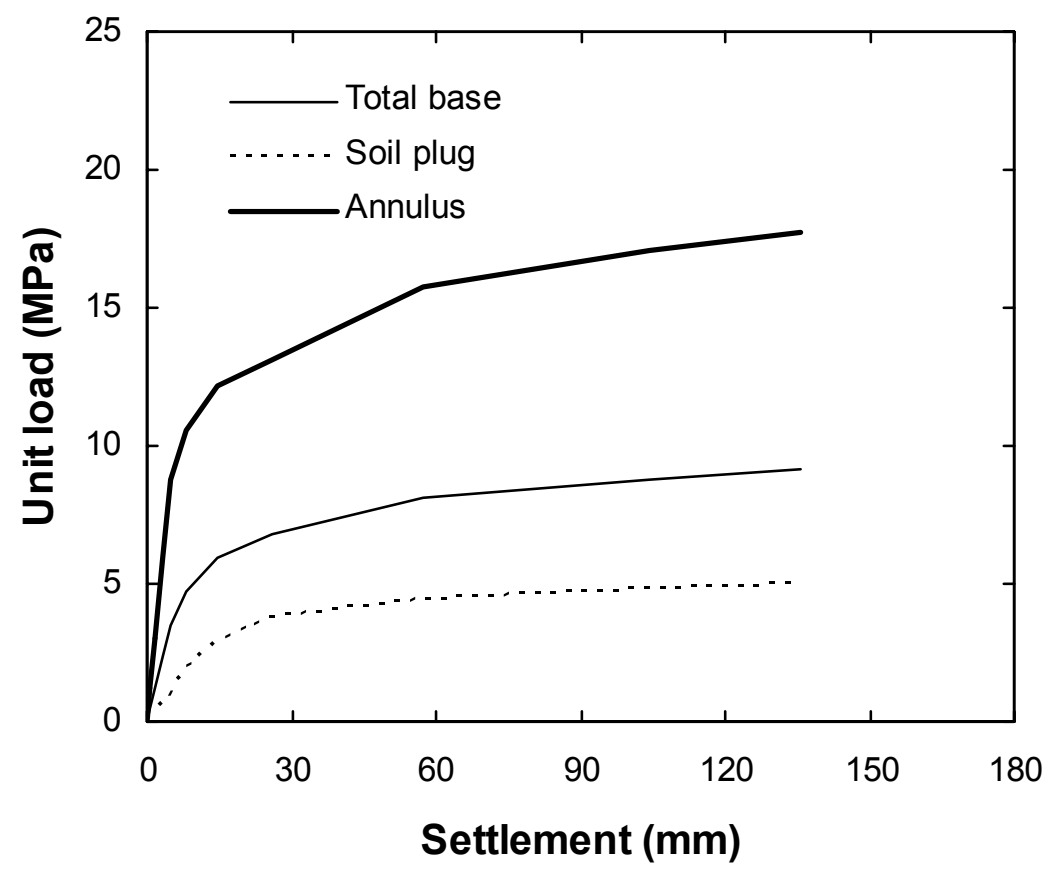

Figure 5.4 Base, plug and annulus resistance from field open-ended pile load tests. 
Size effects in calibration chamber tests are significant for the cone penetration resistance, which is a large-deformation measurement. It was observed that the size effect on penetration resistance becomes more pronounced with increasing relative density and decreasing confining stress (Houlsby and Hitchman 1988, Salgado et al. 1998). Lee and Salgado (2000), on the other hand, showed that size effects in calibration chamber tests are small for small-deformation problems, such as the loading of non-displacement piles up to a settlement level of interest in practice (say, in the range of 1 to $10 \%$ of pile diameter).

Fig. 5.5 shows ratios of the annulus resistance of the open-ended piles measured in the calibration chamber tests to the field cone resistance under the same soil states, as a function of driving depth. The field cone resistances in Fig. 5.5 were calculated using the penetration resistance analysis of Salgado et al. (1997b) through the program CONPOINT. The parameters used in the calculation are those of Table 5.2. As discussed earlier, the annulus resistance $\mathrm{q}_{\text {ann }}$ of open-ended piles in the field can be taken as a value equal or close to the cone resistance $\mathrm{q}_{\mathrm{c}}$. However, the results of Fig. 5.5 show that the annulus resistance $\mathrm{q}_{\mathrm{ann}}$ in the calibration chamber tests are much smaller than the field cone resistance $\mathrm{q}_{\mathrm{c}}$, indicating significant chamber size effects.

The $\mathrm{q}_{\mathrm{ann}} / \mathrm{q}_{\mathrm{c}}$ ratio decreased with increasing relative densities and decreasing driving depths. For loose sand $\left(D_{R}=23 \%\right)$, values of $q_{a n n} / q_{c}$ increase from 0.15 to 0.38 as the driving depth increases from 250 to $760 \mathrm{~mm}$. For dense sand $\left(D_{R}=90 \%\right)$, values of $\mathrm{q}_{\mathrm{ann}} / \mathrm{q}_{\mathrm{c}}$ fall in the 0.1 -0.2 range for the same driving depth range. An explanation for this dependence of $\mathrm{q}_{\mathrm{ann}}$ on driving depth can be found in Houlsby and Hitchman (1988). According to Houlsby and Hitchman (1988), although the soil and stress states in calibration chambers are approximately the same throughout, the chamber cone resistance varies with penetration depth. A typical 


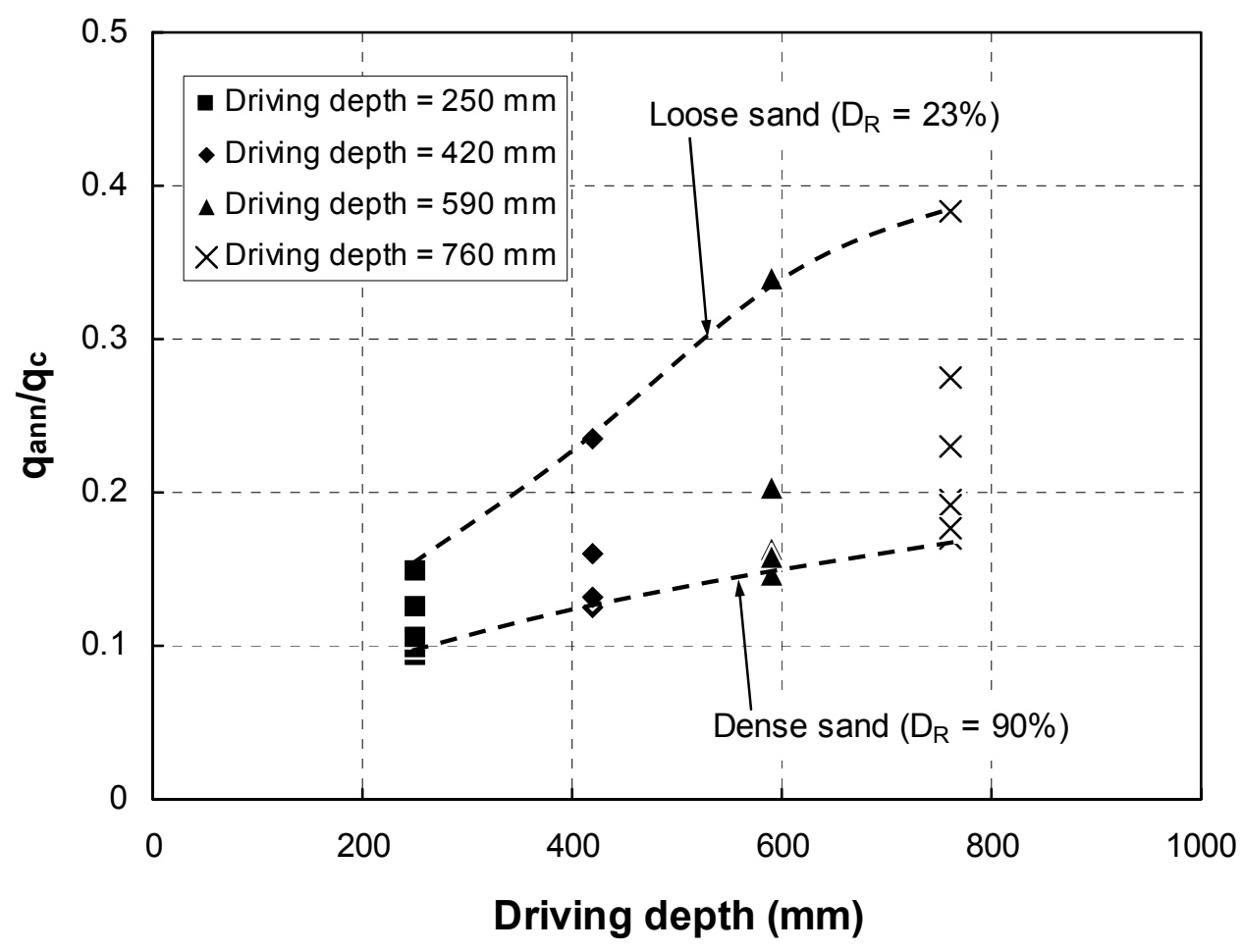

Figure 5.5 Normalized unit annulus resistance as a function of driving depth for calibration chamber open-ended piles 
resistance profile shows an initial build-up stage of the cone resistance for shallow penetration depths, followed by stabilization. Proximity to the top and bottom of the chamber are in part responsible for this trend. The $\mathrm{q}_{\mathrm{ann}} / \mathrm{q}_{\mathrm{c}}$ trends of Fig. 5.5 reflect these observations.

Based on the previous discussion, it can be stated that the size effects on the load capacity of driven piles are significant. These size effects reflect not only the soil sample response during the loading stage, but also the changes caused in the soil sample during the installation process.

\subsubsection{Correction for Size Effect in Calibration Chamber Tests}

Salgado et al. (1998) studied chamber size effects for cone penetration resistance. They expressed their results as plots of the ratio of chamber to field values of cone resistance versus the ratio of chamber to cone diameter. These results are directly applicable to the assessment of size effects on the pile loads for closed-ended piles, whose installation resembles the cone penetration process in that both are full displacement processes. Accordingly, we have corrected pile load capacity based on the ratio of the chamber to pile diameter.

The size effect for open-ended piles in calibration chamber tests was considered as follows: fully plugged open-ended piles are regarded as closed-ended piles and size effects are evaluated using the gross pile base diameter. The calculation of an equivalent diameter is required for open-ended piles not behaving as fully plugged piles. The size effect for partially plugged modes, with IFR values between 0 and $100 \%$, was evaluated using the equivalent pile diameter $\left(\mathrm{d}_{\mathrm{e}}\right)$ computed as follows:

$$
d_{e}=d_{o}-\left(d_{o}-\sqrt{d_{o}^{2}-d_{i}^{2}}\right) \frac{\operatorname{IFR}(\%)}{100}
$$


where $d_{e}=$ equivalent pile diameter for a partially plugged open-ended pile; $d_{o}$ and $d_{i}=$ outer and inner diameters of the open-ended pile, respectively. For the base resistance, the IFR values at the final driving depth were used in (5.1), while the average IFR values throughout the entire driving depth were used for the shaft resistance. Note that the average IFR for a given driving depth is numerically equal to the PLR. Based on the values of $d_{e}$ calculated using (5.1) and the corresponding chamber to $d_{e}$ ratios, the size effect factors for partially plugged open-ended piles can be obtained from Salgado et al. (1998). Table 5.3 shows the equivalent pile diameter $d_{\mathrm{e}}$ and the size effect factor for each calibration chamber test. The equivalent field pile unit resistances were then calculated by dividing the calibration chamber pile unit resistances by the size effect factors given in Table 5.3. These pile unit resistance values, corrected for size effect, are used in the calculation of normalized pile unit resistances in the following section.

\subsection{Pile Load Capacity Based on CPT Results}

There has been considerable research on the estimation of pile load capacity based on the CPT cone resistance $q_{c}$ (e.g., De Beer 1984; Jamiolkowski and Lancellotta 1988; Franke 1989,1993; Ghionna et al. 1993, 1994; Salgado 1995; Lee and Salgado 1999a, b, 2000). Based on the calibration chamber and field pile load tests described earlier, it is possible to propose values of base, plug, annulus and unit shaft resistances of pipe piles in terms of cone resistance $\mathrm{q}_{\mathrm{c}}$. 
Table 5.3. Size effect factor for calibration chamber tests

\begin{tabular}{|c|c|c|c|c|c|c|c|}
\hline \multirow{2}{*}{$\begin{array}{l}\text { Tes } \\
\text { tNo }\end{array}$} & \multirow{2}{*}{$\begin{array}{l}\text { Base } \\
\text { type }\end{array}$} & \multirow{2}{*}{$\begin{array}{l}\text { IFR } \\
(\%)\end{array}$} & \multirow{2}{*}{$\begin{array}{c}\text { Avg. } \\
\text { IFR (\%) }\end{array}$} & \multicolumn{2}{|c|}{ Equivalent diameter $\left(\mathrm{d}_{\mathrm{e}}\right)$} & \multicolumn{2}{|c|}{ Size effect factor } \\
\hline & & & & Base $(\mathrm{m})$ & Shaft (m) & Base & Shaft \\
\hline 1 & Closed & - & - & 0.0427 & 0.0427 & 0.40 & 0.40 \\
\hline 2 & Closed & - & - & 0.0427 & 0.0427 & 0.40 & 0.40 \\
\hline 3 & Closed & - & - & 0.0427 & 0.0427 & 0.40 & 0.40 \\
\hline 4 & Closed & - & - & 0.0427 & 0.0427 & 0.40 & 0.40 \\
\hline 5 & Open & 72.4 & 93.6 & 0.0339 & 0.0313 & 0.43 & 0.45 \\
\hline 6 & Open & 54.1 & 78.1 & 0.0361 & 0.0332 & 0.42 & 0.43 \\
\hline 7 & Open & 50.0 & 69.1 & 0.0366 & 0.0343 & 0.42 & 0.43 \\
\hline 8 & Open & 46.9 & 63.1 & 0.0370 & 0.0350 & 0.41 & 0.43 \\
\hline 9 & Open & 71.1 & 89.6 & 0.0281 & 0.0243 & 0.59 & 0.62 \\
\hline 10 & Open & 56.5 & 75.9 & 0.0311 & 0.0271 & 0.55 & 0.60 \\
\hline 11 & Open & 52.4 & 67.8 & 0.0319 & 0.0288 & 0.55 & 0.58 \\
\hline 12 & Open & 42.6 & 62.1 & 0.0339 & 0.0299 & 0.53 & 0.56 \\
\hline 13 & Open & 75.9 & 94.4 & 0.0271 & 0.0233 & 0.53 & 0.58 \\
\hline 14 & Open & 67.4 & 82.6 & 0.0289 & 0.0257 & 0.51 & 0.54 \\
\hline 15 & Open & 60.5 & 75.4 & 0.0303 & 0.0272 & 0.49 & 0.53 \\
\hline 16 & Open & 53.9 & 70.0 & 0.0316 & 0.0283 & 0.48 & 0.52 \\
\hline 17 & Open & 78.4 & 99.6 & 0.0266 & 0.0222 & 0.45 & 0.47 \\
\hline 18 & Open & 71.4 & 87.1 & 0.0280 & 0.0248 & 0.43 & 0.45 \\
\hline 19 & Open & 67.0 & 81.0 & 0.0289 & 0.0261 & 0.42 & 0.43 \\
\hline 20 & Open & 54.4 & 75.1 & 0.0315 & 0.0273 & 0.41 & 0.42 \\
\hline 21 & Open & 88.0 & 100.0 & 0.0246 & 0.0222 & 0.48 & 0.50 \\
\hline 22 & Open & 76.3 & 88.8 & 0.0270 & 0.0245 & 0.47 & 0.49 \\
\hline 23 & Open & 69.0 & 81.9 & 0.0285 & 0.0259 & 0.45 & 0.48 \\
\hline 24 & Open & 57.4 & 76.7 & 0.0309 & 0.0269 & 0.44 & 0.46 \\
\hline 25 & Open & 84.2 & 100.0 & 0.0254 & 0.0222 & 0.51 & 0.54 \\
\hline 26 & Open & 73.0 & 87.9 & 0.0277 & 0.0246 & 0.49 & 0.51 \\
\hline 27 & Open & 69.5 & 80.8 & 0.0284 & 0.0261 & 0.48 & 0.50 \\
\hline 28 & Open & 60.0 & 75.7 & 0.0304 & 0.0272 & 0.47 & 0.49 \\
\hline 29 & Open & 87.9 & 100.0 & 0.0246 & 0.0222 & 0.52 & 0.55 \\
\hline 30 & Open & 78.6 & 90.7 & 0.0266 & 0.0241 & 0.50 & 0.52 \\
\hline 31 & Open & 73.9 & 84.9 & 0.0275 & 0.0253 & 0.49 & 0.51 \\
\hline 32 & Open & 72.1 & 80.8 & 0.0279 & 0.0261 & 0.49 & 0.50 \\
\hline 33 & Open & 92.6 & 100.0 & 0.0237 & 0.0222 & 0.53 & 0.56 \\
\hline 34 & Open & 82.9 & 94.8 & 0.0257 & 0.0232 & 0.51 & 0.53 \\
\hline 35 & Open & 79.8 & 88.3 & 0.0263 & 0.0246 & 0.50 & 0.52 \\
\hline 36 & Open & 77.8 & 85.0 & 0.0267 & 0.0252 & 0.50 & 0.51 \\
\hline
\end{tabular}




\subsubsection{Open-Ended Piles}

Fig. 5.6 shows the normalized base, shaft, and plug resistances of open-ended piles, obtained from the calibration chamber tests after the correction for size effect, as a function of the relative density $D_{R}$ and the incremental filling ratio IFR. In the figure, the unit base resistance $\mathrm{q}_{\mathrm{b}}$ includes the soil plug $\left(\mathrm{q}_{\mathrm{plug}}\right)$ and annulus $\left(\mathrm{q}_{\mathrm{ann}}\right)$ unit resistances. The base resistances were obtained at the last loading stage of each test, and then divided by the cone resistance $\mathrm{q}_{\mathrm{c}}$ obtained from the program CONPOINT (Salgado et al. 1997b) to determine the normalized base resistance plotted in the charts.

As shown in Figs. 5.6(a) and (b), the normalized base resistance $\mathrm{q}_{\mathrm{b}} / \mathrm{q}_{\mathrm{c}}$ decreases with increasing $D_{R}$ and IFR values. As the $D_{R}$ increases from $23 \%$ to $90 \%$, the range of $\mathrm{q}_{\mathrm{b}} / \mathrm{q}_{\mathrm{c}}$ values decreases from $0.33-0.57$ to $0.21-0.38$, respectively. The normalized soil plug resistance $\mathrm{q}_{\mathrm{plug}} / \mathrm{q}_{\mathrm{c}}$ is given in Figs. 5.6(c) and (d). Similarly to what is observed for the base resistance, the normalized plug resistance $\mathrm{q}_{\mathrm{plug}} / \mathrm{q}_{\mathrm{c}}$ decreases with increasing $\mathrm{D}_{\mathrm{R}}$ and IFR values. These results suggest a close relationship between $\mathrm{D}_{\mathrm{R}}$ and IFR for open-ended piles in sands. The relationship between $D_{R}$ and IFR will be discussed in a later section.

The determination of soil plug resistance is key for the estimation of base resistance in open-ended piles. This is because the annulus resistance, the other component of the base resistance, may be taken as approximately equal to the cone resistance $\mathrm{q}_{\mathrm{c}}$. It is also observed from the figure that, as the IFR values approaches $100 \%$, the plug resistance $\mathrm{q}_{\text {plug }}$ of open-ended piles becomes small compared with the annulus resistance.

The normalized shaft resistance $\mathrm{q}_{\mathrm{s}} / \mathrm{q}_{\mathrm{c}}$ versus $\mathrm{D}_{\mathrm{R}}$ and IFR is also given in Figs. 5.6(e) and (f). Although the values of $\mathrm{q}_{\mathrm{s}} / \mathrm{q}_{\mathrm{c}}$ show more scatter than $\mathrm{q}_{\mathrm{b}} / \mathrm{q}_{\mathrm{c}}$ and $\mathrm{q}_{\mathrm{plug}} / \mathrm{q}_{\mathrm{c}}$, most $\mathrm{q}_{\mathrm{s}} / \mathrm{q}_{\mathrm{c}}$ values fall 


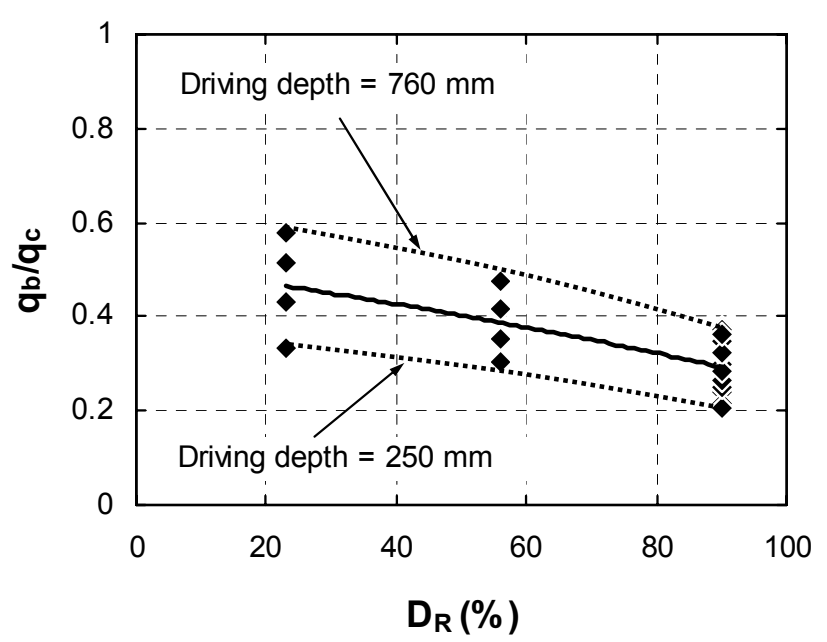

(a)

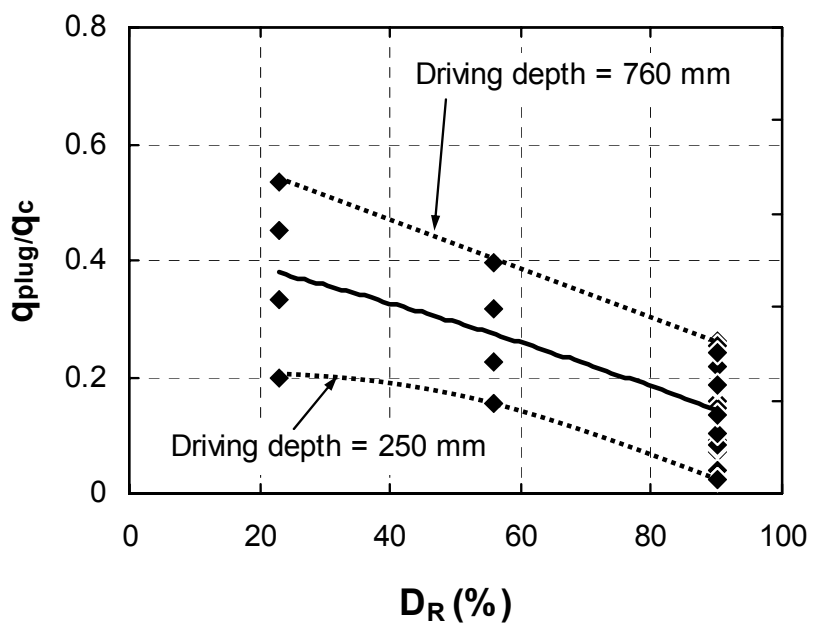

(c)

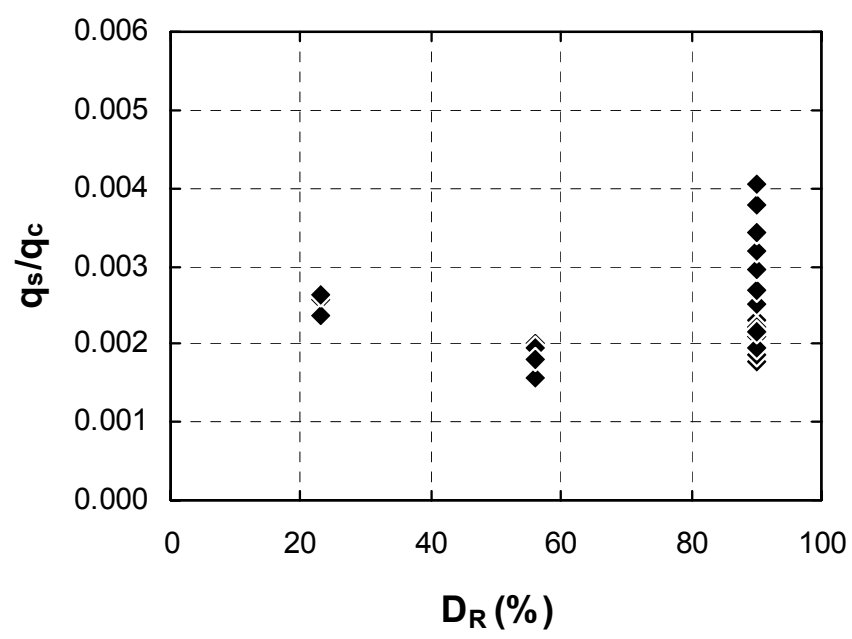

(e)

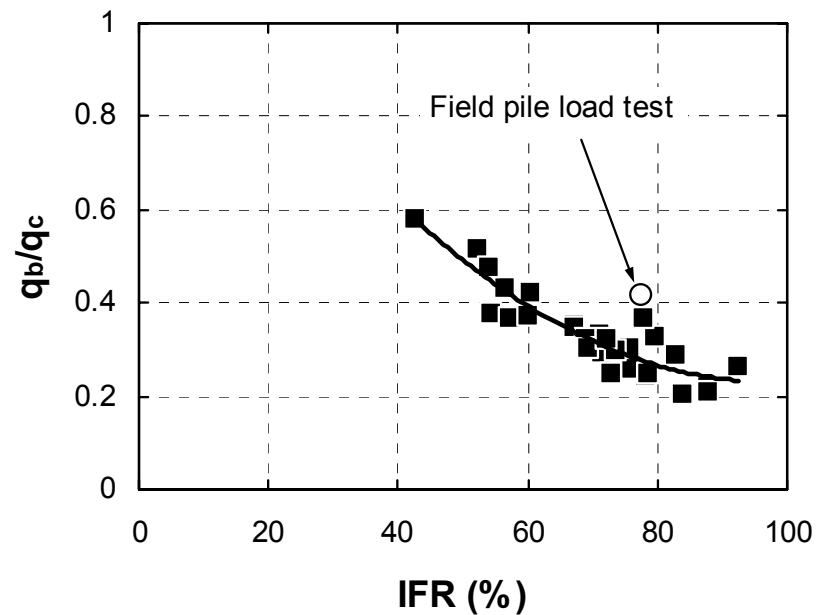

(b)

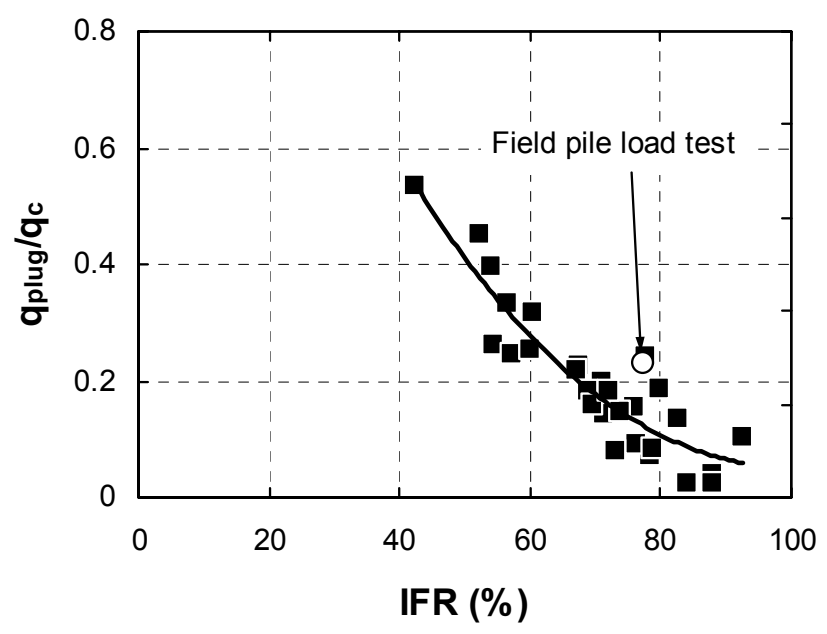

(d)

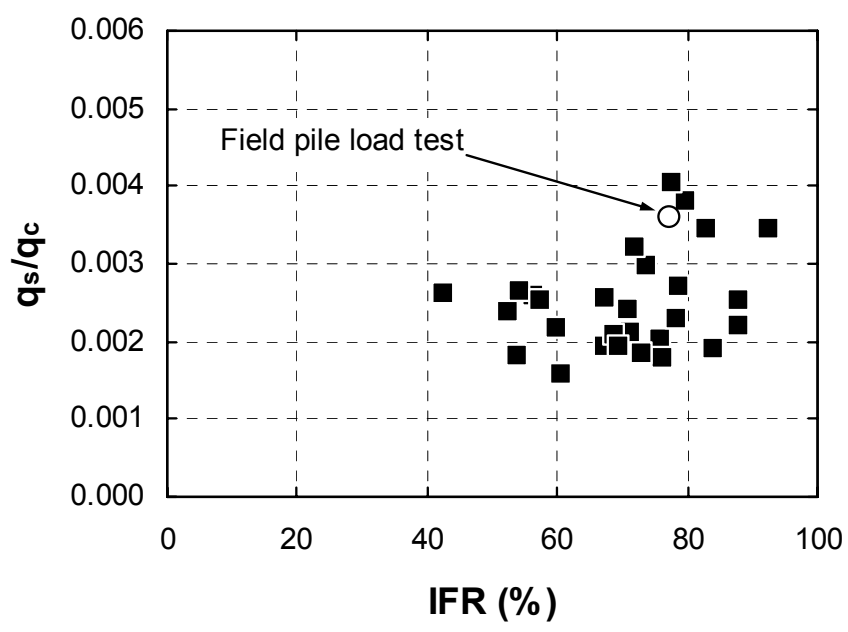

(f)

Figure 5.6 Normalized pile unit resistances for open-ended piles: (a) $q_{b} / q_{c}$ versus $D_{R}$, (b) $q_{b} / q_{c}$ versus IFR, (c) $q_{\text {plug }} / q_{c}$ versus $D_{R}$, (d) $q_{p l u g} / q_{c}$ versus IFR, (e) $q_{s} / q_{c}$ versus $D_{R}$, and (f) $q_{s} / q_{c}$ versus IFR. 
within $0.0016-0.004$. No significant effect of the driving depth on the normalized shaft resistance was observed.

\subsubsection{Closed-Ended Piles}

Fig. 5.7 shows the normalized base and shaft resistances of closed-ended piles as a function of the relative density. According to Paik et al. (1994), the difference between the load capacity of closed- and open-ended piles decreases with increasing driving depth, as the soil plugging effect increases. Values of the ratios of unit resistance for open- and closed-ended piles are given in Table 5.4 .

Since only one soil state was used for the closed-ended pile calibration chamber tests (see Table 5.1), the normalized resistances of closed-ended piles for various soil states were approximated using the resistance ratios of Table 5.3 and the experimental results for open-ended piles. Fig. 5.7(a), obtained in that fashion, shows that the value of $\mathrm{q}_{\mathrm{b}} / \mathrm{q}_{\mathrm{c}}$ decreases as the relative

density increases. For loose sands, with $\mathrm{D}_{\mathrm{R}}$ equal to $23 \%$, the value of $\mathrm{q}_{\mathrm{b}} / \mathrm{q}_{\mathrm{c}}$ was in the $0.60-0.67$ range while for dense sand $\left(D_{R}=90 \%\right)$ it was in the $0.37-0.51$ range. Values of the normalized shaft resistance $\mathrm{q}_{\mathrm{s}} / \mathrm{q}_{\mathrm{c}}$ are shown in Fig. 5.7(b). It is seen that closed-ended piles overall give values of $\mathrm{q}_{\mathrm{s}} / \mathrm{q}_{\mathrm{c}}$ higher than observed for open-ended piles, ranging from 0.0049 to 0.0064 for loose and from 0.0042 to 0.0091 for dense sand.

\subsubsection{Normalized Pile Load Capacity from Field Pile Load Tests}

The load-settlement curves from the field pile load tests shown in Fig. 5.3 were normalized and plotted in Fig. 5.8 in the same manner as was done for the calibration chamber 


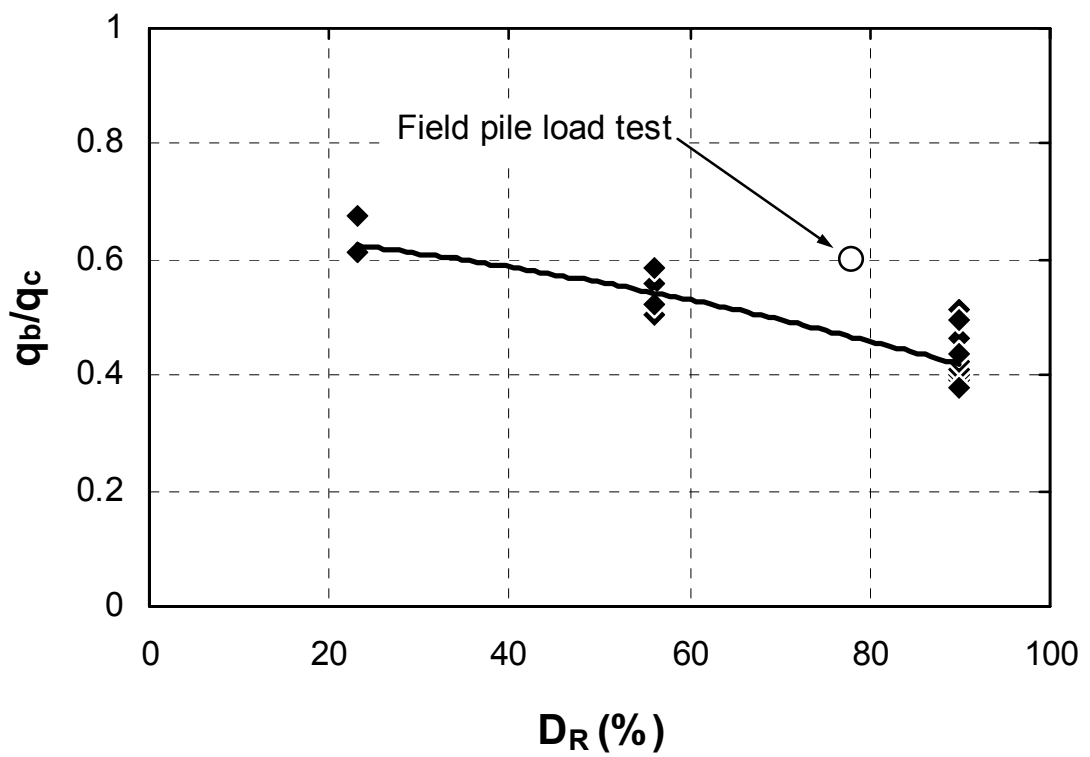

(a)

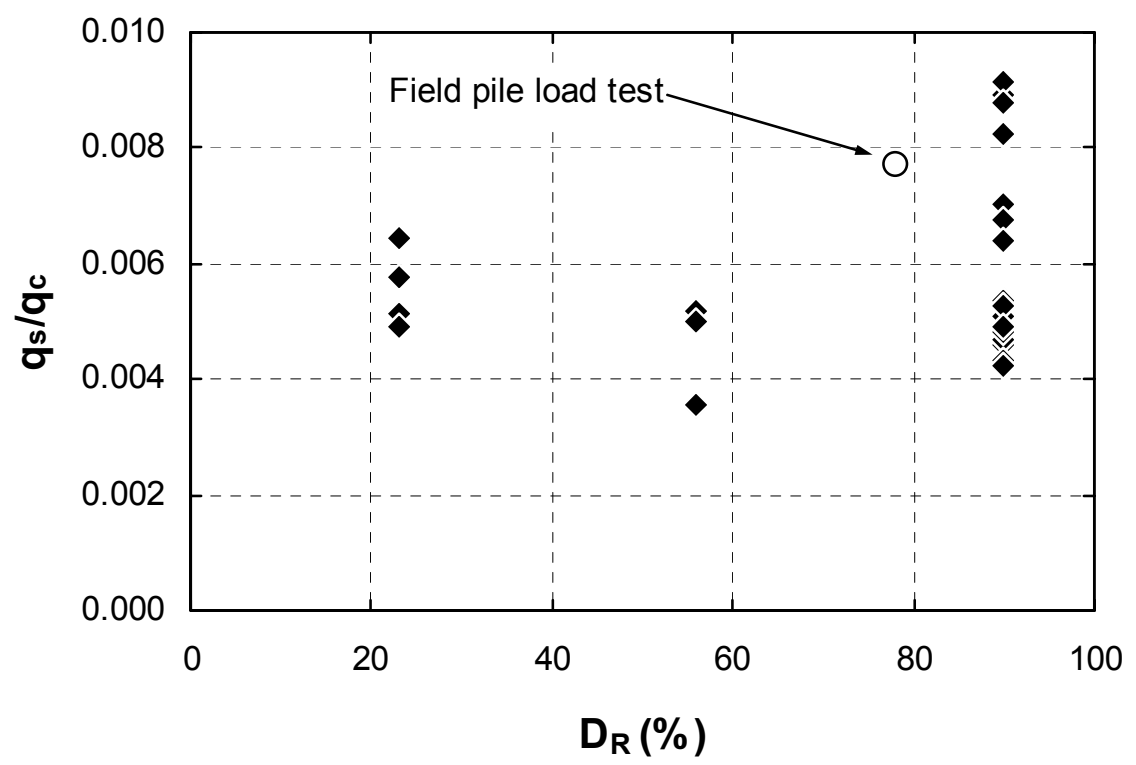

(b)

Figure 5.7 Normalized unit pile resistances for closed-ended piles: (a) $q_{b} / q_{c}$ versus $D_{R}$ and (b) $\mathrm{q}_{\mathrm{s}} / \mathrm{q}_{\mathrm{c}}$ versus $\mathrm{D}_{\mathrm{R}}$. 
Table 5.4 Resistance ratio for closed- and open-ended piles as a function of driving depth (after Paik et al. 1994).

\begin{tabular}{ccc}
\hline \multirow{2}{*}{ Driving depth $(\mathrm{m})$} & \multicolumn{2}{c}{ Ratio of closed- to open-ended pile resistance } \\
\cline { 2 - 3 } & Base resistance & Shaft resistance \\
\hline 0.76 & 0.96 & 1.60 \\
0.59 & 1.03 & 1.78 \\
0.42 & 1.36 & 2.00 \\
0.25 & 1.47 & 1.85 \\
\hline
\end{tabular}




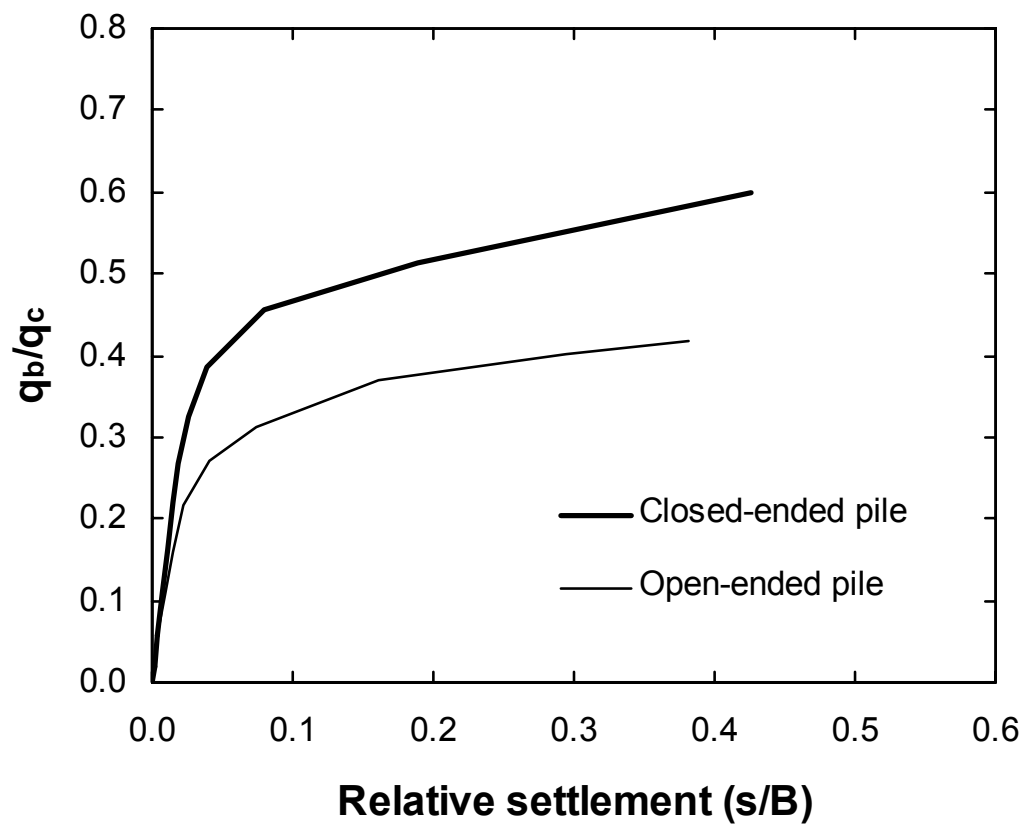

(a)

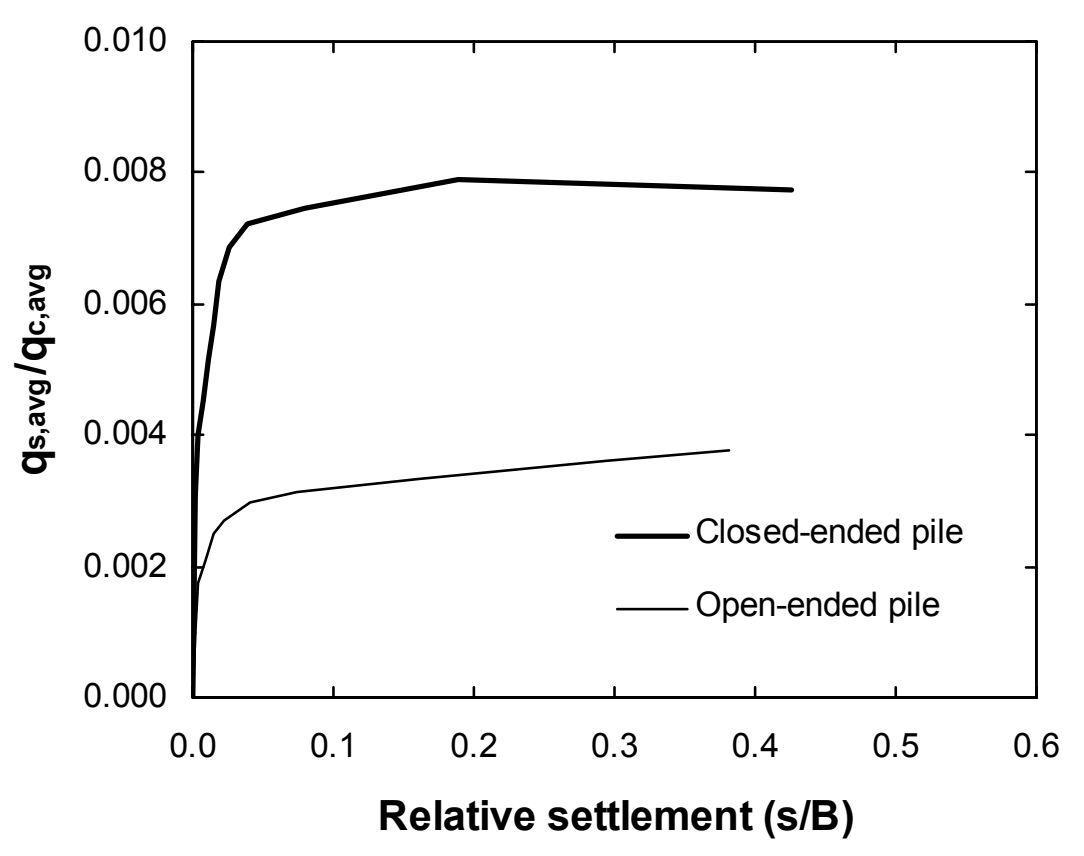

(b)

Figure 5.8 Normalized unit load vs. settlement curves from field pile load test for (a) pile base and (b) pile shaft. 
tests. The normalization of the base resistance [Fig. 5.8(a)] was done with respect to the cone resistances corresponding to the locations of the test pile bases $\left(\mathrm{q}_{\mathrm{c}}=18.7\right.$ and $21.9 \mathrm{MPa}$ for the closed- and open-ended piles, respectively). The normalized shaft resistances [Fig. 5.8(b)] were obtained based on the average $\mathrm{q}_{\mathrm{c}}$ values along the entire pile length driven into soil $\left(\mathrm{q}_{\mathrm{c}}=10.9\right.$ and 12.4 MPa for closed- and open-ended piles, respectively). It should be noted that the normalized shaft resistance in Fig. 5.8 represents the total shaft resistance averaged along the entire embedded pile length.

The normalized base resistance $\mathrm{q}_{\mathrm{b}} / \mathrm{q}_{\mathrm{c}}$ for the closed- and open-ended piles at the last loading stage (corresponding to $\mathrm{s} / \mathrm{B} \approx 0.4$ ) are 0.58 and 0.42 , respectively, while $\mathrm{q}_{\mathrm{b}} / \mathrm{q}_{\mathrm{c}}=0.47$ and 0.32 for $\mathrm{s} / \mathrm{B}=0.1$. The shaft resistances of the closed- and open-ended piles differed more markedly. The normalized shaft resistance $\mathrm{q}_{\mathrm{s}} / \mathrm{q}_{\mathrm{c}}$ for the closed-ended pile was equal to $\mathrm{q}_{\mathrm{s}} / \mathrm{q}_{\mathrm{c}}=$ 0.0077, which is more than twice the value (0.0036) for the open-ended pile.

Values of normalized base resistance $\mathrm{q}_{\mathrm{b}} / \mathrm{q}_{\mathrm{c}}$ for both displacement and non-displacement piles have been proposed based on either experimental or analytical investigation (Schmertmann 1978; Bustamante and Gianeselli 1982; Jamiolkowski and Lancellota 1988; Franke 1989, 1993; Ghionna et al. 1993; Lee and Salgado 1999a, b, 2000). Lee and Salgado (1999a) proposed values of $\mathrm{q}_{\mathrm{b}} / \mathrm{q}_{\mathrm{c}}$ for driven piles based on analyses of non-displacement piles and experimental ratios between the base resistances of displacement and non-displacement piles. De Beer (1988) and Ghionna et al. (1993) proposed values of the base resistance ratio for geometrically identical displacement and non-displacement piles as a function of relative settlement, as given in Table 5.5. In general, the unit base resistances of displacement piles are greater than those of nondisplacement piles, under the same conditions, for relatively small settlements. The difference decreases with increasing settlement, approaching zero at infinite settlement. 
Table 5.5. Base resistance ratio for displacement and non-displacement piles

\begin{tabular}{ccc}
\hline \multirow{2}{*}{$\begin{array}{c}\text { Relative Settlement } \\
(\mathrm{s} / \mathrm{B})\end{array}$} & \multicolumn{3}{c}{$\mathrm{q}_{\mathrm{b}, \mathrm{ND}}{ }^{a} / \mathrm{q}_{\mathrm{b}, \mathrm{D}}{ }^{b}$} \\
\cline { 2 - 3 } & De Beer (1988) & Ghionna et al. (1993) \\
\hline $2.5 \%$ & 0.482 & $0.15-0.21$ \\
$5 \%$ & 0.517 & $0.3-0.5$ \\
$10 \%$ & 0.587 & $0.3-0.7$ \\
$25 \%$ & 0.715 & $\rightarrow 1.0$ \\
$\rightarrow \infty$ & $\rightarrow 1.0$ & $\rightarrow 1.0$ \\
\hline
\end{tabular}

${ }^{a} \mathrm{q}_{\mathrm{b}, \mathrm{ND}}=$ base resistance for non-displacement pile

${ }^{b} \mathrm{q}_{\mathrm{b}, \mathrm{D}}=$ base resistance for displacement pile 
Fig. 5.9 shows the normalized load-settlement curves for the closed- and open-ended piles along with results by Lee and Salgado (1999a) for non-displacement piles (drilled shafts). In the figure, the lower and upper bounds define the range of values for normalized unit base resistance for driven piles (displacement piles) obtained from the $\mathrm{q}_{\mathrm{b}} / \mathrm{q}_{\mathrm{c}}$ values for drilled shafts (nondisplacement piles) multiplied by the base resistance ratios given in Table 5.5. The lower bound of the $\mathrm{q}_{\mathrm{b}} / \mathrm{q}_{\mathrm{c}}$ for displacement piles was obtained using the base resistance ratios of De Beer (1988), while the upper bound was obtained from those of Ghionna et al. (1993). The drilledshaft base load-settlement curve in Fig. 5.9 is from Lee and Salgado (1999a) for $\sigma^{\prime} \approx 100 \mathrm{kPa}$ and $\mathrm{D}_{\mathrm{R}} \approx 90 \%$, which is similar to the soil states for the field tests.

As can be seen in the figure, the measured normalized unit base resistance of the closedended pile was close to the upper bound up to a relative settlement equal to $\mathrm{s} / \mathrm{B}=0.20$. The normalized base resistance of the open-ended pile, on the other hand, falls between the upper and lower bounds. As individual components of the base resistance for the open-ended pile, the annulus and soil plug resistances are also plotted in the figure. The magnitude of the soil plug resistance is comparable to that of the lower bound base resistance (obtained for drilled shafts). This result suggests that, in design, the soil plug resistance for open-ended piles could be conservatively assumed to be equal to the base resistance of a drilled shaft.

\subsubsection{Estimation of IFR for Open-Ended Piles}

As shown in Fig. 5.6, the load capacity of open-ended piles is affected significantly by the values of IFR. However, the IFR cannot be obtained before pile driving, and thus cannot be 


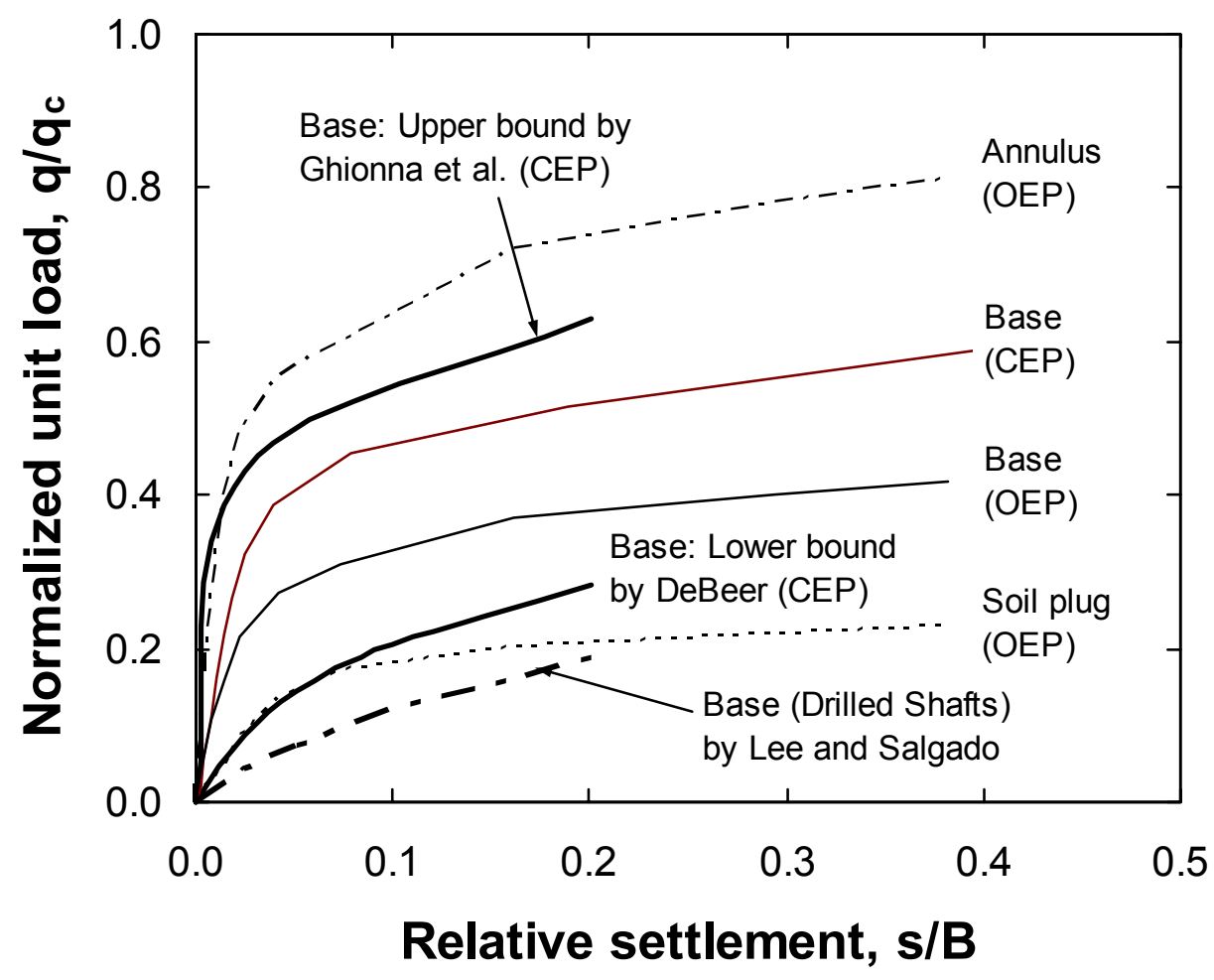

CEP $=$ Closed-ended pile, OEP $=$ Open-ended pile

Figure 5.9 Normalized unit load vs. settlement curves for closed-ended piles (CEP) and openended piles (OEP) compared with lower and upper bounds of base resistance for driven piles. 
directly used for the estimation of the open-ended pile load capacity at the design stage. For the design of open-ended piles, it is therefore necessary to develop a methodology for estimating the IFR from the given soil and pile conditions, so that the relationship between the IFR and the load capacity can be used.

There are two important groups of variables that affect the values of IFR in sands: soil and geometry variables. The relative density is the most important soil variable. The geometry variables include the pile cross-sectional dimensions and driving depths. It is known that, as the relative density increases, the IFR decreases (Klos and Tejchman 1977, De Nicola and Randolph 1997). This is because a loose soil plug tends to densify, while a dense soil plug tends to dilate due to the pile driving vibrations (Murff et al. 1990, Foray et al. 1993, De Nicola and Randolph 1997).

In general, the driving of open-ended piles takes place with high IFR values initially, as driving takes place in an unplugged or partially plugged mode. As the driving depth increases, the IFR tends to drop, and a depth may be reached beyond which driving will proceed in the fully plugged mode. The IFR also decreases with decreasing pile diameter for the same pile driving depth (Paikowski and Whitman 1990). The decreasing IFR values with increasing driving depth may be explained by the formation of the wedged and unwedged soil plug lengths. Fig. 5.10 shows the relationship between the ratio $\left(\mathrm{L}_{\mathrm{up}} / \mathrm{L}_{\mathrm{wp}}\right)$ of the unwedged to wedged plug lengths and the IFR for different driving depths. The calibration chamber tests used for Fig. 5.10 were Tests No. 25 - 28 from Table 5.3. The wedged plug length $\mathrm{L}_{\mathrm{wp}}$, obtained from strain gauges placed on the inner surface of the inner pipe, is approximately $183 \mathrm{~mm}$ irrespective of the pile driving depth. A constant wedged length $\mathrm{L}_{w p}$ implies an increasing $\mathrm{L}_{\mathrm{up}} / \mathrm{L}_{\mathrm{wp}}$ ratio for increasing driving depths. The increasing unwedged soil plug length acts as an increasing 


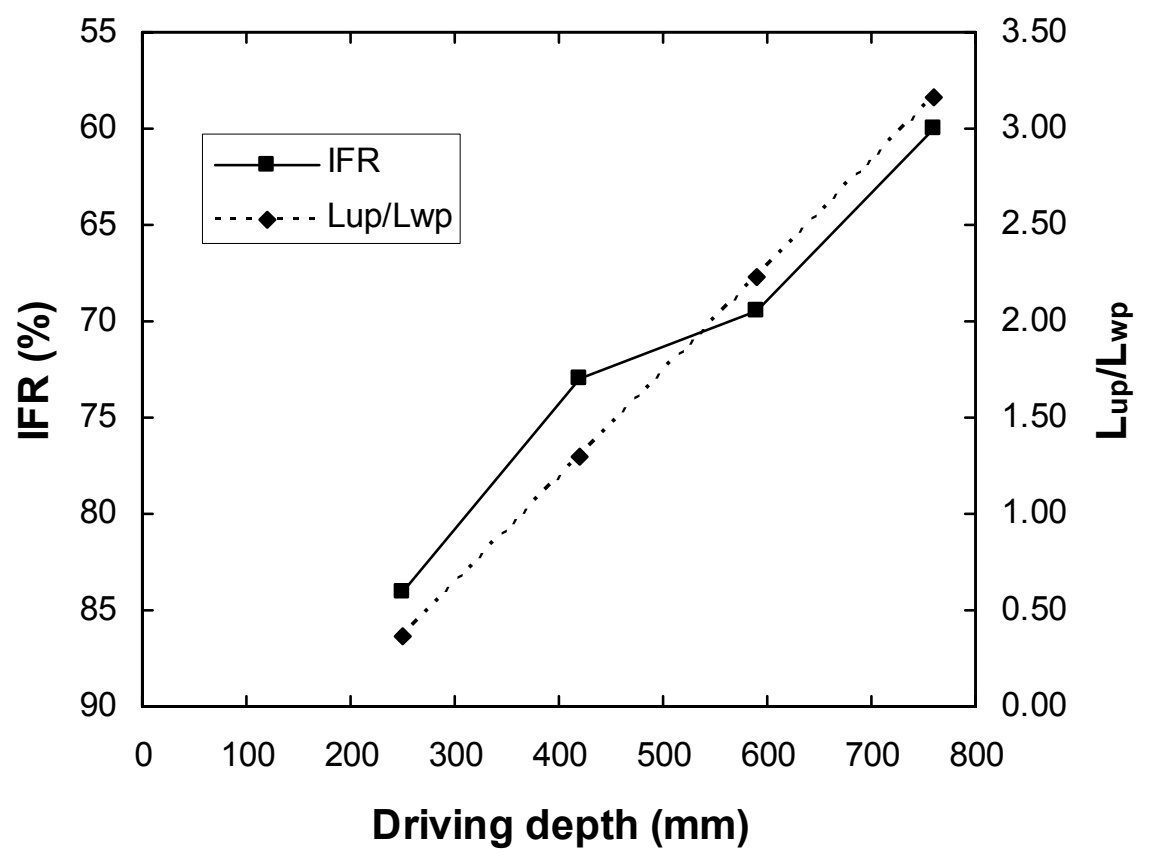

Figure 5.10 Relationships between IFR and $\mathrm{L}_{\mathrm{up}} / \mathrm{L}_{\mathrm{wp}}$ versus driving depth. 
surcharge on the wedged soil plug, which in turn leads to lower IFR values, as shown in Fig. 5.10 .

A correlation of IFR with relative density and pile geometry is needed for IFR estimation in realistic conditions. Fig. 5.11 shows values of normalized IFR versus relative density observed in the calibration chamber and field pile load tests. The values of IFR were normalized as follows:

$$
\begin{gathered}
\operatorname{NIFR}=\frac{\operatorname{IFR}(\%)}{D_{n}} \\
D_{n}=\frac{\text { Driving depth }}{\text { Inner pile diameter }}
\end{gathered}
$$

where NIFR $=$ normalized incremental filling ratio; IFR $=$ incremental filling ratio; $\mathrm{D}_{\mathrm{n}}=$ normalized depth (i.e., driving depth divided by inner diameter of open-ended pile). For the calibration chamber tests, the normalized depths defined as in (5.3) corresponding to driving depths equal to $250,420,590$, and $760 \mathrm{~mm}$ were $6.85,11.51,16.16$, and 20.82 , respectively. It is seen that the values of NIFR decrease with increasing normalized depth and decreasing relative density, as discussed earlier. It is also observed that the effect of the normalized depth on IFR values is substantial, while the relative density has a much more moderate effect. The results in Fig. 5.11 are consistent with findings of Paikowski and Whitman (1990), according to which the soil plug is partially developed until a normalized depth equal to about $D_{n}=25-35$, after which the open-ended pile behaves as fully plugged.

Results from the field pile load test are in good agreement with the IFR- $\mathrm{D}_{\mathrm{R}}$ relationship derived from the calibration chamber tests. As can be seen in Fig. 5.11, the values of NIFR for the field pile load test decrease as the normalized depth increases, following closely the numbers 


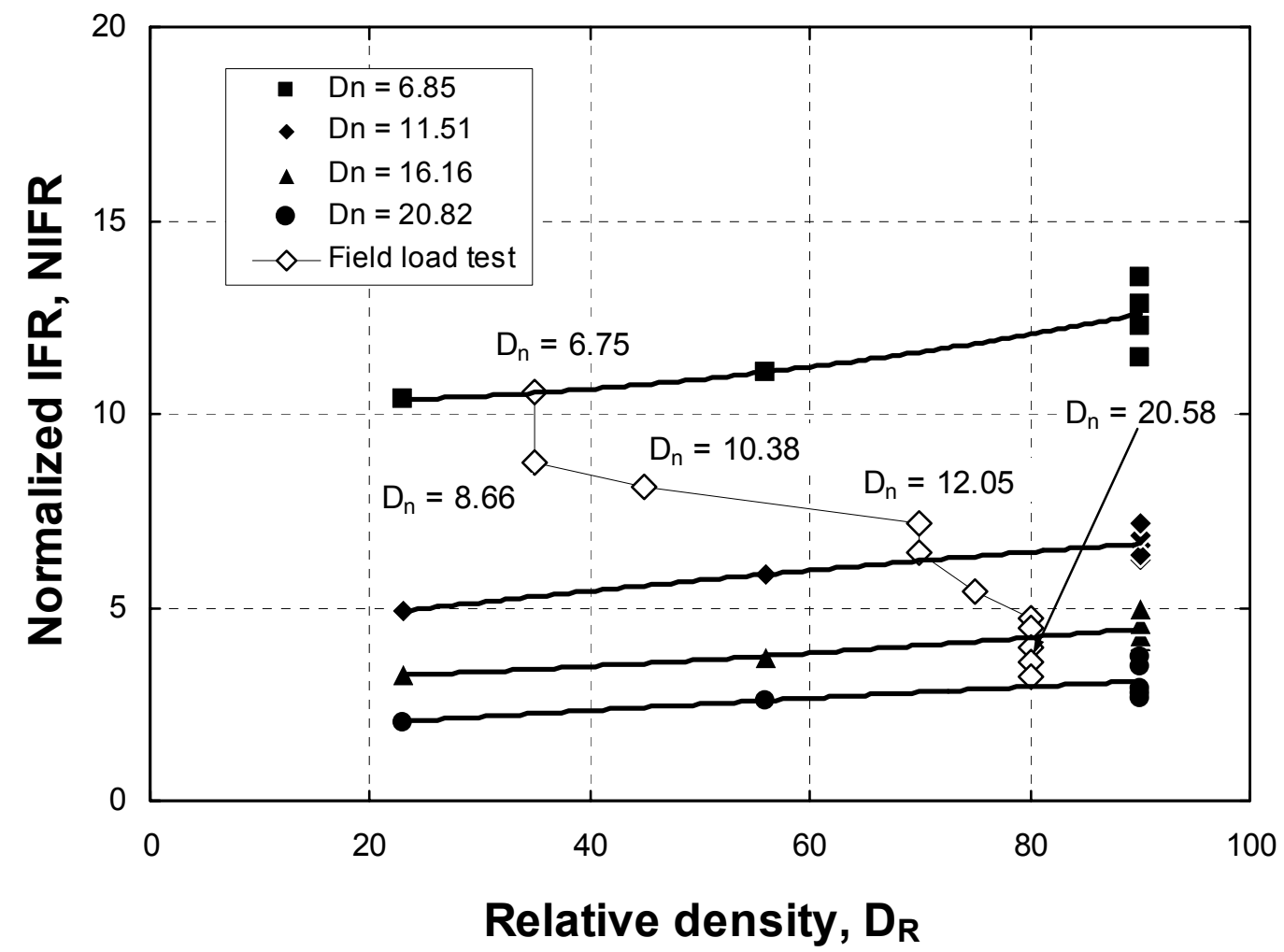

Figure 5.11 Relationship between normalized IFR (NIFR) and relative density $D_{R}$. 
derived from the calibration chamber tests. At a normalized depth equal to $D_{n}=6.75$, the value of NIFR was 10.55 , decreasing to 3.95 at $D_{n}=20.58$. Fig. 5.11 provides a useful tool for designing open-ended piles in practice. The relative density $D_{R}$ can be estimated from the cone resistance $\mathrm{q}_{\mathrm{c}}$ or by other suitable means, and the IFR can be obtained using the results of Fig. 5.11 for given pile dimensions and target driving depth.

\subsubsection{Estimation of Pile Load Capacity Based on CPT Results}

For both closed- and open-ended piles, the total pile load capacity consists of the shaft and base resistances. Table 5.6 shows the values of the normalized unit shaft and base resistances for closed- and open-ended piles we propose for use in design. The values are proposed in terms of the relative density $D_{R}$ and the incremental filling ratio IFR, respectively. The proposed values were obtained based on the results of the calibration chamber load tests and the field pile load tests described in earlier sections.

The unit base resistance $\mathrm{q}_{\mathrm{b}}$ of open-ended piles can be separated into the annulus resistance $\mathrm{q}_{\mathrm{ann}}$, approximately equal to cone resistance $\mathrm{q}_{\mathrm{c}}$, and the plug resistance shown in Fig. 5.6(b). However, we find that it is simpler to base pile design on $\mathrm{q}_{\mathrm{b}}$, using the ratios of Table 5.6 to estimate the base resistance $\mathrm{q}_{\mathrm{b}}$ from the IFR value estimated using Fig. 5.11. The use of Fig. 5.11 requires estimation of relative density. Relative density can be estimated from cone resistance by using the program CONPOINT or by using charts such as those presented by Salgado et al. (1997a). Note that, in practice, piles are embedded into dense sand layers (with relative densities of $80 \%$ or higher) whenever possible. 
Table 5.6. Normalized pile resistance of closed- and open-ended piles

\begin{tabular}{ccccc}
\hline & $\begin{array}{c}\mathrm{D}_{\mathrm{R}} \\
(\%)\end{array}$ & $\begin{array}{c}\text { IFR } \\
(\%)\end{array}$ & $\begin{array}{c}\text { Normalized base } \\
\text { resistance, } \mathrm{q}_{\mathrm{b}} / \mathrm{q}_{\mathrm{c}}\end{array}$ & $\begin{array}{c}\text { Normalized shaft } \\
\text { resistance, } \mathrm{q}_{\mathrm{s}} / \mathrm{q}_{\mathrm{c}}\end{array}$ \\
\hline Closed- & 30 & - & 0.60 & $0.004-0.006$ \\
ended & 50 & - & 0.56 & $0.004-0.006$ \\
piles & 70 & - & 0.50 & $0.004-0.007$ \\
& 90 & - & 0.42 & $0.004-0.009$ \\
\hline & - & 40 & 0.60 & $0.0015-0.003$ \\
Open- & - & 60 & 0.40 & $0.0015-0.003$ \\
ended & - & 80 & 0.27 & $0.0015-0.004$ \\
piles & - & 100 & 0.20 & $0.0015-0.004$ \\
\hline
\end{tabular}




\section{CHAPTER 6}

\section{COMPARISON OF DESIGN METHODS}

\subsection{Introduction}

In this chapter, we compare various design methods for open- and closed-ended piles based on accuracy of pile load capacity calculation and cost comparison. The methods used for the comparison include those proposed in this study as well as several existing design methods.

\subsection{Comparison of Design Methods for Open-Ended Piles}

\subsubsection{Description of Design Methods}

\subsubsection{American Petroleum Institute (API) Method}

According to API method(API, 1991), The total load capacity of piles $\mathrm{Q}_{\mathrm{t}}$ should be determined by the equation.

$$
\mathrm{Q}_{\mathrm{t}}=\mathrm{Q}_{\mathrm{b}}+\mathrm{Q}_{\mathrm{s}}=\mathrm{q}_{\mathrm{b}} \cdot \mathrm{A}_{\mathrm{b}}+\sum q_{s i} A_{s i}
$$

in which $\mathrm{q}_{\mathrm{b}}=$ base resistance; $\mathrm{A}_{\mathrm{b}}=$ gross base area of pile; $\mathrm{q}_{\mathrm{si}}=$ unit shaft resistance within a layer $\mathrm{i}$ of a single soil type; $\mathrm{A}_{\mathrm{si}}=$ side surface area of pile interfacing with layer $\mathrm{i}$. For pipe piles in cohesionless soils, the shaft resistance $\mathrm{q}_{\mathrm{si}}$ is given as: 


$$
\mathrm{q}_{\mathrm{si}}=\mathrm{K} \cdot \sigma_{v i}^{\prime} \cdot \tan \delta
$$

where $\mathrm{K}=$ coefficient of lateral earth pressure; $\sigma_{v i}^{\prime}=$ average effective overburden pressure of soil layer $\mathrm{i}$; and $\delta=$ friction angle between the soil and pile wall. For unplugged piles, $\mathrm{K}$ is assumed to be 0.8 , while it is assumed to be 1.0 for fully plugged piles. For cohesionless soils, the base resistance $\mathrm{q}_{\mathrm{b}}$ can be computed as follows:

$$
\mathrm{q}_{\mathrm{b}}=\sigma_{v}^{\prime} \cdot \mathrm{N}_{\mathrm{q}}
$$

in which $\sigma_{v}^{\prime}=$ effective overburden pressure at the pile base; $\mathrm{N}_{\mathrm{q}}=$ dimensionless bearing capacity factor. Recommended values of $\mathrm{N}_{\mathrm{q}}$ are given in Table 6.1.

Table 6.1 Design parameters for cohesionless siliceous soil

\begin{tabular}{|l|l|c|c|c|c|}
\hline \multicolumn{1}{|c|}{ Density } & \multicolumn{1}{|c|}{$\begin{array}{c}\text { Soil } \\
\text { Description }\end{array}$} & $\begin{array}{c}\text { Soil-Pile } \\
\text { Friction } \\
\text { Angle } \delta \\
\text { (Degrees) }\end{array}$ & $\begin{array}{c}\text { Limiting Skin } \\
\text { Friction Values } \\
(\mathrm{kPa})\end{array}$ & $\mathrm{N}_{\mathrm{q}}$ & $\begin{array}{c}\text { Limiting Unit } \\
\text { End Bearing } \\
\text { Values } \\
(\mathrm{MPa})\end{array}$ \\
\hline $\begin{array}{l}\text { Very Loose } \\
\text { Loose } \\
\text { Medium }\end{array}$ & $\begin{array}{l}\text { Sand } \\
\text { Sand-Silt } \\
\text { Silt }\end{array}$ & 15 & 47.8 & 8 & 1.9 \\
\hline $\begin{array}{l}\text { Loose } \\
\text { Medium } \\
\text { Dense }\end{array}$ & $\begin{array}{l}\text { Sand } \\
\text { Sand-Silt } \\
\text { Silt }\end{array}$ & 20 & 67.0 & 12 & 2.9 \\
\hline $\begin{array}{l}\text { Medium } \\
\text { Dense }\end{array}$ & $\begin{array}{l}\text { Sand } \\
\text { Sand-Silt }\end{array}$ & 25 & 81.3 & 20 & 4.8 \\
\hline $\begin{array}{l}\text { Dense } \\
\text { Very Dense }\end{array}$ & $\begin{array}{l}\text { Sand } \\
\text { Sand-Silt }\end{array}$ & 30 & 95.7 & 40 & 9.6 \\
\hline $\begin{array}{l}\text { Dense } \\
\text { Very Dense }\end{array}$ & $\begin{array}{l}\text { Gravel } \\
\text { Sand }\end{array}$ & 35 & 114.8 & 50 & 12.0 \\
\hline
\end{tabular}




\subsubsection{DRIVEN ( FHWA)}

The program "DRIVEN" was developed by Federal Highway Administration (FHWA, 1998) to analyze the axial capacity of driven piles. DRIVEN, a windows-based computer calculation program, follows the methods and equations presented by Nordlund $(1963,1979)$, Thurman (1964), Meyerhof (1976), Cheney and Chassie (1982), Tomlinson (1979, 1985), and Hannigan, et.al. (1997).

\section{Base Resistance}

The basic equation for the total load capacity of a single pile is the same as equation 6.1. There are two kinds of stress analyses that DRIVEN can consider: total stress analysis and effective stress analysis. For an undrained analysis, $\phi$ equals zero and $\mathrm{c}$ equals the undrained shear strength, $\mathrm{s}_{\mathrm{u}}$. So, the pile base resistance by total stress analysis can be obtained from the equation:

$$
Q_{b}=A_{b} \cdot s_{u} \cdot N_{c}
$$

where $\mathrm{N}_{\mathrm{c}}$ is a dimensionless parameter, typically taken as $\mathrm{N}_{\mathrm{c}}=9$. For effective stress analysis, DRIVEN uses (Thurman 1964):

$$
Q_{b}=A_{b} \cdot \sigma_{v}^{\prime} \cdot \alpha \cdot N_{q}
$$

where $\sigma_{v}^{\prime}=$ effective vertical stress at base level; $\mathrm{N}_{\mathrm{q}}=$ bearing capacity factor (Fig. 6.1a); $\alpha=\mathrm{a}$ dimensionless factor dependent on the relative depth of embedment into the bearing layer $\mathrm{L}_{\mathrm{b}} / \mathrm{B}$ where $\mathrm{L}_{\mathrm{b}}=$ pile length and $\mathrm{B}=$ pile diameter of the pile (Fig. 6.1b). If DRIVEN computes a pile base resistance exceeding the limiting value suggested by Meyerhof(1976) shown in Fig. 6.2, then the limiting value is used by the program. 


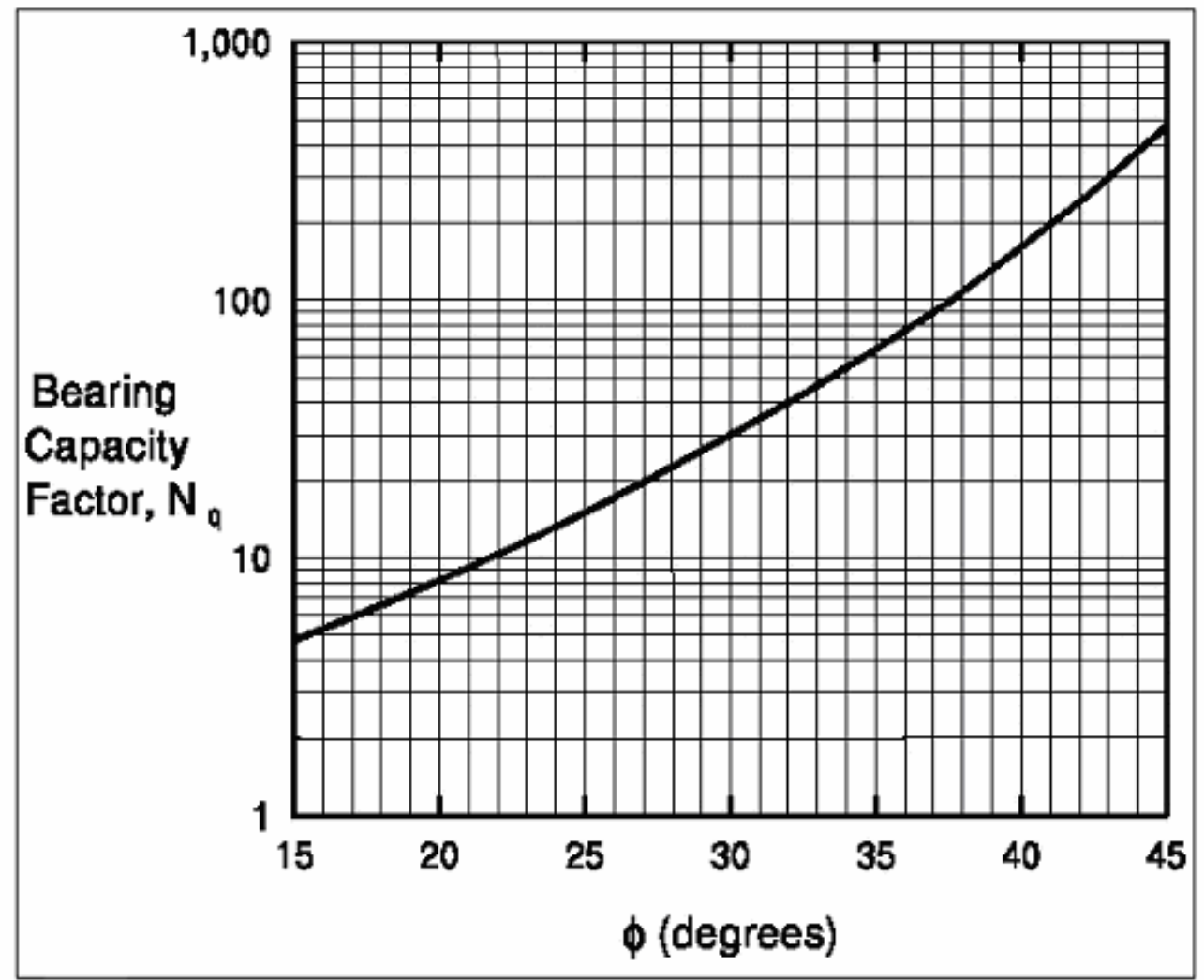

(a)

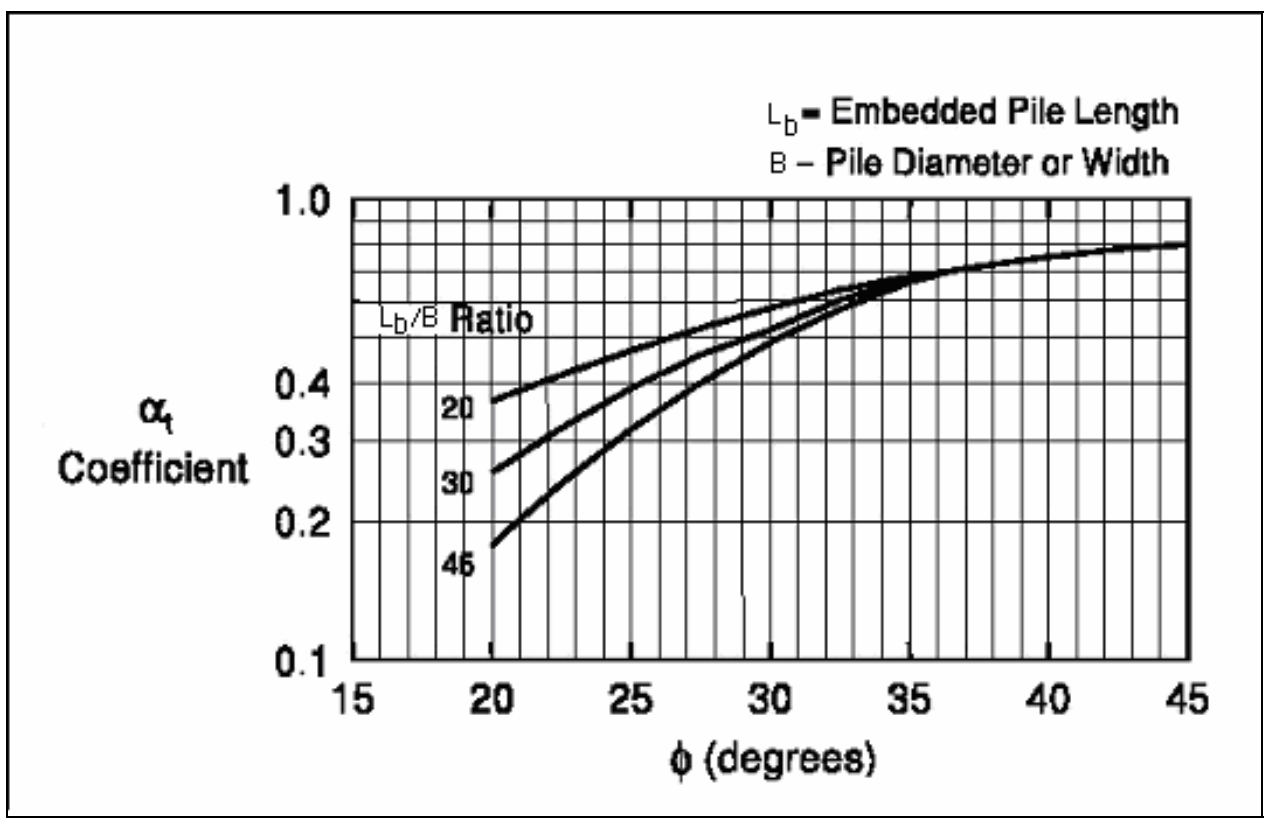

(b)

Figure 6.1 Chart for estimating (a) Bearing capacity factor $\mathrm{N}_{\mathrm{q}}$ (b) dimensionless factor $\alpha$ 


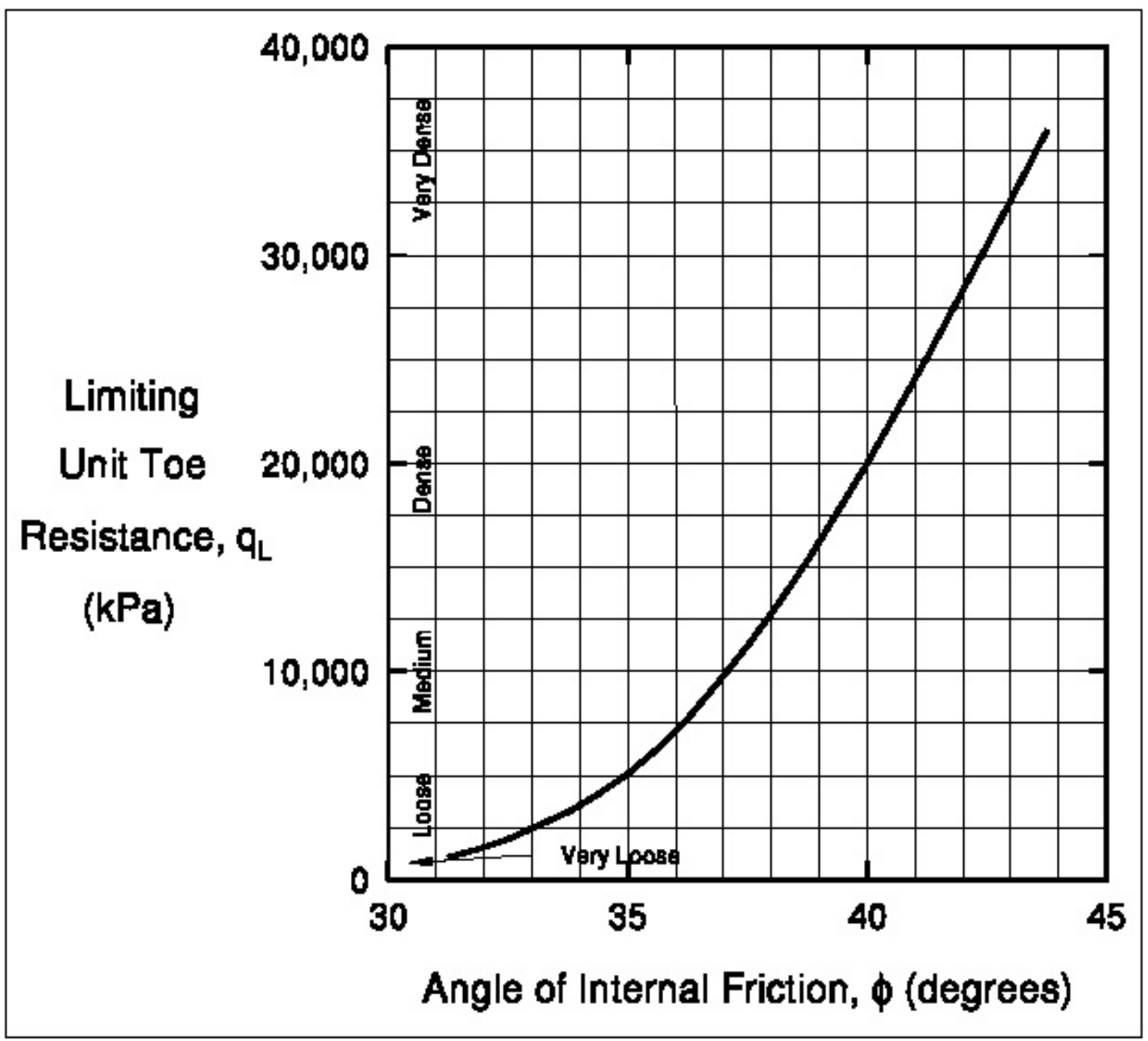

Figure 6.2 Relationship between unit pile base resistance and friction angle for cohesionless soils (after Meyerhof, 1976) 


\section{Shaft Resistance}

For effective stress analyses, the Nordlund(1963) method is used. This method is based on field observations and considers the shape of pile taper and its soil displacement in calculating the shaft resistance. The following shaft resistance equation is suggested:

$$
Q_{s}=\int_{0}^{L} K_{\delta} C_{F} \sigma_{v}^{\prime} \frac{\sin (\varpi+\delta)}{\cos (\varpi)} C_{d} d z
$$

in which $\mathrm{K}_{\delta}=$ coefficient of lateral stress at depth z (Fig. 6.3); $\mathrm{C}_{\mathrm{F}}=$ correction factor for $\mathrm{K}_{\delta}$ when $\delta \neq 0$ (Fig. 6.4); $\sigma_{v}^{\prime}=$ effective overburden pressure; $\varpi=$ angle of pile taper; $\delta=$ pile-soil friction angle; $C_{d}=$ effective pile perimeter.

\section{Plugging of Open-ended Pipe Piles}

The skin friction and end bearing for open-ended pipe piles in sandy soils are dependent on the ratio of pile diameter or width to pile toe depth. The open-ended pipe pile is considered to be either unplugged, acting like a non-displacement pile, or plugged, acting like a displacement pile (i.e. closed-ended pipe pile). The criteria below is used to determine when the pile is considered to be plugged or unplugged.

- Sands

- Skin Friction

Driving/Restrike/Ultimate

$$
\begin{aligned}
& \mathrm{L}_{b}<30 \mathrm{~B}: \text { unplugged (non-displacement pile) } \\
& \mathrm{L}_{b}>30 \mathrm{~B}: \text { plugged (displacement pile) } \\
& \left(\mathrm{B}=\text { pile diameter or width; } \mathrm{L}_{\mathrm{b}}=\right.\text { embedded pile length ) }
\end{aligned}
$$

- End Bearing

$$
\text { Driving: } \quad \mathrm{L}_{\mathrm{b}}<30 \mathrm{~B} \text { : unplugged (no end bearing) }
$$

$$
\mathrm{L}_{b}>30 \mathrm{~B} \text { : plugged (full end bearing) }
$$

Restrike/Ultimate: Plugged (full end bearing) 


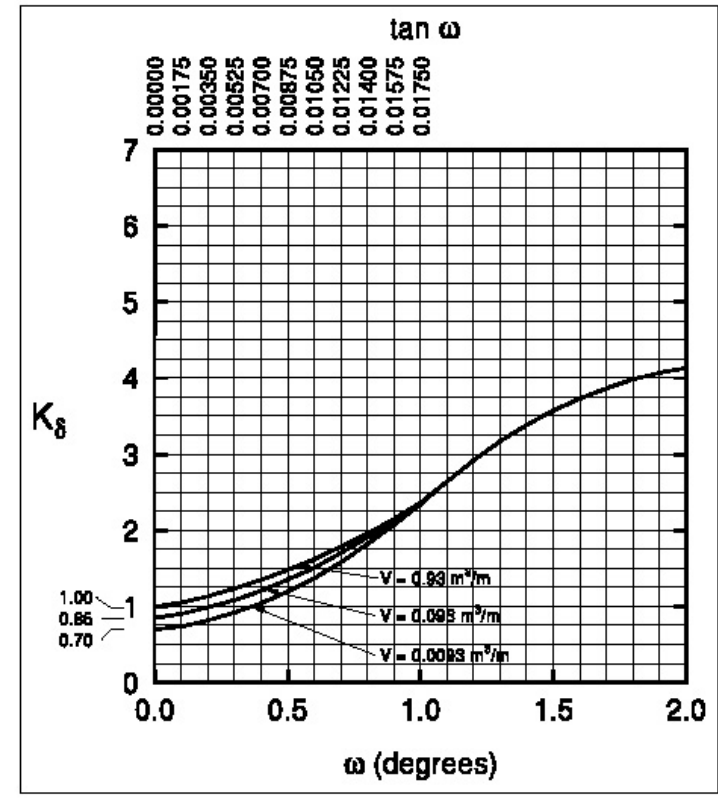

(a)

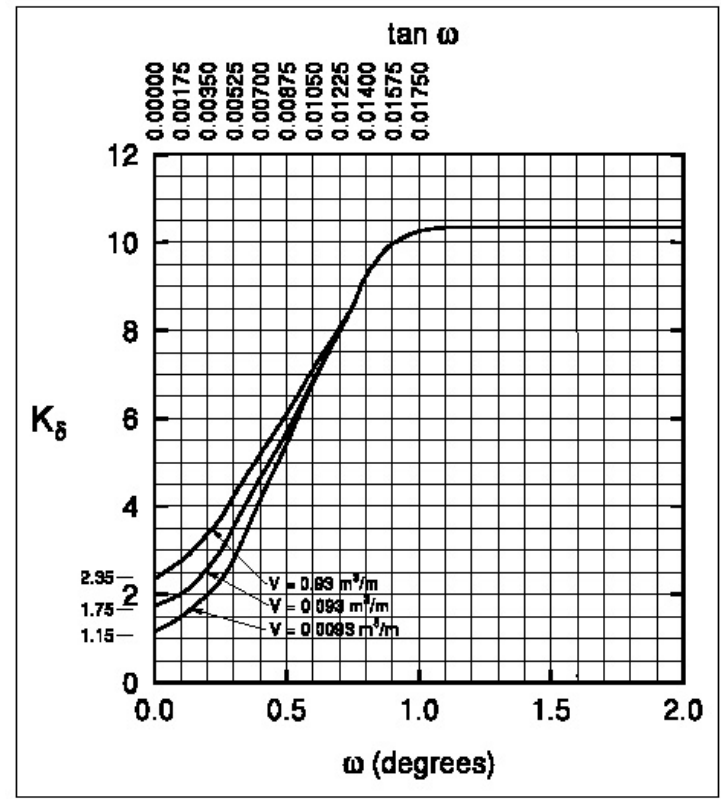

(c)

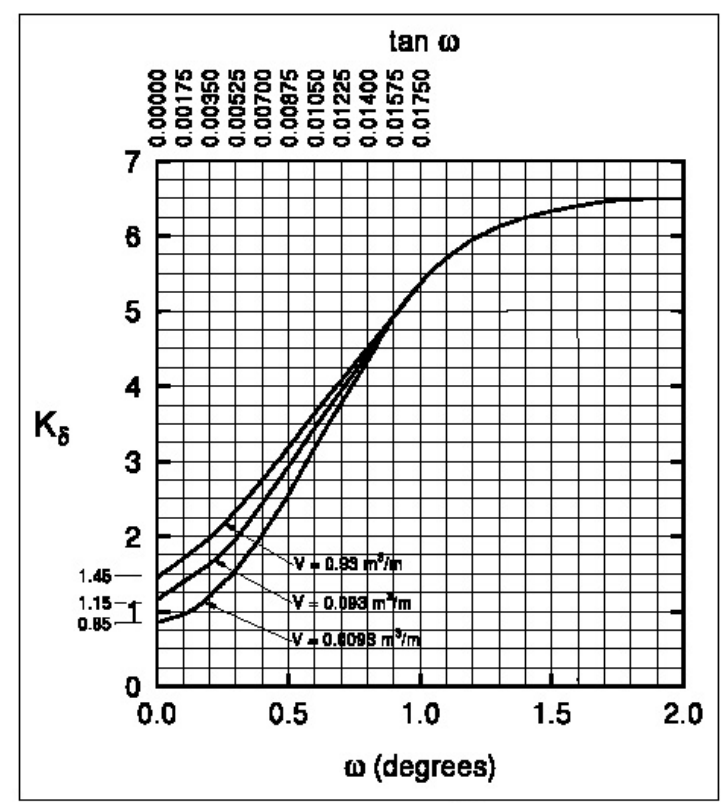

(b)

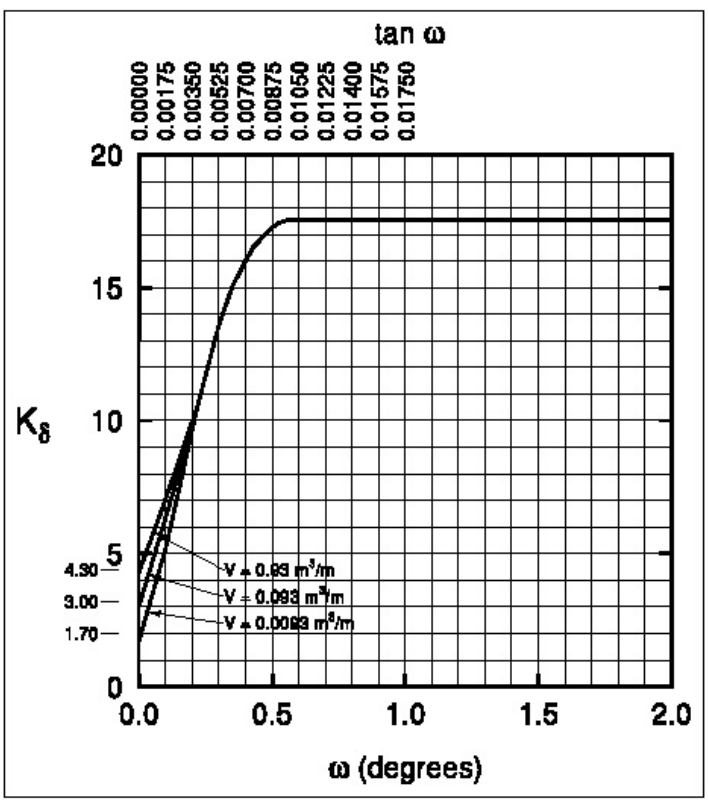

(d)

Figure 6.3 Design curves for evaluating $\mathrm{K}_{\delta}$ when (a) $\phi=25^{\circ}$, (b) $\phi=30^{\circ}$, (c) $\phi=35^{\circ}$, and (d) $\phi=40^{\circ}$ 


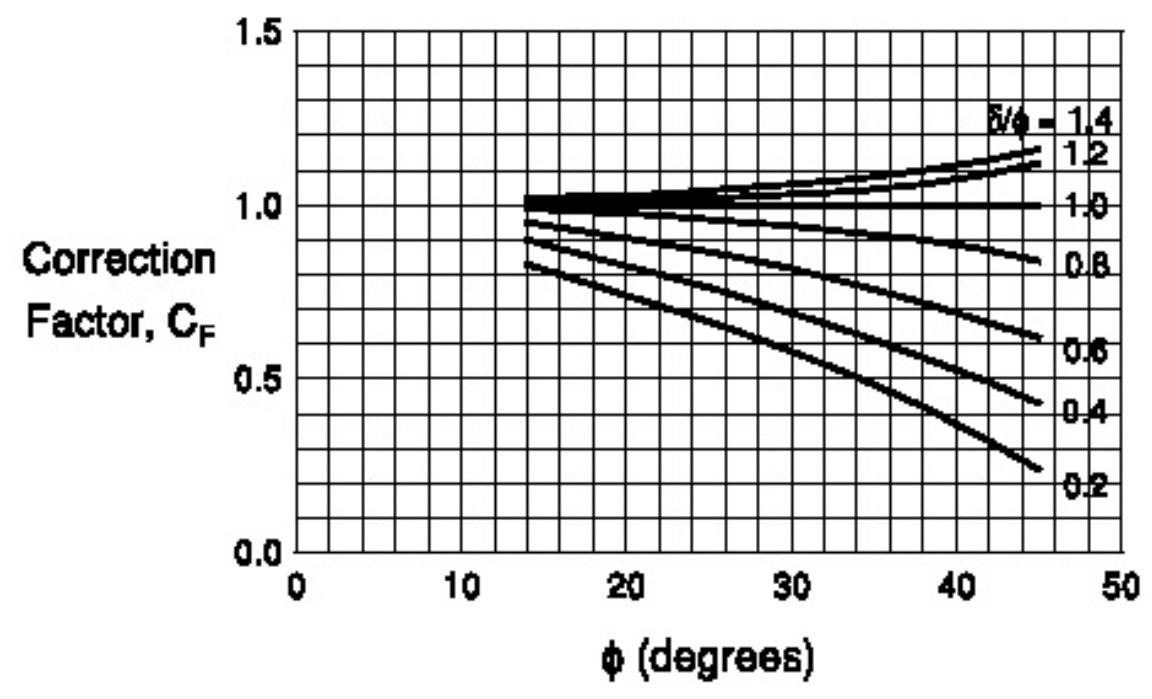

(a)

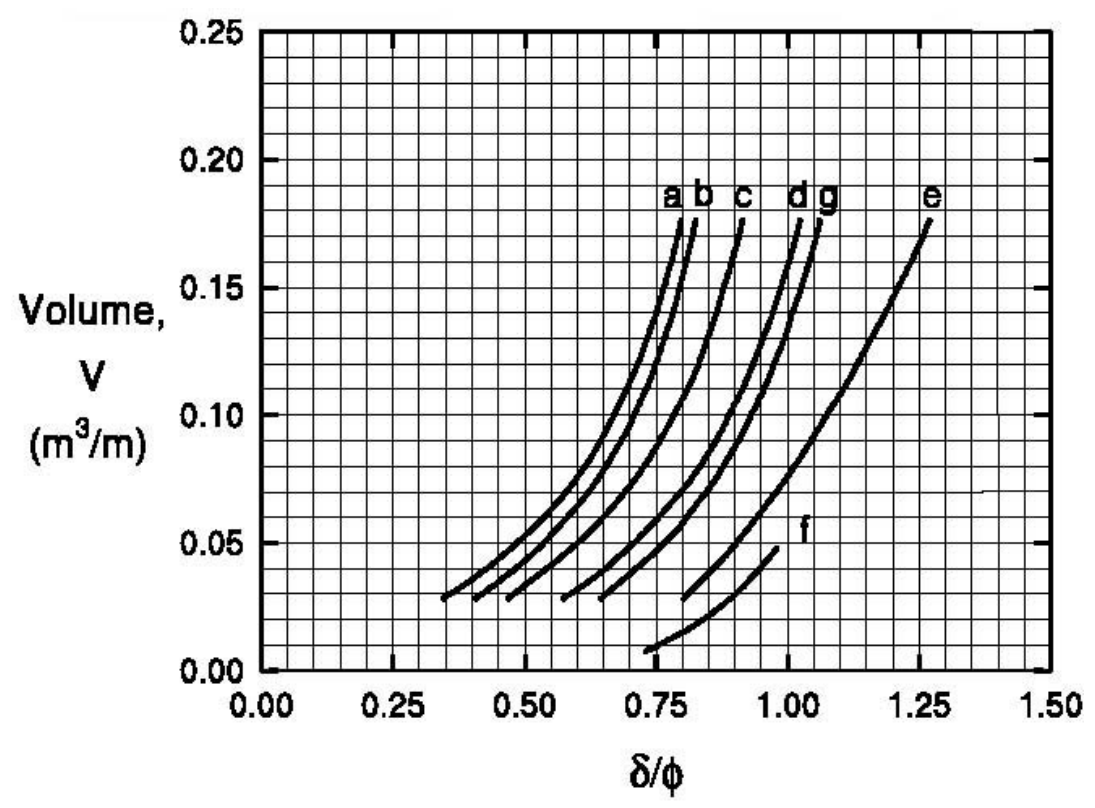
a. Closed end plpe and non-tapered portlon of monotube plles
b. Timber piles
c. Precast concrele piles
d. Raymond step-taper plles
e. Reymond unliorm taper plles
f. H-piles
g. Tapered portion of monotube piles

(b)

Figure 6.4 (a) Correction factor for $\mathrm{K}_{\delta}$ when $\delta \neq \phi$, (b) Relation of $\delta / \phi$ and pile volume $\mathrm{v}$ for various types of piles (after Nordlund 1979) 


\subsubsection{Polish Method}

According to Gwizdala (1997), the ultimate pile load capacity $\mathrm{Q}_{\mathrm{t}}$ is defined as follows:

$$
\mathrm{Q}_{\mathrm{t}} \leq \mathrm{mN}
$$

where $\mathrm{N}=$ load capacity factor; $\mathrm{m}=$ assumed correction factor equal to $0.9,0.8$ and 0.7 for group piles, group of two piles, and single piles respectively. The load capacity factor $\mathrm{N}$ of a single open ended pipe is determined as:

$$
\mathrm{N}=\mathrm{N}_{\mathrm{b}}+\mathrm{N}_{\mathrm{s}}=\mathrm{b}_{1} \mathrm{~S}_{\mathrm{b}} \mathrm{q}_{\mathrm{b}} \cdot \mathrm{A}_{\mathrm{b}}+\sum \mathrm{b}_{2} \mathrm{~S}_{\mathrm{si}} \mathrm{q}_{\mathrm{si}} \cdot \mathrm{A}_{\mathrm{si}}
$$

where $\mathrm{N}_{\mathrm{b}}$ and $\mathrm{N}_{\mathrm{s}}$ = base and shaft load capacity factors; $\mathrm{S}_{\mathrm{b}}$ and $\mathrm{S}_{\mathrm{s}}=$ engineering factors given in Table 6.2; $\mathrm{b}_{1}$ and $\mathrm{b}_{2}=$ reduction factors given in Table 6.3; $\mathrm{A}_{\mathrm{b}}$ and $\mathrm{A}_{\mathrm{si}}=$ base and shaft pile area; $\mathrm{q}_{\mathrm{b}}$ and $\mathrm{q}_{\mathrm{si}}=$ base and shaft resistance.

The base resistance $q_{b}$ is specific for depths, equal to or exceeding the critical depth $\mathrm{L}_{\mathrm{ci}}=\mathrm{L}_{\mathrm{c}}^{0} \sqrt{\mathrm{B}_{\mathrm{i}} / \mathrm{B}_{0}}$, where: $\mathrm{h}_{\mathrm{c}}^{0}=10 \mathrm{~m}, \mathrm{~B}_{0}=0.4 \mathrm{~m}$ and $\mathrm{B}_{\mathrm{i}}$ is the actual base diameter. A linear interpolation should be adopted to determine values of $\mathrm{q}_{\mathrm{b}}$ for depths less than $\mathrm{h}_{\mathrm{ci}}$ with zero taken as the value of $\mathrm{q}_{\mathrm{b}}$ for the initial or equivalent ground level. Table 6.4 shows $\mathrm{q}_{\mathrm{b}}$ as a function of relative density.

The value of the unit shaft resistance $\mathrm{q}_{\mathrm{s}}$, is specified in Table 6.5. Values of $\mathrm{q}_{\mathrm{s}}$ should be used for depths equal to or exceeding $5 \mathrm{~m}$. For smaller depths, the appropriate value of $\mathrm{q}_{\mathrm{s}}$ ought to be determined by interpolation between the table entry and zero for the ground level. 
Table 6.2 Engineering factors $\mathrm{S}_{\mathrm{p}}, \mathrm{S}_{\mathrm{s}}$, and $\mathrm{S}^{\mathrm{w}}$ for sands

\begin{tabular}{|c|c|c|c|c|c|c|}
\hline \multirow{4}{*}{$\begin{array}{l}\text { Type of pile and method of } \\
\text { installing }\end{array}$} & \multicolumn{6}{|c|}{ Values of factors for soils } \\
\hline & \multicolumn{3}{|c|}{$D_{r}>67 \%$} & \multicolumn{3}{|c|}{$\mathrm{D}_{\mathrm{r}}=67 \% \sim 20 \%$} \\
\hline & \multicolumn{2}{|c|}{$\begin{array}{l}\text { Downward } \\
\text { movement } \\
\text { of pile }\end{array}$} & \multirow{2}{*}{$\begin{array}{c}\begin{array}{c}\text { Uplift } \\
\text { of pile }\end{array} \\
S^{\mathrm{w}}\end{array}$} & \multicolumn{2}{|c|}{$\begin{array}{l}\text { Downward } \\
\text { movement } \\
\text { of pile }\end{array}$} & \multirow{2}{*}{$\begin{array}{c}\begin{array}{c}\text { Uplift } \\
\text { of pile }\end{array} \\
\mathrm{S}^{\mathrm{w}}\end{array}$} \\
\hline & $\mathrm{S}_{\mathrm{p}}$ & $\mathrm{S}_{\mathrm{s}}$ & & $\mathrm{S}_{\mathrm{p}}$ & $\mathrm{S}_{\mathrm{s}}$ & \\
\hline $\begin{array}{l}\text { - Closed-end pipe piles } \\
\text { a) driven } \\
\text { b) installed by jetting } \\
\text { (the final } 1 \mathrm{~m} \text { driven) } \\
\text { c) driven with vibr. Equip. }\end{array}$ & $\begin{array}{c}1.0 \\
-\end{array}$ & $\begin{array}{c}0.7 \\
-\end{array}$ & $\begin{array}{c}0.3 \\
-\end{array}$ & $\begin{array}{l}1.0 \\
1.0\end{array}$ & $\begin{array}{l}0.6 \\
0.8\end{array}$ & $\begin{array}{l}0.4 \\
0.5\end{array}$ \\
\hline $\begin{array}{l}\text { - Steel Section piles } \\
\text { a) driven } \\
\text { b) installed by jetting } \\
\text { (the final } 1 \mathrm{~m} \text { driven) } \\
\text { c) driven with vibr. Equip. }\end{array}$ & $\begin{array}{c}1.0 \\
1.0 \\
-\end{array}$ & $\begin{array}{c}0.5 \\
-\end{array}$ & $\begin{array}{c}0.3 \\
-\end{array}$ & $\begin{array}{l}1.0 \\
1.0\end{array}$ & $\begin{array}{l}0.6 \\
0.7\end{array}$ & $\begin{array}{l}0.3 \\
0.4\end{array}$ \\
\hline
\end{tabular}

Table 6.3 Values of $b_{1}$ and $b_{2}$ for sands

\begin{tabular}{|c|c|c|c|c|c|c|c|c|}
\hline \multirow{2}{*}{ No. } & \multicolumn{4}{|c|}{$\mathrm{D}_{\mathrm{r}}=40 \%$} & \multicolumn{4}{c|}{$\mathrm{D}_{\mathrm{r}}=70 \%$} \\
\cline { 2 - 3 } & \multicolumn{2}{|c|}{$\mathrm{L}_{\mathrm{b}} / \mathrm{B}$} & \multirow{2}{*}{$\mathrm{b}_{1}$} & \multirow{2}{*}{$\mathrm{b}_{2}$} & \multicolumn{2}{|c|}{$\mathrm{L}_{\mathrm{b}} / \mathrm{B}$} & \multirow{2}{*}{$\mathrm{b}_{1}$} & \multirow{2}{*}{$\mathrm{b}_{2}$} \\
\cline { 2 - 6 } & moist & wet & & & moist & wet & & \\
\hline 1 & - & - & - & - & 4.0 & 6.0 & 0.22 & 0.27 \\
\hline 2 & 6.0 & 9.0 & 0.28 & 0.61 & 5.5 & 8.0 & 0.50 & 0.35 \\
\hline 3 & 7.5 & 11.5 & 0.78 & 0.61 & 6.5 & 10.0 & 0.90 & 0.37 \\
\hline 4 & 17.0 & 26.0 & 1.00 & 0.61 & 17.0 & 26.0 & 1.00 & 0.65 \\
\hline
\end{tabular}


Table 6.4 Unit base resistance $\mathrm{q}_{\mathrm{b}}$ for different soil types $(\mathrm{kPa})$

\begin{tabular}{|c|c|c|c|c|}
\hline \multirow{2}{*}{ Soil Type } & \multicolumn{4}{|c|}{ Relative Density $\mathrm{D}_{\mathrm{r}}$} \\
\cline { 2 - 5 } & $100 \%$ & $67 \%$ & $33 \%$ & $20 \%$ \\
\hline Gravel, sand-gravel mix & 7750 & 5100 & 3000 & 1950 \\
\hline Coarse and medium sand & 5850 & 3600 & 2150 & 1450 \\
\hline Fine sand & 4100 & 2700 & 1650 & 1050 \\
\hline Silty sand & 3350 & 2100 & 1150 & 700 \\
\hline
\end{tabular}

Table 6.5 Unit shaft resistance $\mathrm{q}_{\mathrm{s}}$ for different soil types $(\mathrm{kPa})$

\begin{tabular}{|c|c|c|c|c|}
\hline \multirow{2}{*}{ Soil Type } & \multicolumn{4}{|c|}{ Relative Density $\mathrm{D}_{\mathrm{r}}$} \\
\cline { 2 - 5 } & $100 \%$ & $67 \%$ & $33 \%$ & $20 \%$ \\
\hline Gravel, sand-gravel mix & 165 & 110 & 74 & 59 \\
\hline Coarse and medium sand & 132 & 74 & 47 & 34 \\
\hline Fine sand & 100 & 62 & 31 & 22 \\
\hline Silty sand & 75 & 45 & 25 & 16 \\
\hline
\end{tabular}




\subsubsection{Predicted and Measured Pile Load Capacity}

Based on the results of pile load capacity calculations previously obtained it was found that the existing methods we examined tend to produce excessively conservative results, while the new methods proposed in this study give results that compare well with the pile load capacities measured in the load tests.

\subsubsection{Example 1}

\section{Soil and Pile Data}

Example 1 is the pile load test performed on the open-ended pile of chapter 3. Basic information for the soil and pile for this example is shown in Table 6.6. Fig. 6.5 shows division of the soil in layers for the calculation of shaft resistance based on CPT and SPT results.

Table 6.6 Soil properties and pile size of example 1

\begin{tabular}{|c||c|c|}
\hline \multirow{4}{*}{ soil property } & soil type & Gravelly sand \\
\cline { 2 - 3 } & $\gamma_{\mathrm{dmax}}$ & $18.64 \mathrm{kN} / \mathrm{m}^{3}$ \\
\cline { 2 - 3 } & $\gamma_{\mathrm{dmin}}$ & $15.61 \mathrm{kN} / \mathrm{m}^{3}$ \\
\cline { 2 - 3 } & $\mathrm{e}_{\max }$ & 0.68 \\
\cline { 2 - 3 } & $\mathrm{e}_{\min }$ & 0.41 \\
\hline \multirow{3}{*}{$\begin{array}{c}\text { Open-ended } \\
\text { pile }\end{array}$} & GWT & $-3 \mathrm{~m}$ \\
\cline { 2 - 3 } & Embedded depth & $7.04 \mathrm{~m}$ \\
\cline { 2 - 3 } & Diameter & $356 \mathrm{~mm}$ \\
\hline \multirow{2}{*}{$\begin{array}{c}\text { Closed-ended } \\
\text { pile }\end{array}$} & Thickness & $32 \mathrm{~mm}$ \\
\cline { 2 - 3 } & Embedded depth & $6.87 \mathrm{~m}$ \\
\hline
\end{tabular}



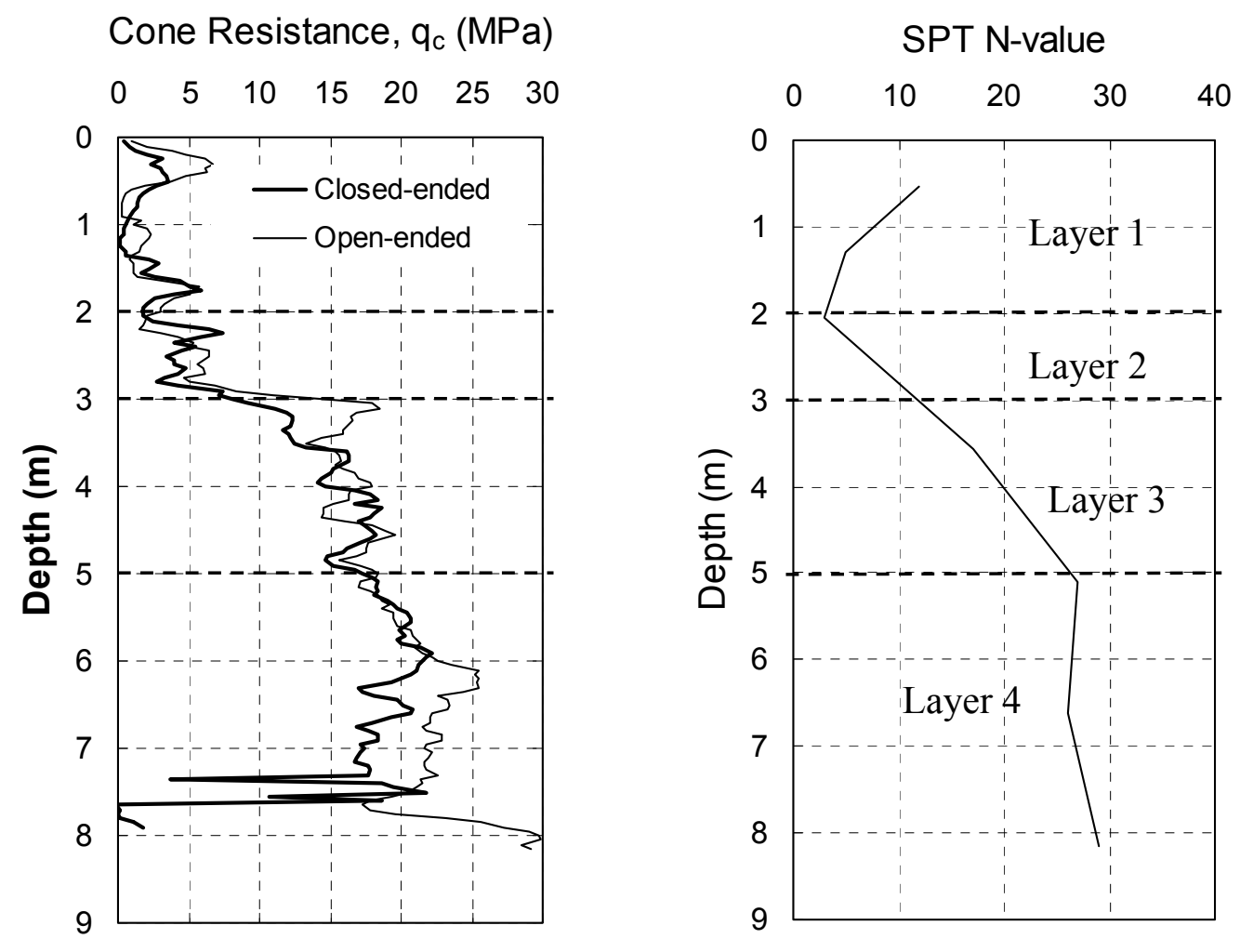

Figure 6.5 Cone resistance $\mathrm{q}_{\mathrm{c}}$ and SPT N-value for pile load test site of example 1 . 


\section{Calculations}

Table 6.7 and Figs. 6.6, 6.7 summarize the results for the design methods considered. Calculation processes for all used methods are shown in appendix-B. For the soil-state based method of chapter 4 , proposed method 1 , the base and shaft load capacity were $75.4 \%$ and $100.9 \%$ of measured values. The base and shaft load capacity using the CPT based method of chapter 5, proposed method 2, were 104.1\% and 75.0\%, respectively. As can be seen in Figs. 6.6 and 6.7, most existing methods show underestimated load capacity values.

Table 6.7 Results of the open-ended pile of example 1

\begin{tabular}{|c||c|c|c|}
\hline & Base Capacity $(\mathrm{kN})$ & Shaft Capacity $(\mathrm{kN})$ & Total Capacity $(\mathrm{kN})$ \\
\hline Measured Capacity & 715.0 & 310.0 & 1025.0 \\
\hline Proposed method 1 & 539.4 & 312.9 & 852.3 \\
\hline Proposed method 2 & 744.5 & 232.4 & 976.9 \\
\hline API & 473.3 & 192.5 & 665.8 \\
\hline DRIVEN & 441.7 & 280.3 & 722.1 \\
\hline Polish & 248.8 & 128.7 & 377.5 \\
\hline
\end{tabular}




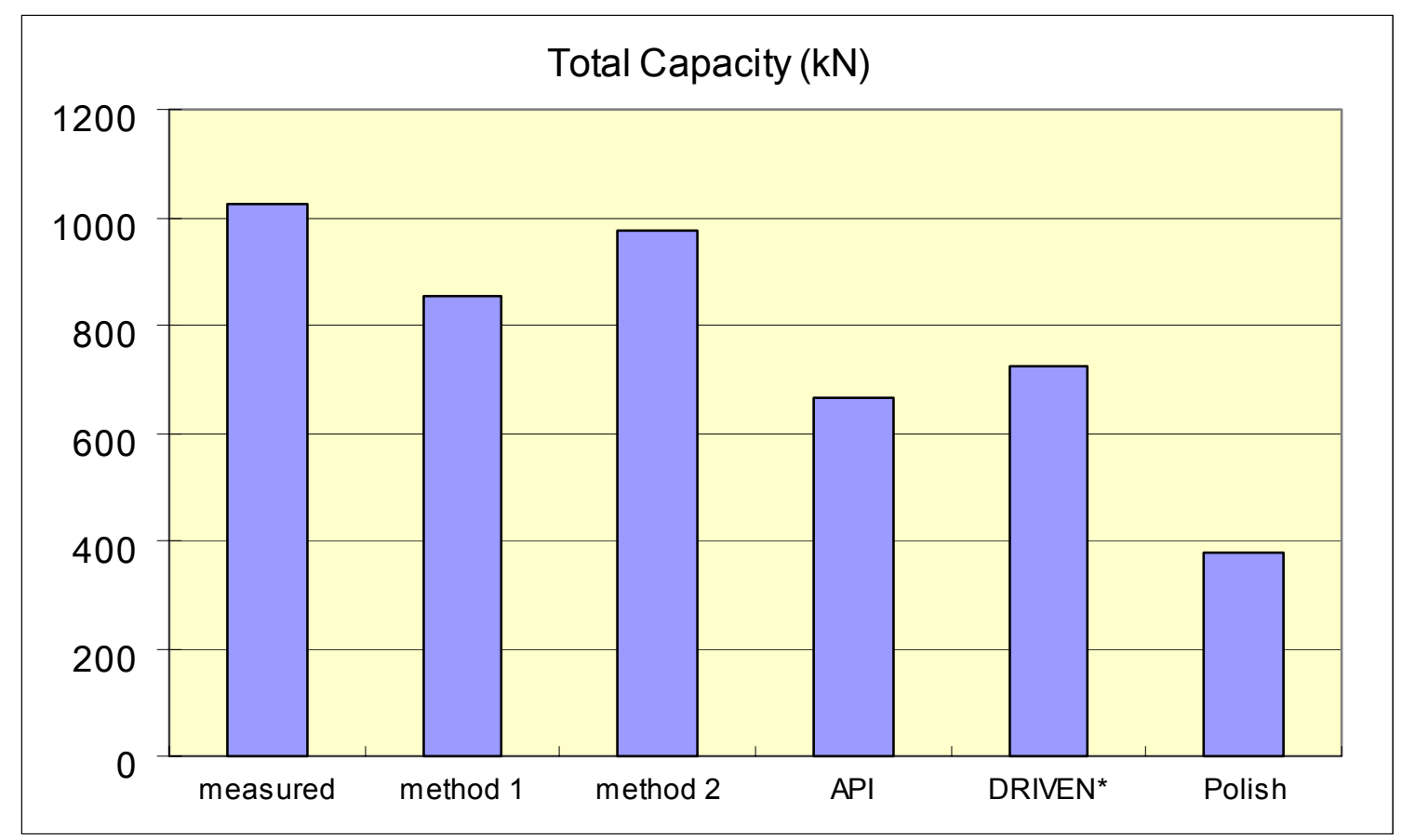

* The program DRIVEN calculates base resistance using Thurman and Meyerhof methods and shaft resistance using Nordlund method

Figure 6.6 Total capacity of the open-ended pile of example 1 


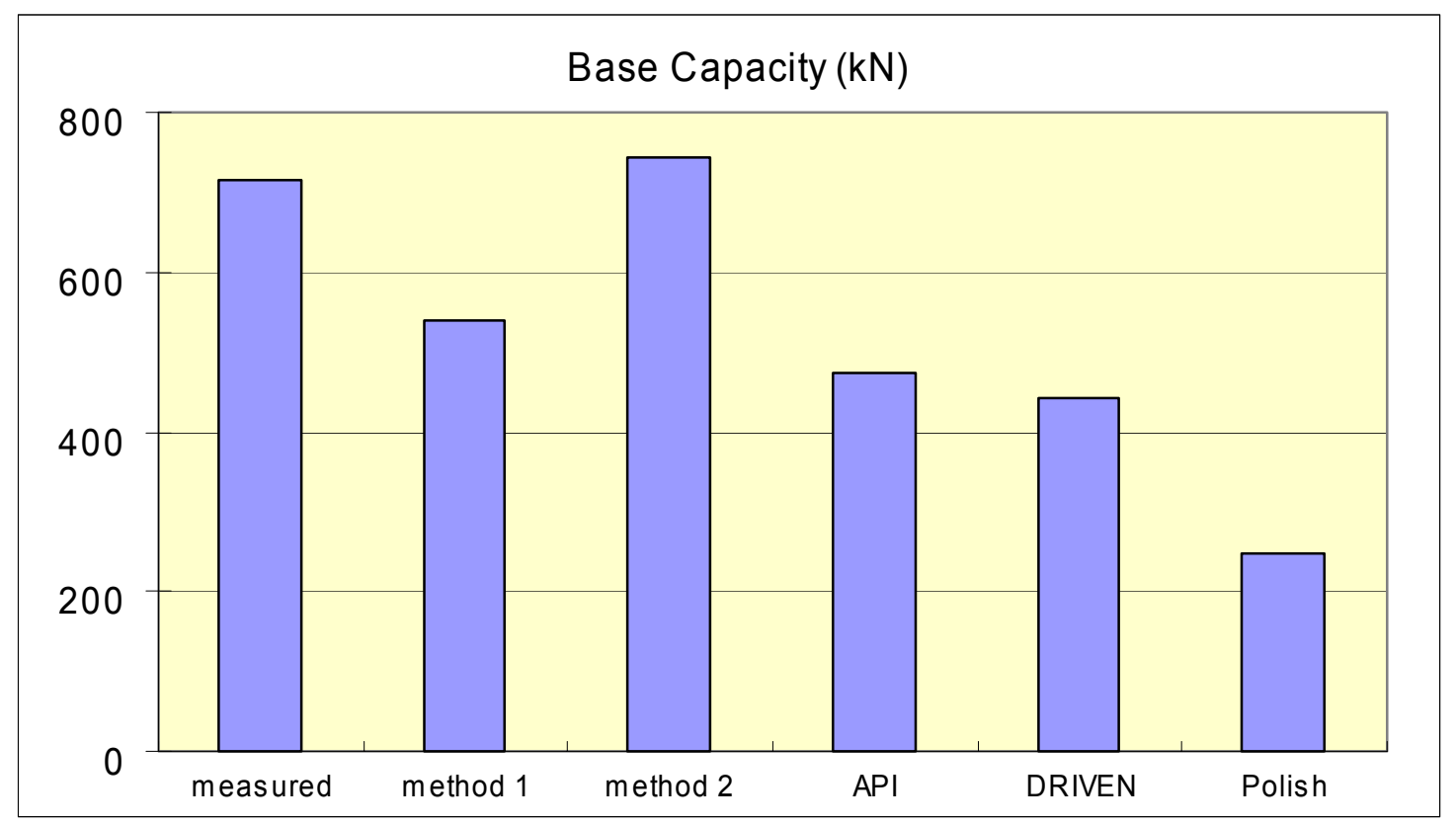

(a)

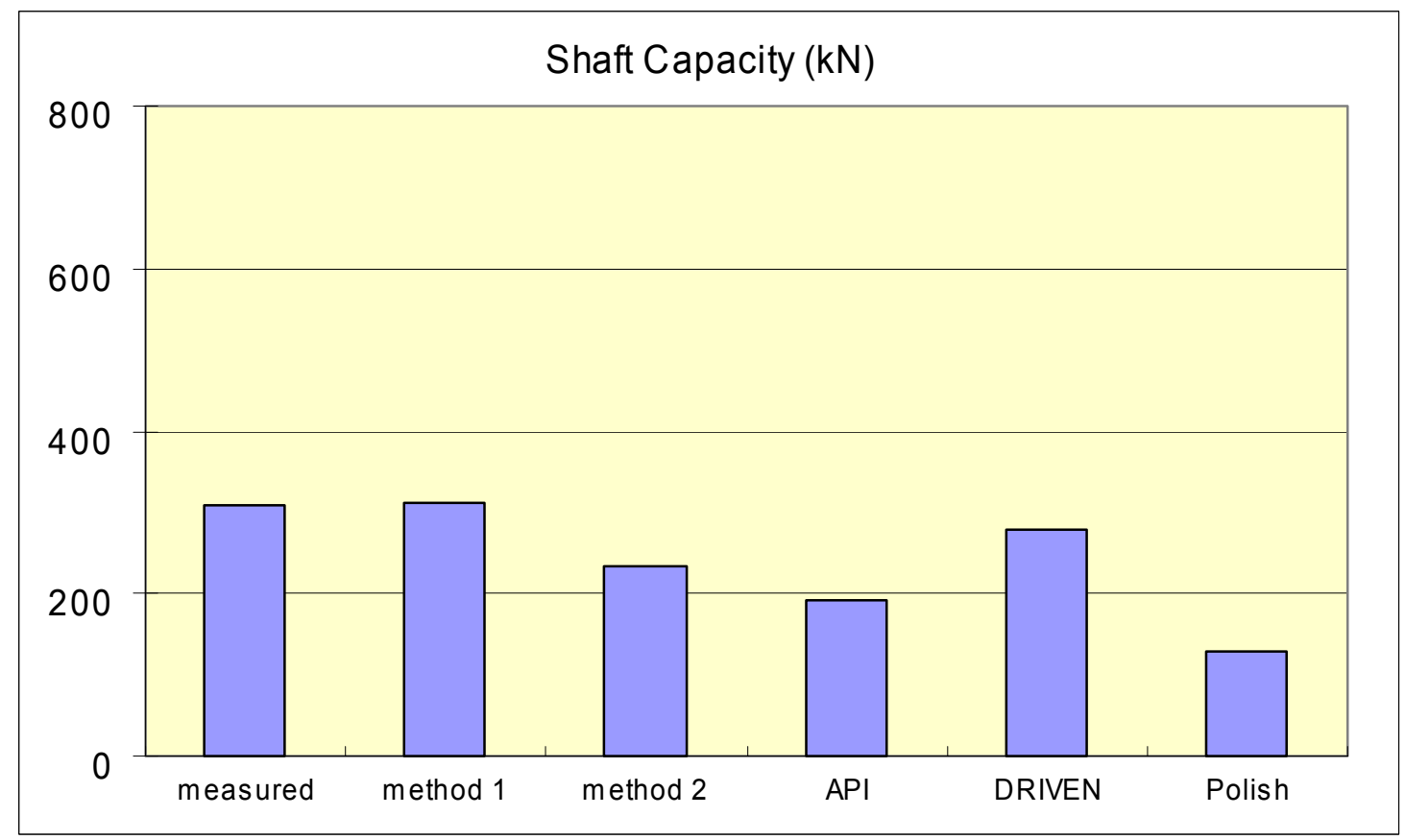

(b)

Figure 6.7 (a) Base capacity and (b) Shaft capacity of the open-ended pile of example 1 


\subsubsection{Example 2}

\section{Soil and Pile data}

Example 2 is based on the pile load test results of Beringen et al. (1979) described in chapter 4. Soil properties and pile dimensions for this example are given in Table 6.8. CPT results in the vicinity of the pile load test are shown in Fig. 6.8.

Table 6.8 Soil properties and pile size of example 2

\begin{tabular}{|c||c|c|}
\hline \multirow{1}{*}{ soil property } & soil type & Dense sand \\
\cline { 2 - 3 } & Average friction angle & $38^{\circ}$ \\
\cline { 2 - 3 } & GWT & $-3.1 \mathrm{~m}$ \\
\hline \multirow{3}{*}{$\begin{array}{c}\text { Open-ended } \\
\text { pile }\end{array}$} & Embedded depth & $7.0 \mathrm{~m}$ \\
\cline { 2 - 3 } & diameter & $356 \mathrm{~mm}$ \\
\hline \multirow{2}{*}{$\begin{array}{c}\text { CLosed-ended } \\
\text { pile }\end{array}$} & Embedded depth & $16 \mathrm{~mm}$ \\
\cline { 2 - 3 } & diameter & $6.75 \mathrm{~m}$ \\
\hline
\end{tabular}

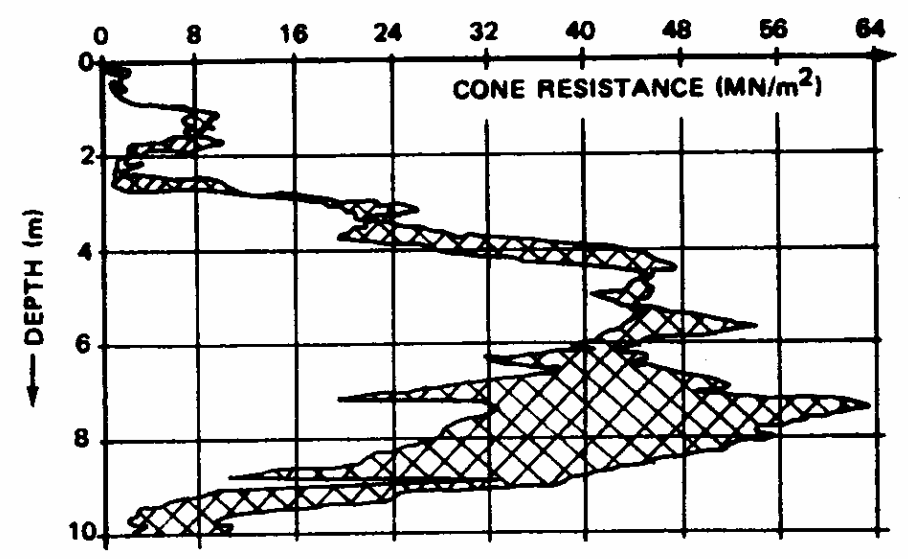

Figure 6.8 CPT profile for pile load test site of example 2. 


\section{Calculations}

Table 6.9 and Figs. 6.9, 6.10 show the calculation results for example 2. As shown in Table 6.9 and Figs. 6.9, 6.10, both proposed methods of chapter 4 and 5 (proposed method 1 and 2) produces results that are in reasonable agreement with measured values for base load capacity (91.6\% and $104.6 \%$ of measured values). For shaft capacity, proposed methods 1 and 2 resulted in $68.0 \%$ and $49.8 \%$ of measured values, suggesting that they may still be conservative. The total capacities computed by DRIVEN, API and polish method were $52.1 \%, 32.7 \%$ and $19.9 \%$ of measured pile load capacity respectively.

Table 6.9 Results of the open-ended pile of example 2

\begin{tabular}{|c|c|c|c|}
\hline & Base Capacity $(\mathrm{kN})$ & Shaft Capacity $(\mathrm{kN})$ & Total Capacity $(\mathrm{kN})$ \\
\hline Measured Capacity & 1390.0 & 830.0 & 2220.0 \\
\hline Proposed method 1 & 1274.1 & 564.2 & 1838.3 \\
\hline Proposed method 2 & 1455.2 & 413.3 & 1868.5 \\
\hline API & 504.2 & 220.8 & 725.0 \\
\hline DRIVEN & 809.8 & 349.0 & 1158.8 \\
\hline Polish & 285.3 & 157.3 & 442.6 \\
\hline
\end{tabular}




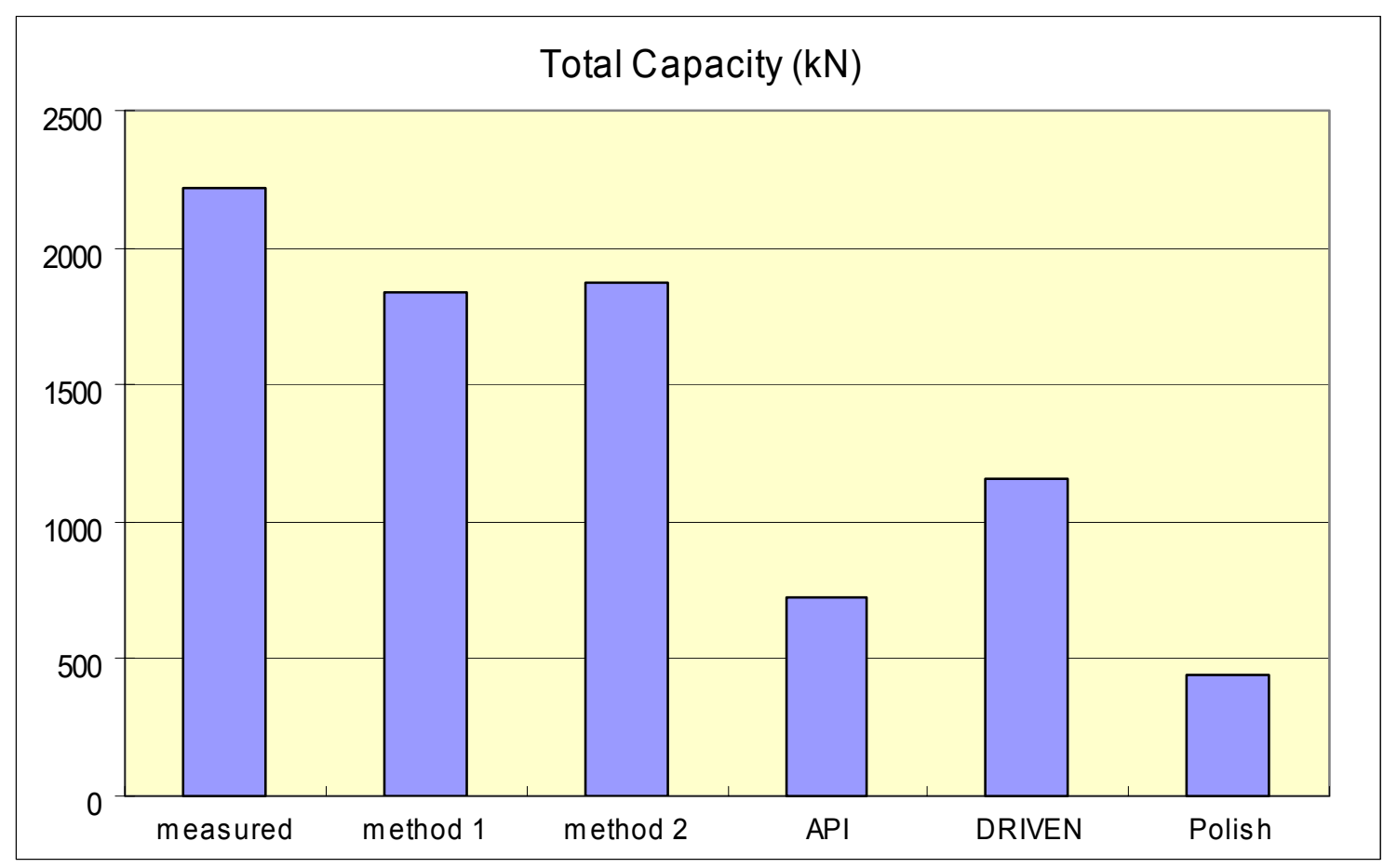

Figure 6.9 Total capacity of the open-ended pile of example 2 


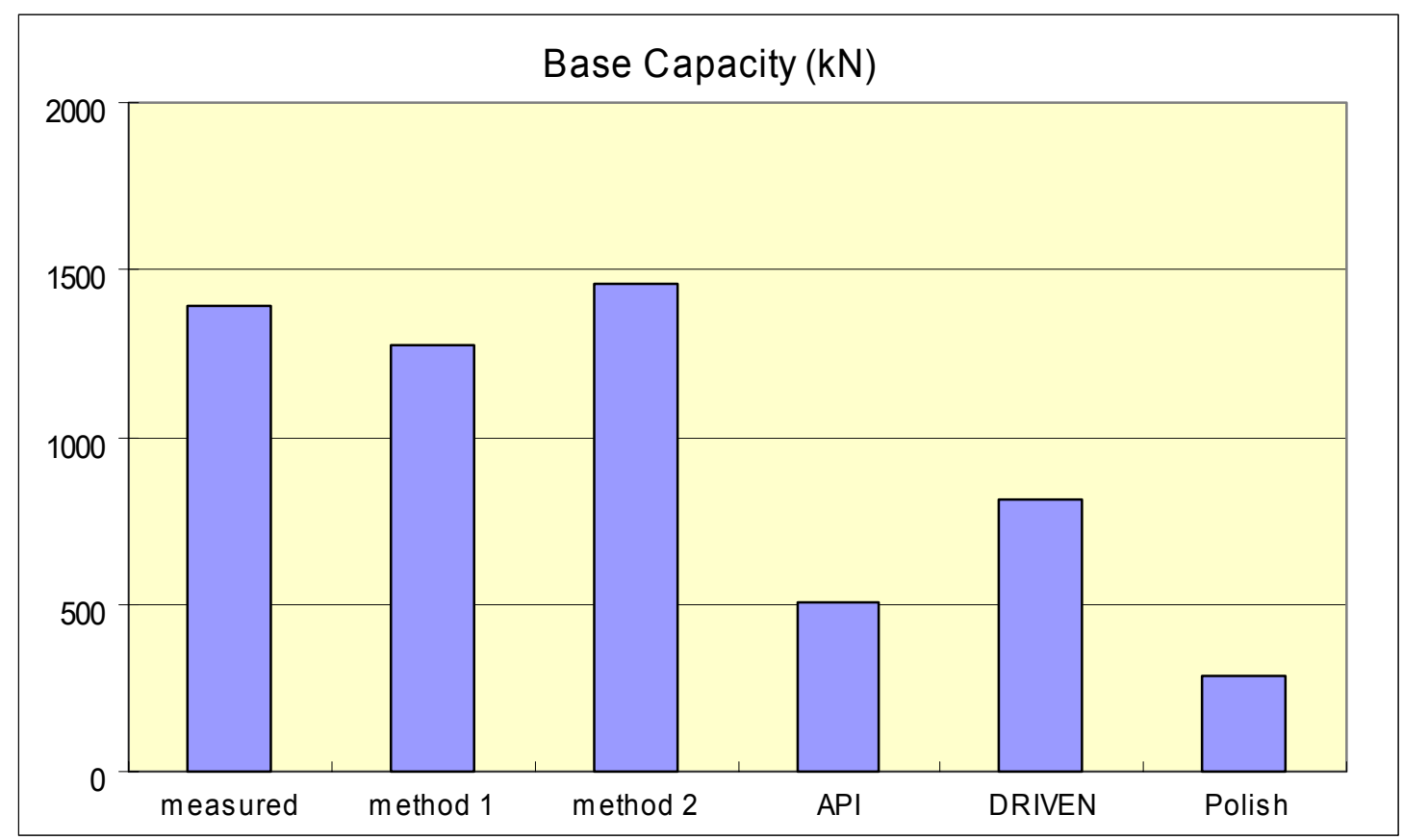

(a)

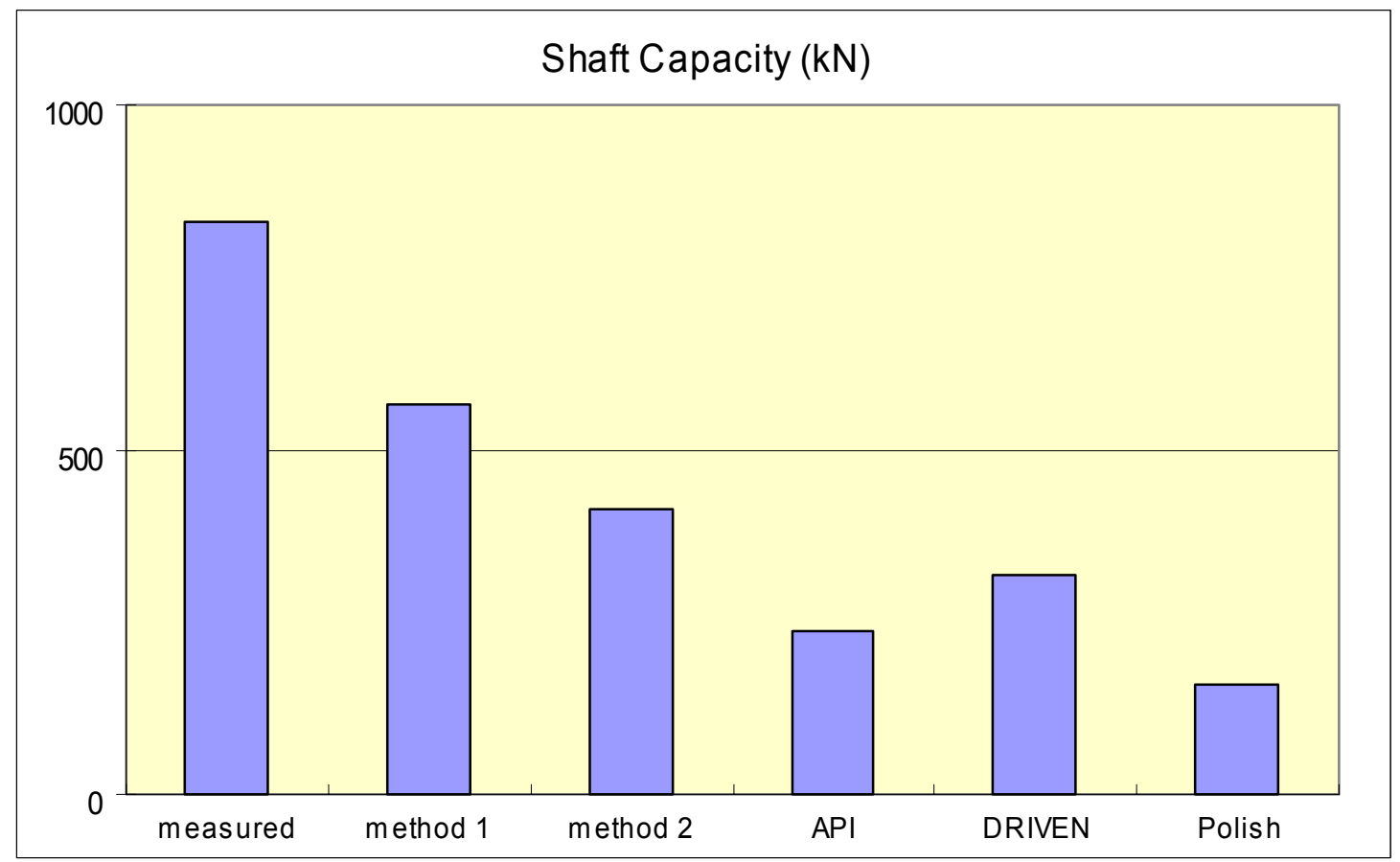

(b)

Figure 6.10 (a) Base capacity and (b) Shaft capacity of the open-ended pile of example 2 


\subsection{Comparison of Design Methods for Closed-Ended Piles}

\subsubsection{Description of Design Methods}

\subsubsection{Meyerhof's Method}

For short piles driven into fairly homogeneous sand, Meyerhof (1983) proposed the following expressions for the base resistance based on SPT results for sands and gravels:

$$
\mathrm{q}_{\mathrm{b}}=0.4 \mathrm{~N}_{\mathrm{s}} \frac{\mathrm{L}_{\mathrm{b}}}{\mathrm{B}} \mathrm{P}_{\mathrm{A}} \leq 4.0 \mathrm{~N}_{\mathrm{s}} \mathrm{P}_{\mathrm{A}}
$$

where $\mathrm{N}_{\mathrm{s}}=$ the average $\mathrm{N}_{\mathrm{SPT}}$ value near the pile base; $\mathrm{P}_{\mathrm{A}} \approx 100 \mathrm{kPa}$ (reference value); $\mathrm{L}_{\mathrm{b}}=$ pile embedment depth; $\mathrm{B}=$ pile diameter. The upper limits of base resistance given in (6.9) are always applied in case of $\mathrm{L}_{b} / \mathrm{B} \geq 10$ for sands and gravels. For pile diameter within the range of $0.5<\mathrm{B} / \mathrm{B}_{\mathrm{R}}<2$, where $\mathrm{B}_{\mathrm{R}}=$ reference length $=1 \mathrm{~m}=40 \mathrm{in}, \mathrm{q}_{\mathrm{b}}$ is reduced using the factor $r_{b}$ as follows:

$$
r_{b}=\left(\frac{B+0.5 B_{R}}{2 B}\right)^{n} \leq 1
$$

where $\mathrm{n}=1,2$, or 3 for loose, medium, or dense sand respectively.

Meyerhof also proposed an expression for shaft resistance for small displacement and large displacement piles in cohesionless soil:

$$
\mathrm{q}_{\mathrm{s}}=\frac{\mathrm{P}_{\mathrm{A}}}{100} \mathrm{~N}_{60}
$$

for small-displacement piles.

$$
\mathrm{q}_{\mathrm{s}}=\frac{\mathrm{P}_{\mathrm{A}}}{50} \mathrm{~N}_{60}
$$

for large-displacement piles. 


\subsubsection{Aoki \& Velloso's SPT Method}

Aoki \& de Alencar Velloso (1975) proposed the following formulas for base and shaft unit resistances for SPT results:

$$
\begin{gathered}
\mathrm{q}_{\mathrm{b}}=\mathrm{n}_{\mathrm{b}} \mathrm{N}_{\mathrm{b}}, \quad \mathrm{n}_{\mathrm{b}}=\frac{\mathrm{K}}{\mathrm{F}_{1}} \\
\mathrm{q}_{\mathrm{si}}=\mathrm{n}_{\mathrm{si}} \mathrm{N}_{\mathrm{si}}, \quad \mathrm{n}_{\mathrm{si}}=\frac{\alpha_{1} \mathrm{~K}}{\mathrm{~F}_{2}}
\end{gathered}
$$

where $\mathrm{n}_{\mathrm{b}}=$ factor to convert SPT blow count to base resistance; $\mathrm{n}_{\mathrm{si}}=$ factor to convert SPT blow count to shaft resistance for layer $\mathrm{i} ; \mathrm{N}_{\mathrm{b}}=$ representative $\mathrm{N}_{\mathrm{SPT}}$ value along the pile base level; $\mathrm{N}_{\mathrm{si}}$ $=$ representative $\mathrm{N}_{\mathrm{SPT}}$ value along the pile shaft in layer $\mathrm{i} ; \mathrm{K}, \alpha_{1}=$ empirical factors depending on soil type (Table 6.10); $\mathrm{F}_{1}, \mathrm{~F}_{2}=$ empirical factors for different pile types (Table 6.11).

Table 6.10 Values of $\mathrm{K}$ and $\alpha$ for different soil types.

\begin{tabular}{|l|c|c|}
\hline \multicolumn{1}{|c|}{ Type of Soil } & $\mathrm{K}$ & $\alpha_{1}(\%)$ \\
\hline Sand & 10.0 & 1.4 \\
Silty sand & 8.0 & 2.0 \\
Clayly silty sand & 7.0 & 2.4 \\
Clayey sand & 6.0 & 3.0 \\
Silty clayey sand & 5.0 & 2.8 \\
\hline Silt & 4.0 & 3.0 \\
Sandy silt & 5.5 & 2.2 \\
Clayey sandy silt & 4.5 & 2.8 \\
Clayey silt & 2.3 & 3.4 \\
Sandy clayey silt & 2.5 & 3.0 \\
\hline Clay & 2.0 & 6.0 \\
Sandy clay & 3.5 & 2.4 \\
Sandy silty clay & 3.0 & 2.8 \\
Silty clay & 2.2 & 4.0 \\
Silty sandy clay & 3.3 & 3.0 \\
\hline
\end{tabular}


Table 6.11 Values of $F_{1}$ and $F_{2}$ for different pile types.

\begin{tabular}{|l||c|c|}
\hline \multicolumn{1}{|c|}{ Type of Pile } & $\mathrm{F}_{1}$ & $\mathrm{~F}_{2}$ \\
\hline Franki Piles & 2.50 & 5.0 \\
Steel Piles & 1.75 & 3.5 \\
Precast Concrete Piles & 1.75 & 3.5 \\
Bored Piles & $3.0-3.50$ & $6.0-7.0$ \\
\hline
\end{tabular}

\subsubsection{Bazaraa and Kurkur's Method}

From Egyptian experience, Bazaara and Kurkur (1986) found correlations for $\mathrm{q}_{\mathrm{b}}$ and $\mathrm{q}_{\mathrm{s}}$ with $\mathrm{N}_{\mathrm{SPT}}$ according to pile type and quality of installation. The proposed pile categories and factors are given in Table 6.12 and 6.13 .

$$
\mathrm{q}_{\mathrm{b}}=\mathrm{n}_{\mathrm{b}} \mathrm{N}_{\mathrm{b}}, \quad \mathrm{q}_{\mathrm{si}}=\mathrm{n}_{\mathrm{si}} \mathrm{N}_{\mathrm{si}}
$$

Table 6.12 Pile categories for selection of $n_{s}$ and $n_{b}$ according to Bazaraa \& Kurkur (1986)

\begin{tabular}{|c|l|}
\hline Pile category & \multicolumn{1}{c|}{ Pile description } \\
\hline I & Prepakt piles using high-pressure mortar injection \\
\hline II & $\begin{array}{l}\text { Driven piles, Bauer piles with careful execution, and Prepakt } \\
\text { piles with low injection pressure }\end{array}$ \\
\hline III & $\begin{array}{l}\text { Bored piles with careful execution and Bauer piles with } \\
\text { some defects in execution }\end{array}$ \\
\hline IV & Bored piles with some defects in execution \\
\hline
\end{tabular}


Table 6.13 Factors $\mathrm{n}_{\mathrm{s}}$ and $\mathrm{n}_{\mathrm{b}}$ according to Bazaraa \& Kurkur (1986)

\begin{tabular}{|c|l|l|}
\hline Pile categories & \multicolumn{1}{|c|}{ Cohesionless soil } & Cohesive soil \\
\hline & $\begin{array}{c}\text { For } \mathrm{B} / \mathrm{B}_{\mathrm{R}} \leq 0.5: \\
\mathrm{n}_{\mathrm{s}}=0.022 \mathrm{P}_{\mathrm{A}} ; \mathrm{n}_{\mathrm{b}}=2 \mathrm{P}_{\mathrm{A}} \\
\text { I and II }\end{array}$ & $\begin{array}{l}\mathrm{n}_{\mathrm{s}}=0.033 \mathrm{P}_{\mathrm{A}} \\
\mathrm{n}_{\mathrm{b}}=0.6 \mathrm{P}_{\mathrm{A}}\end{array}$ \\
\hline & $\mathrm{n}_{\mathrm{s}}=0.044 \mathrm{P}_{\mathrm{A}} \mathrm{B} / \mathrm{B}_{\mathrm{R}} ; \mathrm{n}_{\mathrm{b}}=4 \mathrm{P}_{\mathrm{A}} \mathrm{B} / \mathrm{B}_{\mathrm{R}}$ & \\
\hline III and IV & $\begin{array}{l}\text { For } \mathrm{B} / \mathrm{B}_{\mathrm{R}} \leq 0.5: \\
\mathrm{n}_{\mathrm{s}}=0.0067 \mathrm{P}_{\mathrm{A}} ; \mathrm{n}_{\mathrm{b}}=1.35 \mathrm{P}_{\mathrm{A}}\end{array}$ & $\begin{array}{l}\mathrm{n}_{\mathrm{s}}=0.02 \mathrm{P}_{\mathrm{A}} \\
\mathrm{n}_{\mathrm{b}}=0.4 \mathrm{P}_{\mathrm{A}}\end{array}$ \\
& $\begin{array}{l}\text { For } \mathrm{B} / \mathrm{B}_{\mathrm{R}}>0.5: \\
\mathrm{n}_{\mathrm{s}}=0.0134 \mathrm{P}_{\mathrm{A}} \mathrm{B} / \mathrm{B}_{\mathrm{R}} ; \mathrm{n}_{\mathrm{b}}=2.7 \mathrm{P}_{\mathrm{A}} \mathrm{B} / \mathrm{B}_{\mathrm{R}}\end{array}$ & \\
\hline
\end{tabular}

\subsubsection{LCPC Method}

After numerous CPT tests compared with load tests on several pile types, Bustamante and Gianeselli (1982) presented a pile design method using factors related to both pile and soil types. The basic formula for the LCPC method can be written as:

$$
\begin{aligned}
\mathrm{q}_{\mathrm{b}} & =\mathrm{c}_{\mathrm{b}} \mathrm{q}_{\mathrm{c}} \\
\mathrm{q}_{\mathrm{si}} & =\mathrm{c}_{\mathrm{si}} \mathrm{q}_{\mathrm{ci}}, \quad \mathrm{c}_{\mathrm{si}}=\frac{1}{\alpha_{2}}
\end{aligned}
$$

where $\mathrm{c}_{\mathrm{b}}=$ base resistance factor; $\mathrm{q}_{\mathrm{c}}=$ equivalent cone resistance at pile base level; $\mathrm{c}_{\mathrm{si}}=$ shaft resistance factor; $\mathrm{q}_{\mathrm{ci}}=$ representative cone resistance for the corresponding layer. The values of $\mathrm{c}_{\mathrm{b}}$ and $\mathrm{c}_{\mathrm{si}}$ depend on the nature of the soil and its density as well as the pile installation method. Table 6.14 and 6.15 show the values of $\alpha_{2}$ and $c_{s i}$ with different soil and pile types. The 
equivalent cone resistance $\mathrm{q}_{\mathrm{ca}}$ represents an arithmetical mean of the cone resistance measured along the distance equal to $1.5 \mathrm{~B}$ above and below the pile base.

Table 6.14 Values of $\alpha_{2}$ for different soil and pile types

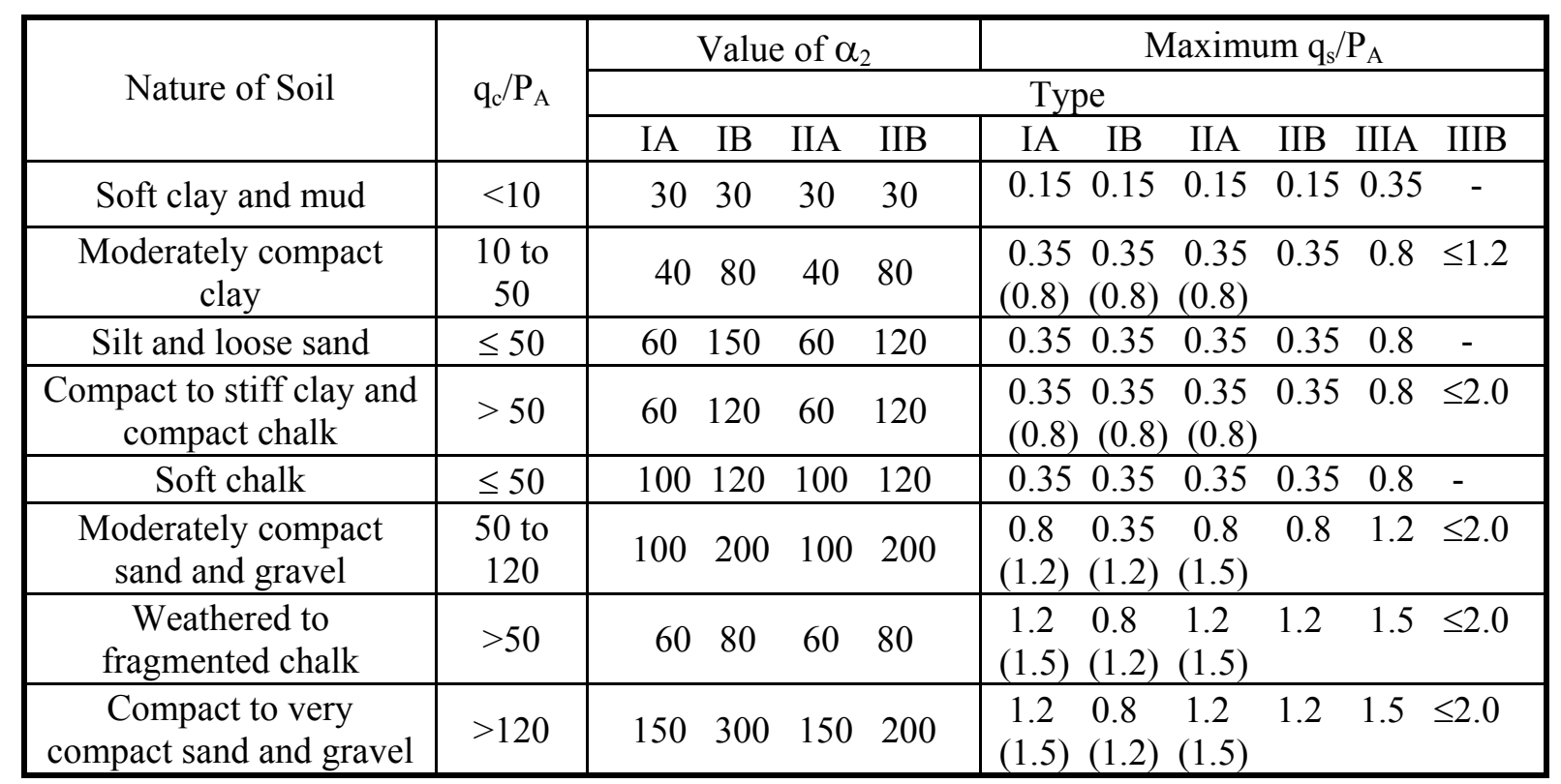

- $\mathrm{P}_{\mathrm{A}}=$ reference stress $=100 \mathrm{kPa}=0.1 \mathrm{MPa}=1 \mathrm{tsf}$

- Type IA: Plane bored piles, mud bored piles, hollow auger piles, cast screwed piles, piers, barrettes, and micropiles with low injection pressure.

- Type IB: Bored piles with steel casing and driven cast piles.

- Type IIA: Driven or jacted precast piles and prestressed concrete piles.

- Type IIB: Driven or jacked steel piles.

- Type IIIA: High pressure grouted piles with diameter greater than $250 \mathrm{~mm}$ and micropiles installed with high injection pressure. 
Table 6.15 Values of $c_{b}$ for different soil and pile types.

\begin{tabular}{|l|c|c|c|}
\hline \multirow{2}{*}{ Nature of Soil } & \multirow{2}{*}{$\mathrm{q}_{\mathrm{c}} / \mathrm{P}_{\mathrm{A}}$} & \multicolumn{2}{|c|}{ Value of $\mathrm{c}_{\mathrm{b}}$} \\
\cline { 3 - 4 } & & Group I & Group II \\
\hline Soft clay and mud & $<10$ & 0.40 & 0.50 \\
Moderately compact clay & 10 to 50 & 0.35 & 0.45 \\
Silt and loose sand & $\leq 50$ & 0.40 & 0.50 \\
Compact to stiff clay and compact silt & $>50$ & 0.45 & 0.55 \\
Soft chalk & $\leq 50$ & 0.20 & 0.30 \\
Moderately compact sand and gravel & 50 to 120 & 0.40 & 0.50 \\
Weathered to fragmented chalk & $>50$ & 0.20 & 0.40 \\
Compact to very compact sand and gravel & 120 & 0.30 & 0.40 \\
\hline
\end{tabular}

\subsubsection{Aoki \& Velloso's CPT Method}

Based on load test and CPT results, Aoki \& de Alencar Velloso (1975) defined the $c_{b}$ and $\mathrm{c}_{\mathrm{si}}$ resistance factors as follows:

$$
\begin{aligned}
& \mathrm{q}_{\mathrm{b}}=\mathrm{c}_{\mathrm{b}} \mathrm{q}_{\mathrm{c}}, \quad \mathrm{c}_{\mathrm{b}}=\frac{1}{\mathrm{~F}_{1}} \\
& \mathrm{q}_{\mathrm{si}}=\mathrm{c}_{\mathrm{si}} \mathrm{q}_{\mathrm{si}}, \quad \mathrm{c}_{\mathrm{si}}=\frac{\alpha_{1}}{\mathrm{~F}_{2}}
\end{aligned}
$$

where $c_{b}=$ factor to convert from $q_{c}$ to base resistance; $c_{s i}=$ factor to convert from $q_{c}$ to shaft resistance for layer $\mathrm{i} ; \mathrm{q}_{\mathrm{c}}=$ representative cone resistance for layer $\mathrm{I} ; \mathrm{F}_{1}, \mathrm{~F}_{2}$, and $\alpha_{1}$ are empirical factors given in Tables 6.10 and 6.11. 


\subsubsection{Predicted and Measured Pile load Capacity Calculations}

\subsubsection{Example 1}

The data for this example were provided under 6.2.2.1. Calculated results for each method used for the closed-ended pile described in 6.2.2.1 are shown in Table 6.16 and Figs. 6.11, 6.12. The base and shaft load capacities from the CPT-based method proposed in chapter 5 (proposed method 2) were $100.4 \%$ and $73.2 \%$ of measured values. As shown in Fig. 6.11, the methods based on SPT results produced a wide range of predicted values: Bazaraa's SPT method resulted in significantly conservative prediction, while Aoki's method give base capacity values higher than the measured results. The DRIVEN program of FHWA also produced significantly conservative results, showing $50.2 \%$ and $32.3 \%$ of measured base and shaft load capacity.

Table 6.16 Results of the closed-ended pile of example 1

\begin{tabular}{|c|c|c|c|c|}
\hline \multicolumn{2}{|c||}{} & Base Capacity $(\mathrm{kN})$ & Shaft Capacity $(\mathrm{kN})$ & Total Capacity $(\mathrm{kN})$ \\
\hline \multicolumn{2}{|c|}{ Measured Capacity } & 866.0 & 633.0 & 1499.0 \\
\hline \multicolumn{2}{|c|}{ Proposed Method 2 } & 870.0 & 474.8 & 1344.8 \\
\hline \multirow{3}{*}{ SPT } & Meyerhof & 1035.0 & 245.2 & 1280.2 \\
\cline { 2 - 5 } & Aoki & 1251.3 & 416.7 & 1668.0 \\
\cline { 2 - 5 } & Bazaraa & 517.6 & 269.7 & 787.3 \\
\hline \multirow{3}{*}{ CPT } & LCPC & 756.5 & 459.3 & 1215.8 \\
\cline { 2 - 5 } & Aoki & 1079.9 & 337.9 & 1417.8 \\
\hline \multicolumn{2}{|c|}{ DRIVEN } & 434.6 & 204.3 & 638.9 \\
\hline
\end{tabular}




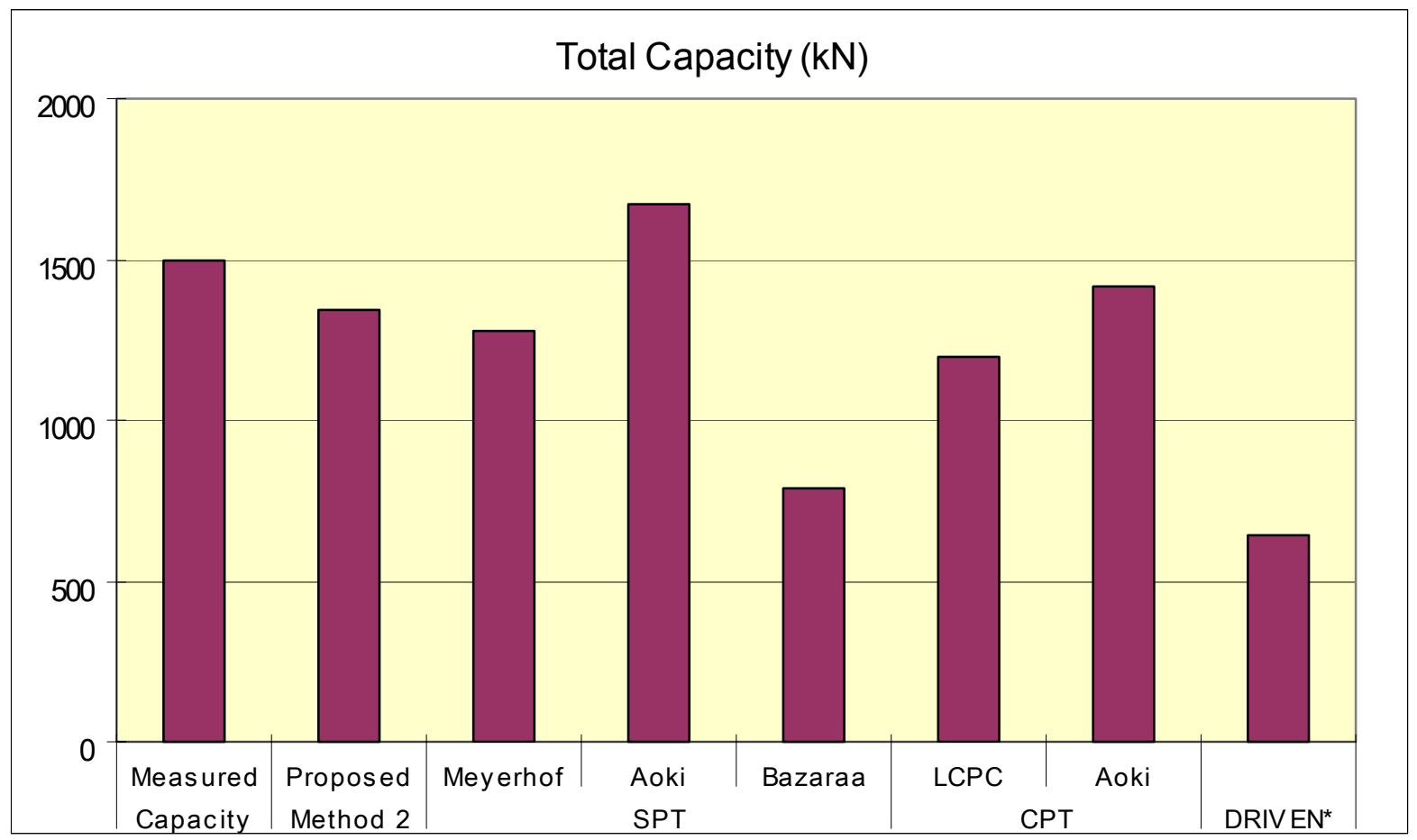

* The program DRIVEN calculates base resistance using Thurman and Meyerhof methods and shaft resistance using Nordlund method

Figure 6.11 Total capacity of the closed-ended pile of example 1 


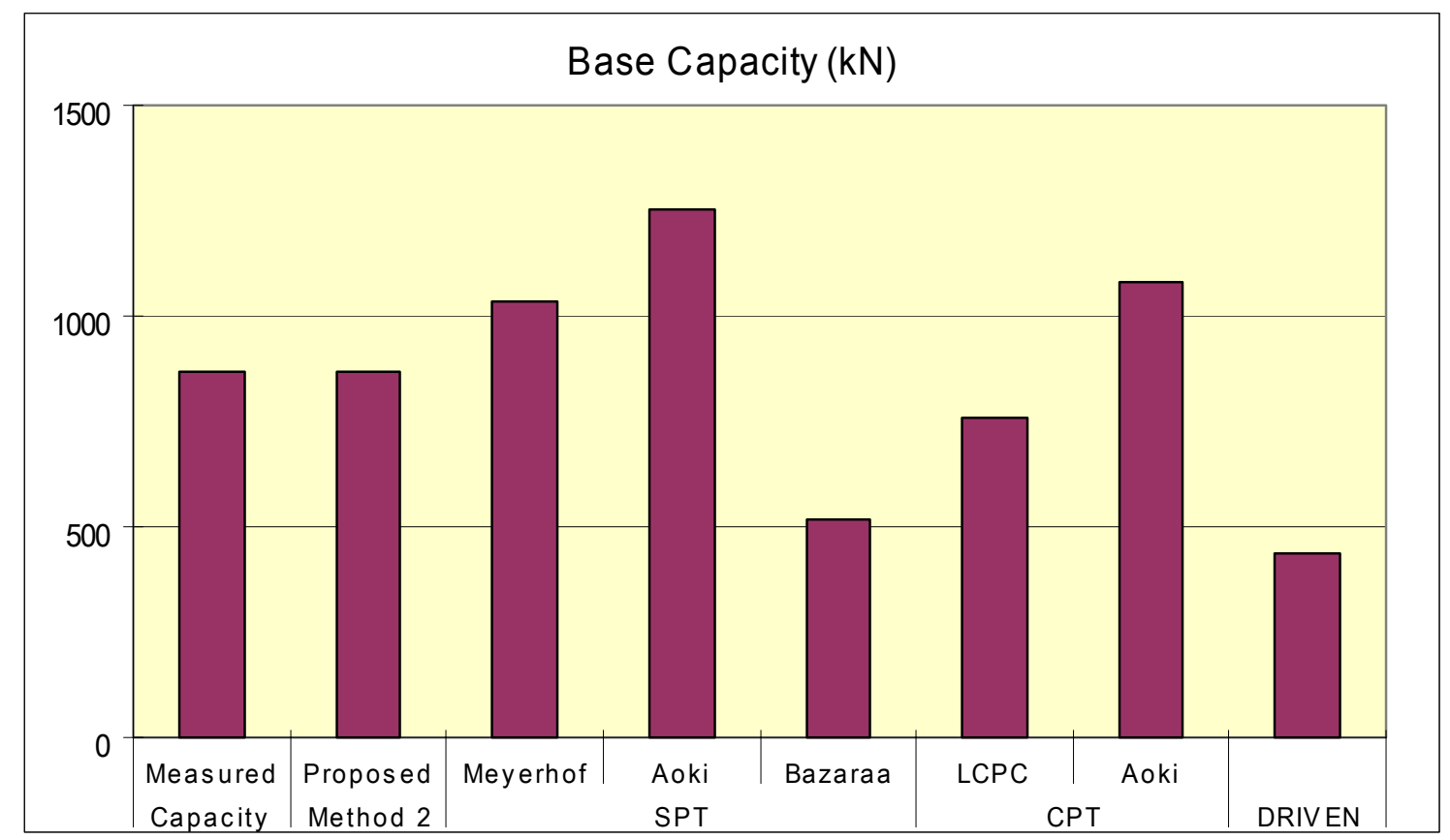

(a)

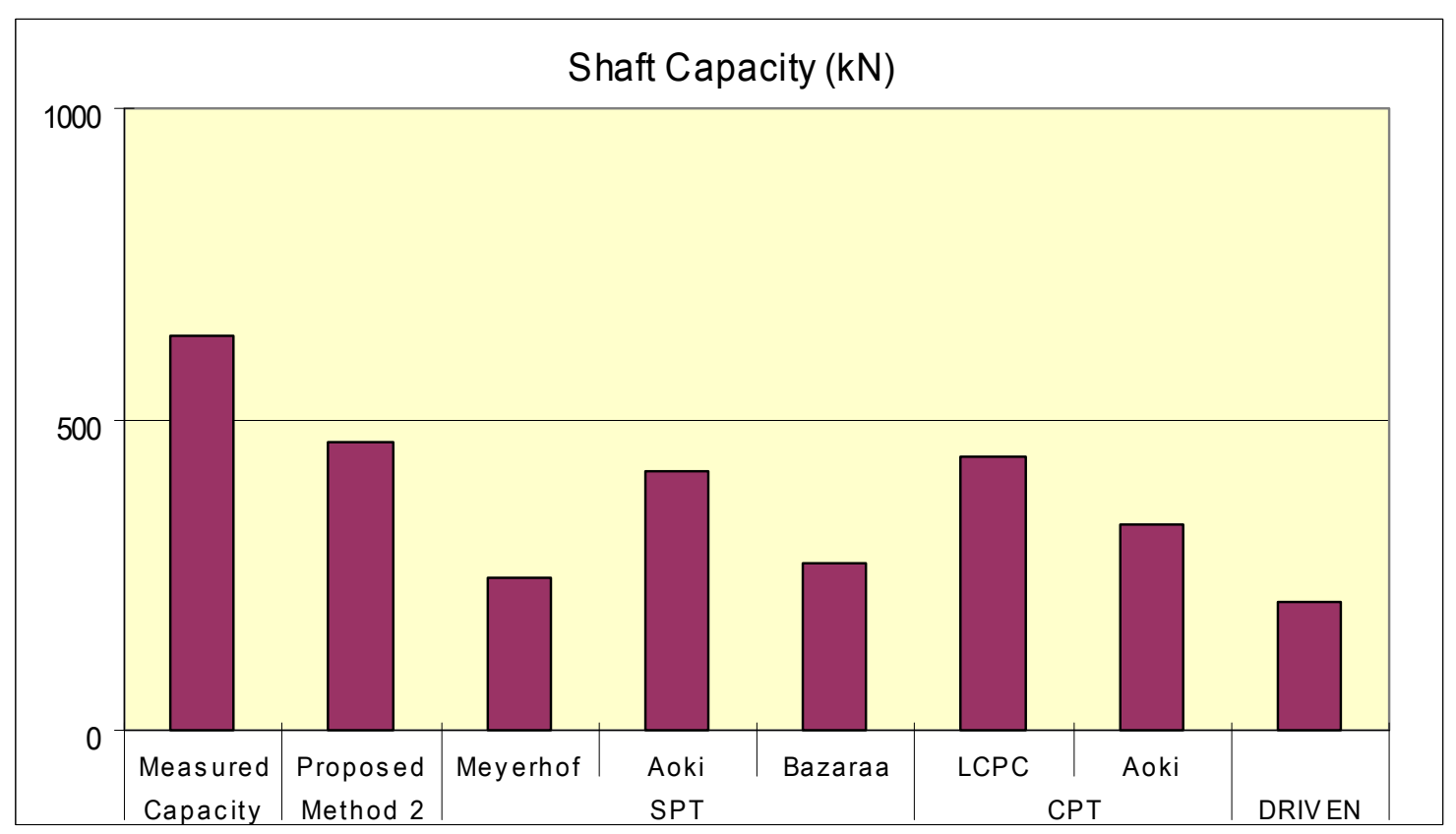

(b)

Figure 6.12 (a) Base capacity and (b) Shaft capacity of the closed-ended pile of example 1 


\subsubsection{Example 2}

The data for this example were provided under 6.2.2.2. Table 6.17 and Figs. 6.13, 6.14 show the calculation results for the closed-ended pile of example 2. The base and shaft load capacity from the pile load test were $1701 \mathrm{kN}$ and $1113 \mathrm{kN}$ at a settlement of $10 \%$ of the pile diameter. As explained in chapter 4, the measured base load capacity was obtained by subtracting the shaft load capacity in tension from the total load capacity in compression. As shown in Fig. 6.13, The CPT-based method of chapter 5 (proposed method 2) produced load capacity values very close to the measured values, $95.6 \%$ and $99.1 \%$ of measured base and shaft load capacities. The LCPC method also produced values in good agreement with measured values, while the results of Aoki and Velloso showed unconservative results. The computed total capacity by DRIVEN was $39.9 \%$ of measured load capacity.

Table 6.17 Results of the closed-ended pile of example 2

\begin{tabular}{|c||c|c|c|}
\hline & Base Capacity $(\mathrm{kN})$ & Shaft Capacity $(\mathrm{kN})$ & Total Capacity $(\mathrm{kN})$ \\
\hline Measured Capacity & 1701.0 & 1113.0 & 2814.0 \\
\hline Proposed Method 2 & 1626.5 & 1102.6 & 2729.1 \\
\hline LCPC & 1712.1 & 833.3 & 2545.4 \\
\hline Aoki \& Velloso & 2444.0 & 664.1 & 3108.1 \\
\hline DRIVEN & 787.5 & 336.3 & 1123.8 \\
\hline
\end{tabular}




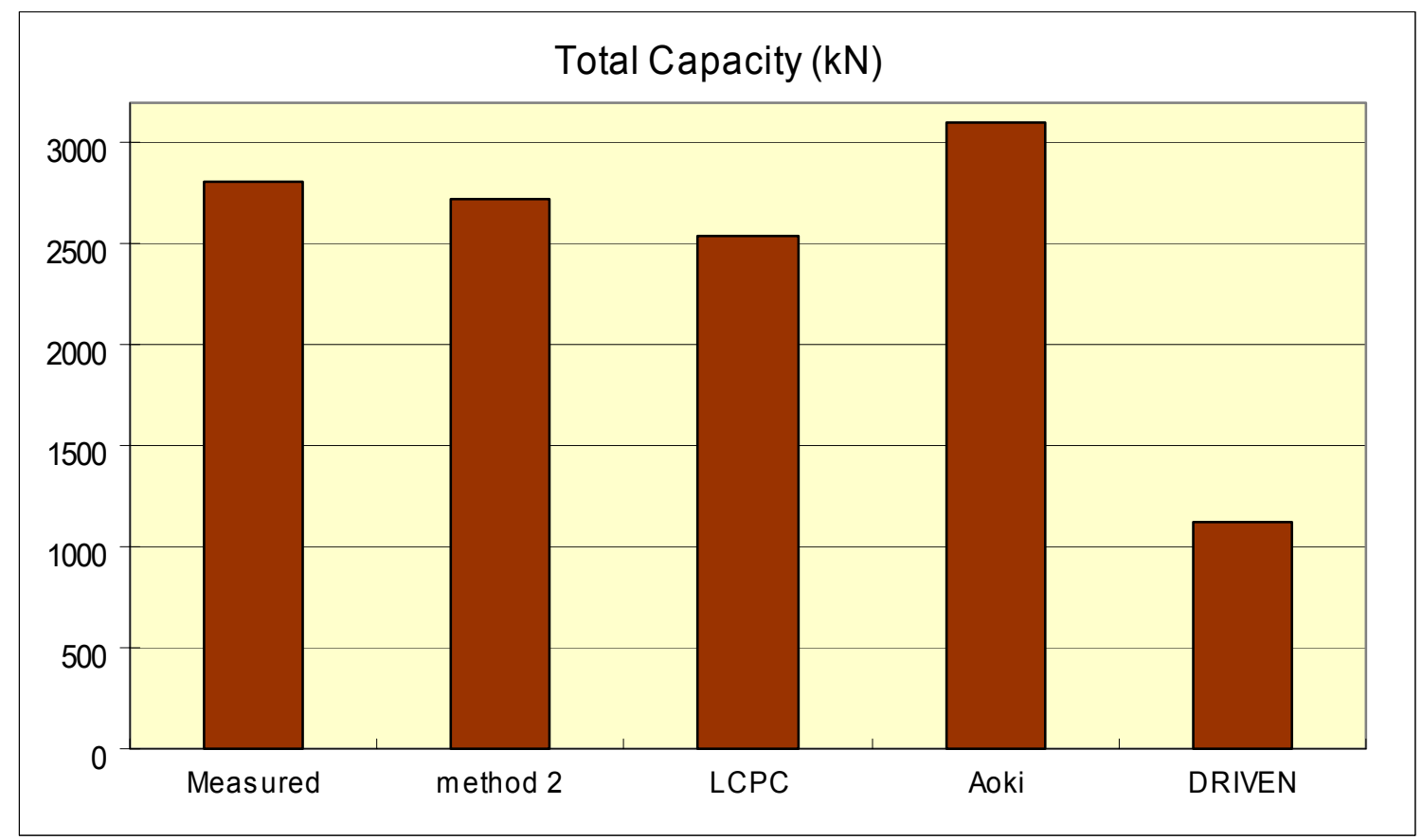

Figure 6.13 Total capacity of the closed-ended pile of example 2 


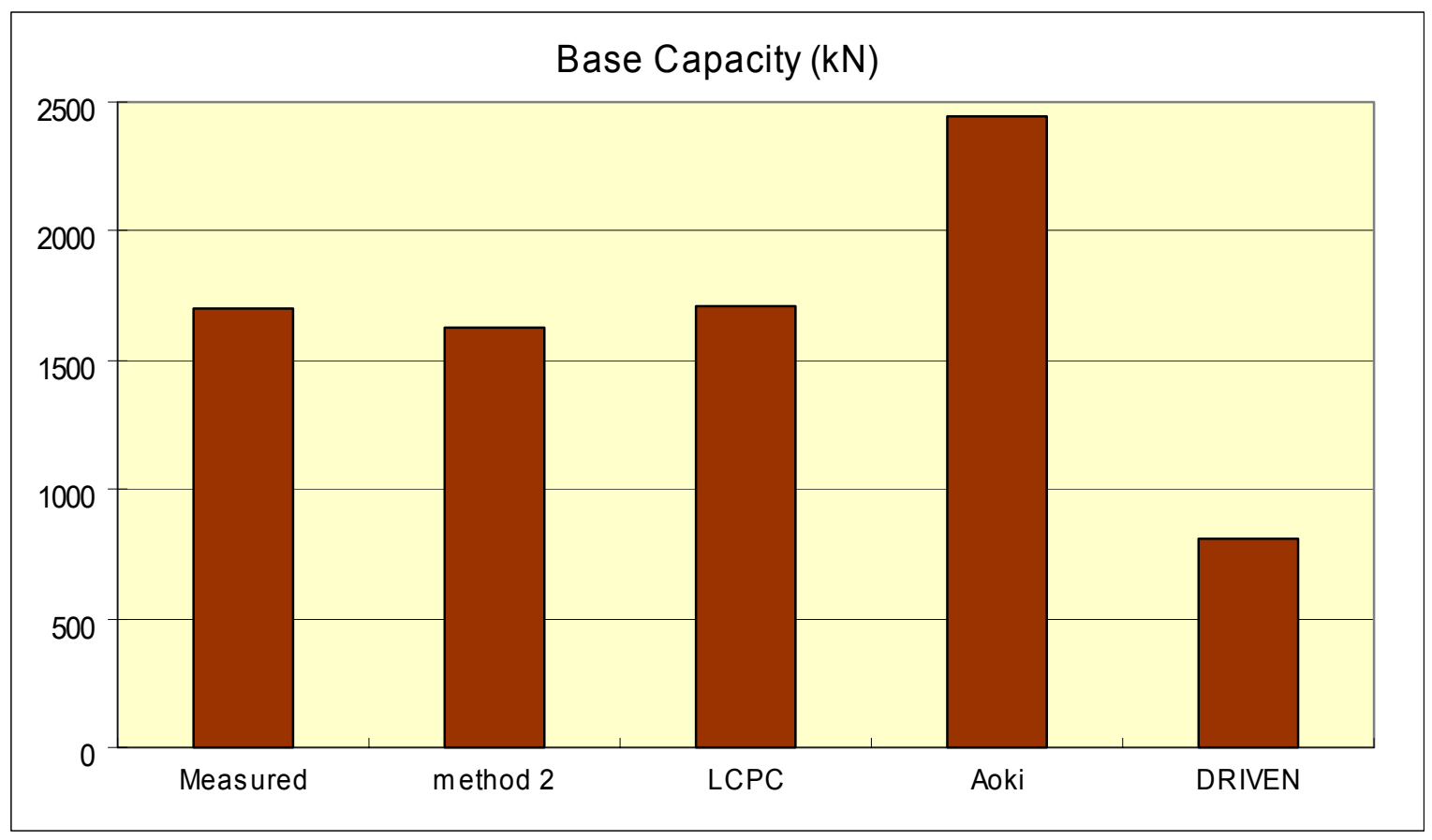

(a)

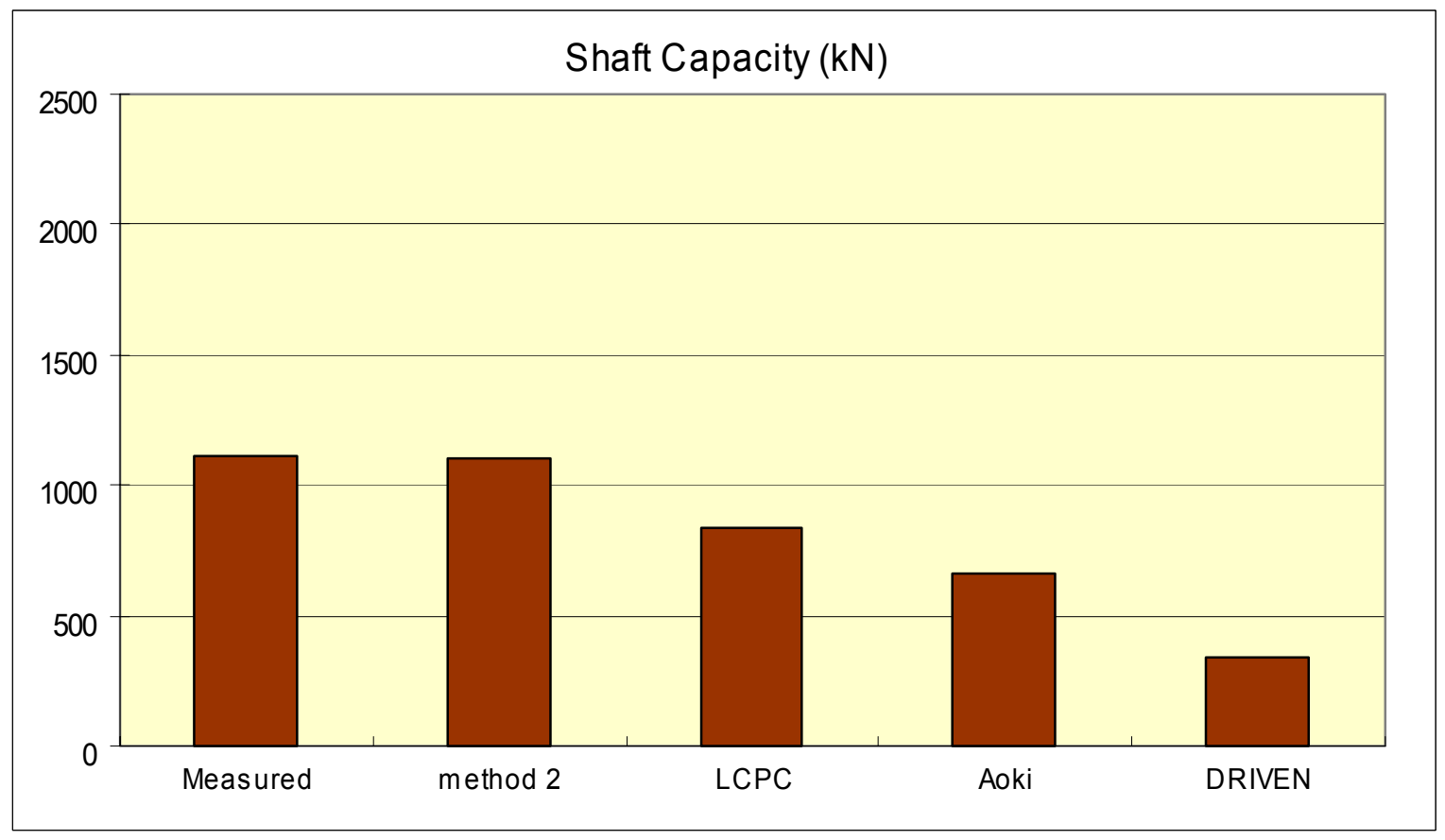

(b)

Figure 6.14 (a) Base capacity and (b) Shaft capacity of the closed-ended pile of example 2 


\subsection{Cost Evaluation}

In this section, we show some calculations that illustrate the impact on costs of using each of the design methods discussed previously for the foundations of a typical bridge. Fig. 6.15 shows a schematic plot of the bridge carrying S.R. 157 over Lemon Creek in Indiana, which has deep pile foundations supporting both bents. The total load, which has to be carried by the piles, is $2970.5 \mathrm{kN}$ per bent. The dead load is $1,484.1 \mathrm{kN}$ and the live load is $1,486.4 \mathrm{kN}$.

It is assumed that the soil profile at the construction site is the same as that where the field pile load tests of chapter 3 were performed. Therefore, the total capacities and pile size of example 1 obtained in the previous section can be used for the cost estimation.

For the given design load, the numbers of piles for a bent and costs associated with each pile design method are given in Tables 6.18 and 6.19. The unit cost for installation of a driven pile foundation was based on Indiana Pay Item Specification (INDOT), which is $\$ 150$ per meter of pile length.

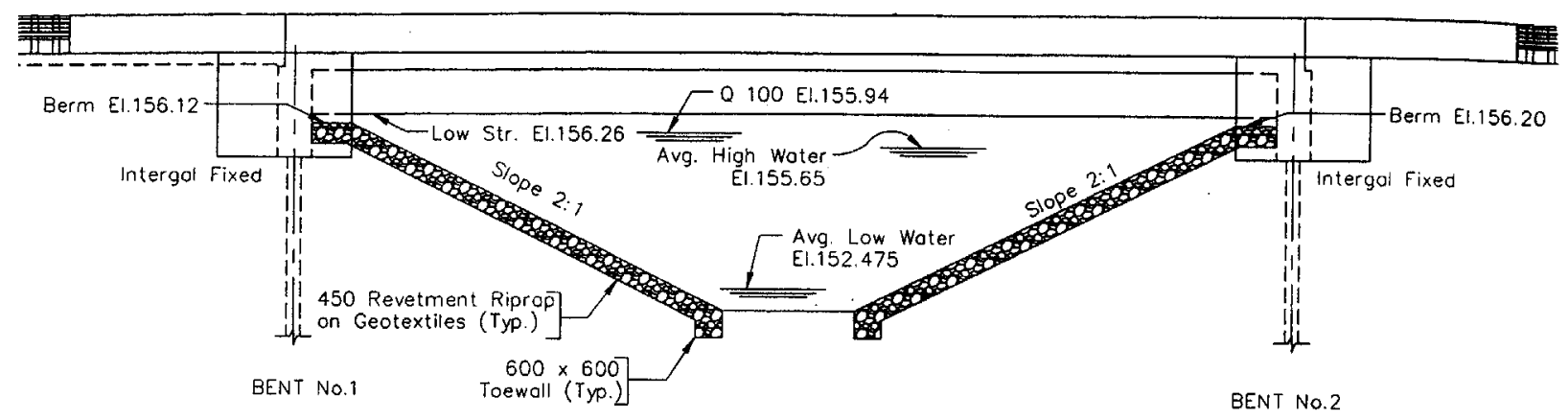

igure 6.15 Schematic plot of the bridge carrying S.R. 157 over Lemon Creek 


\section{(1) Open-ended pile}

Table 6.18 Cost evaluation for open-ended pile foundations

\begin{tabular}{|c||c|c|c|c|c|}
\hline & $\begin{array}{c}\text { Ultimate load } \\
\text { capacity }(\mathrm{kN})\end{array}$ & $\begin{array}{c}\text { Design Load } \\
\text { Capacity }(\mathrm{kN})\end{array}$ & $\begin{array}{c}\text { required pile } \\
\text { humber(per bent) }\end{array}$ & $\begin{array}{c}\text { Total pile } \\
\text { length }(\mathrm{m})\end{array}$ & $\begin{array}{c}\text { Total cost } \\
(\$)\end{array}$ \\
\hline Measured & 1025.0 & 410.0 & $7.24 \Rightarrow 8$ & 112 & 16,800 \\
\hline Method 1 & 852.3 & 340.9 & $8.71 \Rightarrow 9$ & 126 & 18,900 \\
\hline Method 2 & 976.9 & 390.8 & $7.60 \Rightarrow 8$ & 112 & 16,800 \\
\hline API & 665.8 & 266.3 & $11.15 \Rightarrow 12$ & 168 & 25,200 \\
\hline DRIVEN & 722.1 & 288.8 & $10.28 \Rightarrow 11$ & 154 & 23,100 \\
\hline Polish & 377.5 & 151.0 & $19.67 \Rightarrow 20$ & 280 & 42,000 \\
\hline
\end{tabular}

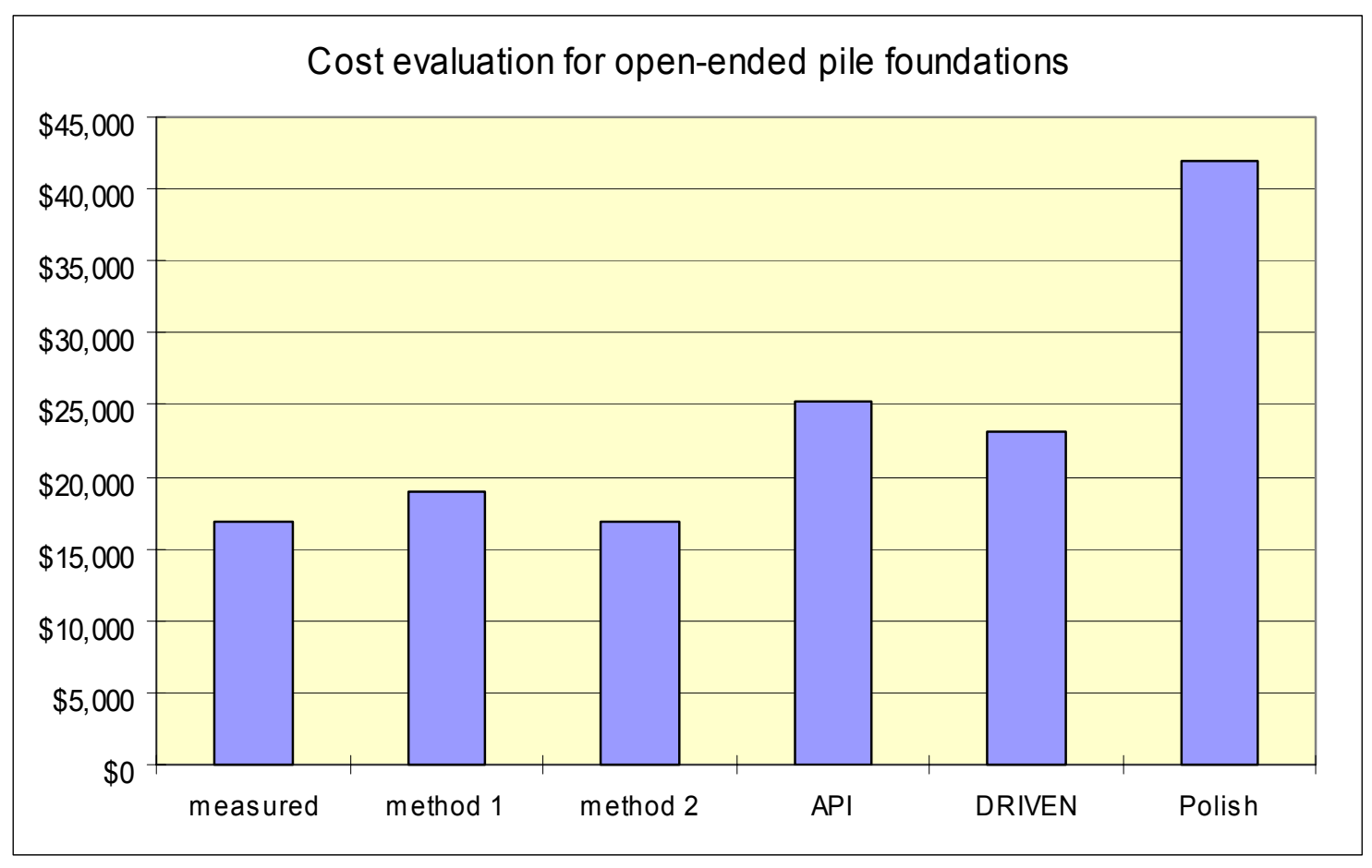

Figure 6.16 Cost evaluation of open-ended pile foundations 
(2) Closed-ended pile

Table 6.19 Cost evaluation for closed-ended pile foundations

\begin{tabular}{|c|c|c|c|c|c|c|}
\hline \multicolumn{2}{|c||}{} & $\begin{array}{c}\text { Ultimate load } \\
\text { capacity }(\mathrm{kN})\end{array}$ & $\begin{array}{c}\text { Design Load } \\
\text { Capacity }(\mathrm{kN})\end{array}$ & $\begin{array}{c}\text { required pile } \\
\text { number }\end{array}$ & $\begin{array}{c}\text { Total pile } \\
\text { length }(\mathrm{m})\end{array}$ & $\begin{array}{c}\text { Total } \\
\text { cost }(\$)\end{array}$ \\
\hline \multirow{2}{*}{ Measured } & 1499.0 & 599.6 & $4.95 \Rightarrow 5$ & 70 & 10,500 \\
\hline \multirow{2}{*}{ Method 2 } & 1344.8 & 537.4 & $5.52 \Rightarrow 6$ & 84 & 12,600 \\
\hline \multirow{2}{*}{ SPT } & Meyerhof & 1280.2 & 512.1 & $5.80 \Rightarrow 6$ & 84 & 12,600 \\
\cline { 2 - 7 } & Aoki & 1668.0 & 667.2 & $4.45 \Rightarrow 5$ & 70 & 10,500 \\
\cline { 2 - 7 } & Bazaraa & 787.3 & 314.9 & $9.43 \Rightarrow 10$ & 140 & 21,000 \\
\hline \multirow{3}{*}{ CPT } & LCPC & 1215.8 & 486.3 & $6.11 \Rightarrow 7$ & 98 & 14,700 \\
\cline { 2 - 7 } & Aoki & 1417.8 & 567.1 & $5.24 \Rightarrow 6$ & 84 & 12,600 \\
\hline \multirow{2}{*}{ DRIVEN } & 638.9 & 255.6 & $11.62 \Rightarrow 12$ & 168 & 25,200 \\
\hline
\end{tabular}

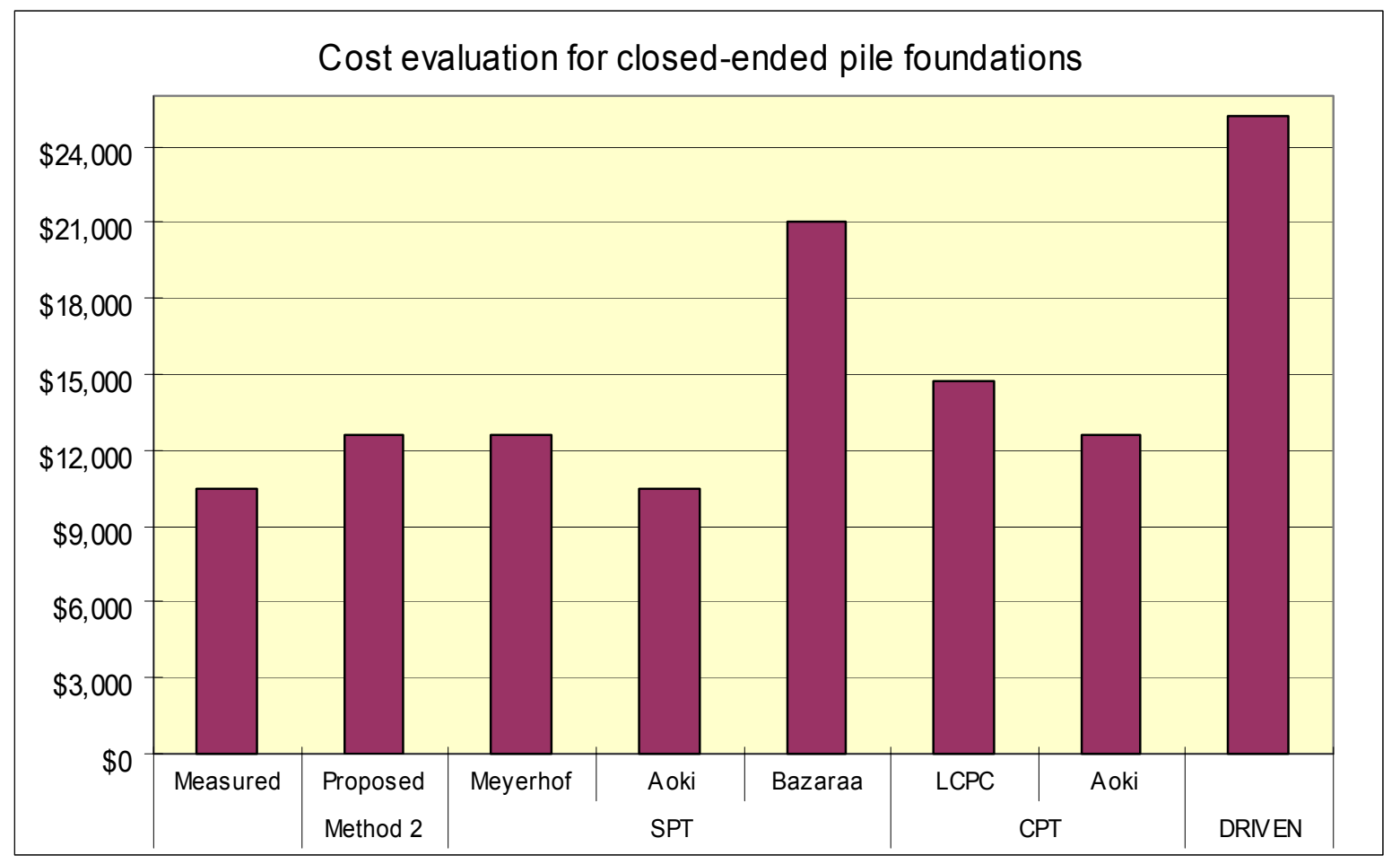

Figure 6.17 Cost evaluation for closed-ended pile foundations 


\subsection{Potential Cost Savings from Implementation of the Proposed Design Method in Indiana}

Table 6.20 shows the total pile length driven in Indiana in the $11 / 17 / 1998-5 / 12 / 2002$ period. The total length of piles driven was $159,774 \mathrm{~m}$, corresponding to an amount of $\$ 14,964,408$. If the some level of underprediction of pile load capacity is observed in all the pile designs done in the state, the annual savings could reach $\$ 2$ million by improving the design process.

Table 6.20 Pile length and cost driven in Indiana (11/17/1998 - 5/12/2002)

\begin{tabular}{|c|c|c|c|c|}
\hline Pile Description & $\begin{array}{c}\text { Number of } \\
\text { projects }\end{array}$ & Pile length & Units & Cost (US \$) \\
\hline $\begin{array}{c}\text { CONCRETE, STEEL } \\
\text { SHELL ENCASED }\end{array}$ & 17 & 57223 & $\mathrm{ft}$ & $1,514,824.37$ \\
\hline $\begin{array}{c}\text { CONCRETE, STEEL } \\
\text { SHELL ENCASED }\end{array}$ & 119 & 76333.53 & $\mathrm{~m}$ & $6,731,285.62$ \\
\hline STEEL H & 25 & 46729.8 & $\mathrm{ft}$ & $1,336,733.55$ \\
\hline STEEL H & 108 & 51788.4 & $\mathrm{~m}$ & $5,381,564.36$ \\
\hline Total & 269 & 159774 & $\mathrm{~m}$ & $14,964,407.90$ \\
\hline
\end{tabular}




\section{CHAPTER 7}

\section{SUMMARY AND CONCLUSIONS}

\subsection{Summary}

Both open-ended and closed-ended pipe piles are often used in practice, but high-quality information available on the bearing capacity of these piles is very limited. The core of the present study was the pile load tests done on two pipe piles: one open-ended and the other closed-ended. The information generated by the load tests is particularly useful and unique for engineers interested in the design of open-ended pipe piles in sand, as detailed data were collected on soil plug formation during driving and on static plug resistance.

In order to study the load capacity of open-ended piles bearing in sand, both an openended and a closed-ended pipe pile with the same diameter were driven to the same depth at the same site. The base of each pile was embedded in a sand layer. The piles were fully instrumented before driving, and load-tested to failure. Cone penetration tests and SPTs were performed both before and after driving at several locations both close and away from the piles. PDA tests were performed during driving. The open-ended pile was assembled and instrumented in a way that allowed measurement of the soil plug length during pile driving, measurement of the friction between the soil plug and the inner surface of the pile, and separation of the contributions of annulus resistance and soil plug resistance to total base resistance. These data, which offer a unique opportunity to advance the understanding of the load response behavior of these piles, were described and analyzed in this study. 
New empirical relationships for pile load capacities of open- and closed-ended piles were proposed. The relationships are based on soil-state parameters and CPT results. The proposed methods were established based on results from the full-scale field pile load tests and model pile load tests in the calibration chamber. The predicted pile load capacities from the proposed methods were compared with measured capacities from case histories and results calculated from existing pile design methods. Cost comparison between the proposed and existing methods was also made. Design savings reach $50 \sim 60 \%$ for piles embedded in strong bearing layers using the design method proposed in this research, compared with the results of DRIVEN program (FHWA).

\subsection{Conclusions}

(1) Driving of open-ended pipe piles can take place with varying degrees of soil plug formation. The open-ended pipe pile in this study was driven in a partially plugged mode. Measurement of the soil plug length during driving permitted calculation of the IFR as a function of penetration depth. It was found, by comparison with the CPT cone resistance profile, that the IFR increased when the relative density of the sand also increased. It was also observed that the cumulative blow count was lower to drive the open-ended pile than the closed-ended pile to the same depth, but that the difference in blow counts was mostly due to the early stages of driving, when the soil plug was not well developed.

(2) From the field pile load tests, it was observed that the base resistance and shaft capacity of the open-ended pile resulted $18 \%$ and $44 \%$ lower than the corresponding values for the closed-ended pile. For the open-ended pile, the plug resistance was only about $30 \%$ of the 
annulus resistance, and the average shear stress between the soil plug and inner surface of the pile was $45 \%$ higher than the outside shaft resistance.

(3) The results of model pile tests show that the IFR decreases with decreasing relative density and horizontal stress, but is independent of the vertical stress. It is also seen that the IFR increases linearly with the PLR, which is defined as the ratio of the soil plug length to pile penetration depth, and can be estimated from the PLR. The base load capacity shows a tendency to increase with decreasing IFR, and it does so at a rate that increases with relative density. The shaft resistance, normalized with respect to horizontal stress, increases with decreasing IFR and with increasing relative density.

(4) Based on the field and calibration chamber pile load tests, new relationships for determination of the load capacity of open-ended piles were proposed. The relationships are based on soil-state variables (relative density and stress state) and CPT results.

(5) The normalized base resistance $\mathrm{q}_{\mathrm{b}} / \mathrm{q}_{\mathrm{c}}$ was obtained from the calibration chamber tests as a function of the relative density $\mathrm{D}_{\mathrm{R}}$ for closed-ended piles, and of both the relative density $D_{R}$ and the incremental filling ratio IFR for open-ended piles. The test results suggest that the annulus resistance $\mathrm{q}_{\mathrm{ann}}$ of open-ended piles can be taken as equal to the cone resistance $\mathrm{q}_{\mathrm{c}}$ for practical purposes. Based on the results by Lee and Salgado (1999a), the lower and upper bounds of $\mathrm{q}_{\mathrm{b}} / \mathrm{q}_{\mathrm{c}}$ for closed-ended piles were also obtained. It was found that the $\mathrm{q}_{\mathrm{b}} / \mathrm{q}_{\mathrm{c}}$ values of closed-ended piles are approximately the same as the upper bound values, while the normalized plug resistance $\mathrm{q}_{\mathrm{plug}} / \mathrm{q}_{\mathrm{c}}$ of open-ended piles is approximately equal to the lower bound values, corresponding closely to $\mathrm{q}_{\mathrm{b}} / \mathrm{q}_{\mathrm{c}}$ of non-displacement iles.

(6) For more effective application of the results presented in this report to the design of openended pipe piles, the relationship between the incremental filling ratio IFR and the 
relative density $D_{R}$ was expressed as a function of pile driving depth. The use of the relationship between IFR and $D_{R}$ allows the estimation of IFR, and thus the estimation of the pile load capacity of open-ended piles before pile driving.

(7) Based on the cost comparison between the proposed and existing methods, it was observed that use of the proposed methods can result in significant cost savings.

(8) It is necessary to develop more confidence on the proposed methods by performing additional instrumental pile load tests and then publicizes widely the results. 


\section{REFERENCES}




\section{LIST OF REFERENCES}

American Petroleum Institute (1991). Recommended Practice for Planning, Designing and Constructing Fixed Offshore Platforms, $19^{\text {th }}$ Ed. API RP2A, Dallas, Texas.

American Petroleum Institute RP2A (1993). "Recommended practice of planning, designing and constructing fixed offshore platforms." $20^{\text {th }}$ edition, Washington.

Aoki, N. and Velloso, D. A. (1975). "An approximate method to estimate the bearing capacity of piles." Proceedings of $5^{\text {th }}$ Pan-American Conference of Soil Mechanics and Foundation Engineering, Bueno Aires, Vol. 1, 367-376.

Ata, A., and Vipulanandan, C. (1999). "Factors affecting mechanical and creep properties of silicate-grouted sand.” J. Geotech. and Geoenvir. Engrg., ASCE, 125(10), 868-876.

Bazaraa, A. R. and Kurkur, M. M. (1986). "N-values used to predict settlements of piles in Egypt. In: Clemence(ed), Use of In Situ Tests in Geotechnical Engineering. ASCE Geotechnical Special Publication 6: 462-474

Beringen, F. L. (1979). "Results of loading tests on driven piles in sand.” Recent Developments in the design and construction of piles, London, 213-225.

Brucy, F., Meunier, J., and Nauroy, J. F. (1991), "Behavior of pile plug in sandy during and after driving." Proc. $23^{\text {rd }}$ Annual Offshore Technology Conf., 1:145-154.

Bruno, D., and Randolph, M. F. (1999). "Dynamic and static load testing of model piles Driven into dense sand.” J. Geotech. and Geoenvir. Engrg., ASCE, 125(11), 988-998.

Bustamante, M. and Gianeselli, L. (1982). "Pile Bearing Capacity Prediction by Means of Static Penetrometer CPT", Proceedings of $2^{\text {nd }}$ European Symposium on Penetration Testng, Vol. 2, pp. $493-500$.

Carter, J. P., Randolph, M. F., and Wroth, C. P. (1979). "Some aspects of the performance of open- and closed-ended piles.” Numerical Method in Offshore Piling, London, 165-170.

Chin, F. V. (1970). "Estimation of the ultimate load of piles not carried to failure." Proc. $2^{\text {nd }}$ Southeast Asian Conf. on soil Engrg., 81-90. 
Choi, Y., and O'Neill, M. W. (1997). "Soil plugging and relaxation in pipe pile during earthquake motion.” J. Geotech. and Geoenvir. Engrg., ASCE, 123(10), 975-982.

De Beer, E. (1984). "Different Behavior of Bored and Driven Piles", Proceedings of VI Conference on Soil Mechanics and Foundation Engineering, Budapest (G. Petrasovits ed.), pp. $307-318$.

De Beer, E. (1988). "Different Behavior of Bored and Driven Piles", Proceedings of Deep Foundation on Bored and Auger Piles (Van Impe ed.), Ghent, pp. 47 - 82.

De Nicola, A. and Randolph, M. F. (1997). "The Plugging Behaviour of Driven and Jacked Piles in Ssand", Geotechnique 47, No. 4, pp. $841-856$.

Federal Highway Administration, “Driven 1.0 User's Manual.” Publication No. FHWA-SA-98074.

Franke, E. (1989). "Co-Report to Discussion, Session B, on Large Diameter Piles", 12 ICSMFE, Rio de Janeiro, Brazil.

Franke, E. (1993). “Design of Bored Piles, Including Negative Skin Friction and Horizontal Loading”, Proceedings of $2^{\text {nd }}$ International Geotechnical Seminar on Deep Foundations on Bored and Auger Piles (Van Impe, ed.), Balkema, Rotterdam, pp. 43 - 57.

Froy, P., Colliat, J. L., and Nauroy, J. F. (1993). "Bearing Capacity of Driven Model Piles in Dense Sands from Calibration Tests", Proceedings of the $25^{\text {th }}$ Annual Offshore Technology Conference, Houston, OTC 7194, pp. $655-665$.

Ghionna, V. N., Jamiolkowsi, M., Lancellotta, R. and Pedroni, S. (1993). "Base Capacity of Bored Piles in Sands from In-Situ Tests", Proceedings of $2^{\text {nd }}$ International Geotechnical Seminar on Deep Foundations on Bored and Auger Piles (Van Impe ed.), Balkema, Rotterdam, pp. $67-74$.

Ghionna, V. N., Jamiolkowsi, M., Pedroni, S. and Salgado, R. (1994). "The Tip Displacement of Drilled Shafts in Sands", Proceedings of Settlement '94 (Yeung and Felio ed.), Vol. 2, Geotechnical Engineering Division, ASCE, June, pp. 1039 - 1057.

GRL and Associates, Inc. (2000). INDOT pile load tests-SR 9 in LaGrange, Indiana, GRL Job No. 007060, Cleveland, Ohio, p. 7.

Gwizdala, K. (1997). "Polish design methods for single axially loaded piles." Proc. ERCT3 Seminar, Brussells, 291-306. 
Houlsby, G. T. and Hitchman, R. (1988). "Calibration Chamber Tests of a Cone Penetrometer in Sand", Geotechnique 38, No. 1, pp. 39-44.

Indiana Department of Transportation, "Standard specification book."

Jamiolkowski, M. and Lancellotta, R. (1988). "Relevance of In-Situ Test Results for Evaluation of Allowable Base Resistance of Bored Piles in Sands", Proceedings of I International Geotechnical Seminar on Deep Foundations on Bored and Auger Piles (Van Impe ed.), Ghent, pp. $107-120$.

Kindel, C. E. (1977). "Mechanism of soil resistance for driven pipe piles." $4^{\text {th }}$ International Symposium of the Waterway, Port, Costal and Ocean Division of American Society of Civil Engineering, March, 2:251-268.

Klos, J. and Tejchman, A. (1977). "Analysis of Behavior of Tubular Piles in Subsoil", Proceedings of the $9^{\text {th }}$ International Conference on soil Mechanics and Foundation Engineering, Vol. 1, Tokyo, pp. $605-608$.

Klos, J., and Tejchman, A. (1981). "Bearing capacity calculation for pipe piles." Proc. $10^{\text {th }}$ Int. Conf. on Soil Mech. and Foun. Eng., Stockholm, 2, 751-754.

Kraft, L. M., Jr. (1991). "Performance of axially loaded pipe piles in sand." J. Geotech. Engrg., ASCE, 117(2), 272-296.

Lee, J. H. and Salgado, R. (1999a). "Determination of Pile Base Resistance in Sands", Journal of Geotechnical and Geoenvironmental Engineering, ASCE, Vol. 125, No. 8, pp 673 - 683.

Lee, J. H. and Salgado, R. (1999b). "Pre-failure Loading Response of Foundations in Sands", Proceedings of 2nd International Symposium on Pre-failure Deformation Characteristics of Geomaterials, Torino, Italy, 667-674.

Lee, J. H. and Salgado, R. (1999c). "Pile Design Based on Cone Penetration Test Results", Report, Joint Transportation Research Program, Report No. FHWA/IN/JTRP-99/8.

Lee, J. H. and Salgado, R. (2000), "Analysis of Calibration Chamber Plate Load Tests", Canadian Geotechnical Journal, Vol. 37, No.1, pp. 14-25.

Lee, J. H. and Salgado, R. (2001). "Non-linear Finite Element Analysis of Calibration Chamber Plate Load Tests for Sands", Proceedings of the $10^{\text {th }}$ International Conference on Computer Methods and Advances in Geomechanics, Vol. 2., Tucson, Arizna, Jan. pp 941 - 946. 
Lehane, B. M., and Randolph, M. F. (2001). "Evaluation of a minimum base resistance for driven pipe piles in siliceous sand.“ Journal of Geotechnical and Geoenvironmental Engineering, ASCE, accepted for publication.

Leong, E. C. and Randolph, M. F. (1991). "Finite Element Analyses of Soil Plug Response", International Journal for Numerical and Analytical Methods in Geomechanics, Vol. 15, pp. 121-141.

Lu, S. S. (1985). "Pile driving practice in china." Proc. Int. Symp. on Penetrability and drivability of Piles, San Francisco, 1, 13-20.

MaCammon, N. R., and Golder, H. Q. (1970). "Some loading tests on long pipe piles." Geotechnique, 20(2), 171-184.

Murff, J. D., Raines, R. D., and Randolph, M. F. (1990). "Soil Plug Behavior of Piles in Sand", Proceedings of the $22^{\text {nd }}$ Offshore Technology Conference, Houston, OTC 6421, pp. $25-$ 32.

Mansur, C. I., and Hunter, A. H. (1970). "Pile tests-Arkansas river project." J. Soil Mech. and Found. Engrg. Div., ASCE, 95(5), 1545-1582.

Meyerhof, G. G. (1976). "Bearing capacity and settlement of pile foundations." J. Geotech. Engrg. Div., ASCE, 102(3), 197-228.

Meyerhof, G. G. (1983). "Scale effects of ultimate pile capacity.” Journal of the Geotechnical Engineering, ASCE, 109(6), 797-806.

Miller, G. A., and Lutenegger, A. J. (1997). "Influence of pile plugging on skin friction in overconsolidated clay.” J. Geotech. Engrg., ASCE, 123(6), 525-533.

Nauroy, J. F., and Le Tirant, P. (1983). "Model Tests of Calcareous Sands", Proceedings of the Conference on Geotechnical Practice in Offshore Engineering, ASCE, pp. 356 - 369.

O’Neill, M. W. and Raines, R. D. (1991). "Load Transfer for Pipe Piles in Highly Pressured Dense Sand”, Journal of Geotechnical Engineering, ASCE, Vol. 117, No. 8, pp. 1208 1226.

Paik, K. H. and Lee, S. R. (1993). "Behavior of Soil Plugs in Open-ended Model Piles Driven into Sands", Marine Georesources and Geotechnology, Vol. 11, pp. 353-373.

Paik, K. H. and Lee, S. R., and Park, H. I. (1994). "Investigation of Possible Practical Applicability of Open-ended PHC pile", Journal of Korean Society of Civil Engineers, Vol. 
14 No. 4, pp. 965 - 975.

Paik, K. H. and Salgado, R., Lee, J. H., and Kim, B. J. (2001). "The Behavior of Open- and Closed-ended piles Driven into Sand”, Journal of Geotechnical and Geoenvironmental Engineering, ASCE, submitted for publication.

Paikowski, S. G. and Whitman, R. V. (1990). "The Effects of Plugging on Pile Performance and Design”, Canadian Geotechnical Journal, Vol. 27, pp. 429 - 440.

Paikowski, S. G., Whitman, R. V., and Baligh, M. M. (1989). "A New Look at the Phenomenon of Offshore Pile Plugging”, Marine Geotechnology, Vol. 8, pp. 213 - 230.

Parkin, A. K., and Lunne, T. (1982). "Boundary effects in the laboratory calibration of a cone penetrometer for Sand.” Proc. $2^{\text {nd }}$ Europ. Symp. Penetration Testing, 2:761-768.

Raines, R. D., Ugaz, O. G., and O’Neill, M. W. (1992). “Driving characteristics of open-toe piles in dense sand." J. Geotech. Engrg., ASCE, 118(1), 72-88

Randolph, M. F., Steinfelt, J. S., and Wroth, C. P. (1979). "The Effect of Pile Type on Design Parameters for Driven Piles”, Proceedings of $7^{\text {th }}$ European Conference on Soil Mechanics, Vol. 2, British Geotechnical Soceity, London, UK, pp. 107 - 114.

Randolph, M. F., Leong, E. C., and Houlsby, G. T. (1991). "One-dimensional Analysis of Soil Plug in Pipe Piles", Geotechnique 41, No. 4, pp. 587 - 598.

Robinsky, E. I., and Morrison, C. E. (1964). "Sand displacement and compaction around model friction piles.” Can. Geotech. J., Ottawa, Canada, 1, 2:81.

Salgado, R. (1995). "Design of Piles in Sands Based on CPT Results", Proceedings of X PanAmerican Conference of Soil Mechanics and Foundation Engineering, Vol. 3, Guadalajara, pp. $1261-1274$.

Salgado, R., Mitchell, J. K. and Jamiolkowski, M. (1997). "Cavity Expansion and Penetration Resistance in Sands", Journal of Geotechnical and Geoenvironmental Engineering, ASCE, 123(4), $344-354$.

Salgado, R., Mitchell, J. K., and Jamiolkowski, M. (1998). "Calibration Chamber Size Effects on Penetration Resistance in Sand", Journal of Geotechnical and Geoenvironmental Engineering, ASCE, 124(9), 878 - 888.

Schmertmann, J. H. (1978). Guidelines for Cone Penetration Test, Performance and Design, U.S. Department of Transportation, FHWA-TS-78-209. 
Schnaid, F. and Houlsby, G. T. (1991). "An Assessment of Chamber Size Effects in the Calibration of In Situ Tests in Sand", Geotechnique 41, No. 3, pp. 437 - 445.

Smith, I. M., To, P., and Wilson, S. M. (1986). "Plugging of Pipe Piles", Proceedings of the $3^{\text {rd }}$ the International Conference on Numerical Methods in Offshore Piling, Nantes, France, pp. $53-73$.

Szechy, C. H. (1959). "Tests with tubular piles.” AcTa Technica of the Hungarian Academy of Science, Vol. 24, 181-219.

Szechy, C. H. (1961). "The effect of vibration and driving upon the voids in granular soil surrounding a pile.” Proc. $5^{\text {th }}$ Int. Conf. on Soil Mech. and Found. Engrg., Paris, France, 2, 161-164.

Tan, R. H. S., and Hanna, T. H. (1974). "Long piles under tensile loads in sands." Geotech. Engrg., 5(2), 109-124.

Yamagata, K., Fukuya, T., and Omote, S. (1985). "Penetrability of open-ended steel pipe piles on land." Proc. Int. Symp. on Penetrability and drivability of Piles, San Francisco, 1, 123126. 
APPENDIX - A 
Design Calculations

\author{
FOR
}

\author{
Static Pile Load Test
}

(USE REACTION PILE AS REACTION LOAD)

School of Civil Engineering

\author{
PuRdue University
}


〈Calculation of Bearing Copacity for Test Pile> * Details of the Test Pile

- OPen-ended pipe pile (PP 14, $t=0,438^{\prime \prime}$ )

- Pile penetration depth, $D_{p}=7.4 \mathrm{~m}(24.28 \mathrm{tt})$

Elev. of soil surface $=262.4 \mathrm{~m}$

Elev. of pile tip $=255.0 \mathrm{~m}$

- Length of the test Pile $=8.0 \mathrm{~m}$

* Estimation of End Bearing Capacity

- It is assumed that the test pile will be completely plugged at penetration depth of $7.4 \mathrm{~m}$

- Formula for End Bearing Capacity (Meyerhof. 1976)

$$
\begin{gathered}
Q_{p}=4 N_{\text {corr }} \cdot A_{p} \text { (ton) } \\
N_{\text {corr }}=\left[0.77 \log \left(\frac{20}{\sigma_{v}^{\prime}}\right)\right] \bar{N} \\
\text { where } \sigma_{v}^{\prime}=\text { effective vertical stress at the } \\
\text { pile tip (tom } \left./ \mathrm{ft}^{2}\right)
\end{gathered}
$$


$\bar{N}$ =average $N$-value within the range of depth from 4D above to ID below the pile tip

$D=$ pile diameter

$A_{p}=$ gross sectional area of pile $\left(t t^{2}\right)$

$$
=\frac{\pi \times(14 / 12)^{2}}{4}=1.069 \mathrm{At}^{2}
$$

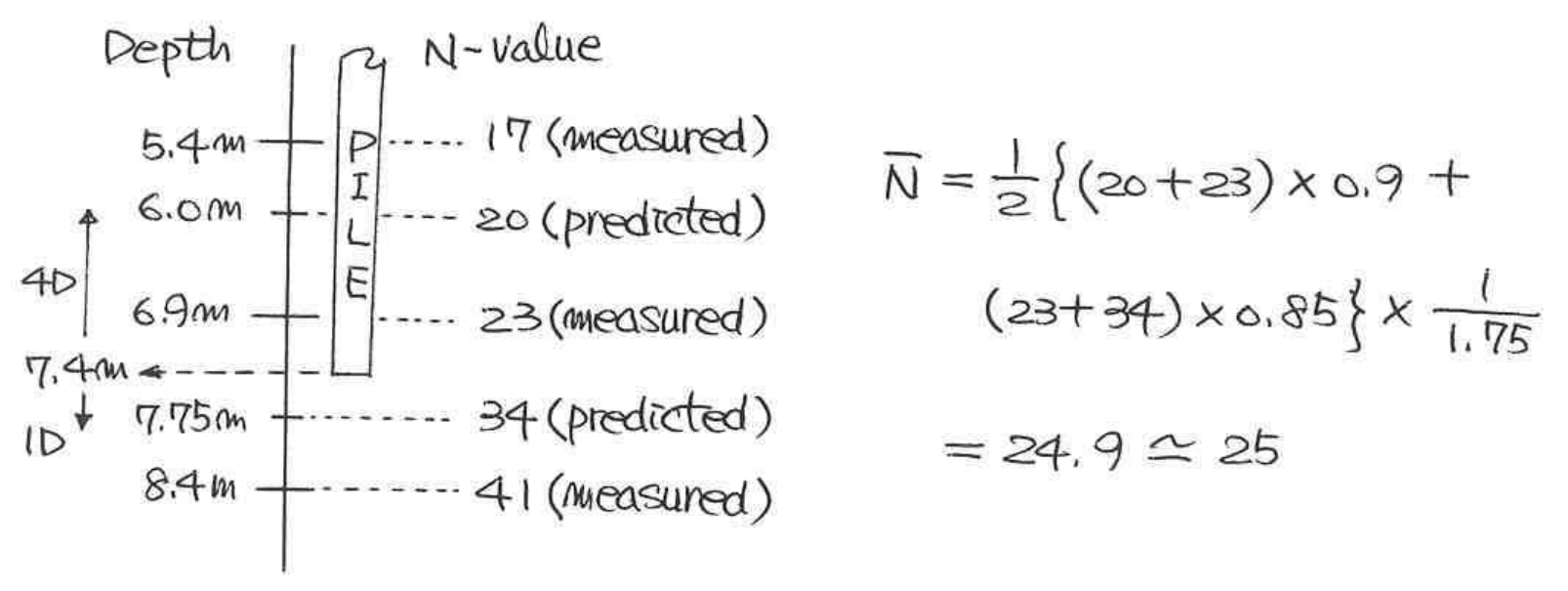

Generally, $\gamma^{\prime}$ of sand $=0.9 \mathrm{tam} / \mathrm{m}^{3}$

$$
\begin{aligned}
& \sigma_{v}^{\prime}=0.9 \mathrm{t} / \mathrm{m}^{3} \times 7.4 \mathrm{~m} \times \frac{1}{3.281^{2}} \mathrm{~m}^{2} / \mathrm{Ht}^{2}=0.62 \mathrm{ton} / \mathrm{ft}^{2} \\
& N_{\text {corr }}=\left[0.77 \log _{10}\left(\frac{20}{0.62}\right)\right] \times 25=29 \\
& \therefore Q_{p}=4 \mathrm{Nccrr} \cdot A_{p}=4 \times 29 \times 1.069=124.0 \mathrm{ton} .
\end{aligned}
$$

171 
* Estimation of Shaft Resistance.

- Formula (Meyerhot, 1976)

$$
Q_{s}=\frac{\bar{N} A_{s}}{50} \text { (tom) }
$$

where, $\bar{N}=$ average value of $N$ along pile shaft

$$
\begin{aligned}
A_{s} & =\text { gross surface area of pile shaft }\left(\mathrm{ft}^{2}\right) \\
& =\pi \times \frac{14}{12} \times 24.28=88.991 \mathrm{H}^{2}
\end{aligned}
$$

Depth (m) N-value

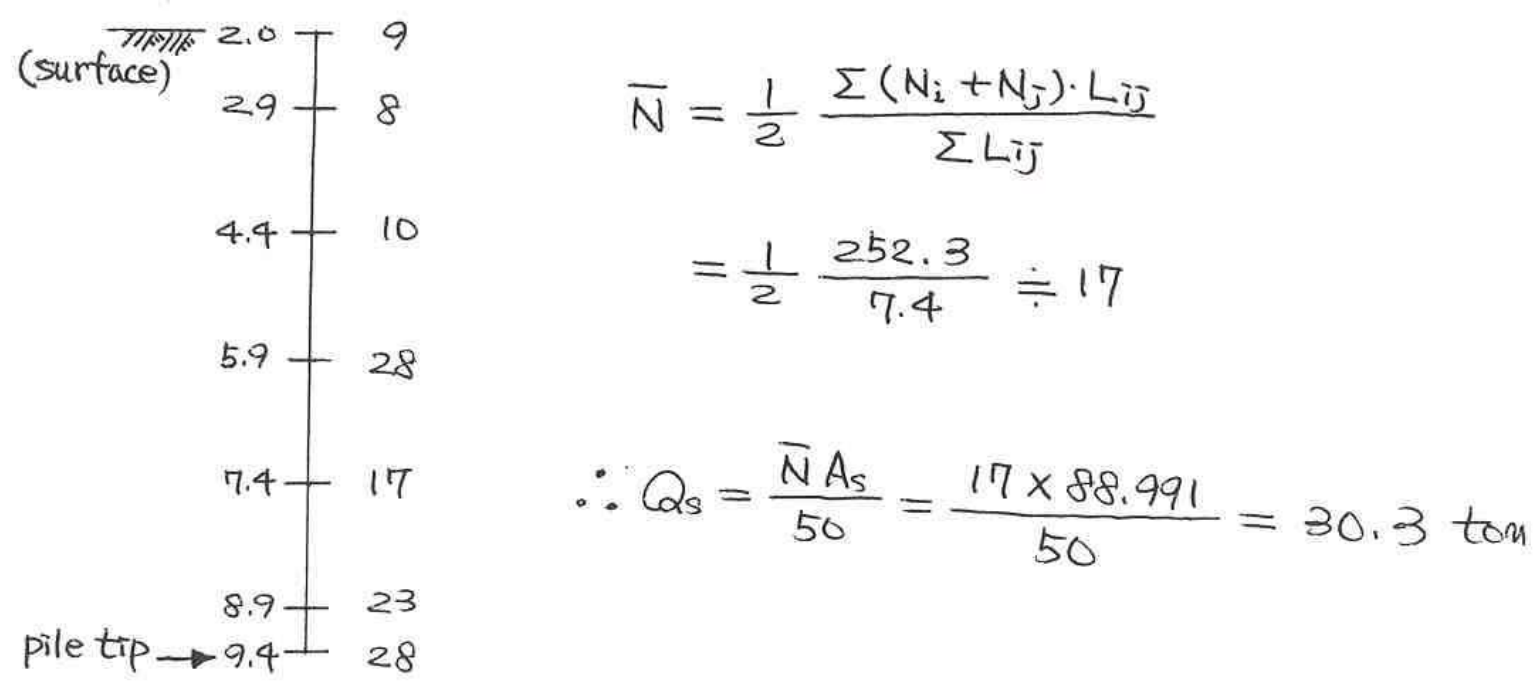

* Ulltimate total Capacity for Test Pile

$$
\begin{gathered}
\cdot P_{u}=Q_{p}+Q_{s}=124.0+30.3 \text { tom }=154.3 \text { tom } \\
\therefore P_{u} \simeq 155 \text { tom (342 kips) }
\end{gathered}
$$


Design of Reaction Pile>

* Details of Reaction Pile

- Use a Steel H pile (HP 12×74)

web: $d_{w}($ depth $)=12.13^{\prime \prime}$

$t_{w}$ (thickness) $=0.605^{\prime \prime}$

flange: $w_{f}$ (width) $=12.215^{\prime \prime}$

$t_{f}$ (thickness) $=0.610^{\prime \prime}$

- Pile penetration depth, $D_{\mathrm{RP}}=11.0 \mathrm{~m}=36.09 \mathrm{ft}$

* Estimate of Tensile Capacity

- It is assumed that tensile capacity is equal to the shaft resistance of nondisplacement pile.

- Formula for mondisplacement pile (Meyerhof, 1976)

$$
Q_{\text {ten }}=\frac{\bar{N} \cdot A_{s}}{100} \text { (ton) }
$$

Where $\bar{N}=$ average value of $N$ along pile shaft

$$
\begin{aligned}
A_{s} & =\text { gross surface area of pile shaft }\left(f t^{2}\right)^{-} \\
& =\left(4 w_{f}-2 t_{\omega}+2 d_{\omega}\right) \times D_{R P} \\
& =5.993 D_{R P}\left(f t^{2}\right)
\end{aligned}
$$

173 


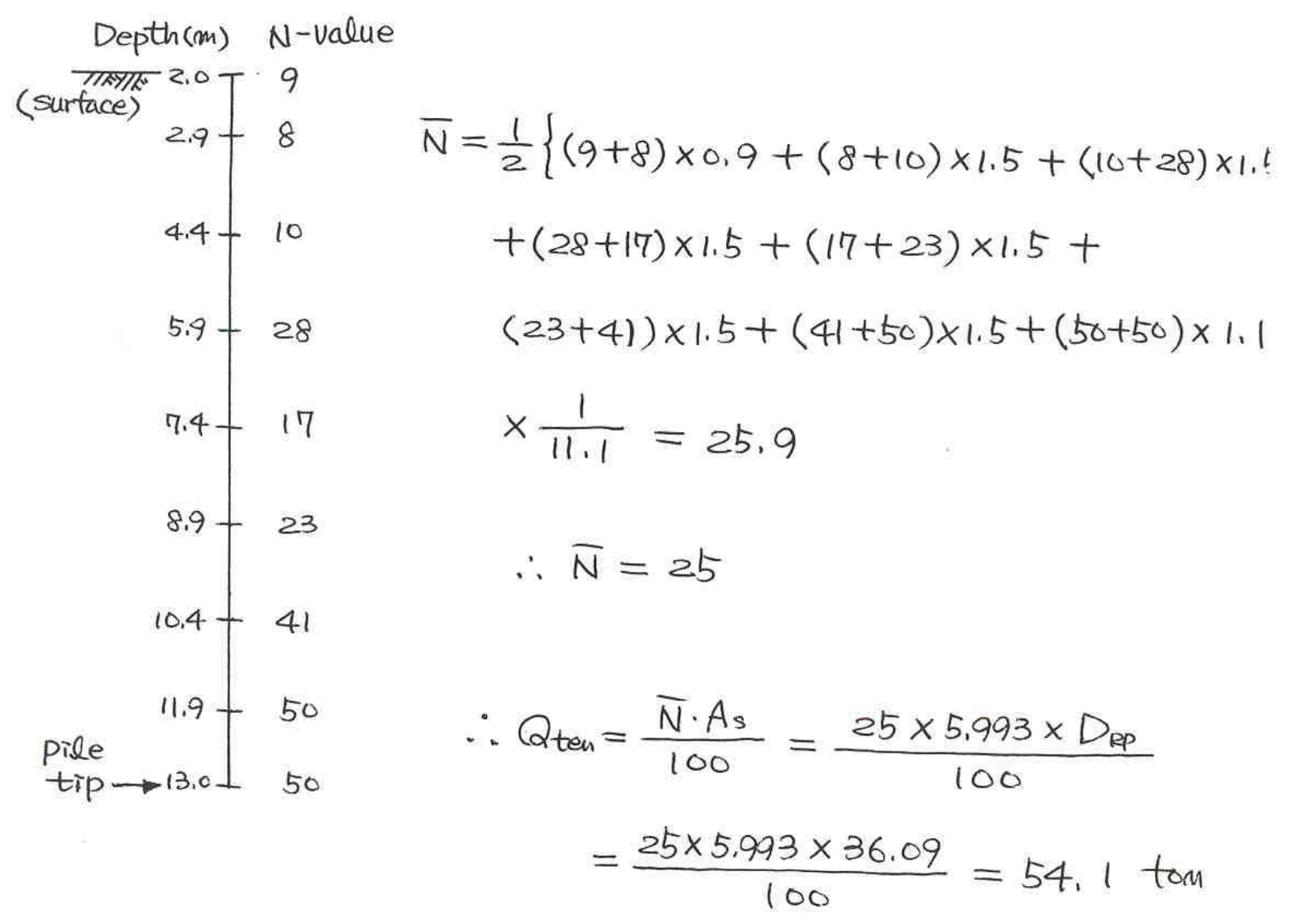

- Allowable Tensile Capacity

$$
\begin{gathered}
Q_{\text {all }}=\frac{Q_{\text {ten }}}{F S}=\frac{54.1}{2.0}=27.0 \text { tom. } \\
\therefore Q_{\text {all }}=27 \text { tom }(59.5 \text { kips })
\end{gathered}
$$


<Design of Reaction Frame for Pile Load Test) * Details of Pile Load test

- Maximum test load $=342$ kips

- Use $6 \mathrm{H}$-pile as reaction pile

Number of reaction pile $=\frac{P_{u}}{Q_{\text {ale }}}=\frac{342}{59.5}=5.8 \simeq 6$

- Pile load test will be performed using one spreader beam, two test beams and six reaction piles as shown in the figure below.

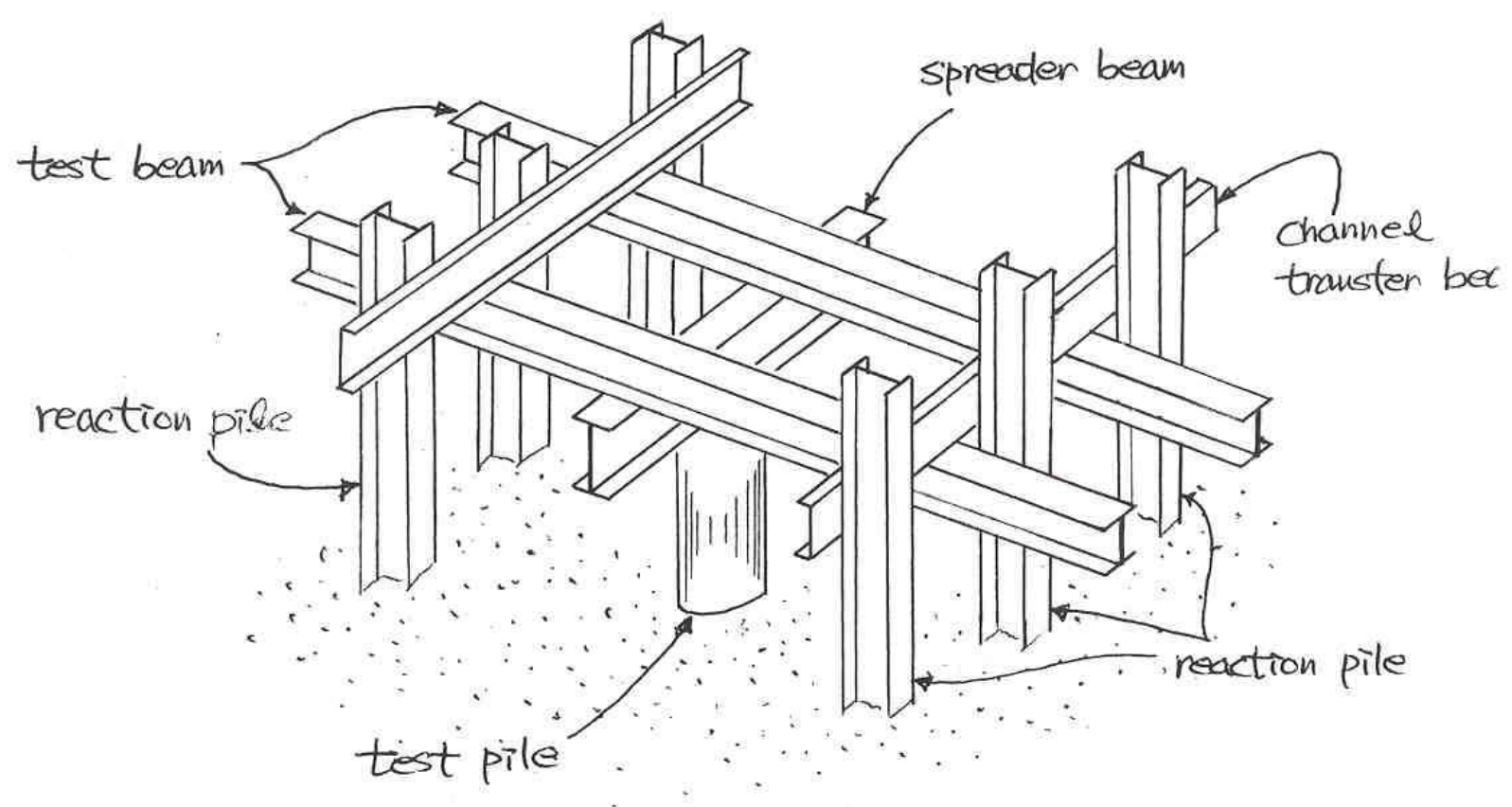


* Design of Spreader Beam

- Sizing Spreader Beam

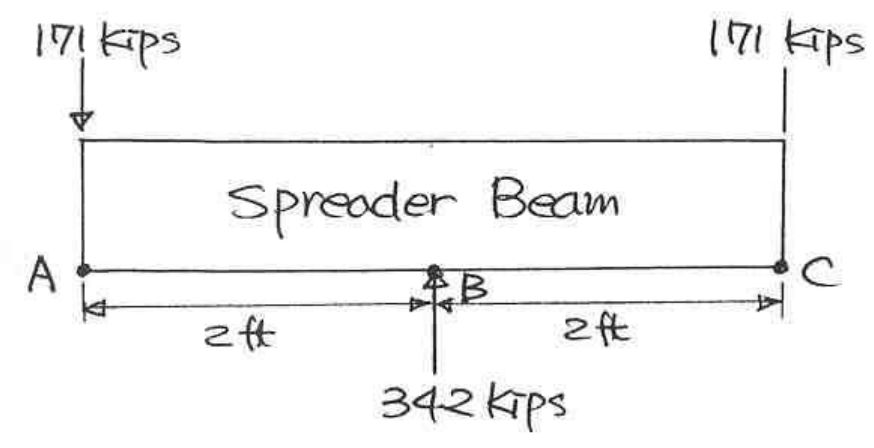

- The 342 kips test load will be carried by one spreader beam

- Using A36 steel ( $\left.F_{y}=36 \mathrm{ksi}\right)$

- Allowable bending stress, $f_{b}$

$$
f_{b}=0.6 F_{y}=0.6 \times 36=21.6 \mathrm{ksi}
$$

- Maximum bending moment (at point B)

$$
M_{\text {max }}=171 \text { kips } \times 2 H=342 \text { kips }-H
$$

- Sectional modulus required

$$
S_{\text {req }}=\frac{M_{\max }}{f_{b}}=\frac{342(\mathrm{kp}-(t) \times 12(\mathrm{~m} / \mathrm{ft})}{21.6}=190 \mathrm{~m}^{3}
$$

- Use W24 $\times 94$ Beam $\left(S=222 \mathrm{in}^{3}\right)$

$$
F_{S}=\frac{S}{S_{\text {req }}}=\frac{222}{190}=1.17 \quad \text { O. kI }
$$

176 
- Verify Allowable Bending Stress, $\sigma_{b}$

$$
\begin{aligned}
\cdot \sigma_{b}=\frac{M_{\max }}{S} & =\frac{342 \times 12}{222}=18.49 \mathrm{ksi} \\
\sigma_{b} & <f_{b}(=21.6 \mathrm{ksi}) \quad 0 . \mathrm{k!} !
\end{aligned}
$$

- Check shear Stress

- Allowable shear stress, $f_{s}$

$$
f_{s}=0.4 F_{y}=0.4 \times 36=14.4 \mathrm{ksi}
$$

- Depth and web thickness of W24 694 beam

depth, $d_{w}=24.31 \mathrm{in}$

web thickness $=0.515 \mathrm{~m}_{\mathrm{n}}=t_{\mathrm{w}}$

- Maximum shear load $=171$ kips (at point B)

- Maximin shear stress, $\tau_{\max }$

$$
\begin{gathered}
\tau_{\max }=\frac{171}{d \omega \times t_{\omega}}=\frac{171}{24.31 \times 0.515}=13.66 \mathrm{ksi} \\
\tau_{\max }<f_{s}(=14.4 \mathrm{ksi}) \quad 0 . \mathrm{k} !
\end{gathered}
$$

177 
- Check Need for Stiffeners

- Concentrated load $=342$ kips

- web thickmess of spreader beam, $t_{w}=0.515 \mathrm{in}$

- If the load is applied to the spreader beam over

a $9 \times 9 \mathrm{in}$ area, compressive stress, $\sigma_{c}$ at toe of web is

$$
\begin{aligned}
\sigma_{c}= & \frac{342 \mathrm{kips}}{9 \times t_{\omega}}=\frac{342}{9 \times 0.515}=73.79 \mathrm{ksi} \\
& \sigma_{c}>0.75 F_{y}(=0.75 \times 36 \mathrm{ksi}=27 \mathrm{ksi}) \\
\therefore & \text { web stiffeners meed }
\end{aligned}
$$

- Required area, Areq

$$
\text { Areq }=\frac{342}{0.75 \mathrm{Fy}_{y}}=\frac{342}{27}=12.67 \mathrm{im}^{2}
$$

- Additiomal area, Aadd

$$
A_{d d}=A_{\text {req }}-9 \times 0.515=12.67-4.635=8.035 \mathrm{~mm}^{2}
$$

- Use four 24" $\times 4.275^{\prime \prime} \times 0.5^{\prime \prime}$ stiffeners, two on each side of web spaced $3 \pi$. either side of beam centerline

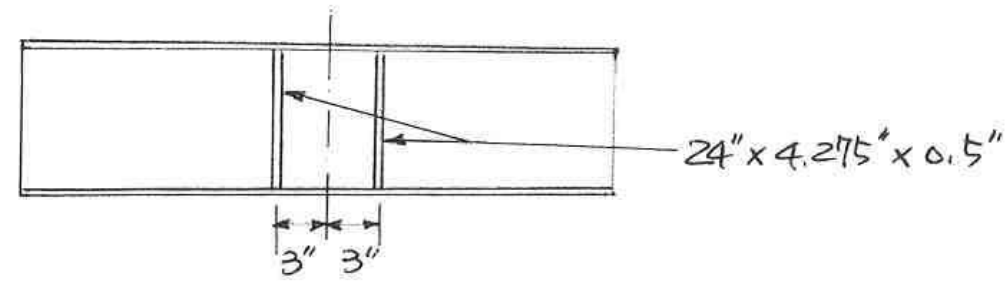


- Check Deflection

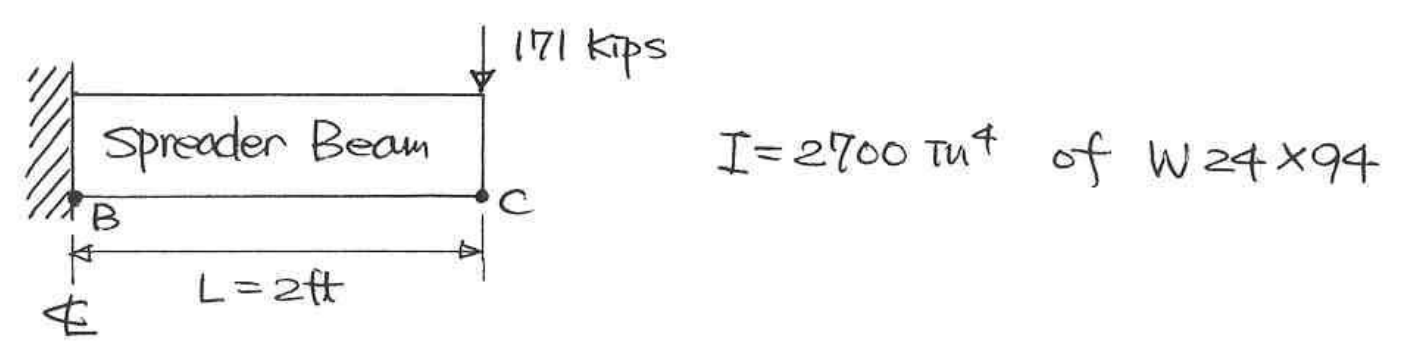

- Elastic modulus of A36 steel, $E=29000 \mathrm{ksi}$

- Maximum deflection, $\Delta_{\max }$

$$
\Delta_{\max }=\frac{P L^{3}}{3 E I}=\frac{171 \times(2 \times 12)^{3}}{3 \times 29000 \times 2700}=0.01 \mathrm{~m} \quad 0 . \mathrm{k!}
$$

* Design of Test Beam.

- Sizing Test Beam

- The test load (34 kips) will be carried by two test beams.

- Half of maximum test load (171 kips) will be applied to the center of every test beam.

- Distance between test and reaction piles $=8 \mathrm{H}$

- Using A36 steel ( $F_{y}=36 \mathrm{ksi}$ )

179 


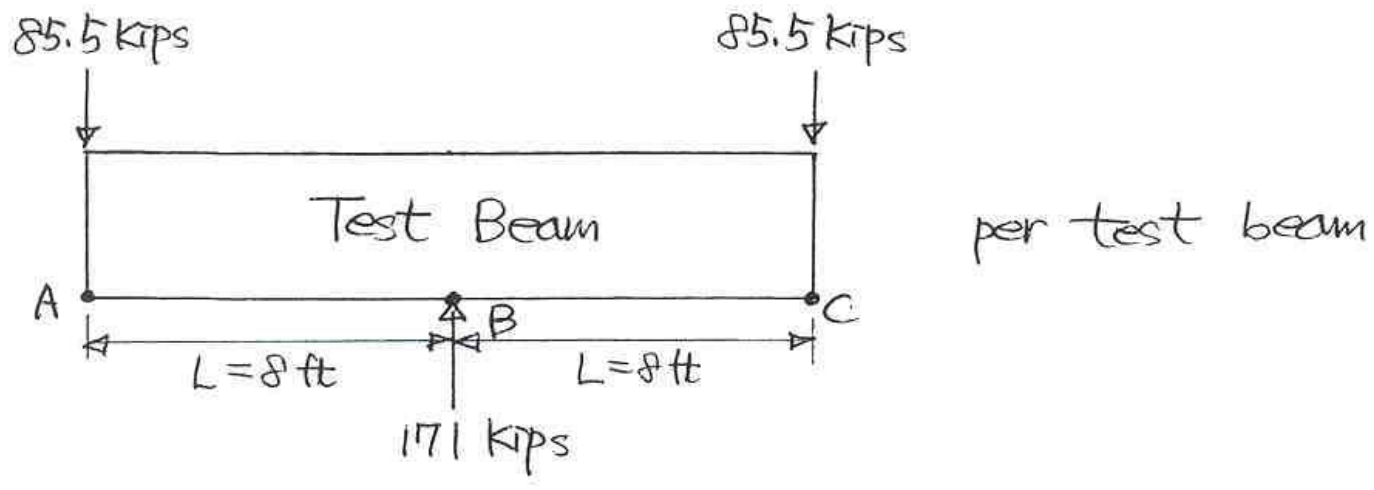

- Maximum bending moment

$M_{\text {max }}=85.5 \mathrm{kips} \times 8 \mathrm{tt}=684 \mathrm{kip}-\mathrm{ft}$ (at point $B$ )

- Section modulus required

$$
S_{\text {rez }}=\frac{M_{\max }}{f_{b}}=\frac{684(\mathrm{kpp}-\mathrm{ft}) \times 12(\mathrm{in} / \mathrm{tt})}{21.6}=380 \mathrm{in}^{3}
$$

- Use $W 27 \times 161$ beam $\left(S=455 \mathrm{in}^{3}\right)$

$$
F_{s}=\frac{S}{S_{\text {req }}}=\frac{455}{380}=1.20 \quad \text {. }
$$

- Verify Allowable Bending Stress, $\sigma_{b}$

- $\sigma_{b}=\frac{M_{\max }}{\mathrm{s}}=\frac{684 \times 12}{455}=18.04 \mathrm{ksi}$

$$
\sigma_{b}<f_{b}(=21.6 \mathrm{ksi}) \quad \text { O.K! }
$$


- Check Shear Stress

- Allowable shear stress, $f_{s}=0,4 F_{y}=14,4 \mathrm{ksi}$

- Depth and web thickmess of $W 27 \times 161$ beam depth, $d_{w}=27.59 \mathrm{mn}$

web thickmess, $t_{\omega}=0.66 \mathrm{in}$

- Maximum shear load $=85.5$ kips (at potnt B)

- Maxinum shear stress, Zmax

$$
\begin{gathered}
\tau_{\max }=\frac{85.5}{d_{\omega} \times t_{\omega}}=\frac{85.5}{27.59 \times 0.66}=4.70 \mathrm{ksi} \\
\tau_{\max }<f_{s}(=14.4 \mathrm{ksi})
\end{gathered}
$$

- Check Need for Stiffeners

- Concentrated load $=171$ kips

- Web thickness of test beam, $t_{w}=0.66$ in

- Since the concentrated load is transfered by the spreader beam, compressive stress, $\sigma_{c}$ at toe of web is

$$
\sigma_{c}=\frac{171}{t_{\omega(s)} \times t_{\omega(t)}}=\frac{171}{0.515 \times 0.66}=503.09 \mathrm{ksi}
$$


where $t_{w(s)}, t_{w(t)}=$ web thickness of spreader and test beams respectively

$$
\sigma_{c}>0.75 F_{y}\left(=27 k s i_{i}\right)
$$

$\therefore$ Web stiffeners need

- Required area. Ares

$$
\text { Are }=\frac{171}{0.75 \mathrm{Fy}_{\mathrm{y}}}=\frac{171}{27}=6.34 \mathrm{in}^{2}
$$

- Additional area. Add

$$
A_{d d}=A_{r e q}-0.515 \times 0.66=6.0 \mathrm{in}^{2}
$$

- Use two $25.43 \mathrm{in} \times 6.68 \mathrm{in} \times 0.5 \mathrm{in}$ stiffeners, one on each side of web along spreader beam.

- The load (85.5kTp) is transferred to two loadtransfer channel $(c 15 \times 33,9)$, so compressive stress, $\sigma_{c}$ at toe of we h is

$$
\sigma_{c}=\frac{85.5}{t_{\omega(t)} \times\left(2 \times t_{\omega(0)}\right)}=\frac{85.5}{0.66 \times(2 \times 0.4)}=161.93 \mathrm{ksi}
$$

where $t_{w(c)}=$ web thickness of load-transter shane

182 


\section{$\sigma_{c}>0.75 F_{y}(=27 \mathrm{ksi})$ \\ $\therefore$ Web Stiffeners need}

- Required area, Areq

$$
A_{\text {req }}=\frac{85.5}{0.75 \mathrm{Fg}}=\frac{85.5}{27}=3.17 \mathrm{in}^{2}
$$

- Additional area. Add

$$
A_{d d}=A_{\text {req }}-0,66 \times(2 \times 0.4)=2,64 \pi^{2}
$$

- Use four $25.43 \mathrm{~m} \times 2.0$ "in $\times 0.4 \mathrm{~m}$ stiffeners, two on each side of web along lood-transfer channels.

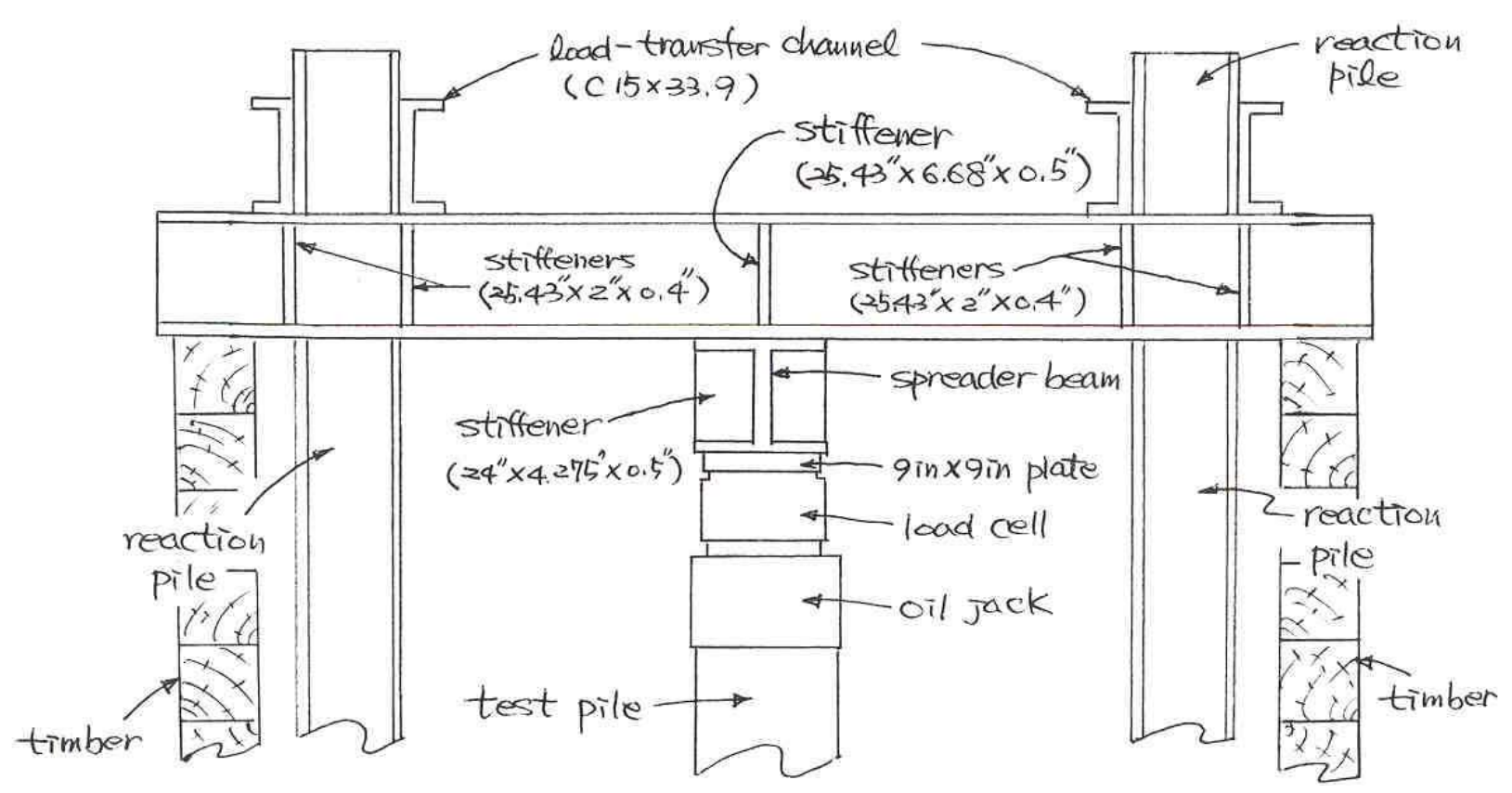


- Check Deflection

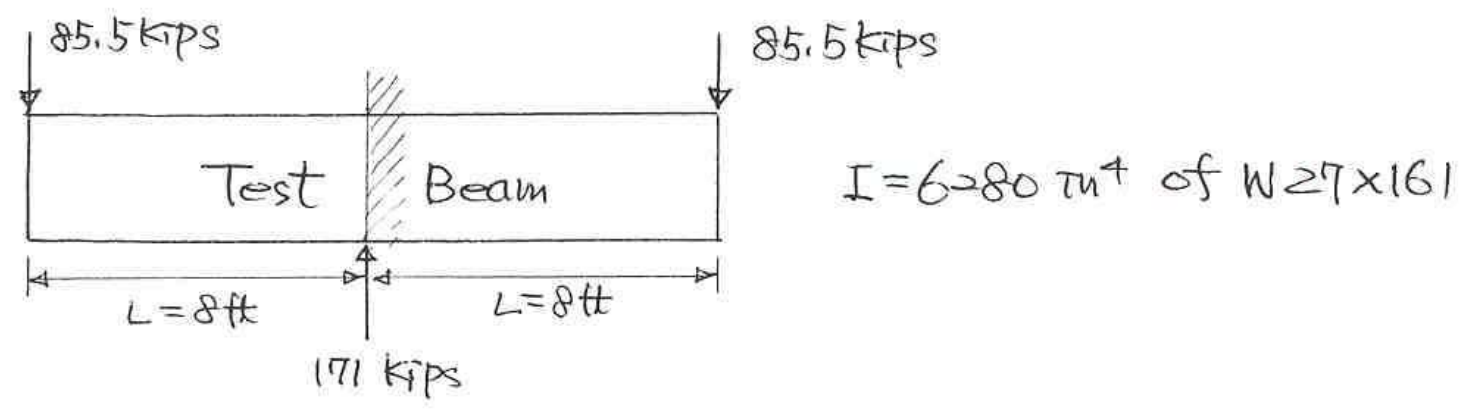

- Elastic modulus of A36 steel, $E=29000 \mathrm{ksi}$

- Maximum deflection. $\Delta_{\max }$

$$
\begin{aligned}
& \Delta_{\max }=\frac{P L^{3}}{3 E I}=\frac{85.5 \times(8 \times 12)^{3}}{3 \times 29000 \times 6280}=0.138 \mathrm{in} \\
& \text { not big enough! }
\end{aligned}
$$

* Design of Load-Transfer Channel

- Sizing Load-Transter Channel.

- The test load (342kips) will be supported by six reaction piles, so the 171 kips load be supported by three reaction piles.

- Distance between reaction piles $=4 \mathrm{ft}$

- Using $A 36$ steel ( $F y=36 \mathrm{ksi}$ ) 


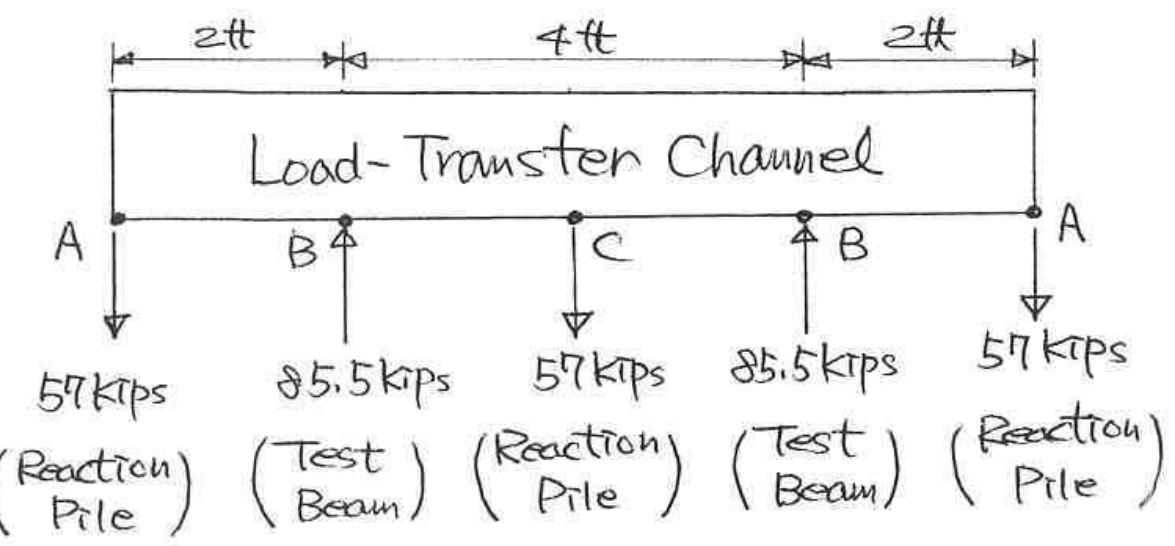

- Allowable bending stress, $f_{b}=0,6 F y=21.6 \mathrm{ksi}$

- Maximum bending moment

$$
M_{\max }=57 \mathrm{kTps} \times 2 t t=114 \mathrm{kips}-t
$$

- Section modulus required

$$
S_{\text {req }}=\frac{M_{\max }}{f_{b}}=\frac{114\left(\mathrm{kmp}-\mathrm{t}_{\mathrm{t}}\right) \times 12(\mathrm{mn} / \mathrm{tt})}{21.6}=63.34 \mathrm{in}^{3}
$$

- Use two $C 15 \times 33.9\left(S=42 \mathrm{~m}^{3}\right)$

$$
F_{S}=\frac{2 \times S}{S_{r e q}}=\frac{2 \times 42}{63.34}=1.33 \quad 0 . \mathrm{K!}
$$

- Verify Allowable Bending Stress, $\sigma_{b}$

$$
\begin{aligned}
\cdot \sigma_{b}=\frac{M_{\max }}{2 \times s} & =\frac{114 \times 12}{2 \times 42}=16.29 \mathrm{ksi} \\
\sigma_{b} & <f_{b}(=21.6 \mathrm{ksi}) \quad 0 . \mathrm{k} !
\end{aligned}
$$

185 
- Check Shear Stress

- Allowable shear stress, $f_{s}=0.4 F_{y}=14.4 \mathrm{ksi}$

- Depth and web thickmess of $c 15 \times 33.9$ chamnel.

depth, $d_{w}=15.0 \mathrm{~m}$

web thickness, $t_{w}=0.4 \mathrm{in}$

- Maximum shear load $=57.0$ kips (at point B)

- Maximum shear stress, $\tau_{\max }$

$$
\begin{gathered}
\tau_{\max }=\frac{57}{2 \times\left(d_{\omega} \times t_{\omega}\right)}=\frac{57}{2 \times(15.0 \times 0.4)}=4.75 \mathrm{ksi} \\
\tau_{\max }<f_{s}(=14.4 \mathrm{ksi}) \quad \quad 0 . \mathrm{kg}
\end{gathered}
$$

- Check Need for Stiffeners.

- The load (85.5kips) is transfered to two loadtransfer channels through the test beam, so compressive stress, $\sigma_{c}$ at toe of web is

$$
\sigma_{c}=\frac{85.5}{t_{w(t)} \times\left(2 \times t_{w(0)}\right)}=\frac{85.5}{0.66 \times(2 \times 0.4)}=161.93 \mathrm{ksi}
$$

where $t_{w(t)}, t_{w(c)}=$ web thickmess of test beam and lond-transfer channel respectively 


$$
\begin{aligned}
b_{s t}, t_{s t}= & \text { width and thickness of the } \\
& \text { stiffener for test beam }
\end{aligned}
$$

$$
\begin{gathered}
\sigma_{c}=\frac{85.5}{2 \times\{0.66 \times 0.4+2 \times(2 \times 0.4)\}}=22.94 \mathrm{ksi} \\
\sigma_{c}<0.75 \mathrm{~F}_{y}(=27 \mathrm{ksi}) \quad 0 . \mathrm{k} !
\end{gathered}
$$

\section{* Design of Weld between React. Pile and Channel}

- The reaction load of reaction pile (57kips) is transfered by two load-transter channel.

- Load per load-transfer channel $=28,5 \mathrm{kips}$

- Use $\frac{1}{4} "$ fillet weld

$$
\text { (allowable working load per inch }=2500 \mathrm{lbs} \text { ) }
$$

- Length of weld required, lw (per channel)

$$
l_{\omega}=\frac{28.5 \times 1000}{2500}=11.4 \mathrm{in}
$$

- If weld entire contact length between flange of channel and reaction pile.

$$
\text { entive contact length }=2 \times 12.215=24.43^{\prime \prime}
$$




$$
F_{S}=\frac{24.43}{11.4}=2.14 \quad 0 . \mathrm{K} !
$$

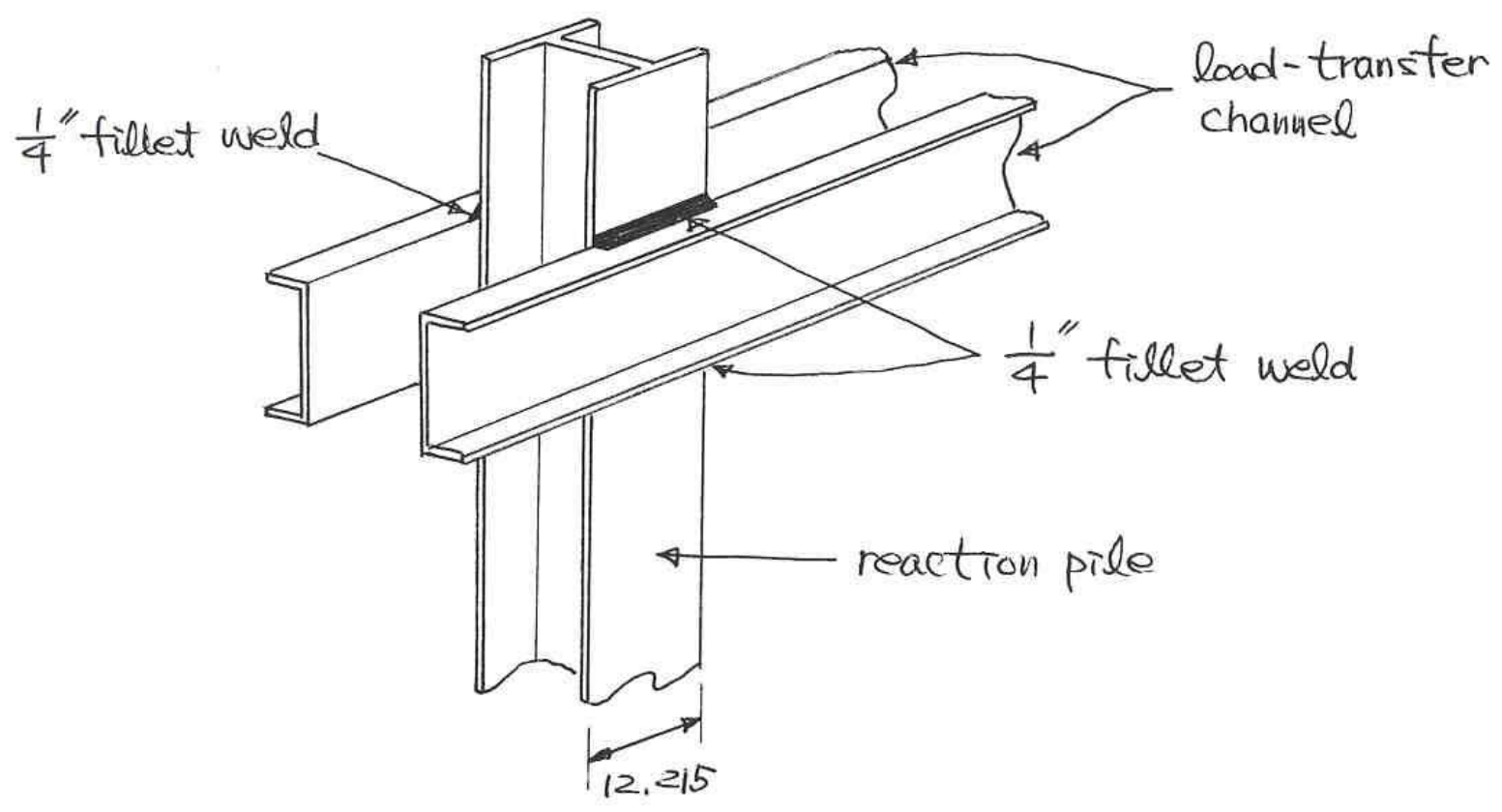




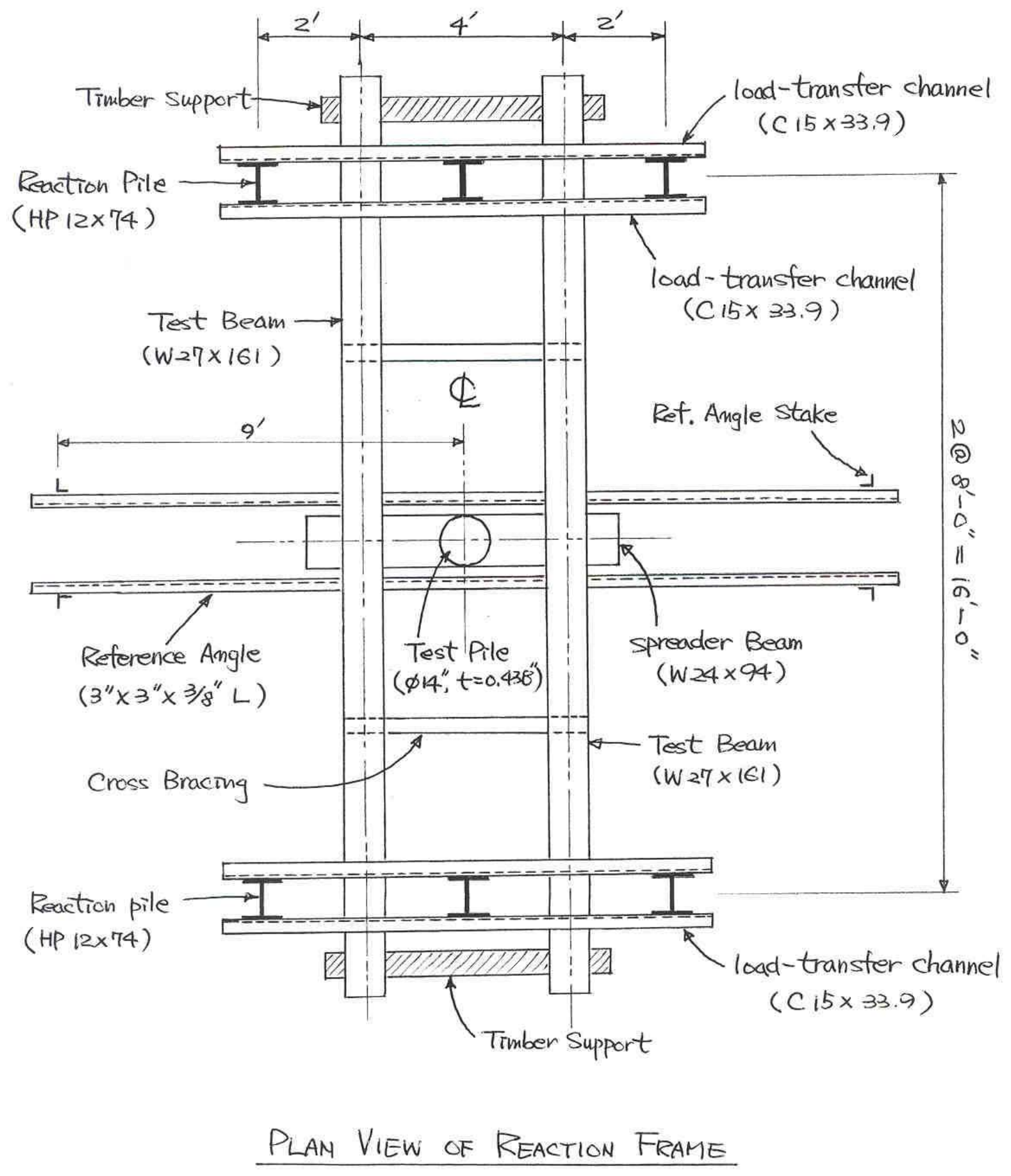




\section{APPENDIX - B}

Design Calculations of example 1 and 2 of Open- and Closed-ended Piles 


\section{B.1 Open-Ended Pile}

\section{B.1.1 API Method}

\section{(1) Example 1}

- Shaft resistance

(1) Layer $1(0 \sim 2 \mathrm{~m})$

roughly assume $\gamma_{d}$ to obtain $\mathrm{D}_{\mathrm{r}}$ from correlation graph: $\gamma_{d}=16.6 \mathrm{kN} / \mathrm{m}^{3}$

$$
\begin{aligned}
& \mathrm{K}_{\mathrm{o}}=(1-\sin \phi) \mathrm{OCR}^{\sin \phi}=(1-\sin 33.3) \cdot 1.5^{\sin 33.3}=0.56 \\
& \sigma_{h}=16.6 \times 1 \times 0.56=9.30 \mathrm{kPa} \\
& \text { average } \mathrm{q}_{\mathrm{c}}=3 \mathrm{MPa}, \\
& \text { from Fig. } \mathrm{B} 1, \mathrm{D}_{\mathrm{r}}=38 \%
\end{aligned}
$$

$$
D_{r}=\frac{\gamma_{d \text { max }}}{\gamma_{d}} \times \frac{\gamma_{d}-\gamma_{d \text { min }}}{\gamma_{d \text { max }}-\gamma_{d \text { min }}} \times 100
$$

from (B.1); $\quad \gamma_{d}=16.6 \mathrm{kN} / \mathrm{m}^{3}$

$$
\begin{aligned}
& \mathrm{q}_{\mathrm{si}}=\mathrm{K} \cdot \sigma_{v}^{\prime} \cdot \tan \delta \\
& \mathrm{K}=0.8, \delta=20(\text { from Table } 6.1), \sigma_{v}^{\prime}=1 \times 16.6=16.6 \mathrm{kPa} \\
& \mathrm{q}_{\mathrm{s} 1}=0.8 \times 16.6 \times \tan 20=4.83 \mathrm{kPa} \\
& \mathrm{q}_{\mathrm{s} 1} \cdot \mathrm{A}_{1}=4.83 \times 2 \times 0.356 \pi=10.80 \mathrm{kN}
\end{aligned}
$$

(2) Layer 2 (2 3m)

roughly assume $\gamma_{d}: \gamma_{d}=16.9 \mathrm{kN} / \mathrm{m}^{3}$

$$
\sigma_{h}=(16.6 \times 2+16.9 \times 0.5) \times 0.56=23.3 \mathrm{kPa}
$$

average $\mathrm{q}_{\mathrm{c}}=6 \mathrm{MPa}$,

from Fig. B1, $\mathrm{D}_{\mathrm{r}}=50 \%$

from (B.1); $\quad \gamma_{d}=16.9 \mathrm{kN} / \mathrm{m}^{3}$

$$
\begin{aligned}
& \mathrm{K}=0.8, \quad \delta=20(\text { from Table } 6.1), \sigma_{v}^{\prime}=16.6 \times 2+16.9 \times 0.5=41.7 \mathrm{kPa} \\
& \mathrm{q}_{\mathrm{s} 2}=0.8 \times 41.7 \times \tan 20=12.14 \mathrm{kPa} \\
& \mathrm{q}_{\mathrm{s} 2} \cdot \mathrm{A}_{2}=12.14 \times 1 \times 0.356 \pi=13.58 \mathrm{kN}
\end{aligned}
$$




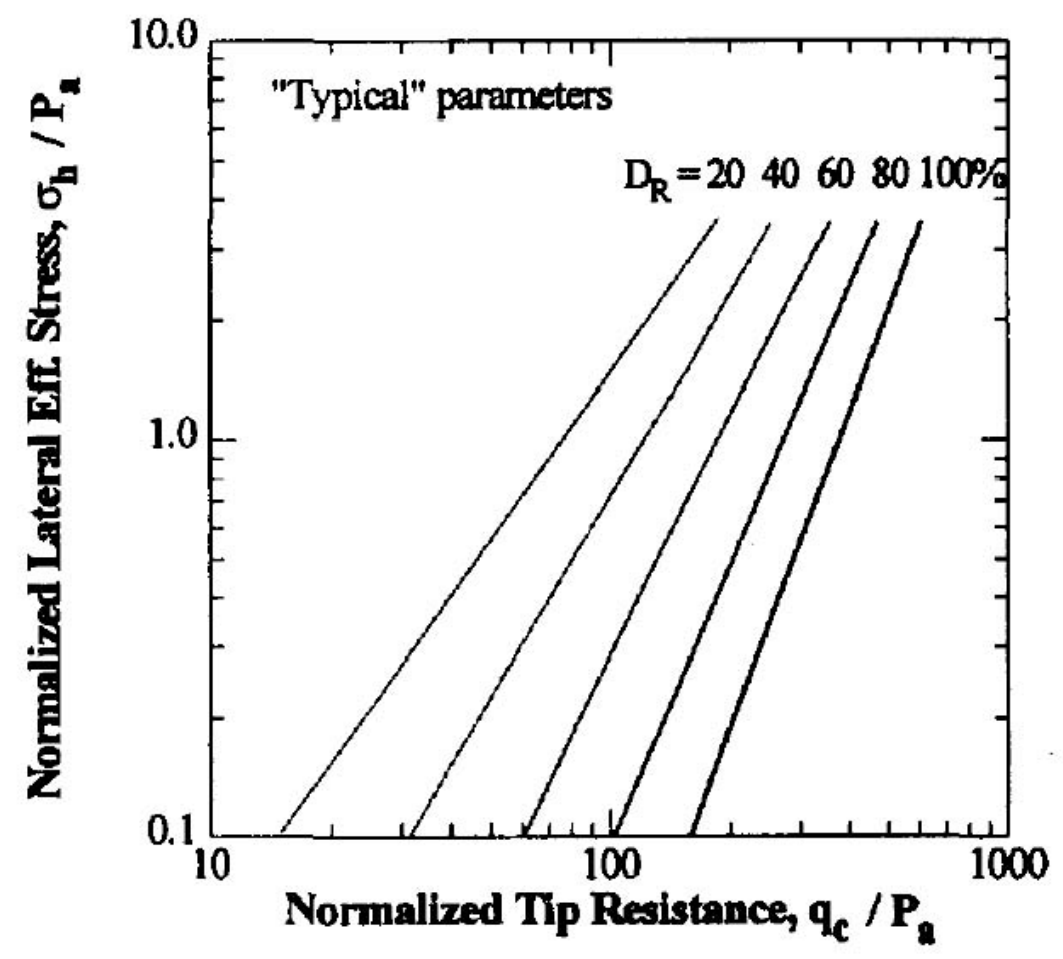

Fig. B.1 Normalized tip resistance versus normalized lateral stress and $D_{R}$ based on CONPOINT results (after Salgado et al.1997) 
(3) Layer 3 (3 5m)

roughly assume $\gamma_{\text {sub }}: \gamma_{\text {sub }}=11 \mathrm{kN} / \mathrm{m}^{3}$

$$
\sigma_{h}=(16.6 \times 2+16.9 \times 1+11 \times 1) \times 0.56=34.2 \mathrm{kPa}
$$

from Fig. B1， $\mathrm{D}_{\mathrm{r}}=75 \%$

$$
D_{r}=\frac{e_{\max }-e}{e_{\max }-e_{\min }} \times 100
$$

from (B.2); $\quad \mathrm{e}=0.48$

under GWT

$$
\begin{aligned}
& \mathrm{G}=2.67 \\
& \gamma_{\text {sat }}=\frac{G_{s}+e}{1+e} \cdot \gamma_{w}=\frac{2.67+0.48}{1+0.48} \cdot 9.8=20.9 \mathrm{kN} / \mathrm{m}^{3} \\
& \gamma_{\text {sub }}=20.9-9.8=11.1 \mathrm{kN} / \mathrm{m}^{3} \\
& \mathrm{~K}=0.8, \quad \delta=30(\text { from table }) \\
& \sigma_{v}^{\prime}=16.6 \times 2+16.9 \times 1+11.1 \times 1=61.2 \mathrm{kPa} \\
& \mathrm{q}_{\mathrm{s} 3}=0.8 \times 61.2 \times \tan 30=28.27 \mathrm{kPa} \\
& \mathrm{q}_{\mathrm{s} 3} \cdot \mathrm{A}_{3}=28.27 \times 2 \times 0.356 \pi=63.23 \mathrm{kN}
\end{aligned}
$$

(4) Layer 4 (5 7m)

roughly assume $\gamma_{d}: \gamma_{d}=11.5 \mathrm{kN} / \mathrm{m}^{3}$

$$
\sigma_{h}=(16.6 \times 2+16.9 \times 1+11.1 \times 2+11.5 \times 1) \times 0.56=46.93 \mathrm{kPa}
$$

from Fig. B1， $\quad \mathrm{D}_{\mathrm{r}}=90 \%$

from (B.2); $\mathrm{e}=0.44$

$$
\begin{aligned}
& \gamma_{\text {sat }}=21.2 \mathrm{kN} / \mathrm{m}^{3}, \quad \gamma_{\text {sub }}=21.2-9.8=11.4 \mathrm{kN} / \mathrm{m}^{3} \\
& \mathrm{~K}=0.8, \quad \delta=35(\text { from Table } 6.1) \\
& \sigma_{v}^{\prime}=16.6 \times 2+16.9 \times 1+11.1 \times 2+11.4 \times 1=83.7 \mathrm{kPa} \\
& \mathrm{q}_{\mathrm{s} 4}=0.8 \times 83.7 \times \tan 35=46.9 \mathrm{kPa} \\
& \mathrm{q}_{\mathrm{s} 4} \cdot \mathrm{A}_{4}=46.9 \times 2 \times 0.356 \pi=104.9 \mathrm{kN}
\end{aligned}
$$

$\mathrm{Q}_{\mathrm{s}}=\mathrm{q}_{\mathrm{s} 1} \cdot \mathrm{A}_{1}+\mathrm{q}_{\mathrm{s} 2} \cdot \mathrm{A}_{2}+\mathrm{q}_{\mathrm{s} 3} \cdot \mathrm{A}_{3}+\mathrm{q}_{\mathrm{s} 4} \cdot \mathrm{A}_{4}=10.8+13.58+63.2+104.9=192.5 \mathrm{kN}$ 
- Base resistance

$$
\begin{gathered}
\mathrm{q}_{\mathrm{b}}=\sigma_{v}^{\prime} \cdot \mathrm{N}_{\mathrm{q}} \\
\sigma_{v}^{\prime}=16.6 \times 2+16.9 \times 1+11.1 \times 2+11.4 \times 2=95.1 \mathrm{kPa} \\
\mathrm{N}_{\mathrm{q}}=50(\text { from Table } 6.1) \\
\mathrm{q}_{\mathrm{b}}=\sigma_{v}^{\prime} \cdot \mathrm{N}_{\mathrm{q}}=95.1 \times 50=4755 \mathrm{kPa} \quad(<12 \mathrm{MPa}, \text { limit value }) \\
\mathrm{Q}_{\mathrm{b}}=\mathrm{q}_{\mathrm{b}} \cdot \mathrm{A}_{\mathrm{p}}=4755 \times \frac{0.356^{2}}{4} \pi=473.3 \mathrm{kN} \\
\therefore \mathrm{Q}_{\mathrm{t}}=\mathrm{Q}_{\mathrm{s}}+\mathrm{Q}_{\mathrm{b}}=192.5+473.3=665.8 \mathrm{kN}
\end{gathered}
$$

(2) Example 2

- Shaft resistance

(1) Layer $1(0 \sim 2.2 \mathrm{~m})$

$$
\begin{aligned}
& \mathrm{K}=0.8, \delta=25 \quad(\text { from Table } 6.1), \\
& \gamma_{d}=18 \mathrm{kN} / \mathrm{m}^{3}, \quad \sigma_{v}^{\prime}=1.1 \times 18=19.8 \mathrm{kPa} \\
& \mathrm{q}_{\mathrm{s} 1}=0.8 \times 19.8 \times \tan 25=7.4 \mathrm{kPa} \\
& \mathrm{q}_{\mathrm{s} 1} \cdot \mathrm{A}_{1}=7.4 \times 2.2 \times 0.356 \pi=18.2 \mathrm{kN}
\end{aligned}
$$

(2) Layer $2(2.2 \sim 5 \mathrm{~m})$

$$
\begin{aligned}
\mathrm{K} & =0.8, \delta=30(\text { from Table } 6.1), \gamma_{\text {wet }}=20 \mathrm{kN} / \mathrm{m}^{3}(2.2 \sim 3.1 \mathrm{~m}), \gamma_{\text {sat }}=21 \mathrm{kN} / \mathrm{m}^{3} \\
\sigma_{v}^{\prime} & =\left[\frac{18 \times 2.2 \times 2+20 \times 0.9}{2} \times 0.9+\frac{(18 \times 2.2+20 \times 0.9) \times 2+(21-9.8) \times 1.9}{2} \times 1.9\right] \div 2.8 \\
& =61.9 \mathrm{kN} / \mathrm{m}^{2} \\
\mathrm{q}_{\mathrm{s} 2} & =0.8 \times 61.9 \times \tan 30=28.6 \mathrm{kPa} \\
\mathrm{q}_{\mathrm{s} 2} & \cdot \mathrm{A}_{2}=28.6 \times 2.8 \times 0.356 \pi=89.6 \mathrm{kN}
\end{aligned}
$$


(3) Layer $3(5 \sim 7 \mathrm{~m})$

$$
\begin{aligned}
& \mathrm{K}=0.8, \delta=35(\text { from table } 6.1), \gamma_{\text {sat }}=21 \mathrm{kN} / \mathrm{m}^{3} \\
& \sigma_{v}^{\prime}=18 \times 2.2+20 \times 0.9+(21-9.8) \times 2.9=90.1 \mathrm{kPa} \\
& \mathrm{q}_{\mathrm{s} 3}=0.8 \times 90.1 \times \tan 35=50.5 \mathrm{kPa} \\
& \mathrm{q}_{\mathrm{s} 3} \cdot \mathrm{A}_{3}=50.5 \times 2 \times 0.356 \pi=113.0 \mathrm{kN} \\
& \mathrm{Q}_{\mathrm{s}}=\mathrm{q}_{\mathrm{s} 1} \cdot \mathrm{A}_{1}+\mathrm{q}_{\mathrm{s} 2} \cdot \mathrm{A}_{2}+\mathrm{q}_{\mathrm{s} 3} \cdot \mathrm{A}_{3}=18.2+89.6+113.0=220.8 \mathrm{kN}
\end{aligned}
$$

- Base resistance

$$
\begin{gathered}
\mathrm{q}_{\mathrm{b}}=\sigma_{v}^{\prime} \cdot \mathrm{N}_{\mathrm{q}} \\
\sigma_{v}^{\prime}=18 \times 2.2+20 \times 0.9+(21-9.8) \times 3.9=101.3 \mathrm{kN} / \mathrm{m}^{2} \\
\mathrm{~N}_{\mathrm{q}}=50 \quad(\text { from Table } 6.1) \\
\mathrm{q}_{\mathrm{b}}=\sigma_{v}^{\prime} \cdot \mathrm{N}_{\mathrm{q}}=101.3 \times 50=5065 \mathrm{kPa} \quad(<12 \mathrm{MPa}, \text { limit value }) \\
\mathrm{Q}_{\mathrm{s}}=\mathrm{q} \cdot \mathrm{A}_{\mathrm{p}}=5065 \times \frac{0.356^{2}}{4} \pi=504.2 \mathrm{kN} \\
\therefore \mathrm{Q}_{\mathrm{d}}=\mathrm{Q}_{\mathrm{s}}+\mathrm{Q}_{\mathrm{b}}=220.8+504.2=725.0 \mathrm{kN}
\end{gathered}
$$




\section{B.1.2 DRIVEN}

\section{(1) Guidelines of running DRIVEN program}

Fig. B.2 shows the main screen for the DRIVEN program. The file menu contains options to create a new file and open an existing pile.

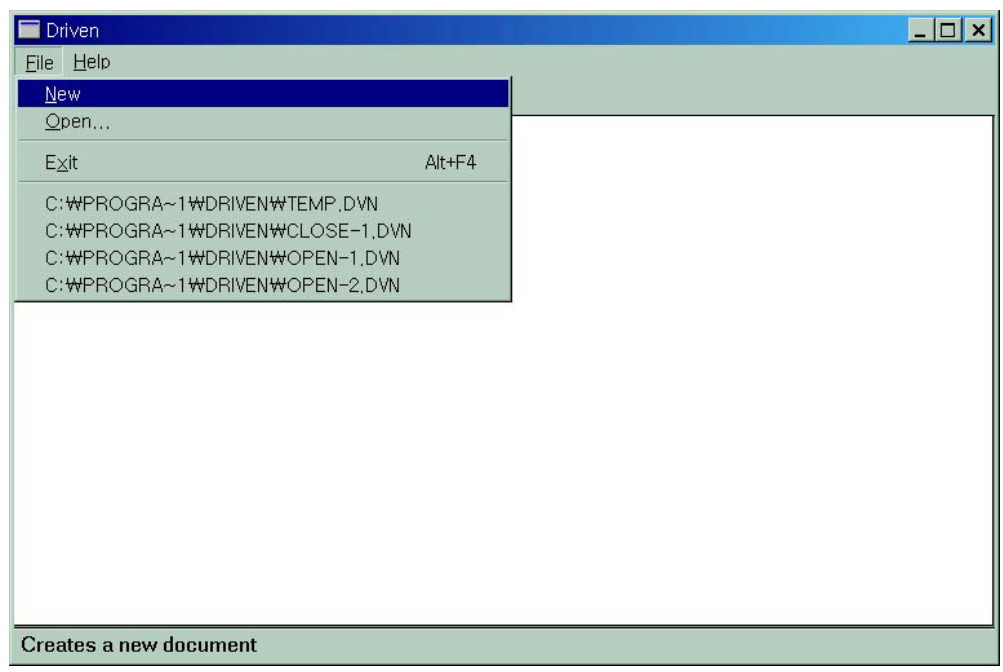

Figure B.2 The driven program, main window.

After selecting the 'New' button on the file menu, input user interface dialog box pops up(Fig. B.3).

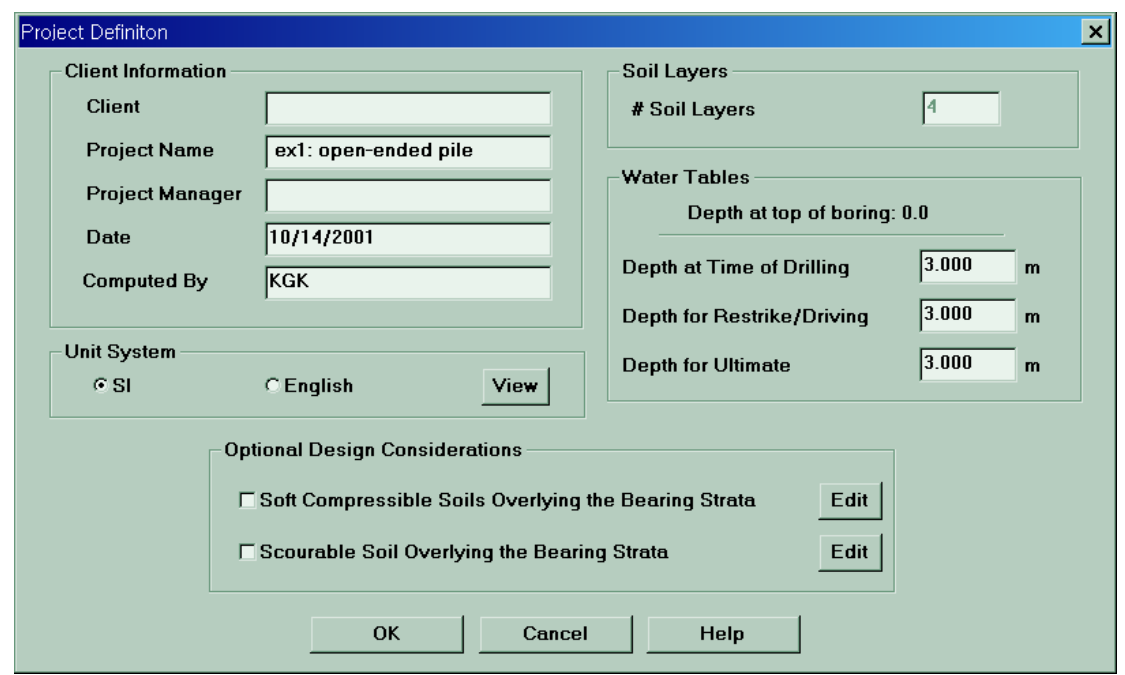

Figure B.3 Project definition input screen 
Fig. B.4 shows an input screen for soil profiles. This screen is where the soil profile is completed along with the pile parameters. The left-hand side of the screen presents a visual representation of the soil profile. The right-hand side of the screen contains two major grouping boxes labeled "Layer General Data" and "Layer Soil Type". The Layer General Data section defines three parameters common to all soil types used within the DRIVEN program. These are depth to bottom of layer, total unit weight of soil, and driving strength loss. The Layer Soil Type section is dependent upon the type of soil chosen for the current layer. If "cohesionless" is selected for soil layer type, the program will prompt two internal friction angles, one for shaft resistance and one for base resistance (DRIVEN 1.0 User's Manual). The dialog box shown in Fig. B.5 allows SPT ' $\mathrm{N}$ ' values to be entered so the DRIVEN program can determine equivalent internal friction angle for the soil layer.

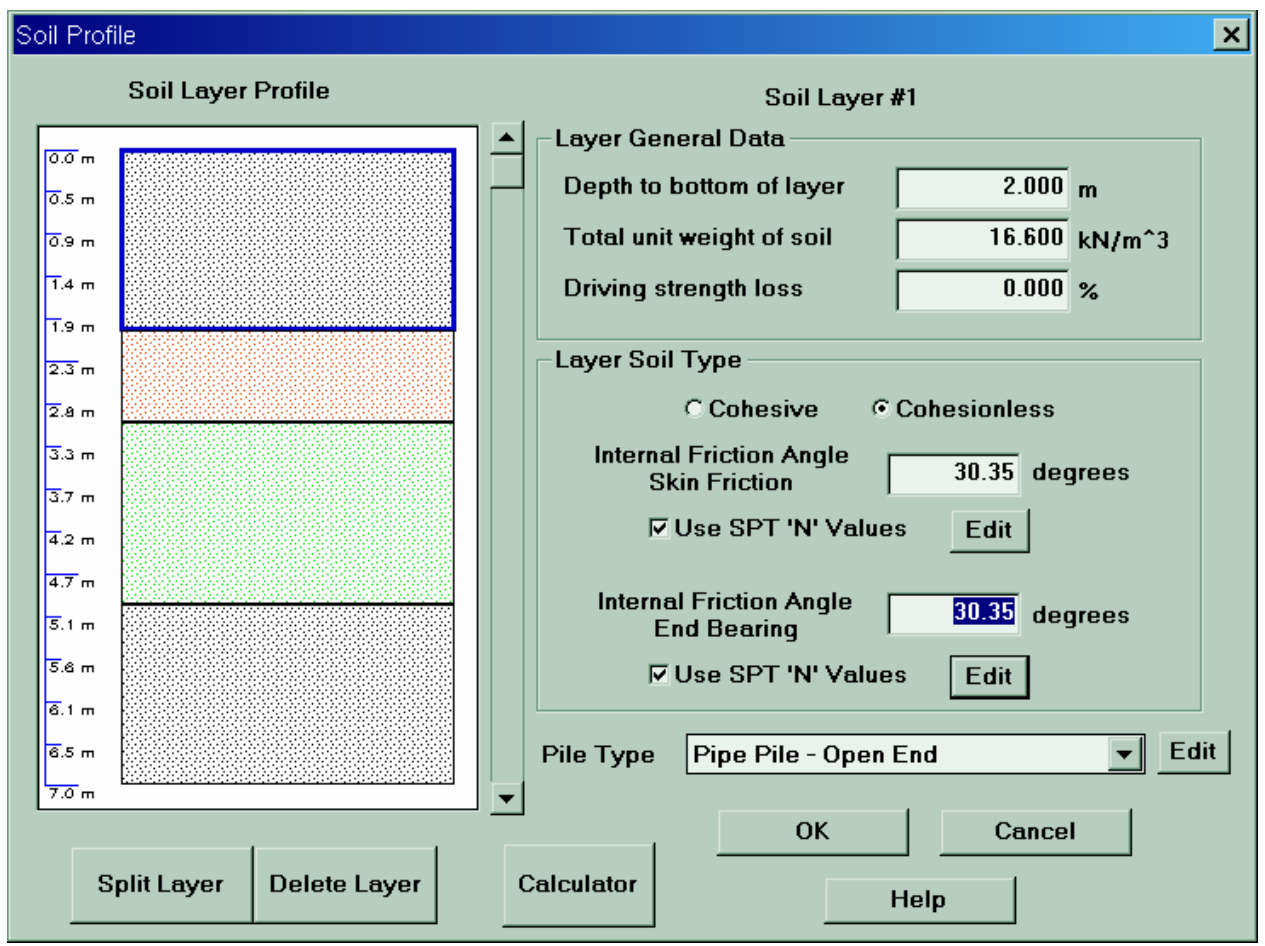

Figure B.4 Soil profile of example 1 


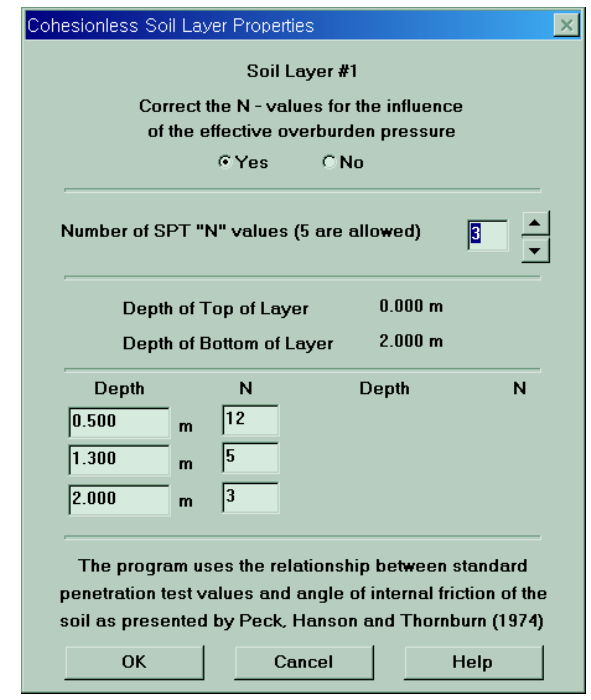

Figure B.5 Dialog box for determining the internal friction angle from SPT 'N' values.

The Pile Type Selection box displays the currently selected pile. If a pile has been selected, pressing the 'Edit' button located just to the right hand side of the pile name can change its parameters. Fig. B.6 shows the pile parameter box of open-ended pipe pile.

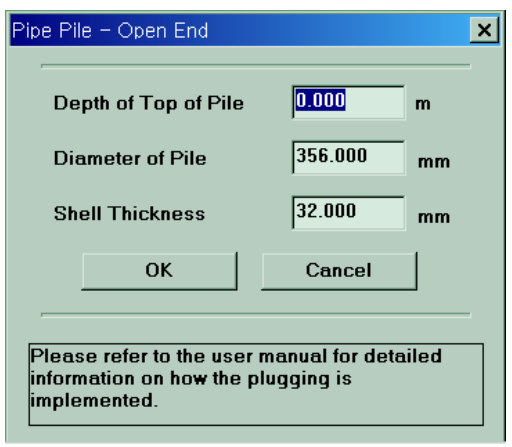

Figure B.6 the dialog box for open-ended pipe pile 
(2) Results of Example 1

Fig. B.7 shows computation results of the open-ended pile of example 1 by DRIVEN program. The capacity section is located in the bottom part of the screen. This section displays the results versus depth for the shaft and base resistance, along with the total capacity.

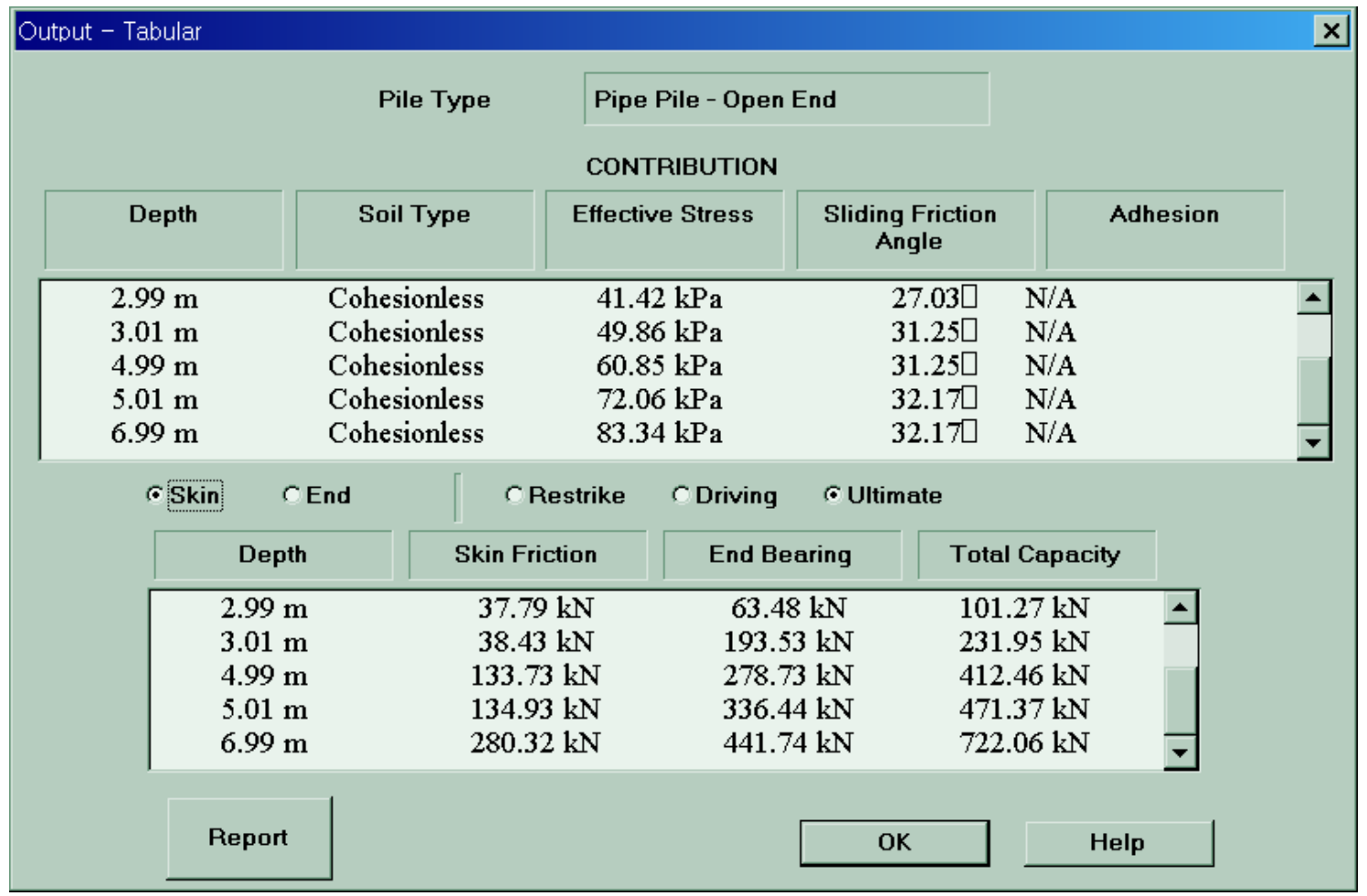

Figure B.7 Results of the open-ended pile of example 1 
(3) Results of Example 2

Fig. B.8 shows the soil layer profile of example 2. The detail description for soil property of example 2 is already shown at section 6.2.2.1.

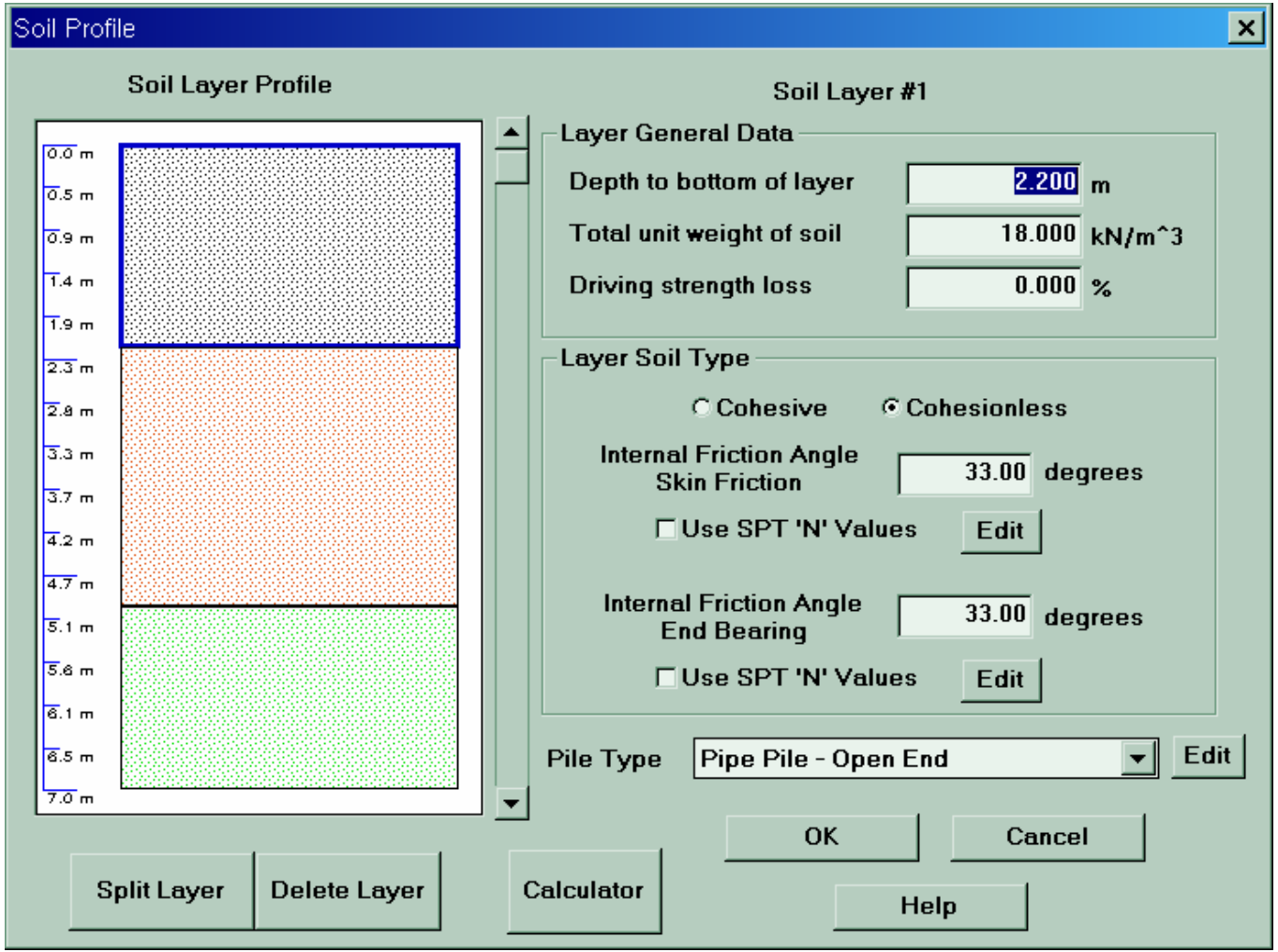

Figure B.8 Soil Profile of example 2 
- Results

Fig. B.9 shows the computation results of example 2. As can be seen in Fig. B.9, the shaft resistance capacity is $349.0 \mathrm{kN}$, base resistance capacity is $809.8 \mathrm{kN}$, and total capacity is $1158.8 \mathrm{kN}$.

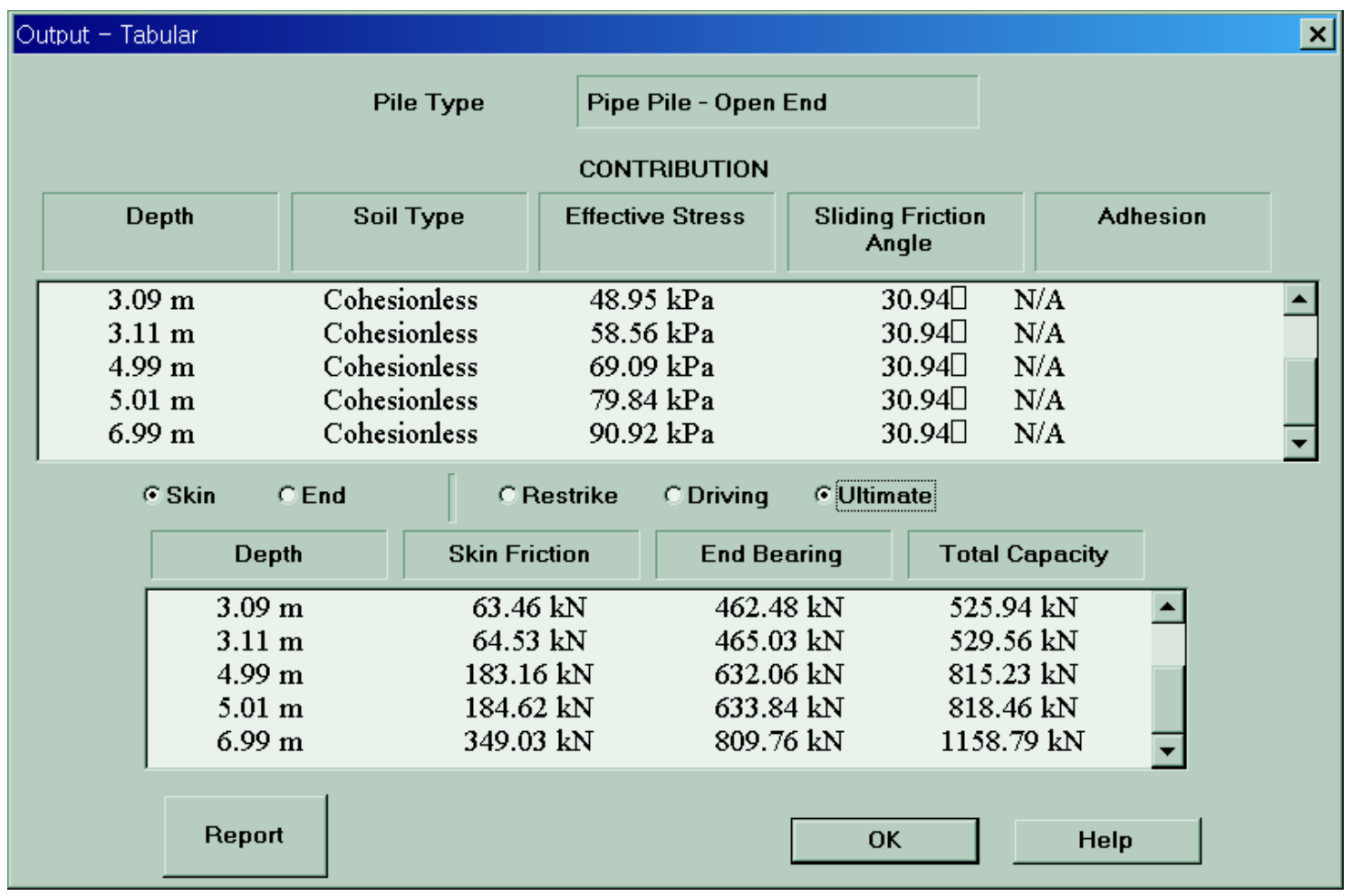

Figure B.9 Results of the open-ended pile of example 2 


\section{B.1.3 Polish Method}

(1) Example 1

- Shaft resistance

(1) Layer $1(0 \sim 2 \mathrm{~m})$

from the previous calculation at B.1.1, $\mathrm{D}_{\mathrm{r}}=38 \%$

from Table 6.5; $\mathrm{q}_{\mathrm{s} 1, \max }=51 \mathrm{kPa} \quad$ ( obtained by interpolation )

critical depth for shaft resistance $=5 \mathrm{~m}$

$\mathrm{q}_{\mathrm{s} 1}=1 / 5 \times 51=10.2 \mathrm{kPa}$

from Table 6.2 and $6.3 ; \mathrm{S}_{\mathrm{s}}=0.9, \mathrm{~b}_{2}=0.61$

$\mathrm{N}_{\mathrm{s} 1}=0.61 \times 0.9 \times 10.2 \times 0.356 \pi \times 2=12.5 \mathrm{kN}$

(2) Layer $2(2 \sim 3 \mathrm{~m})$

$\mathrm{D}_{\mathrm{r}}=50 \%, \quad$ from Table $6.5 ; \mathrm{q}_{\mathrm{s} 2, \max }=60.5 \mathrm{kPa}$

$\mathrm{q}_{\mathrm{s} 2}=2.5 / 5 \times 60.5=30.3 \mathrm{kPa}$

from Table 6.2 and $6.3 ; \mathrm{S}_{\mathrm{s}}=0.9, \mathrm{~b}_{2}=0.61$

$\mathrm{N}_{\mathrm{s} 1}=0.61 \times 0.9 \times 30.3 \times 0.356 \pi \times 1=18.6 \mathrm{kN}$

(3) Layer $3(3 \sim 5 \mathrm{~m})$

$\mathrm{D}_{\mathrm{r}}=75 \%$, from Table $6.5 ; \mathrm{q}_{\mathrm{s} 3, \max }=88.1 \mathrm{kPa}$

$\mathrm{q}_{\mathrm{s} 3}=4 / 5 \times 88.1=70.4 \mathrm{kPa}$

from Table 6.2 and $6.3 ; \mathrm{S}_{\mathrm{s}}=0.8, \mathrm{~b}_{2}=0.4$

$\mathrm{N}_{\mathrm{s} 1}=0.4 \times 0.8 \times 70.4 \times 0.356 \pi \times 2=50.4 \mathrm{kN}$

(4) Layer $4(5 \sim 7 \mathrm{~m})$

from $\mathrm{D}_{\mathrm{r}}=90 \%$, from Table $6.5 ; \mathrm{q}_{\mathrm{s} 4, \max }=114.4 \mathrm{kPa}$

from Table 6.2 and 6.3; $\mathrm{S}_{\mathrm{s}}=0.8, \mathrm{~b}_{2}=0.50$

$\mathrm{N}_{\mathrm{s} 1}=0.5 \times 0.8 \times 114.4 \times 0.356 \pi \times 2=102.4 \mathrm{kN}$

$\sum \mathrm{N}_{\mathrm{s}}=12.5+18.6+50.4+102.4=183.9 \mathrm{kN}$ 
- Base resistance

$$
\begin{aligned}
& \mathrm{S}_{\mathrm{p}}=1.0, \mathrm{~b}_{1}=1.0 \\
& \text { from Table } 6.4, \mathrm{q}_{\mathrm{b}, \max }=5100 \mathrm{kPa} \quad(\text { obtained by interpolation }) \\
& \mathrm{h}_{\mathrm{c}}=10 \mathrm{~m}\left(\mathrm{D}_{\mathrm{i}}=356 \mathrm{~mm}<400 \mathrm{~mm}\right) \\
& \quad \mathrm{q}_{\mathrm{b}}=5100 \times 7 / 10=3570 \mathrm{kN} \\
& \mathrm{N}_{\mathrm{p}}=1.0 \times 1.0 \times 3570 \times 0.356^{2} \cdot \pi / 4=355.4 \mathrm{kN} \\
& \mathrm{N}=\mathrm{N}_{\mathrm{p}}^{\prime}+\mathrm{N}_{\mathrm{s}}^{\prime}=183.9+355.4=539.3 \mathrm{kN} \\
& \quad \mathrm{m}^{\prime}=0.7 \text { for single pile } \\
& \mathrm{Q}_{\mathrm{t}}=\mathrm{mN}=0.7 \times 539.3=377.5 \mathrm{kN}
\end{aligned}
$$

(2) Example 2

(1) Layer 1 (1 2.2m)

average $\mathrm{q}_{\mathrm{c}}=4 \mathrm{MPa}, \mathrm{K}_{\mathrm{o}}=0.7, \sigma_{h}=18 \times 1.1 \times 0.7=13.9 \mathrm{kPa}$

from Fig. B1， $\quad \mathrm{D}_{\mathrm{r}}=43 \%$

from Table $6.5 \mathrm{q}_{\mathrm{s} 1, \max }=40 \mathrm{kPa}$

critical depth for shaft resistance $=5 \mathrm{~m}$

$\mathrm{q}_{\mathrm{s} 1}=1.1 / 5 \times 40=12 \mathrm{kPa}$

from Table 6.2 and 6.3; $\mathrm{b}_{2}=0.61, \mathrm{~S}_{\mathrm{s}}=0.9$

$\mathrm{N}_{\mathrm{s} 1}=0.61 \times 0.9 \times 13.9 \times 0.356 \pi \times 2.2=18.8 \mathrm{kN}$

(2) Layer $2(2.2 \sim 5 \mathrm{~m})$

average $\mathrm{q}_{\mathrm{c}}=23 \mathrm{MPa}, \mathrm{K}_{\mathrm{o}}=0.7$,

$$
\begin{aligned}
\sigma_{h} & =\left[\frac{18 \times 2.2 \times 2+20 \times 0.9}{2} \times 0.9+\frac{(18 \times 2.2+20 \times 0.9) \times 2+(21-9.8) \times 1.9}{2} \times 1.9\right] \div 2.8 \times 0.7 \\
& =43.3 \mathrm{kN} / \mathrm{m}^{2}
\end{aligned}
$$


from Fig. B1,$\quad D_{r}=90 \%$

from Table $6.5 \mathrm{q}_{\mathrm{s} 2, \max }=114 \mathrm{kPa}$

$\mathrm{q}_{\mathrm{s} 2}=3.6 / 5 \times 114=82 \mathrm{kPa}$

from Table 6.2 and 6.3; $\mathrm{b}_{2}=0.37, \quad \mathrm{~S}_{\mathrm{s}}=0.8$

$\mathrm{N}_{\mathrm{s} 1}=0.37 \times 0.8 \times 82 \times 0.356 \pi \times 2.8=76.0 \mathrm{kN}$

(3) Layer $3(5 \sim 7 \mathrm{~m})$

average $\mathrm{q}_{\mathrm{c}}=43 \mathrm{MPa}, \mathrm{K}_{\mathrm{o}}=0.7$,

$\sigma_{h}=\{18 \times 2+20 \times 1.1+(21-9.8) \times 2.9\} \times 0.7=63.3 \mathrm{kPa}$

from Fig. B1， $\quad \mathrm{D}_{\mathrm{r}}=100 \%$

from Table 6.5, $\mathrm{q}_{\mathrm{s} 3, \max }=132 \mathrm{kPa}$

from Table 6.2 and $6.3 ; b_{2}=0.55, \quad \mathrm{~S}_{\mathrm{s}}=0.8$

$\mathrm{N}_{\mathrm{s} 1}=0.55 \times 0.8 \times 132 \times 0.356 \pi \times 2=129.9 \mathrm{kN}$

$\sum \mathrm{N}_{\mathrm{s}}=18.8+76.0+129.9=224.7 \mathrm{kN}$

from Table 6.4, $\mathrm{q}_{\mathrm{c}, \max }=5850 \mathrm{kPa}$

$\mathrm{h}_{\mathrm{c}}=10 \mathrm{~m} \quad\left(\mathrm{D}_{\mathrm{i}}=356 \mathrm{~mm}<400 \mathrm{~mm}\right)$

$\mathrm{q}_{\mathrm{c}}=5850 \times 7 / 10=4095 \mathrm{kN}$

from Table 6.2 and $6.3 ; \quad S_{p}=1.0, b_{1}=1.0$

$$
\begin{aligned}
& \mathrm{N}_{\mathrm{p}}=1.0 \times 1.0 \times 4095 \times 0.356^{2} \cdot \pi / 4=407.6 \mathrm{kN} \\
& \mathrm{N}=\mathrm{N}_{\mathrm{p}}^{\prime}+\mathrm{N}_{\mathrm{s}}^{\prime}=224.7+407.6=632.3 \mathrm{kN} \\
& \quad \mathrm{m}=0.7 \text { for single pile } \\
& \mathrm{Q}_{\mathrm{d}}=\mathrm{mN}=0.7 \times 632.3=442.6 \mathrm{kN}
\end{aligned}
$$




\section{B.1.4 Proposed CPT-based Method}

The new CPT-based design method for open-ended piles was proposed in chapter 5.

Following the Procedure in chapter 5, IFR values were estimated based on the relative density $\mathrm{D}_{\mathrm{R}}$ and the normalized depth $\mathrm{D}_{\mathrm{n}}$.

(1) example 1

- Shaft resistance

(1) layer $1(0 \sim 2 \mathrm{~m})$

average $\mathrm{q}_{\mathrm{c}}=3 \mathrm{MPa}, \mathrm{D}_{\mathrm{r}}=38 \%, \quad \mathrm{D}_{\mathrm{n}}=\frac{1}{0.292}=3.4$

from Fig. 5.11; NIFR=20

$\mathrm{IFR}=3.4 \times 20=68 \%$

from Fig. 5.6 (f)

$\frac{\mathrm{q}_{\mathrm{s}}}{\mathrm{q}_{\mathrm{c}}}=0.0021, \quad \mathrm{q}_{\mathrm{s}}=0.0021 \times 3 \times 10^{3}=6.3 \mathrm{kPa}$

(2) layer $2(2 \sim 3 \mathrm{~m})$

average $\mathrm{q}_{\mathrm{c}}=6 \mathrm{MPa}, \mathrm{D}_{\mathrm{r}}=50 \%, \quad \mathrm{D}_{\mathrm{n}}=\frac{2.5}{0.292}=8.6$

from Fig. 5.11; NIFR $=9$

IFR $=8.6 \times 9=77.4 \%$

From Fig. 5.6 (f)

$\frac{\mathrm{q}_{\mathrm{s}}}{\mathrm{q}_{\mathrm{c}}}=0.0024, \quad \mathrm{q}_{\mathrm{s}}=0.0024 \times 6 \times 10^{3}=14.4 \mathrm{kPa}$

(3) layer $3(3 \sim 5 \mathrm{~m})$

average $\mathrm{q}_{\mathrm{c}}=17 \mathrm{MPa}, \mathrm{D}_{\mathrm{r}}=75 \%, \quad \mathrm{D}_{\mathrm{n}}=\frac{4}{0.292}=13.7$ 
from Fig. 5.11; NIFR $=6$

$\mathrm{IFR}=13.7 \times 6=82.2 \%$

From Fig. 5.6 (f)

$\frac{\mathrm{q}_{\mathrm{s}}}{\mathrm{q}_{\mathrm{c}}}=0.0026, \quad \mathrm{q}_{\mathrm{s}}=0.0026 \times 17 \times 10^{3}=44.2 \mathrm{kPa}$

(4) layer $4(5 \sim 7 \mathrm{~m})$

average $\mathrm{q}_{\mathrm{c}}=22 \mathrm{MPa}, \mathrm{D}_{\mathrm{r}}=90 \%, \quad \mathrm{D}_{\mathrm{n}}=\frac{6}{0.292}=20.5$

from Fig. 5.11; NIFR = 3.1

$\mathrm{IFR}=20.5 \times 3.3=67.7 \%$

From Fig. 5.6 (f)

$\frac{\mathrm{q}_{\mathrm{s}}}{\mathrm{q}_{\mathrm{c}}}=0.0021, \quad \mathrm{q}_{\mathrm{s}}=0.0021 \times 22 \times 10^{3}=46.2 \mathrm{kPa}$

$\mathrm{Q}_{\mathrm{s}}=(6.3 \times 2+14.4 \times 1+44.2 \times 2+46.2 \times 2) \times 0.356 \pi=232.4 \mathrm{kN}$

- Base resistance

$\mathrm{D}_{\mathrm{n}}=\frac{7}{0.292}=24.0$

from Fig. 5.11; NIFR=2.8

IFR $=24.0 \times 2.8=67.2 \%$

From Fig. 5.6 (b)

$$
\begin{aligned}
\frac{\mathrm{q}_{\mathrm{b}}}{\mathrm{q}_{\mathrm{c}}}=0.34, \quad \mathrm{q}_{\mathrm{b}}=22 \times 10^{3} \times 0.34=7480 \mathrm{kPa} \\
\mathrm{Q}_{\mathrm{b}}=7480 \times \frac{0.356^{2} \pi}{4}=744.5 \mathrm{kN} \\
\mathrm{Q}_{\mathrm{t}}=\mathrm{Q}_{\mathrm{b}}+\mathrm{Q}_{\mathrm{s}}=744.5+232.4=976.9 \mathrm{kN}
\end{aligned}
$$


(2) Example 2

- Shaft resistance

(1) layer $1(0 \sim 2.2 \mathrm{~m})$

average $\mathrm{q}_{\mathrm{c}}=4 \mathrm{MPa}, \mathrm{D}_{\mathrm{r}}=43 \%, \quad \mathrm{D}_{\mathrm{n}}=\frac{1.1}{0.324}=3.4$

from Fig. 5.11; $\quad$ NIFR $=21$

$\mathrm{IFR}=3.4 \times 21=71.4 \%$

From Fig. $5.6(f)$

$\frac{\mathrm{q}_{\mathrm{s}}}{\mathrm{q}_{\mathrm{c}}}=0.0022, \quad \mathrm{q}_{\mathrm{s}}=0.0022 \times 4 \times 10^{3}=8.8 \mathrm{kPa}$

(2) layer $2(2.2 \sim 5 \mathrm{~m})$

average $\mathrm{q}_{\mathrm{c}}=23 \mathrm{MPa}, \mathrm{D}_{\mathrm{r}}=90 \%, \quad \mathrm{D}_{\mathrm{n}}=\frac{3.6}{0.324}=11.1$

from Fig. 5.11; NIFR $=7$

$\mathrm{IFR}=11.1 \times 6.4=77.7 \%$

From Fig. 5.6 (f)

$\frac{\mathrm{q}_{\mathrm{s}}}{\mathrm{q}_{\mathrm{c}}}=0.0025, \quad \mathrm{q}_{\mathrm{s}}=0.0025 \times 23 \times 10^{3}=57.5 \mathrm{kPa}$

(3) layer $3(5 \sim 7 \mathrm{~m})$

average $\mathrm{q}_{\mathrm{c}}=43 \mathrm{MPa}, \mathrm{D}_{\mathrm{r}}=100 \%, \quad \mathrm{D}_{\mathrm{n}}=\frac{6}{0.324}=18.5$

from Fig. 5.11; $\quad$ NIFR $=3.8$

$\mathrm{IFR}=18.5 \times 3.8=70.3 \%$

From Fig. 5.6 (f)

$\frac{\mathrm{q}_{\mathrm{s}}}{\mathrm{q}_{\mathrm{c}}}=0.0022, \quad \mathrm{q}_{\mathrm{s}}=0.0022 \times 43 \times 10^{3}=94.6 \mathrm{kPa}$

$\mathrm{Q}_{\mathrm{s}}=(8.8 \times 2.2+57.5 \times 2.8+94.6 \times 2) \times 0.356 \pi=413.3 \mathrm{kN}$ 
- Base resistance

$$
\begin{aligned}
& \mathrm{D}_{\mathrm{n}}=\frac{7}{0.324}=21.6 \\
& \text { from Fig. 5.11; NIFR }=3.1 \\
& \text { IFR=21.6×3.1=67.0\% } \\
& \text { From Fig. 5.6 (b) } \\
& \frac{\mathrm{q}_{\mathrm{b}}}{\mathrm{q}_{\mathrm{c}}}=0.34, \quad \mathrm{q}_{\mathrm{b}}=43 \times 10^{3} \times 0.34=14,620 \mathrm{kPa} \\
& \mathrm{Q}_{\mathrm{b}}=14,620 \times \frac{0.356^{2} \pi}{4}=1,455.2 \mathrm{kN} \\
& \therefore \mathrm{Q}_{\mathrm{t}}=\mathrm{Q}_{\mathrm{b}}+\mathrm{Q}_{\mathrm{s}}=1,455.2+413.3=1,868.5 \mathrm{kN}
\end{aligned}
$$




\section{B.2 Closed-Ended Piles}

\section{B.2.1 Proposed CPT-based Method}

(1) Example 1

- Shaft resistance

(1) Layer $1(0 \sim 2 \mathrm{~m})$

average $\mathrm{q}_{\mathrm{c}}=3 \mathrm{MPa}$, average $\mathrm{N}=7$

roughly assume $\gamma_{d}$ to obtain $\mathrm{D}_{\mathrm{r}}$ from correlation graph: $\gamma_{d}=16.6 \mathrm{kN} / \mathrm{m}^{3}$

$$
\begin{aligned}
& \mathrm{K}_{\mathrm{o}}=(1-\sin \phi) \mathrm{OCR}{ }^{\sin \phi}=(1-\sin 33.3) \cdot 1.5^{\sin 33.3}=0.56 \\
& \sigma_{h}=16.6 \times 1 \times 0.56=9.30
\end{aligned}
$$

from Fig. B. 1, $\mathrm{D}_{\mathrm{r}}=38 \%$

from Fig. 5.7 (b)

$$
\frac{\mathrm{q}_{\mathrm{s}}}{\mathrm{q}_{\mathrm{c}}}=0.0051, \quad \mathrm{q}_{\mathrm{s}}=0.0051 \times 3 \times 10^{3}=15.3 \mathrm{kPa}
$$

(2) Layer $2(2 \sim 3 \mathrm{~m})$

average $\mathrm{q}_{\mathrm{c}}=4 \mathrm{MPa}$, average $\mathrm{N}=7$, roughly assume $\gamma_{d}=16.9 \mathrm{kN} / \mathrm{m}^{3}$

$$
\sigma_{h}=(16.6 \times 2+16.9 \times 0.5) \times 0.56=23.3 \mathrm{kPa}
$$

from Fig. B.1, $\mathrm{D}_{\mathrm{r}}=35 \%$

from Fig. 5.7 (b)

$$
\frac{\mathrm{q}_{\mathrm{s}}}{\mathrm{q}_{\mathrm{c}}}=0.0053, \quad \mathrm{q}_{\mathrm{s}}=0.0053 \times 4 \times 10^{3}=21.2 \mathrm{kPa}
$$

(3) Layer 3 (3 5m)

average $\mathrm{q}_{\mathrm{c}}=15 \mathrm{MPa}$, average $\mathrm{N}=20$, roughly assume $\gamma_{d}=11 \mathrm{kN} / \mathrm{m}^{3}$

$$
\sigma_{h}=(16.6 \times 2+16.9 \times 1+11 \times 1) \times 0.56=34.2 \mathrm{kPa}
$$

from Fig. B.1, $\mathrm{D}_{\mathrm{r}}=70 \%$

from Fig. 5.7 (b) 
$\frac{\mathrm{q}_{\mathrm{s}}}{\mathrm{q}_{\mathrm{c}}}=0.0053, \quad \mathrm{q}_{\mathrm{s}}=0.0053 \times 15 \times 10^{3}=79.5 \mathrm{kPa}$

(4) Layer 4 (5 6.87m)

average $\mathrm{q}_{\mathrm{c}}=19 \mathrm{MPa}$, average $\mathrm{N}=27$, roughly assume $\gamma_{d}=11.5 \mathrm{kN} / \mathrm{m}^{3}$

$\sigma_{h}=(16.6 \times 2+16.9 \times 1+11.1 \times 2+11.5 \times 0.94) \times 0.56=46.5 \mathrm{kPa}$

from Fig. B1， $\mathrm{D}_{\mathrm{r}}=80 \%$

from Fig. 5.7 (b),

$\frac{\mathrm{q}_{\mathrm{s}}}{\mathrm{q}_{\mathrm{c}}}=0.0061, \quad \mathrm{q}_{\mathrm{s}}=0.0061 \times 19 \times 10^{3}=115.9 \mathrm{kN} / \mathrm{m}^{2}$

$\mathrm{Q}_{\mathrm{s}}=(15.3 \times 2+21.2 \times 1+78 \times 2+115.9 \times 1.87) \times 0.356 \pi=474.8 \mathrm{kN}$

- Base resistance

average $\mathrm{q}_{\mathrm{c}}=19 \mathrm{MPa}, \mathrm{D}_{\mathrm{r}}=80 \%$

from the Fig. 5.7 (a)

$\frac{\mathrm{q}_{\mathrm{b}}}{\mathrm{q}_{\mathrm{c}}}=0.46, \quad \mathrm{q}_{\mathrm{b}}=0.46 \times 19 \times 10^{3}=8740 \mathrm{kN} / \mathrm{m}^{2}$

$\mathrm{Q}_{\mathrm{b}}=8740 \times \frac{0.356^{2} \pi}{4}=870.0 \mathrm{kN}$

$\mathrm{Q}_{\mathrm{t}}=\mathrm{Q}_{\mathrm{s}}+\mathrm{Q}_{\mathrm{b}}=474.8+870.0=1344.8 \mathrm{kN}$

(2) Example 2

(1) Layer $1(0 \sim 2.2 \mathrm{~m})$

average $\mathrm{q}_{\mathrm{c}}=4 \mathrm{MPa}, \mathrm{D}_{\mathrm{r}}=43 \%$

from the Fig. 5.7 (b)

$\frac{\mathrm{q}_{\mathrm{s}}}{\mathrm{q}_{\mathrm{c}}}=0.0046, \quad \mathrm{q}_{\mathrm{s}}=0.0046 \times 4 \times 10^{3}=18.4 \mathrm{kPa}$

(2) Layer $2(2.2 \sim 5 \mathrm{~m})$ 
average $\mathrm{q}_{\mathrm{c}}=23 \mathrm{MPa}, \mathrm{D}_{\mathrm{r}}=90 \%$

from the Fig. 5.7 (b)

$$
\frac{\mathrm{q}_{\mathrm{s}}}{\mathrm{q}_{\mathrm{c}}}=0.0065, \quad \mathrm{q}_{\mathrm{s}}=0.0065 \times 23 \times 10^{3}=149.5 \mathrm{kPa}
$$

\section{(3) Layer $3(5 \sim 6.75 \mathrm{~m})$}

average $\mathrm{q}_{\mathrm{c}}=43 \mathrm{MPa}, \mathrm{D}_{\mathrm{r}}=100 \%$

from the Fig. 5.7 (b)

$$
\frac{\mathrm{q}_{\mathrm{s}}}{\mathrm{q}_{\mathrm{c}}}=0.007, \quad \mathrm{q}_{\mathrm{s}}=0.007 \times 43 \times 10^{3}=301.0 \mathrm{kPa}
$$

$$
\mathrm{Q}_{\mathrm{s}}=(18.4 \times 2.2+149.5 \times 2.8+301 \times 1.75) \times 0.356 \pi=1102.6 \mathrm{kN}
$$

- Base resistance

average $\mathrm{q}_{\mathrm{c}}=43 \mathrm{MPa}, \mathrm{D}_{\mathrm{r}}=100 \%$

from the Fig. 5.7 (a)

$$
\frac{\mathrm{q}_{\mathrm{b}}}{\mathrm{q}_{\mathrm{c}}}=0.38, \quad \mathrm{q}_{\mathrm{b}}=0.38 \times 43 \times 10^{3}=16,340 \mathrm{kPa}
$$

$$
\mathrm{Q}_{\mathrm{b}}=16,340 \times \frac{0.356^{2} \pi}{4}=1,626.5 \mathrm{kN}
$$

$\mathrm{Q}_{\mathrm{t}}=\mathrm{Q}_{\mathrm{s}}+\mathrm{Q}_{\mathrm{b}}=1102.6+1626.5=2729.1 \mathrm{kN}$ 


\section{B.2.2 Meyerhof's Method (Example 1)}

- Shaft resistance

(1) Layer 1 and $2(0 \sim 3 \mathrm{~m})$

average $\mathrm{N}=7$

For large-displacement piles in cohesionless soil

$$
\mathrm{q}_{\mathrm{s}}=\frac{\mathrm{P}_{\mathrm{a}}}{50} \mathrm{~N}_{60}=2 \times 7=14 \mathrm{kN} / \mathrm{m}^{2}
$$

(2) Layer $3(3 \sim 5 \mathrm{~m})$

average $\mathrm{N}=20$

$\mathrm{q}_{\mathrm{s}}=2 \times 20=40 \mathrm{kN} / \mathrm{m}^{2}$

(3) Layer $4(5 \sim 6.87 \mathrm{~m})$

average $\mathrm{N}=26$

$$
\mathrm{q}_{\mathrm{s}}=2 \times 26=52 \mathrm{kN} / \mathrm{m}^{2}
$$

$\mathrm{Q}_{\mathrm{s}}=(14 \times 3+40 \times 2+52 \times 1.87) \times 0.356 \pi=245.2 \mathrm{kN}$

- Base resistance

$$
\begin{aligned}
& \quad 0.4 \mathrm{~N}_{60} \frac{\mathrm{D}}{\mathrm{B}} \mathrm{P}_{\mathrm{a}}=0.4 \times 26 \times 6.87 / 0.356 \times 100=20,069 \mathrm{kPa} \\
& 4.0 \mathrm{~N}_{60} \mathrm{P}_{\mathrm{a}}=4 \times 26 \times 100=10,400 \mathrm{kPa}<20,069 \mathrm{kPa} \\
& \therefore \mathrm{q}_{\mathrm{b}}=10,400 \mathrm{kN} / \mathrm{m}^{2} \\
& \mathrm{Q}_{\mathrm{b}}=10,400 \times \frac{0.356^{2} \pi}{4}=1035 \mathrm{kN} \\
& \mathrm{Q}_{\mathrm{d}}=\mathrm{Q}_{\mathrm{s}}+\mathrm{Q}_{\mathrm{b}}=245.2+1035=1280.2 \mathrm{kN}
\end{aligned}
$$




\section{B.2.3 Aoki-Vello's SPT Method (Example 1)}

- Shaft resistance

Steel pile: $F_{1}=1.75, F_{2}=3.5$ (from Table 6.11)

Sand: $\mathrm{K}=10 \mathrm{P}_{\mathrm{a}}=1000 \mathrm{kPa} ， \alpha_{1}=0.014$ (from Table 6.10)

$\mathrm{n}_{\mathrm{s}}=\frac{\alpha_{1} \mathrm{~K}}{\mathrm{~F}_{2}}=\frac{0.014 \times 1000}{3.5}=4$,

(1) Layer 1 and $2(0 \sim 3 m)$

- $\mathrm{N}$ value used at Aoki's method is for $72 \%$ velocity energy ratio. For the consistency, the observed $\mathrm{N}$ value should be corrected to the value which would have been measured with $72 \%$ energy ratio.

$$
\begin{aligned}
& \mathrm{N}_{72}=7 \times 0.6 / 0.72 \approx 6 \\
& \text { from }(6.14), \quad \mathrm{q}_{\mathrm{s} 1}=4 \times 6=24 \mathrm{kPa}
\end{aligned}
$$

(2) Layer $3(3 \sim 5 \mathrm{~m})$

$$
\mathrm{N}_{72}=20 \times 0.6 / 0.72 \approx 17
$$

from (6.14), $\quad \mathrm{q}_{\mathrm{s} 2}=4 \times 17=68 \mathrm{kPa}$

(3) Layer $4(5 \sim 6.87 \mathrm{~m})$

$$
\mathrm{N}_{72}=26 \times 0.6 / 0.72 \approx 22
$$

from (6.14), $\quad \mathrm{q}_{\mathrm{s} 3}=4 \times 22=88 \mathrm{kPa}$

$\mathrm{Q}_{\mathrm{s}}=(24 \times 3+68 \times 2+88 \times 1.87) \times 0.356 \pi=416.7 \mathrm{kN}$

- Base resistance

$$
\mathrm{n}_{\mathrm{b}}=\frac{\mathrm{K}}{\mathrm{F}_{1}}=\frac{1000}{1.75}=571.4
$$

from (6.13), $\quad \mathrm{q}_{\mathrm{b}}=571.4 \times 22=12,570.8 \mathrm{kPa}$

$$
\begin{gathered}
\mathrm{Q}_{\mathrm{b}}=12570.8 \times \frac{0.356^{2} \pi}{4}=1251.3 \mathrm{kN} \\
\mathrm{Q}_{\mathrm{d}}=\mathrm{Q}_{\mathrm{s}}+\mathrm{Q}_{\mathrm{b}}=416.7+1251.3=1668.0 \mathrm{kN}
\end{gathered}
$$




\section{B.2.4 Bazaraa and Kurkur's Method (Example 1)}

Pile category : II

$$
\begin{aligned}
& \mathrm{B} / \mathrm{B}_{\mathrm{R}}=0.356 \\
& \mathrm{n}_{\mathrm{s}}=0.022 \mathrm{P}_{\mathrm{A}}=2.2, \quad \mathrm{n}_{\mathrm{b}}=2 \mathrm{P}_{\mathrm{A}}=200 \quad(\text { from Table } 6.13)
\end{aligned}
$$

- Shaft resistance

(1) Layer 1 and $2(0 \sim 3 \mathrm{~m})$

$$
\begin{aligned}
& \text { average } \mathrm{N}=7 \\
& \mathrm{q}_{\mathrm{s}}=2.2 \times 7=15.4 \mathrm{kPa}
\end{aligned}
$$

(2) Layer $3(3 \sim 5 \mathrm{~m})$

$$
\begin{aligned}
\text { average } \mathrm{N} & =20 \\
\mathrm{q}_{\mathrm{s}}=2.2 \times 20 & =44 \mathrm{kPa}
\end{aligned}
$$

(3) Layer $4(5 \sim 6.87 \mathrm{~m})$ average $\mathrm{N}=26$

$$
\mathrm{q}_{\mathrm{s}}=2.2 \times 26=57.2 \mathrm{kPa}
$$$$
\mathrm{Q}_{\mathrm{s}}=(15.4 \times 3+44 \times 2+57.2 \times 1.87) \times 0.356 \pi=269.7 \mathrm{kN}
$$

- Base resistance

$$
\begin{gathered}
\mathrm{q}_{\mathrm{b}}=200 \times 26=5200 \mathrm{kPa} \\
\mathrm{Q}_{\mathrm{b}}=5200 \times \frac{0.356^{2} \pi}{4}=517.6 \mathrm{kN} \\
\mathrm{Q}_{\mathrm{d}}=\mathrm{Q}_{\mathrm{s}}+\mathrm{Q}_{\mathrm{b}}=269.7+517.6=787.3 \mathrm{kN}
\end{gathered}
$$




\section{B.2.5 LCPC Method}

(1) Example 1

- Shaft resistance

(1) Layer $1(0 \sim 2 \mathrm{~m})$

from Table 6.14, $\alpha_{2}=120$

$$
\mathrm{C}_{\mathrm{si}}=1 / \alpha_{2}=1 / 120=0.0083
$$

average $\mathrm{q}_{\mathrm{c}}=3 \mathrm{MPa}$

$$
\mathrm{q}_{\mathrm{s}}=0.0083 \times 3 \times 10^{3}=24.9 \mathrm{kPa}
$$

(2) Layer $2(2 \sim 3 \mathrm{~m})$

$$
\alpha_{2}=120, \quad C_{s i}=1 / \alpha_{2}=1 / 120=0.0083
$$

average $\mathrm{q}_{\mathrm{c}}=4 \mathrm{MPa}$

$\mathrm{q}_{\mathrm{s}}=0.0083 \times 4 \times 10^{3}=33.2 \mathrm{kPa}$

(3) Layer $3(3 \sim 5 \mathrm{~m})$

$$
\alpha_{2}=200, \mathrm{C}_{\mathrm{si}}=1 / \alpha_{2}=1 / 200=0.005
$$

average $\mathrm{q}_{\mathrm{c}}=15 \mathrm{MPa}$

$$
\mathrm{q}_{\mathrm{s}}=0.005 \times 15 \times 10^{3}=75 \mathrm{kPa}
$$

(4) Layer $4(5 \sim 6.87 \mathrm{~m})$

$$
\begin{aligned}
& \alpha_{2}=200, \mathrm{C}_{\mathrm{si}}=1 / \alpha_{2}=1 / 200=0.005 \\
& \text { average } \mathrm{q}_{\mathrm{c}}=19 \mathrm{MPa} \\
& \mathrm{q}_{\mathrm{s}}=0.005 \times 19 \times 10^{3}=95 \mathrm{kPa} \\
& \mathrm{Q}_{\mathrm{s}}=(24.9 \times 2+33.2 \times 1+75 \times 2+95 \times 1.87) \times 0.356 \pi=459.27 \mathrm{kN}
\end{aligned}
$$

- Base resistance

From Table 6.15, $\mathrm{C}_{\mathrm{b}}=0.4$

$\mathrm{q}_{\mathrm{b}}=0.4 \times 19 \times 10^{3}=7600 \mathrm{kPa}$ 


$$
\begin{gathered}
Q_{b}=7600 \times \frac{0.356^{2} \pi}{4}=756.5 \mathrm{kN} \\
Q_{t}=Q_{s}+Q_{b}=459.3+756.5=1215.8 \mathrm{kN}
\end{gathered}
$$

(2) Example 2

- Shaft resistance

(1) Layer $1(0 \sim 2.2 \mathrm{~m})$

$$
\begin{aligned}
& \alpha_{2}=120, \mathrm{C}_{\mathrm{s} 1}=1 / \alpha_{2}=1 / 120=0.0083 \\
& \text { average } \mathrm{q}_{\mathrm{c}}=4 \mathrm{MPa} \\
& \mathrm{q}_{\mathrm{s} 1}=0.0083 \times 4 \times 10^{3}=33.2 \mathrm{kPa}
\end{aligned}
$$

(2) Layer $2(2.2 \sim 5 \mathrm{~m})$

$$
\alpha_{2}=200, \mathrm{C}_{\mathrm{s} 2}=1 / \alpha_{2}=1 / 200=0.005
$$

average $\mathrm{q}_{\mathrm{c}}=23 \mathrm{MPa}$

$$
\mathrm{q}_{\mathrm{s} 2}=0.005 \times 23 \times 10^{3}=115 \mathrm{kPa}
$$

(3) Layer $3(5 \sim 6.75 \mathrm{~m})$

$$
\begin{aligned}
& \alpha_{2}=200, \mathrm{C}_{\mathrm{s} 3}=1 / \alpha_{2}=1 / 200=0.005 \\
& \text { average } \mathrm{q}_{\mathrm{c}}=43 \mathrm{MPa} \\
& \mathrm{q}_{\mathrm{s} 3}=0.005 \times 43 \times 10^{3}=215 \mathrm{kPa}, \text { but maximum } \mathrm{q}_{\mathrm{s}}=200 \mathrm{kN} / \mathrm{m}^{2} \\
& \mathrm{Q}_{\mathrm{s}}=(33.2 \times 2.2+115 \times 2.8+200 \times 1.75) \times 0.356 \pi=833.3 \mathrm{kN}
\end{aligned}
$$

- Base resistance

From Table 6.15, $\mathrm{C}_{\mathrm{b}}=0.4$

$$
\begin{gathered}
\mathrm{q}_{\mathrm{b}}=0.4 \times 43 \times 10^{3}=17,200 \mathrm{kPa} \\
\mathrm{Q}_{\mathrm{b}}=17,200 \times \frac{0.356^{2} \pi}{4}=1712.1 \mathrm{kN} \\
\mathrm{Q}_{\mathrm{t}}=\mathrm{Q}_{\mathrm{s}}+\mathrm{Q}_{\mathrm{b}}=833.3+1712.1=2545.4 \mathrm{kN}
\end{gathered}
$$




\section{B.2.6 Aoki \& Velloso's CPT Method}

(1) Example 1

Steel pile: $F_{1}=1.75, F_{2}=3.5$

$$
\mathrm{c}_{\mathrm{s}}=\frac{\alpha_{1}}{\mathrm{~F}_{2}}=\frac{0.014}{3.5}=0.004
$$

- Shaft resistance

(1) Layer $1(0 \sim 2 \mathrm{~m})$

$$
\text { average } \mathrm{q}_{\mathrm{c}}=3 \mathrm{MPa}
$$

$$
\mathrm{q}_{\mathrm{s}}=0.004 \times 3 \times 10^{3}=12 \mathrm{kPa}
$$

(2) Layer $2(2 \sim 3 \mathrm{~m})$

$$
\text { average } \mathrm{q}_{\mathrm{c}}=4 \mathrm{MPa}
$$

$\mathrm{q}_{\mathrm{s}}=0.004 \times 4 \times 10^{3}=16 \mathrm{kPa}$

(3) Layer $3(3 \sim 5 \mathrm{~m})$

$$
\begin{aligned}
& \text { average } \mathrm{q}_{\mathrm{c}}=15 \mathrm{MPa} \\
& \mathrm{q}_{\mathrm{s}}=0.004 \times 15 \times 10^{3}=60 \mathrm{kPa}
\end{aligned}
$$

(4) Layer $4(5 \sim 6.87 \mathrm{~m})$

$$
\begin{aligned}
& \text { average } \mathrm{q}_{\mathrm{c}}=19 \mathrm{MPa} \\
& \mathrm{q}_{\mathrm{s}}=0.004 \times 19 \times 10^{3}=76 \mathrm{kPa} \\
& \mathrm{Q}_{\mathrm{s}}=(12 \times 2+16 \times 1+60 \times 2+76 \times 1.87) \times 0.356 \pi=337.9 \mathrm{kN}
\end{aligned}
$$

- Base resistance

$$
\begin{aligned}
& \mathrm{c}_{\mathrm{b}}=\frac{1}{\mathrm{~F}_{1}}=\frac{1}{1.75}=0.571 \\
& \mathrm{q}_{\mathrm{b}}=0.571 \times 19 \times 10^{3}=10,849 \mathrm{kPa}
\end{aligned}
$$




$$
\begin{gathered}
Q_{b}=10,849 \times \frac{0.356^{2} \pi}{4}=1079.9 \mathrm{kN} \\
Q_{t}=Q_{s}+Q_{b}=337.9+1079.9=1417.8 \mathrm{kN}
\end{gathered}
$$

(2) Example 2

Steel pile: $F_{1}=1.75, F_{2}=3.5$

$$
\mathrm{c}_{\mathrm{s}}=\frac{\alpha_{1}}{\mathrm{~F}_{2}}=\frac{0.014}{3.5}=0.004
$$

(1) Layer $1(0 \sim 2.2 \mathrm{~m})$

$$
\text { average } \mathrm{q}_{\mathrm{c}}=4 \mathrm{MPa}
$$

$$
\mathrm{q}_{\mathrm{s}}=0.004 \times 4 \times 10^{3}=16 \mathrm{kPa}
$$

(2) Layer $2(2.2 \sim 5 \mathrm{~m})$

$$
\begin{aligned}
& \text { average } \mathrm{q}_{\mathrm{c}}=23 \mathrm{MPa} \\
& \mathrm{q}_{\mathrm{s}}=0.004 \times 23 \times 10^{3}=92 \mathrm{kPa}
\end{aligned}
$$

(3) Layer $3(5 \sim 6.75 \mathrm{~m})$

$$
\begin{aligned}
& \text { average } \mathrm{q}_{\mathrm{c}}=43 \mathrm{MPa} \\
& \mathrm{q}_{\mathrm{s}}=0.004 \times 43 \times 10^{3}=172 \mathrm{kPa} \\
& \mathrm{Q}_{\mathrm{s}}=(16 \times 2.2+92 \times 2.8+172 \times 1.75) \times 0.356 \pi=664.1 \mathrm{kN}
\end{aligned}
$$

- Base resistance

$$
\begin{gathered}
\mathrm{c}_{\mathrm{b}}=\frac{1}{\mathrm{~F}_{1}}=\frac{1}{1.75}=0.571 \\
\mathrm{q}_{\mathrm{b}}=0.571 \times 43 \times 10^{3}=24,553 \mathrm{kPa} \\
\mathrm{Q}_{\mathrm{b}}=24,553 \times \frac{0.356^{2} \pi}{4}=2444.0 \mathrm{kN} \\
\mathrm{Q}_{\mathrm{t}}=\mathrm{Q}_{\mathrm{s}}+\mathrm{Q}_{\mathrm{b}}=664.1+2444.0=3108.1 \mathrm{kN}
\end{gathered}
$$




\section{B.2.7 DRIVEN Program}

(1) Example 1

Figs. B.10 and B.11 show calculation results of example 1 and 2 from the program DRIVEN.

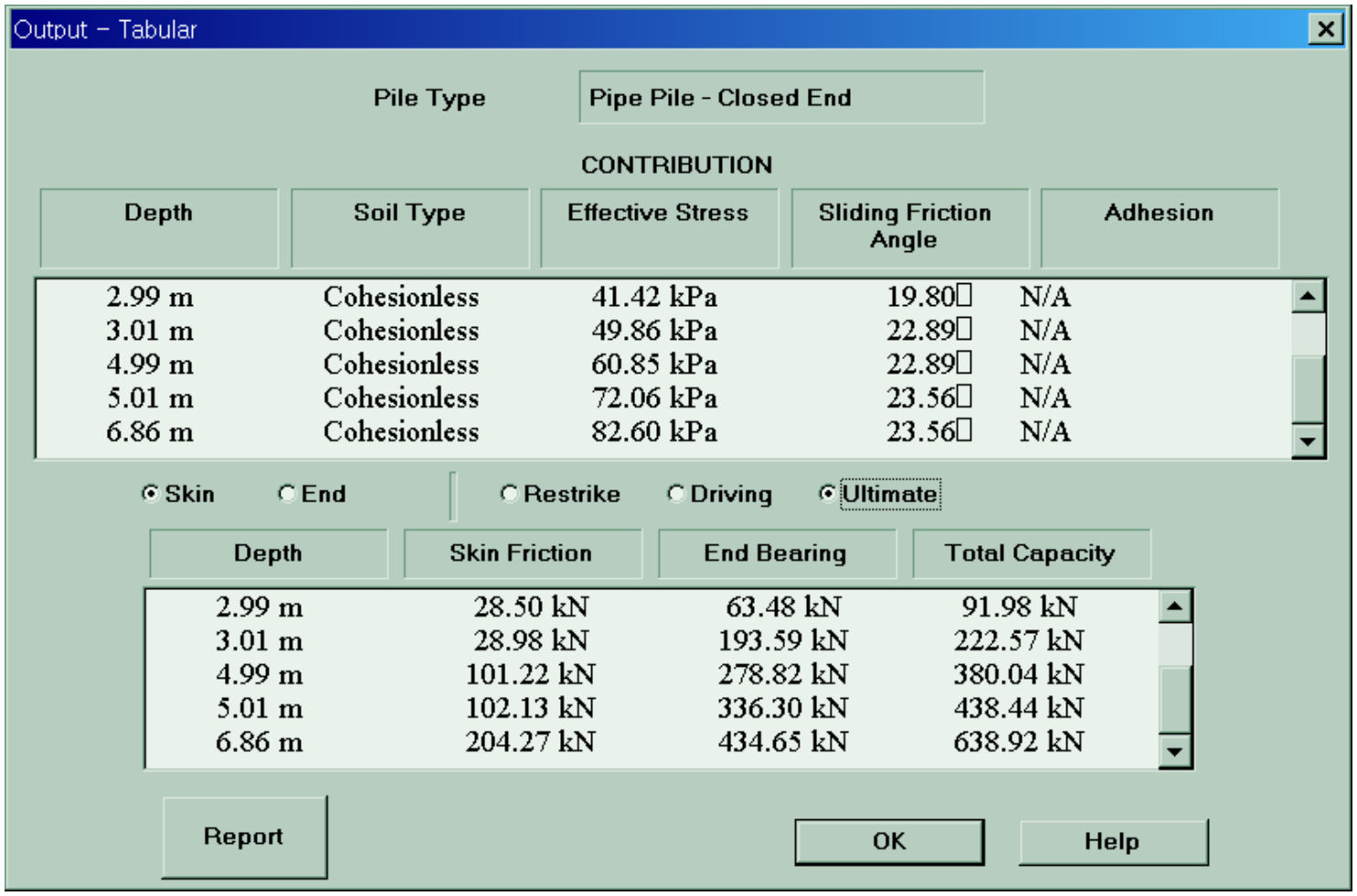

Figure B.10 Calculation results of the closed-ended pile of example 1 


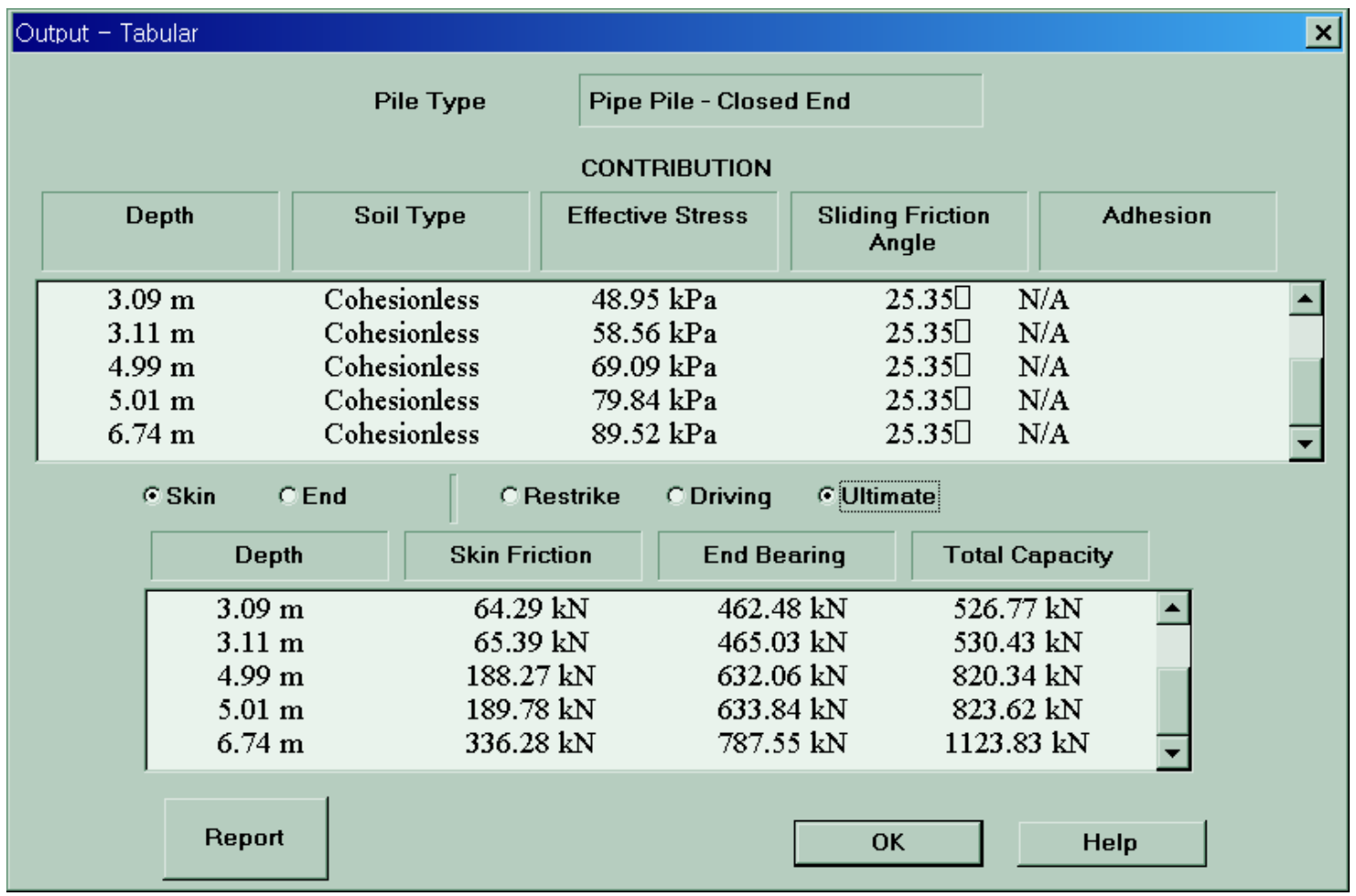

Figure B.11 Calculation results of the closed-ended pile of example 2 